\title{
Mechanisms of neuronal loss in aging and Alzheimer's disease
}

Citation for published version (APA):

Rutten, B. P. F. (2005). Mechanisms of neuronal loss in aging and Alzheimer's disease. [Doctoral Thesis, Maastricht University]. Maastricht University. https://doi.org/10.26481/dis.20051021br

Document status and date:

Published: 01/01/2005

DOI:

10.26481/dis.20051021br

Document Version:

Publisher's PDF, also known as Version of record

\section{Please check the document version of this publication:}

- A submitted manuscript is the version of the article upon submission and before peer-review. There can be important differences between the submitted version and the official published version of record.

People interested in the research are advised to contact the author for the final version of the publication, or visit the DOI to the publisher's website.

- The final author version and the galley proof are versions of the publication after peer review.

- The final published version features the final layout of the paper including the volume, issue and page numbers.

Link to publication

\footnotetext{
General rights rights.

- You may freely distribute the URL identifying the publication in the public portal. please follow below link for the End User Agreement:

www.umlib.nl/taverne-license

Take down policy

If you believe that this document breaches copyright please contact us at:

repository@maastrichtuniversity.nl

providing details and we will investigate your claim.
}

Copyright and moral rights for the publications made accessible in the public portal are retained by the authors and/or other copyright owners and it is a condition of accessing publications that users recognise and abide by the legal requirements associated with these

- Users may download and print one copy of any publication from the public portal for the purpose of private study or research.

- You may not further distribute the material or use it for any profit-making activity or commercial gain

If the publication is distributed under the terms of Article $25 \mathrm{fa}$ of the Dutch Copyright Act, indicated by the "Taverne" license above, 


\title{
Mechanisms of Neuronal Loss in Aging and Alzheimer's Disease
}

\author{
Bart P.F. Rutten
}


(C) Bart PF Rulten, Maastricht, 2005 ISBN 90-9020038-X

Coverdesign by Peter J Rutten

Typesetting by Michal Slawiński

Printed in Poland 


\title{
Mechanisms of Neuronal Loss in Aging and Alzheimer's Disease
}

\author{
Proefschrift
}

ter verkrijging van de graad van doctor aan de Universiteit Maastricht

op gezag van de Rector Magnificus, Prof. Mr. GPMF Mols volgens het besluit van het College van Decanen in het openbaar te verdedigen op vrijdag 21 oktober 2005 om 12.00 uur door Bart Paulus Franciscus Rutten 


\section{Promotor}

Prof. Dr. H.W.M. Steinbusch

\section{Copromotor}

Dr. C. Schmitz

\section{Beoordelingscommissie}

Prof. dr. J. van Os (voorzitter)

Prof. dr. P.R. Hof (Mount Sinai School of Medicine, New York)

Prof. dr. J. Jolles

Prof. dr. F.W. van Leeuwen (Nederlands Instituut voor Hersenonderzoek)

Prof. dr. F.C.S. Ramaekers 
"(Denn) nicht übermässige Bedenken und lähmende Verzagtheit helfen den Wissenschaften vorwärts und haben ihnen vorwärts geholfen, sondern ein gesunder Optimismus, der in froher Zuversicht nach neuen Wegen der Erkenntnis sucht, da er überzeugt ist, dass sie zu finden sein werden. "

„Excessive reservations and paralyzing despondency have not helped the sciences to advance nor are they helping them to advance, but a healthy optimism that cheerfully searches for new ways to understand, as it is convinced that it will be possible to find them."

Dr. Alois Alzheimer 



\section{CONTENTS}

Chapter 1 Introduction

Chapter 2 Prenatal protracted gamma irradiation 43

at very low dose rate over several days induces severe neuronal loss in rat hippocampus and cerebellum

Chapter 3 The aging brain: fewer neurons might be better

Chapter 4 The aging brain: accumulation of DNA damage or loss 79 of neurons

Chapter 5 Antioxidants in Alzheimer's disease: from bench

to bedside (and back again)

Chapter 6 Caloric restriction attenuates nuclear DNA damage accumulation and age-related neuronal shrinkage in mouse hippocampus without inducing neuronal loss

Chapter 7 No alterations of hippocampal neuronal number and synaptic bouton number in a transgenic mouse model expressing the beta-cleaved $\mathrm{C}$-terminal APP fragment

Chapter 8 Hippocampal neuron loss exceeds amyloid plaque load in a transgenic mouse model of Alzheimer's disease

Chapter 9 Age-related loss of synaptophysin immunoreactive presynaptic boutons within the hippocampus of APP7515L, PS1 ${ }^{\text {M:46L }}$ and APP751 ${ }^{\text {sL/PS1 }} 1^{\text {Miatl. }}$ transgenic mice

Chapter 10 Discussion

Summary

Samenvatting

Dankwoord

Curriculum Vitae

Publications 
Chapter 1

General introduction

\section{Mechanisms of Neuronal Loss in Aging and Alzheimer's Disease}




\section{INTRODUCTION}

Inevitably every one is getting older day by day and year by year. In early life, becoming older is connected with development, maturation and specialization of the brain. The older people become, the higher the risks are of developing age-related diseases and disabilities. As a result, the elderly population is subject to an increased burden of age-related diseases such as cardiovascular disorders, cancer, diabetes, and mental health disorder. Alzheimer's disease (AD) is the most common mental health disorder during aging. $\mathrm{AD}$ was once thought to be a rare disorder, but it is now considered a prevalent devastating disease with severe impact on millions of people and their families. Despite the ubiquitous presence and our familiarity with aging and $\mathrm{AD}$, very little is known about the molecular and cellular events underlying neuronal alterations during aging and in $\mathrm{AD}$. So far, there is no available treatment which modifies the molecular and cellular processes involved in AD pathogenesis. To develop rational and effective strategies for prevention or attenuation of neuronal alterations and neuronal loss during aging and in $\mathrm{AD}$, it is crucial to identify the molecular and cellular events that underlie these events. Neuronal loss can be described as loss of neurons or neuronal components and several aspects of neuronal loss (such as loss of neurons or synaptic terminals) can be measured with modern techniques. Animal studies are very useful in the elucidation of molecular and cellular events involved in aging or $A D$ as they allow the investigatation of the effects of modifications of molecules in vivo. The general aim of my thesis was to scrutinize the roles of various molecular and cellular aspects putatively involved in neuronal loss in aging and AD. This was done by analyzing mouse models of aging and $\mathrm{AD}$ with quantitative neuromorphologic, immunohistochemical and molecular techniques. In the first section of this Chapter, background information is provided on the aging process in the brain. Then, the current knowledge of the molecular and cellular events involved in the pathogenesis of $\mathrm{AD}$ is described. Finally, current questions and issues on the mechanisms underlying neuronal loss in aging and $\mathrm{AD}$ and on potential strategies to attenuate these mechanisms are discussed. On the basis of these questions and issues, I formulated hypotheses which were tested during my research.

\section{THE AGING BRAIN}

\section{Epidemiology of aging}

Aging is an inevitable process associated with a decline of physiologic function and an increased incidence of disease. Nowadays, approximately 600 million people in the world are 60 years old or more. This huge population of aged individuals is associated with a high incidence and prevalence of age-related diseases. Age-related diseases and disabilities seriously influence the lives of affected people themselves as well as they place a tremendous burden on relatives and on society. Importantly, the population of people older than 60 years is expected to double by 2025 and to reach 2 billion by 2050 (World Health Organization, www.who.int/hpr/ageing/ index.htm).

Thus, there is a high need for the elucidation of molecular and cellular events responsible for alterations in the brain during aging with the ultimate aim to prevent age-related diseases and disabilities. 


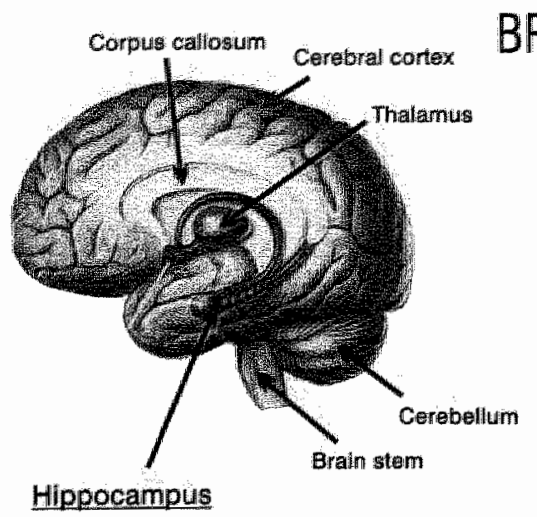

\section{BRAIN}
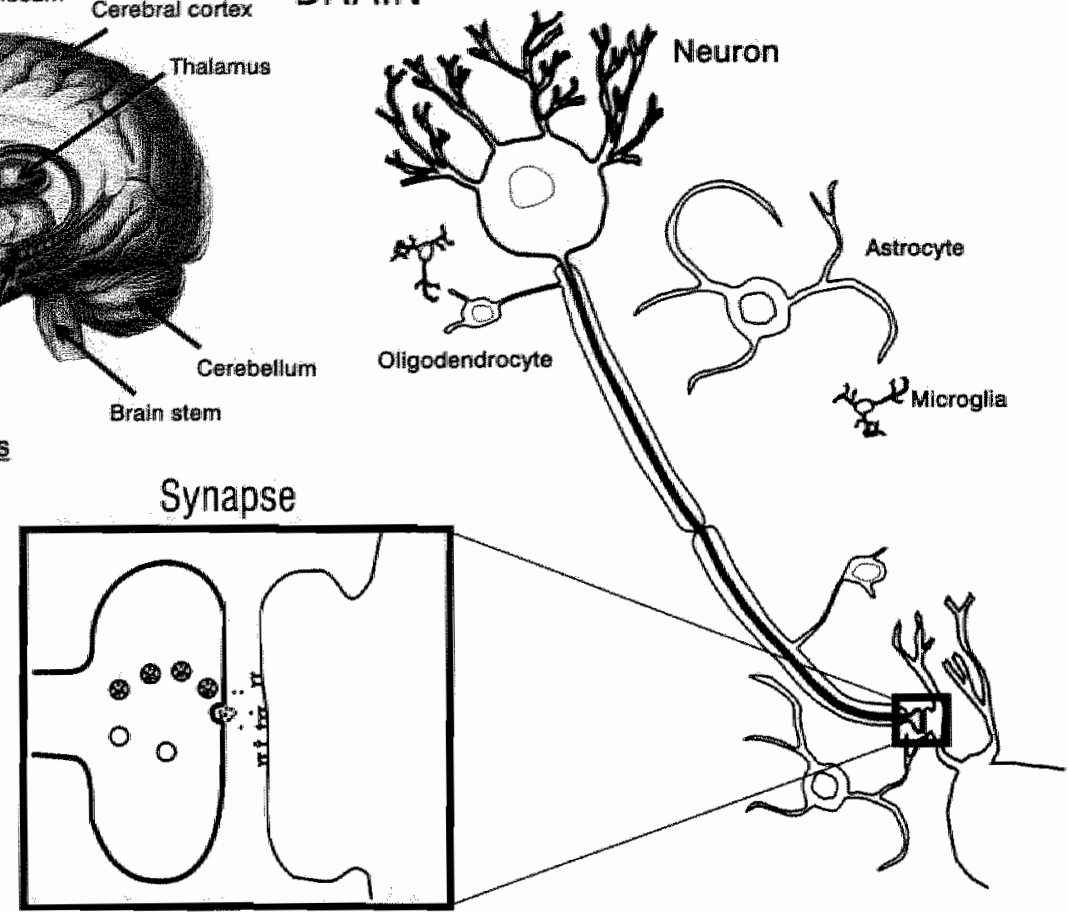

Figure 1. Cellular anatomy of the brain. The brain consist of many distinct brain regions, all having distinct functions which are always dependent on the interaction and connectivity between multiple brain regions. A few brain regions. and their names are indicated with arrows in the schematic drawing at the top lefi of Figure 1 . One of the indicated regions is the hippocampus which is a crucial region for learning and mernory processes and a region involved in the selectwely meunowherability in aging and Alzheimer s disease. Every brain region is anatomically characterized by the presence of a huge number of neurons, which communicated with other neurons via certain connections, called synapses. These neurons and synapses work as complicated circuitries involving various neurotransmitters and electrical impulses. Just how they do so is only slowty coming to light. The billions of cells in the brain can be subdivided into warlows topes and subrypes of cells each having a distinct morphology, Biology and function. Neurons are the specialized cells of the nerwous system responsible for the transmission of electrical impulses to and from the central nerwows system. Neurons consist of a cell body, a dendritic tree from which afferent electrical information reaches the cell body and the axom, which is the efferen fiber ensheated by myelin (from oligodendrocyres) and which transmits alectrical signals to the axonal terminat. At the axonal terminal, signat molecules are released into the synaptic cleft whict con acthate specific weceptors located on spines of the dendritic tree of the nex neurom. Together, the axonal terminal, symaptic cleft and postsywaptic spine form an entity called the symapse. Many different types of neurons exist in the brain making wse of many diffenent signating molecules. Glia cells are the most numerous types of cells in the brain and can be subdivided into astrocyes, oligodendrocyes and microglia. Astrocyres and microglia cells are activated and recnited to sites of injury. Besides supportive and nourishing, astrocytes have been implicated in formation of symapses, swmaptic plasticity and the regulation of the bload-brain-barrier. Similar to astrocytes, microglia cells may become activated in case of injury to the nervots system and can migrate lowards sides of injury where they can degrade waste material. Oligodendrocytes form the myelin sheets that encircle and surround the weuronal axons. In doing so, they allow the neurons to transmit signals with an incredible accuracy and speed. Endothelial cells are cells lining the interior of blood vessels. Together with the processes of astrocytes and the pial surface, endothelial cells form the anatomical basis for the blood-brain-barrier allowing only certain molecules to enter the brain. A newron and its synapse, assrocytes, microghia cells and oligodendrocytes are depicted at the right in Figure 1. 


\section{Molecular and cellular events in aging of the brain}

Aging is characterized on the cellular level by decrements in maximum cellular function, accumulation of damage and loss of reserve capacity. ${ }^{1-3}$ These changes are most pronouncedly observed in organs containing post-mitotic cells such as the brain. ${ }^{1,4}$ The brain is considered our most vital organ, responsible for everything from involuntary life support functions to the essence of personality and memory. To understand how the brain works, and what occurs during aging, one has to go to the basics of brain anatomy and brain physiology. Although the knowledge on how the brain works is growing rapidly, we have only limited knowledge of the processes which are responsible for human behavior and its disorders. Some important aspects of neuroanatomy, i.e. several brain regions and cell types, and the unit that transmits signals from one neuron to the other (i.e. the symapse), are depicted in Figure 1. While the brain can age successfully, its cells normally encounter considerable adversities during live. An adversity central to the aging process is the increased production of free radicals which promotes damage to and dysfunction of various metabolic and signaling pathways. ${ }^{2,45}$ Free radicals are molecules with a free electron thereby reacting readily with other molecules. Free radicals and radical-derived reactive species are present in all cells and can damage all major cellular constituents at higher concentration. ${ }^{6}$ At lower concentrations, though, they may also play important roles as regulatory mediators in signaling processes. ${ }^{7}$ Most free radicals are derived from oxygen molecules and are often described as oxygen radicals.

The main production sites of free radicals are the oxidative-phosphorylation-protein complexes of the mitochondrial respiratory chain where oxygen radicals are generated as side effect of the production of the "energy molecule" ATP (i.e. adenosine-triphosphate). ${ }^{8,9}$ The way that ATP molecules are generated changes during aging such that more free radicals are produced per ATP molecule. ${ }^{8}$ A description of sources of free radicals and oxygen radicals as well as a description of the molecules involved in detoxification of oxygen radicals, $i_{\text {e }}$. antioxidants, and their roles in aging is given in more detail in Chapters 3 and 5 of this thesis. Comparative studies between various animals (having different aging rates) have shown that the rate of mitochondrial oxygen radical generation is directly related to the steady-state level of oxidative damage to DNA and is inversely correlated with miaximum longevity in higher vertebrates. $1,8-10$ If oxygen radicals are not scavenged by antioxidants, they can damage all macromolecules in cells such as nucleic acids, lipid membranes, and proteins carbohydrates. ${ }^{2}$ Next to an increased production of free radicals, age-related alterations in the mitochondrial respiratory chain may also result in a metabolic compromise," which particularly affects neurons as these cells are highly dependent on ATP production. Energy-dependent enzymatic processes may thereby become inefficient in their actions. ${ }^{1,69}$ Consequently, biosynthesis of DNA, degradation and resynthesis of proteins, ${ }^{12.13}$ and DNA repair processes ${ }^{14,15}$ may show substantial age-related alterations with for example unrepaired DNA damage ${ }^{16_{1} 17}$ as a result. In addition, an appropriate energy supply to cells is necessary for proper maintenance of calcium homeostasis (important for a multitude of cellular functions). Aging is associated with considerable alterations in calcium homeostasis in several types of cells in the brain. ${ }^{18.19}$ These adverse events urge neurons and other cell types of the brain to adapt during aging by increasing their ability to cope with stress, and by remodeling neuronal circuits (Figure 2).419 Changes in the cellular structure of the brain and the functions of its neuronal circuits are controlled by an array of intercellular 


\begin{tabular}{l} 
Molecular damage and energy dysregulation \\
ONAdamage \\
Protein modifications \\
$\begin{array}{l}\text { Caloric intake } \\
\text { Protein aggregation } \\
\text { Lipid peroxidation }\end{array}$ \\
\hline
\end{tabular}

Figure 2. Scheme adapted from reference 4 representing a current working frame on some of the most important molecular and cellwar events in the aging brain. Aging is characterized by a progressive accumulation of damaged molecules and impcired energy metabolism. Newrons and gita cells may adapt by increasing their ability to cope with stress and may thereby compensate for damaged cellular components. If adiptation is not successful, molecular damage to neurons and inflammatory processes result in synaptic dysfinction or loss, in neuromal degeneration and potentially in neuromal death.

signaling molecules and intracellular signal transduction pathways. Several of these cellular signal transduction systems show substantial alterations during aging. ${ }^{18,19}$ Examples for the aging central nervous system are gene transcription, ${ }^{20}$ cellular calcium homeostasis, ${ }^{21}$ protein phosphorylation (alterations in kinases and phosphatases), ${ }^{22}$ and the response to DNA damage. ${ }^{16}$ With respect to the latter example, cells with DNA damage may respond by activating different pathways. They may attempt to repair DNA damage by increasing DNA repair activities, they may inactivate themselves to prevent further damage or they may initiate cell death pathways. ${ }^{16}$ Recent evidence suggested that in aging the normal (appropriate) response to genotoxic stress is altered..$^{23}$ It was suggested in particular that the apoptosis cell-death pathway is significantly reduced during aging. ${ }^{24}$ Another major strategy for neurons and other cells in the brain to cope with accumulating damage, is to degrade damaged molecules. Damaged proteins can be degraded into into small molecules which can subsequently been used for resynthesis of new proteins. ${ }^{23}$ The ubiquitin-proteasome pathway in concert with the endolysosomal pathway (both of which are mainly dependent on ATP) are major pathways responsible for recognition and degradation of misfolded, damaged proteins. ${ }^{4,26}$ The efficiency of these pathways however reduces during aging ${ }^{12,13,25,27}$ leading to an increased amount of damaged and misfolded proteins which can accumulate in the form of protein aggregation such as lipofucscin, $\alpha$-synuclein and others. ${ }^{4,26-28}$ If adaptation to age-related damage is not successful, damaged macromolecules 
accumulate in neurons and can elicit an inflammatory response (Figure 2). Astrocytes and microglia cells are cells mediating the inflammatory response and are recruited to sites of injury and damage. ${ }^{4}$ They may support injured neurons or remove waste material, but can also affect neuronal integrity. ${ }^{4}$ Thus, inflammatory cells are regarded as helpful in normal conditions but can also have toxic effects when overstimulated in certain pathologic conditions.

To complicate the understanding of these matters, the aforementioned age-related molecular and cellular changes affect each other and may create a cascade of degenerating events. ${ }^{16,26}$ In doing so, age-related alterations may ultimately result in dysfunction of synapses and neurons, and to cell death (Figure 2). ${ }^{4,26}$

A more detailed description of recent advances in understanding the roles of oxidative stress, antioxidants, age-related accumulation of DNA damage and the response to DNA damage in the aging brain can be found in Chapters 3 and 5 of this thesis, and in several recent review articles. ${ }^{4,26}$

\section{Selective neurovulnerability in the aging brain}

The brain is not uniformly affected to the same degree by aging. Selective brain regions and types of neuron have been observed to preferentially harbor age-related alterations (see also Chapter 3 ). The cerebral cortex and hippocampus are characterized as brain regions severely affected during aging. ${ }^{29}$ Studies on volumes and metabolism, for example, have indicated that the frontal cortex and medial temporal cortex (wherein the hippocampus is located) are more severely affected than other regions during aging. ${ }^{30,31}$ Molecular studies have furthermore indicated that the cerebral cortex and hippocampus show a higher level of nuclear and mitochondrial DNA damage during aging than other regions. ${ }^{16,17,32}$ In addition, histochemical studies have indicated that protein aggregations and synaptic alterations also preferentially affect types of neuron of the cerebral cortex and hippocampus during aging. ${ }^{29,33,34}$ Traditionally, age-related dysfunction was believed to result from death of neurons during aging. Yet, recent studies, carried out with improved methodologies, have indicated that neurons in the cerebral cortex and hippocampus show no reductions in their total number during aging. ${ }^{14,15}$ Together these findings indicate that age-related dysfunction of cortical and hippocampal regions is connected with local atrophy, decreased metabolism, accumulation of DNA damage, protein aggregations and synaptic alterations and not with age-related loss of neurons. Nevertheless, this does not exclude that types of neuron in other brain regions can be subject to substantial age-related loss of neurons. In this respect, recent studies have suggested a so far unknown inverse correlation between types of neurons showing an age-related decline in the rate of nDNA repair and types of neurons showing a reduction in number of neurons during aging (see Chapter 3 for further details). ${ }^{14,15}$ The basis and relevance of this aspect as well as of other aspects involved in the selective neurovulnerability during aging are currently unclear. Nonetheless, one may argue that the alterations occurring during normal aging might set the stage for dysfunction of the brain during aging and for the pathogenesis of neurodegenerative disorders that may be triggered by particular genetic predispositions or environmental factors., ${ }^{46,34}$ 


\section{Strategies to attenuate age-related neurodegeneration}

Several strategies have been employed to attenuate age-related neurodegenerative processes in the brain. Alhough most of them have not been successful so far, some strategies have appeared to show a substantial impact on age-related neurodegeneration.

\section{Antioxidants}

Antioxidants are molecules characterized by their ability to scavenge and neutralize free radicals. 6.35 .36 More than ten thousand compounds are known to have antioxidant properties. Endogenous antioxidants, such as superoxide dismutase, catalase and glutathione peroxidase are produced by cells themselves and are enzymatic. ${ }^{36}$ Exogenous antioxidants on the other hand, are non-enzymatic, and can be taken up into the body via the diet ${ }^{36}$ In Chapter 5 of this thesis, the actions and effects of antioxidants during the aging process are described in more detail. Attenuation of age-related oxidative clamage and degenerative events may be achieved by upregulation of the natural defense to oxygen radicals, i.e. to increase the amounts or activities of antioxidants. $4,37,38$ In line with this way of thinking are reports in the literature showing that depletion from normal amounts of antioxidants can result in a reduced life span, accelerated age--related changes and enhanced injury. ${ }^{39-42}$ Furthermore, overexpression or supplementation of antioxidants has been reported to attenuate age-related and neurodegenerative changes in mammals and to extend life span in lower organisms. ${ }^{42-49}$ However, other studies suggest that the correlation between upregulating antioxidants and atteruating age-related changes and extending life span, may not be that simple. ${ }^{46,50,51}$ One drawback of some of these studies is that they were carried out on animal species (e.g. yeast, roundworms and fruitflies) which are distant from humans in a phylogenetically and evolutionary perspective. In this respect, mammalian species offer better, more physiologic models to study the effects of antioxidants on the aging process in the brain. The number of studies carried out to asses the effects of antioxidants on the aging brain is however limited. One study reported that mice overexpressing normal human $\mathrm{Cu} / \mathrm{Zn}$ superoxide dismutase (the isoform mainly active in the cellular cytoplasm) had reduced oxidative damage in the central nervous system at high age as compared with control mice. ${ }^{44,52}$ Another study showed that a diet enriched in polyphenols, i.e. natural antioxidants, decreased age-related changes in the central nervous system and in behavior in rats. ${ }^{53}$ Furthermore, according to a recent study dietary antioxidants may ameliorate age-related disorders of cognitive functions in dogs. ${ }^{54}$ Together these studies indicate that the use of antioxidants can decrease age-related damage and dysfunction in the brain. Although it seems attractive to simultaneously upregulate endogenous and exogenous antioxidants as tools to attenuate age-related free-radical induced damage, it remains to be established whether the combination of both endogenous and exogenous antioxidants results in pronounced attenuation of age-related changes in those regions and types of neuron in the mammalian central nervous system most affected during aging.

\section{Caloric restriction}

Although it was already found in 1935 that dietary caloric restriction (CR) prolongs mean and maximum life span, ${ }^{55}$ it was not until the 1970 's and $1980^{\prime}$ s that these finding were confirmed 
in studies reporting that restriction of dietary caloric intake resulted in an extension of maximum life span by as much as $50 \%$ in roundworms and rodents and attenuated the risk of the mosit prominent age-related diseases such as cardiovascular disease, cancer and diabetes in rodents. ${ }^{56,57} \mathrm{Up}$ to now, dietary restriction of calories is the only intervention strategy which has consistently been shown to extend life span and to attenuate age related degenerative events in several animal species. ${ }^{58,59}$ The exact molecular and cellular events underlying these effects however remain largely elusive. So far, gene expression studies have indicated that CR suppresses several signaling pathways which are normally upregulated in the aging process. ${ }^{20}$ Some of the molecules involved in these pathways are proteins expressed in response to oxidative stress ${ }^{59}$, proteins involved in energy metabolism, ${ }^{18,58,59}$ proteins involved in regulation of the calcium homeostasis ${ }^{19}$ and molecules involved in the immune response. ${ }^{19} \mathrm{CR}$ has furthermore been shown to stabilize mitochondrial function associated with a decreased oxygen radical production (mainly at respiratory chain complex $\mathrm{I}$ ) ${ }^{1}$ to stimulate DNA repair ${ }^{60}$ and to enhance the expression of other genes involved in neuronal survival and plasticity such as protein chaperones and neurotrophic factors. ${ }^{4}$ Interestingly, some reponts have indicated that caloric restriction is associated with a reduced number of synapses ${ }^{61}$ in cerebral cortex and retinal ganglion cellls, ${ }^{62}$ i.e. alterations which - at first glance - do not seem beneficial to the brain. Thus, although almost all studies point to a beneficial action of CR on the aging process in the brain, the current knowledge on the underlying molecular and cellular mechanisms is still very limited. It is also unknown so far whether the actions of CR show a regional or cell type specificity in the brain, as it is plausible that signalling pathways in distinct regions or cell types respond differently to $\mathrm{CR}$.

\section{Other strategies}

An increasing number of reports in the literature indicate that physical and mental activities are positively related with cognitive functions at older age. ${ }^{63,64}$ Animal studies are in line with the findings of beneficial actions of exercise and point to induction of neurorestorative and neuroplastic changes as an underlying mechanism. ${ }^{5}$ Besides these hopeful reports, a number of observational studies of postmenopausal women have indicated that estrogen replacement therapy may protect against age-associated memory decline in non-demented women. ${ }^{65 * 67}$ Recent findings in animal models point to enhanced synaptic plasticity as the responsible cellular event induced by estrogen supplementation. ${ }^{68}$ However, further studies are necessary to pinpoint the mechanism(s) responsible for the observed enhanced synaptic plasticity and prospective studies with large cohorts should be implemented before actual conclusions can be made in this respect.

\section{ALZHEIMER'S DISEASE}

\section{Historical perspective}

The German neuropsychiatrist Alois Alzheimer was the first to describe a patient displaying several cardinal symptoms of a disease which was later to bear Alzheimer"s name. Alzheimer described the relatively young woman Auguste Deder who suffered progressively from 
symptoms of cognitive impairments, problems with reading and writing and a gradual loss of other higher mental functions. After Auguste Deder"s death in 1906, Alzheimer examined her brain and described a thinner cerebral cortex than normal and two other abnormalities: senile plaques and neurofibrillary tangles. Alzheimer defined the clinicopathological syndrome of Augustc Deder as "presenile dementia" and presented her case in 1906 on a conference in Munich and published his findings in 1907.69 After this first description, more cases with similar symptomatology were recognized and described by Alzheimer and others. After several reports of eases with the same symptomatology, Kraepelin (who was the head of the Munich clinic where Alzheimer worked at that time) initiated the definition of a syndrome and proposed to attach Alzheimer's name to the disease. ${ }^{70}$ For decades after Alzheimer's first description, little progress was made in defining and elucidating the pathogenesis of $\mathrm{AD}$, although there was growing awareness of the commonness of the disease. In the 1960's the development of electron microscopy allowed for the first time to describe the characteristic neuropathologic lesions (i.e. senile plaques and neurofibrillary tangles) in the brains of $\mathrm{AD}$ patients on the ultrastructural level. The use of neurochemical techniques, which became available in the 1970's, allowed for the first definition of neurochemical changes in AD. These observations led to the development of the first pharmacological agents for $\mathrm{AD}$ which focused on the restoration of a certain neurotransmitter, acetylcholine. These agents are currently among the few medications which are proven to be effective in decreasing the progression of some of cognitive symptoms in AD. However, research carried out in the 1980's and 1990's indicated that several - if not all - neurotransmitters show deficits and alterations in AD. It is now well known that the neuropathology of $\mathrm{AD}$ is characterized by the presence of senile plaques and neurofibrillary tangles, but also by neuron and synaptic loss in selective regions (but involving various neurotransmitter systems). These findings have prompted researchers towards further investigations of the molecular and cellular mechanism underlying and preceding the formation of senile plaques and neurofibrillary tangles and their connections with neuronal and synaptic loss. It has been observed that neuritic plaques mainly consist of the $\beta$-amyloid protein (AB) and neurofibrillary tangles of hyperphosphorylated tau protein. In parallel to these two classical hallmarks, a hot debate emerged between researchers favoring different theories on the pathogenesis of AD. Some scientists ("Tauists") favored the idea that hyperphosphorylation of tau protein is the key event whereas others ("Baptists") favored the production and accumulation of $A \beta$ as the key event in the cascade of AD pathophysiology. ${ }^{71}$ The finding by scientists in the 1990 's that mutations in the genes of presenilin-1, presenilin-2, and amyloid precursor protein are responsible for early onset-familial cases of $A D$ and lead to enhanced generation of $A \beta$ protein bolstered the "baptistic" idea that $A B$ containing plaques were the crucial aspects of $A D$ pathogenesis (reviewed in ref. 72). Other studies indicated however that the presence of neurofibrillary tangles in certain brain regions correlated better with the clinical symptoms of AD patients than any other neuropathologic correlate (including plaques).$^{73}$ In addition to these findings, another genetic variant, the ApoE4 genotype was found to be a main genetic risk factor for AD. Over the last years, considerable progress in neuropathological, neurochemical, and molecular studies on $\mathrm{AD}$ has been made resulting in the emersion of a rough outline of the disease cascade. This progress and the related efforts to identify targets for therapeutic intervention have been markedly assisted by the development of cellular and animal models. 


\section{Diagnosis of Alzheimer's disease}

Dementia, a syndrome characterized by deteriorating cognitive functions with significant impact on patients' daily life, is one of the most common age-related mental health problems. ${ }^{\text {t4 }}$ Dementia is commonly recognized by physicians with use of the criteria of the Diagnostic and Statistical Manual of Mental Disorders, fourth edition. ${ }^{75.76} \mathrm{AD}$ is the most important caise of dementia. $A D$ is a progressive neuropsychiatric disorder clinically characterized by a decline in memory, thinking, comprehension, calculation, language, learning capacity and judgment. ${ }^{74}$ The diagnosis of $\mathrm{AD}$ is commonly based on the criteria developed by the National Institute of Neurologic and Communicative Disorders and Stroke-AD and Related Disorders Association, ${ }^{77}$ according to which the diagnosis is classified as definite (i.e. clinical diagnosis with postmortem histologic confirmation), probable (i.e., typical clinical syndrome without histologic confirmation), or possible (i.e. atypical clinical features but no alternative diagnosis apparent; no histologic confirmation). According to the age of onset (and genetic predisposition), $\mathrm{AD}$ can be manifested in two forms: $: 78$

1. Familial - early onset - form of $\mathrm{AD}$ consisting of patients harboring autosomal dominant mutations. Symptoms may begin at an early age (as early as thirty years) and approximately $3-5 \%$ of all $\mathrm{AD}$ cases are of this familial form. ${ }^{78}$

2. Sporadic - late onset form - of $A D$ in which no single genetic mutation is identified in these patients to be responsible for the disease. Symptoms generally begin from an age of $65{ }^{78}$

\section{Epidemiology of Alzheimer's disease}

The number of people with $\mathrm{AD}$ in the Netherlands currently stands at around $125,000{ }^{79}$ With every five years of age, the percentage of persons with $\mathrm{AD}$ increases by a factor two ${ }^{74,80}$ The influence of age on the prevalence of $A D$ is underscored by studies reporting that a very low percentage $(<1 \%)$ of people under an age of 65 have $A D$, whereas 10-30\% of people aged 85 and more have $\mathrm{AD}$ (depending on the inclusion criteria). ${ }^{31-83}$ Due to the increased number of elderly people in the general population, these numbers will substantially increase over the next decades, ${ }^{79}$ and if curative treatments fail to emerge, the number of people with $\mathrm{AD}$ in the Netherlands will be approximately 150,000 by 2010 and 290,000 by $2050,{ }^{79}$ while the number of people with $\mathrm{AD}$ in Europe has been estimated to reach 20 million by $2050^{8.4}$

The annual incidence rate of $A D$ is approximately $1 \%$ in people aged 65 to 70 years and increases to approximately $6-8 \%$ in people over age $85 .{ }^{74}$ The incidence rates of $A D$ are slightly higher for women and for people of certain races. ${ }^{80,85}$ The duration of $A D$ varies considerably from 2 to 20 years, ${ }^{85}$ although the median survival time for AD patients has been estimated to be 3 to 4 years. ${ }^{86}$ The risk of developing AD or another dementia at some point during life depends on the incidence rate and life expectancy from birth and has thus been found to be considerably higher in women ( 12 and $19 \%$ ) than in men (6 to $10 \%))^{87}$ The cost of caring for patients with $\mathrm{AD}$ is enormous and has been estimated at approximately $€ 100,000$ per patient per 10 years. ${ }^{8 \mathrm{~B}}$ 
Together these figures designate that AD places a very serious burden on general society which will be even greater in the near future.

\section{Genes and genetic risk of $A D$}

Mutations in three genes have been found in patients with the familial form of AD: mutations in the genes for amyloid precursor protein (APP) on chromosome 21,92 presenilin 1 (PS1) on chromosome $14^{92-94}$ and presenilin 2 (PS2) on chromosome 1.95,96 Of these three genetic mutations, mutations in PS1 are responsible for most cases of familial AD ${ }^{90}$ Together, these three mutations only account for a small proportion of AD patients (approximately $3-5 \%$ ). ${ }^{78}$

An allelic variant of another gene, the ApoE4 genotype, ${ }_{3}^{97}$ has been found to be associated with both familial and sporadic AD. ${ }^{98-100}$ People with a single ApoE4 allele have a twofold increased risk of $\mathrm{AD}$, whereas the risk is fivefold increased in people with two ApoE4 alleles. The proportions of $A D$ related to the ApoE4 genotype is approximately 20\%. Additional putative loci for genetic variants or mutations have been identified on chromosomes $12 \mathrm{p} 12$ and $10 \mathrm{q} 24 .{ }^{85}$

\section{Risk modifiers of $A D$}

Several environmental, genetic and life style factors are known to influence the risk of $A D .^{85}$ The risk of $\mathrm{AD}$ has been found to be significantly higher among poorly-educated people than among well-educated people, ${ }^{102,103}$ and significantly lower in people raised in a nurturing and supportive environment than people not raised under these circumstances. ${ }^{03,104}$ Other recent studies suggest that people engaged in physical or mental activities during late life, preferably complex or dynamic activities, have a lower risk of $\mathrm{AD}{ }^{63,64}$ Traumatic head injury earlier in life is connected to an increased risk of $A D^{105}$ Furthermore, a large proportion of patients with Down syndrome (trisomy of chromosome 21) develops AD symptoms already at an early age. ${ }^{106}$ The risk of $A D$ is also two to three-fold increased in people with a positive family history for Down syndrome. ${ }^{107,108}$ Dietary intake of natural or supplementary antioxidants, ${ }^{109-101}$ the use of anti-inflammatory agents ${ }^{12,113}$, and the use of lipid-lowering agents or statins ${ }^{114-116}$ have recently been associated with a decreased risk of AD. Use of estrogen by postmenopausal women has furthermore been associated with a lower risk of AD. ${ }^{65-67}$ In this respect, however, two clinical trials of estrogen replacement in women with $\mathrm{AD}$ failed to show a significant benefit. ${ }^{117,1 \mathrm{~s}}$ In people with hyperlipidemia, diabetes or hypertension, the risk of AD is increased. ${ }^{\| 19}$ " 120 Moderate alcohol consumption however has recently been associated with a reduced risk of AD. ${ }^{121}$ Prospective studies with large cohorts have furthermore shown that smokers have a two-to fourfold increased risk of $\mathrm{AD}$, with a particular increased risk among smokers harboring the ApoE4-genotype. ${ }^{122,123}$ 


\section{Neuropathology of Alzheimer's Disease}

The classical hallmarks in the neuropathology of $\mathrm{AD}$ are the neuritic plaques and neurofibrillary tangles (Figure 3). ${ }^{124} \mathrm{AD}$ neuropathology is additionally characterized by the presence of diffuse plaques, atrophy of the brain and loss of neurons and synapses. ${ }^{124}$

\section{Neuritic plaques}

Neuritic plaques are microscopic foci of extracellular $A \beta$ deposition associated with and surrounded by injured axons and dendrites. ${ }^{125}$ They are preferentially found in limbic and other association cortices and in hippocampus. Neuritic plaques contain extracellular deposits of $A \beta$ in a filamentous, star-shaped masses of $A \beta$ fibrils (Figure $3 \mathrm{~A}$ ). ${ }^{125}$ Their cores are detectable by Congo red or Thioflavin $S$ histochemistry. Plaques usually contain both $A \beta 40$ and $A \beta 42$ although most of the fibrillar $A \beta$ found in neuritic plaques is composed of $A \beta 42$, the more hydrophobic form and particularly prone to aggregation. ${ }^{72,126}$ The injured or dystrophic neurites are often dilated and tortuous and are marked by ultrastructural abnormalities that include enlarged lysosomes, numerous mitochondria, and paired helical filaments. ${ }^{125}$ Neuritic plaques are also intimately associated and surrounded by activated microglia and reactive astrocytes which display abundant glial filaments. ${ }^{127}$ Microglia cells are usually located within and adjacent to the central amyloid core of the neuritic plaque, whereas astrocytes often ring the outside of the plaque, with some of their processes extending towards the core of the plaque. The time in which such a neuritic plaque develops in $\mathrm{AD}$ is unknown, but these lesions probably evolve gradually over a substantial period of time. ${ }^{72}$

\section{Diffuse plaques}

Diffuse plaques are aggregations of $A \beta$ with relatively light, amorphous $A \beta$ immunoreactivity without a clearly fibrillar core. Diffuse plaques are found in limbic and association cortices but also in many brain regions not clearly implicated in the typical symptomatology of AD. ${ }^{125}$ They mainly consist of A 42 species, ${ }^{128-130}$ appear to be associated with little or no detectable neuritic dystrophy, ${ }^{72}$ and represent most likely precursor lesions of neuritic plaques. ${ }^{72}$ Healthy aged humans free of $A D$ often show diffuse plaques in limbic and association cortices, the same regions where $A D$ patients show mixtures of diffuse and neuritic plaques. ${ }^{72}$

\section{Amyloid angiopathy}

Small arterioles, venules, and capillaries within the cortex of $\mathrm{AD}$ patients frequently bear small amyloid deposits (Figure $3 \mathrm{~A}$ ). ${ }^{131}$ The $\mathrm{A} \beta$ species principally involved in microvascular angiopathy is $A \beta 40$, although the initial depositions may contain $A \beta 42 .{ }^{132}$ The extent of amyloid 
angiopathy varies widely anong $\mathrm{AD}$ brains that have relatively similar burdens of parenchymal (i.e, plaque associated) $A \beta^{72}$ and the contribution of microvascular amyloidosis to cortical dysfunction occuring in $A D$ remains largely unclear. ${ }^{13}$. Vessels with $A \beta$ can furthermore be observed in the brains of elderly subjects without $A D$, a condition called congophilic amyloid angiopathy. ${ }^{134}$ Vesselss with $A \beta$ deposits may rupture and may thus lead to cerebral hemorrhages, ${ }^{\text {s. }}$ although the large majority of AD patients do not experience cerebral hemorrhages.

\section{Neurotibrillary tangles}

Neurofibrillary tangles (NFT) are large bundles of abnormal fibers of hyperphosphorylated tau protein. Tau protein is a microtubule-associated protein with a supportive function in the cell's cytoskeleton and is involved in axonal transport. The gene of tau protein is located on chromosome 17 and mutations in this gene account for a rare disease called frontotemporal dementia with parkinsonism. ${ }^{135}$ A variety of kinases have been shown to be capable of phosphorylating tau in vitro. ${ }^{136}$ Nevertheless, it has not become clear which kinases are principally responsible for initiating the hyperphosphorylation of tau in vivo eventually leading to its dissociation from microtubules and aggregation into insoluble paired helical filaments. ${ }^{72}$ NFT are normally located intraneuronally although they can also be found in the extracellular space as so called 'ghost tangles', which are presumably NFT of neurons that have died..$^{37,138}$ Electron microscopy has indicated that most of the NFT-fibers consist of pairs of 10-nm filaments wound into helices, called paired helical filaments (PHF) and that NFT-fibres are not bound to membranes. ${ }^{137}$ Notably, NFT are mostly formed in large projection neurons having long axons. ${ }^{138,139}$ Proper function of these projection neurons depends on a strong cytoskeleton, a well regulated axonal transport system and a well regulated energy supply.

\section{Neuron loss}

Neuron loss has classically been considered as a key feature in AD neuropathology. The question whether neurons are lost in a certain brain region is however not easily answered for two important reasons. First, the technologies currently available do not allow the investigation of the number of neurons in the same individual for more than one time during the individual's live. Because microscopic resolution is necessary to address numbers of neurons, scientists can currently only achieve this resolution by investigating post mortem brain tissue. Usually the results of these analyses are then grouped according to the age or disease state of the individuals analyzed and subsequently compared. Thus this strategy cannot fully answer whether the same individual has lost neurons during aging. However, this approach has been adapted by many investigators to address research questions concerning reductions in neuron numbers. A second problem in answering this 'neuron loss' question is that, up to recently, scientist have been using biased methods to quantify the numbers of neurons within a region of interest. 140,141 In this respect, recent developments in quantitative neuromorphology have resulted into better methods allowing high precision estimations of total numbers of neurons by using stereollogic quantification techniques. ${ }^{140,141}$ However, these modern stereologic methods have not been applied extensively on $\mathrm{AD}$ brains yet. The few stereologic studies on $\mathrm{AD}$ carried out so far though, have indicated substantial loss of neurons within area CAl of the hippocampus, ${ }^{73,142-i 45}$ 

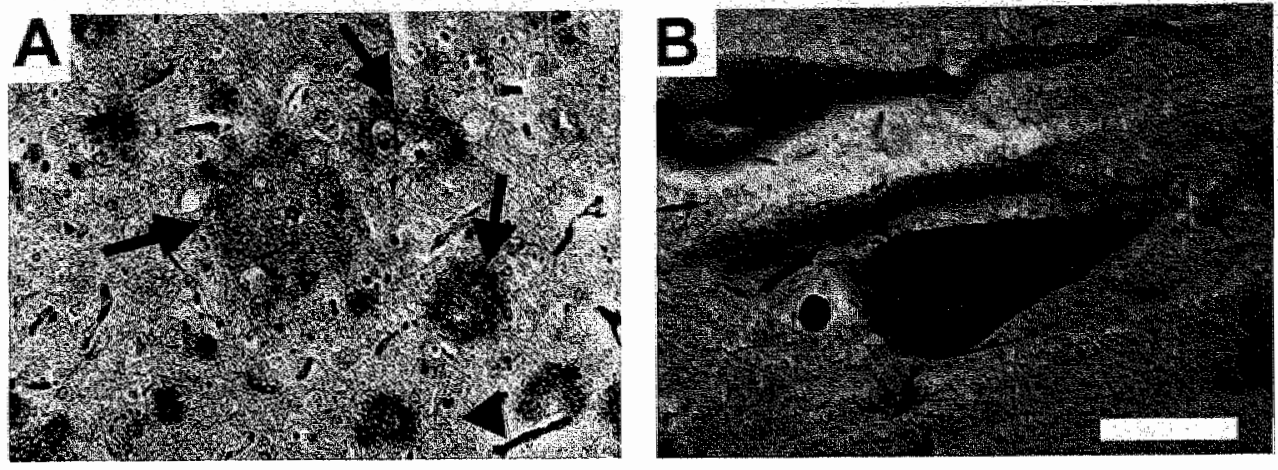

Figure 3. Photomicrographs of two classical hallmarks of AD newropathology, A depicts $\beta$-annyloid containg platums (arraws indicate a few meuritic plaques of warious size and the arrowhead indicates a vessul with amyloid angiopathy) and $B$ depicts neurons with neurofibrillary tangles. Scale bar represents $150 \mu m$ in A and 20 um in $B$.

in prefrontal cortex (Brodmann's area 9) ${ }^{73,138,146}$ and in entorhinal cortex of AD patients as compared to age-matched controls. ${ }^{145,147,148}$ However, no significant loss of neurons was observed within area $\mathrm{CA} 2 / 3$ of the hippocampus of $\mathrm{AD}$ patients. ${ }^{144}$ It was furthermore found that loss of neurons within area CA1 correlated well with the level of $A D$ neuropathology staging according to the Braak staging ${ }^{149}$ and with cognitive status as tested with the Mini Mental State Examination. ${ }^{73}$ Thus, these stereologic studies confirm that $A D$ is characterized by substantial neuron loss in selective brain regions. Nevertheless, there is still a high demand for additional stereologic studies to further scrutinize the selective neurovulnerability in AD brain, to describe temporal and spatial features of neuron loss and to compare these with the temporal and spatial development of other neuropathologic hallmarks. In this respect, some aspects have already been elucidated. For example, recent studies indicated that cognitive deficits in AD were closely reflected by NFT and loss of neurons in hippocampus and frontal cortex in AD, and not by the burden of extracellular neuritic plaques. ${ }^{73}$ Furthermore, it has been demonstrated that neuronal populations that differ in proness to NFT formation are lost at different rates in AD, and that nonphosphorylated neurofilament protein-enriched neurons emerge as a strikingly vulnerable subpopujation of neurons. ${ }^{138,146,147}$ As these neurons are crucial in furnishing key subsets of corticocortical connections, their preferential loss indicates that neurons providing connections between association cortices and the hippocampus are at high risk for degeneration in $A D .^{34,73}$

Finally, it should be mentioned that shrinkage of neuronal cell bodies and reductions in the dendritic trees of neurons are prevalent neuronal abnormalities which may precede and accompany frank neuronal loss. ${ }^{150-192}$

\section{Synapse loss}

A multitude of evidence in the literature has converged and pinpoints to synaptic failure and synaptic loss as key events responsible for cognitive decline in AD patients (reviewed in ref. 153-155). It is noteworthy that studies have found loss of synapses, for example as measured by densities and numbers of synaptophysin-immunoreactive-presynaptic-boutons, to be 
substantially greater than loss of neurons in AD. ${ }^{156}$ Similar to the pattern of neuronal loss in AD, selectwe regions in brains of AD patients show the most pronounced synaptic alterations. These regions are the prefrontal cortex, the hippocampal stratum moleculare receiving inputs from the entorhinal cortex, and the stratum radiatum of hippocampal area CA129,34 Interestingly, these same regions are also known to shown alterations in synaptic content and function during aging, albeit much less pronounced than in AD. ${ }^{157-159}$ The exact mechanisms underlying the synaptic alterations and syraptic loss in AD remain however elusive.

Thus, the neuropathology of $\mathrm{AD}$ is characterized by $\mathrm{A} \beta$ containing plaques, hyperphosphorylated tau containg NFT, loss of neurons and loss of synapses. All of these hallmarks have a certain, partially overlapping, regional selectivity. To describe the temporal and regional development of NFT and neuritic plaques, neuropathologists have formulated certain staging schemes. Two of the most validated and used schemes for staging the neuropathology of AD are the Braak staging ${ }^{160}$ and the CERAD staging. ${ }^{161}$ The CERAD staging is based on (semi)quantitative assessment of neuritic plaques (CERAD), plaques and NFT in neocortex and hippocampus, ${ }_{3}^{161}$ whereas the Brak staging is mainly based on the hierarchic spreading of NFT. ${ }^{160}$

\section{Treatment of AD}

The current standard of medical care for mild to moderate AD includes treatment with acetylcholinesterase inhibitors and with an $\mathrm{N}$-methyl-D-aspartate receptor antagonist, memantine (which has recently been approved for the treatment of advanced AD in the United States). ${ }^{74}$ These drugs however have only modest symptomatic effects and are of limited benefit to most patients. ${ }^{74}$ Some medication is available for mood disorders, agitation or psychosis which can occur in late stages of the disease. Most importantly, however, no treatment with a strong disease-modifying effect is currently available. ${ }^{74,162}$

In summary, the growing aging population and the concomitant increasing incidence of various age-related diseases and disabilities place an enormous burden on society. To develop preventative and therapeutic strategies, it is crucial to identify the molecular and cellular mechanisms underlying aging and age-related disorders. $\mathrm{AD}$ is the most prevalent age-related mental health disorder with an enormous impact on individual patients, their families and society. Unfortunately, there is currently no efficient treatment strategy for AD at hand. The elucidation of the pathogenetic cascade of $\mathrm{AD}$ is therefore of utmost importance with the ultimate goal to develop effective preventative and therapeutic strategies to combat this devastating disease.

\section{The $A \beta$ cascade hypothesis of AD pathogenesis}

Several hypotheses on the pathogenetic cascade of AD have been formulated and none of these is without any controversy. The genetic evidence that familial cases of AD are caused by mutations in presenilins and in A.PP, and the biochemical evidence that these mutations lead to an enhanced generation of $A \beta$ protein have led to the proposal of the $A \beta$ cascade hypothesis of AD pathogenesis. ${ }^{2,163,164}$ In this respect, cellular and animal models have been and are still very useful in determining the functions and molecular characteristics of factors putatively involved in $\mathrm{AD}$ pathogenesis. ${ }^{165}$ 


\section{Amyloid precursor protein and its processing to $A \beta$}

APP is a member of the family of Amyloid Precursor-Like Proteins (APLP). 16.167 The APLP family comprises polypeptides with molecular weights varying between 110 and $140 \mathrm{kDa}$ which are ubiquitously expressed. The main members of this family are APP, APLPI and APLP2. The molecules can have various molecular weights as a result of alternative splicing and a vatiety of posttranslational modifications. ${ }^{168-171}$ Although APP has mainly been discussed in the literature as the source of $A B$, it has become evident over the last years that APP and its fragments have roles in normal physiology. Mice genetically engineered to lack both APP and APLP2 or both APLP1 and APLP2 die during late embryogenesis or shortly after birth while mice genetically engineered to be only deficient in either APP, APLP1, or APLP2 are viable and have only minor neurological deficits. ${ }^{12}$ APLP2 seems to have a critical role in these developmental problems: mice lacking $A P P$ and $A P L P 1$ are viable whereas mice lacking APP or APLP1 in combination with a lack of APLP2 die early postnatally. ${ }^{17}$ Furthermore, mice lacking all three APP genes have been reported to be subject to a high incidence of cortical dysplasia including excencephaly, polymicrogyria, and neuronal migration defects. ${ }^{174}$ These findings suggest an important role for the APLP gene family in neurodevelopment and neuronal migration. ${ }^{175}$ Besides this, APP has been proposed to play neurotrophic and neuroprotective roles. This is based on findings that the level of APP protein increased in neurons after various forms of injury to the central nervous system, ${ }^{176-178}$ and that various strains of APP overexpressing mice have shown enhanced synaptophysin immunoreactivity. ${ }^{176,179,180}$ Mice lacking APP showed furthermore substantial disturbances in long term potentiation in hippocampal area CA1 when investigated at higher: ages (i.e. 12 and 24 months of age). ${ }^{181}$ APP is a single transmembrane polypeptide that is translocated into the endoplasmic reticulum during translation. ${ }^{170}$ Posttranslationally modifications
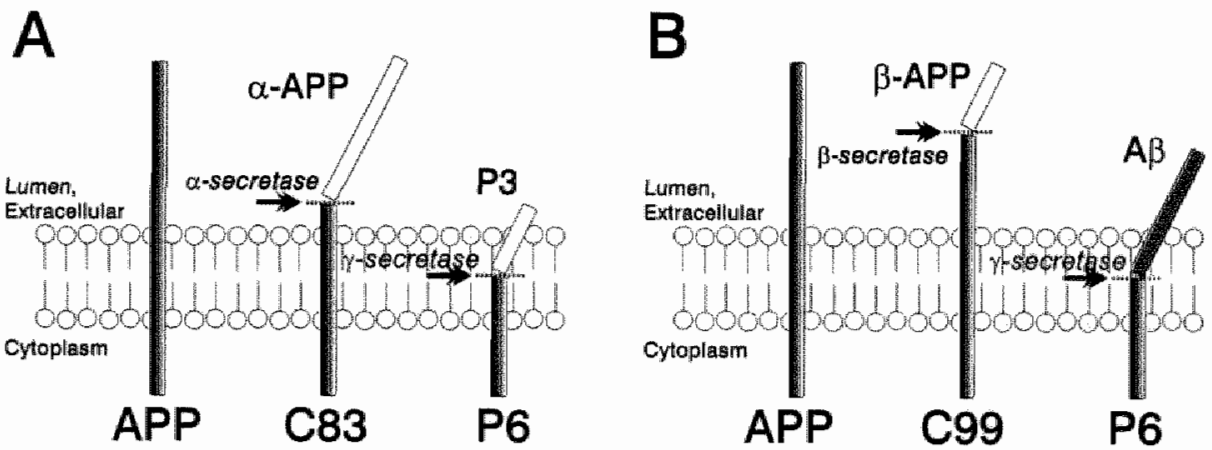

Figure 4. Scheme of the wo main pathways responsible for processing of Amylotd Precursor Protew. APP is a transmembrawe protein whth its C-lerminat site located within the cytoplasm and the N-terminal site in the extracellular space or in the lumen of vesicles belonging to the secretory system. A depicts pathway A in which APP is cleaved by

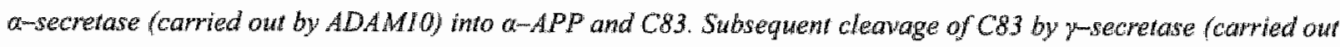
by a multipnotein complex with PSI and PS2 imwolwed) an then release whe P3 and PO fragments. $B$ deptcts pathway $B$ in which $A P P$ is cleaved by $\beta$-secretase (carried out by $B A C E-1$ ) into $\beta-A P P$ and $C 99$. Subsequent cleavge of $C 99$ by y-secretase can then release the Ap molecule and PO fragment. Although also occurring whiler normal conditions, pathway $B$ has been implicated to have the overhand in the pathogenesis of $A D$. 
occur in the secretory system of the cell where APP molecules "mature". 170 The half-life of APP is relatively brief (approximately 1 hour in most cell types). ${ }^{170}$ APP can undergo a variety of proteolytic cleavages thereby releasing derivatives into vesicle lumens (of organelles) and into extracellular space (Figure 4). These processes occur predominantly during and after the trafficking of APP through the secretory system. The first proteolytic cleavage is made by the $a$-secretase molecule and occurs 1.2 amino acids $\mathrm{N}$-terminal to the single transmembrane domain of APP. ${ }^{18,183}$ Recent studies have shown that certain members of the metalloprotease familly, i.e. the so called ADAM proteins, are responsible for $\alpha-$ secretase cleavage. ${ }^{124}$ APP cleavage by $\alpha-$-secretase results in the release of the large soluble ectodomain fragment ( $\alpha$-APPs) into the lumen/extracellular space and retention of an 83-residue $\mathrm{C}$-terminal fragment (C83) in the membrane (Figure $4 \mathrm{~A}) .^{1.34}$ Alternatively to $\alpha$-secretase cleavage, APP molecules can be cleaved by $\beta$-secretase generating a slightly smaller ectodomain fragment $(\beta-A P P s)$ ) and retaining a 99-residue $\mathrm{C}$-terminal fragment ( $\mathrm{C} 99)$ in the membrane (Figure $4 \mathrm{~B}$ ). ${ }^{185}$ Cleavage by $\beta$-secretase, is performed by the recently identified protein called $B A C E-1 .{ }^{186,187}$ This cleavage can be followed by cleavage at the $C$-terminus of the $A \beta$ region by a multi-protein complex called $\gamma$-secretase (Figure $4 B$ ). Presenilin- 1 and presenilin-2, are two out of many proteins forming this complex. ${ }^{188-190}$ Cleavage of $\mathrm{C} 99$ by $\gamma$-secretase generates the $\mathrm{A} \beta$ peptide (either $A \beta 40$ or $A \beta 42$ ) and a fragment called P6 (Figure $4 \mathrm{~B}$ ). Although $\alpha$-secretase cleavage normally has the overhand, both pathways of APP processing (Figure $4 \mathrm{~A}$ and B) can occur in physiologic conditions. ${ }^{191}$ In line with this, $A \beta$ has been detected in both cerebrospinal fluid and plasma in healthy subjects throughout life. ${ }^{.92}$ In addition to the generation of $A \beta$, the sequential actions of the $\alpha$-and $\gamma$-secretases produce a fragment called P3 (Figure 4A). ${ }^{193}$ Precisely where during its intracellular trafficking A.PP is cleaved by $\alpha-\beta$-, and $\gamma$-secretase cleavages is not settled yet. ${ }^{72}$ It is known that a-APPs can be generated at the plasma membrane ${ }^{194}$ and in vesicles of the late compartment of the cellular secretory systems. ${ }^{195}$ The $\beta$-secretase cleavage step can occur in the late compartment of the cellular secretory systems. ${ }^{196}$ The sites of $\gamma$-secretase cleavage are not entirely clear so far: ${ }^{197}$ Accumulating evidence suggests that $A \beta 40$ and $A \beta 42$ are mainly generated during the internalization and endosomal processing of APP. ${ }^{198,199}$ It is still elusive whether $A B 42$ is generated early in the secretory trafficking of APP or principally after APP has reached the cell surface. ${ }^{72}$ Evidence suggests that secretase-cleavages of APP occur at or near the cell surface, perllaps in substantial part in recycling endosomes. ${ }^{188,199}$ APP can be anterogradely transported by fast axonal transport systems ${ }^{200}$ and is present in axonal terminals. ${ }^{201}$ Other recent studies have reported that APP can also be transported retrogradely towards the cell body and to somatodendritic surfaces. ${ }^{202}$ APP is abundantly expressed in neurons which can secrete substantial amounts of $A \beta{ }^{\mid 91}$ Besides neurons, other cells types (astrocytes, microglia, and endothelial and smooth muscle cells) express APP and can release A $\beta .{ }^{191}$ Once formed, $A \beta$ peptides can be catabolized by proteases, some of which have recently been identified to be neprilysin, insulin-degrading enzyme, and angiotensin-converting enzyme. ${ }^{203,204}$ Thus, evidence accumulates for a physiological role of APP in development, neuronal migration, injury response and synaptic action. ${ }^{178,205}$ The exact functions and molecular targets of APP and the various fragments after secretase cleavages of APP remain largely unclear. 
Missense mutatation in APP, PS1 and PS2

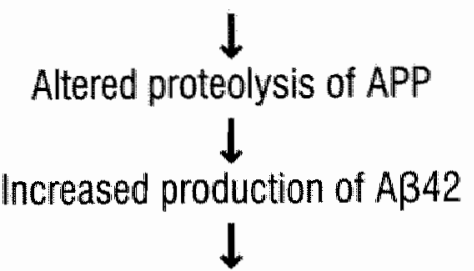

Progressive accumulation and aggregation in brain interstitial fluid

Deposition of aggregated $A \beta 42$ as diffuse plaques

Aggregation of $A \beta 40$ into diffuse $A \beta 42$ plaques

Accrual of certain plaque-associated proteins

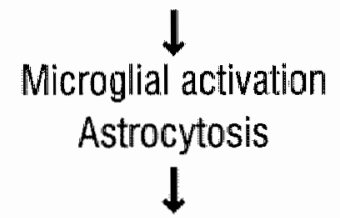

Progressive neuritic injury within amyloid plaques and elsewhere in the neuropil

Disruption of neuronal metabolic and ionic homeostasis and oxidative injury
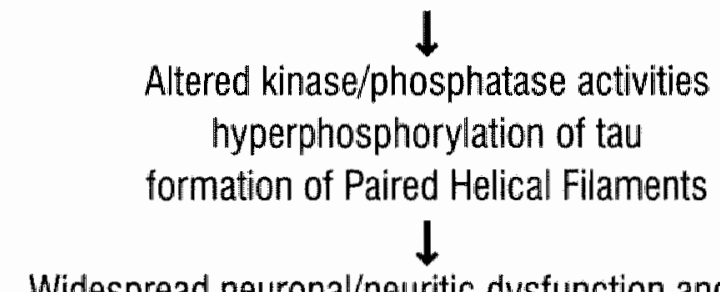

Widespread neuronal/neuritic dysfunction and death in hippocampus and cerebral cortex with progressive neurotransmitter deficits

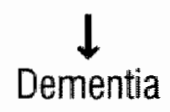

Figure 5. Scheme adapted from reference 72 depicting a sequence of pathogenetic steps of famitial forms of Alzheimer s disease according to the Af cascade hypothesis. 


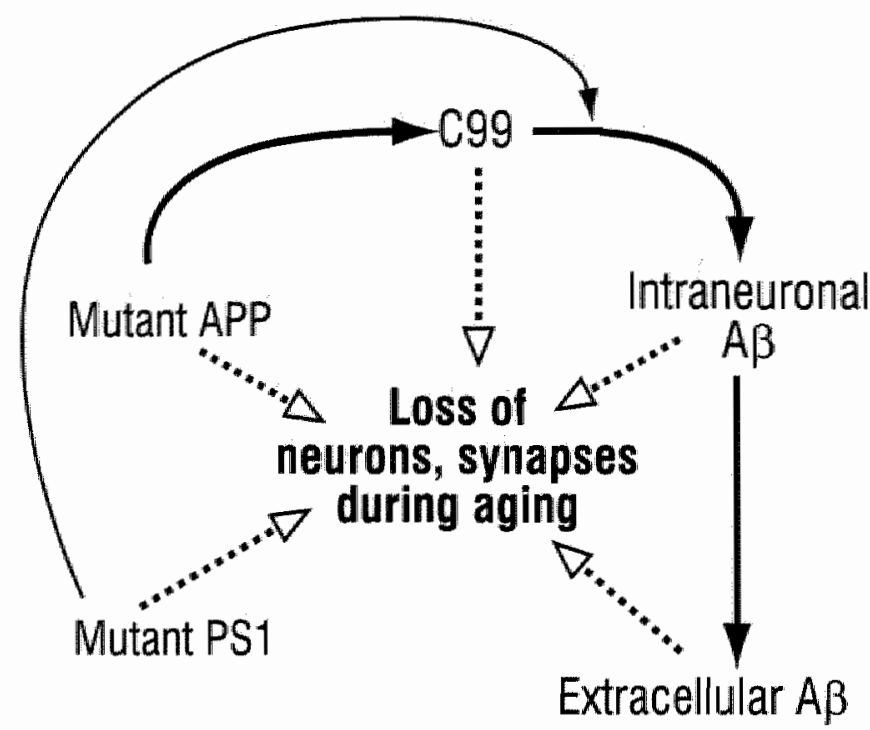

Figure 6. Scheme summarizing the major candidates for age-related loss of neurons and synapses in $A D$ according to the A $\beta$ cascade hypothesis. These candidates are mutant APP. mutant PSI, the C99 fragment of APP, intraneurowal A $\beta_{\text {. }}$ extraceltular oligomeric $A \beta$, and extracelular fibrillar $A B$. The dashed lines represent underermined associations. Note that PSI mediates $\gamma$-secretase cleavage of the C99 fragment of APP into AB (thin-lined arrow).

\section{Presenilins}

Presenilins (PS) are integral multipass membrane proteins responsible for regulated intramembrane proteolysis of various proteins such as APP, Notch 1, ErbB-4, and E-cadherin. ${ }^{189,206}$ PS1 and PS2 are expressed throughout the brain and their genes are located on chromosome $\mathbb{1}$ and 14 , respectively. Presenilins undergo constitutive endoproteolysis into fragments within endoplasmic reticulum vesicles and undergo stabilization in the Golgi apparatus. ${ }^{207}$ Once formed, multiple presenilin fragments can associate into higher molecular mass complexes. Mice genetically engineered to lack presenilins die early during development and display defects in neurogenesis and neuronal differentiation. ${ }^{208}$ These effects are mainly a result of defective Notch signaling. ${ }^{208}$ When the lethal embryonic effect of the PS1 deficit was circumvented by a conditional knockout approach, loss Cajall-Retzius cells in the neocortex and associated disturbances in cortical lamination and radial glial development were observed in live born animals. ${ }^{209}$ These findings indicate that PS1 is critically involved in neurodevelopment. As mentioned before, mutations in PS1 and PS2 cause early-onset cases of AD. Mice expressing the same mutations in presenilins as familial $\mathrm{AD}$ patients are born viable without major abnormalities but do show disturbances of calcium homeostasis, have increased levels of oxidative stress, ${ }^{210,211}$ and increased levels of $A \beta 42$ and $A \beta 433^{212}$ The increased generation of $A \beta$ is mediated by a mutation-induced gain-of-function of the $\gamma$-secretase cleavage of APP. Controversy exists whether the presenilins participate directly in $\gamma$-secretase cleavage or whether they play an indirect role via membrane trafficking. ${ }^{188.189}$ In summary, presenilins are involved in several important molecular signaling pathways and play important roles in normal development and physiology. 213,214 


\section{The cascade of events}

The $A \beta$ cascade hypothesis poses that $A \beta$ is the key molecule in the pathogenesis of $A D$ and that aggregation of $A \beta$ leads to oxidative injury, dysfunction and loss of synapses and neurons, the formation of neurofibrillary tangles, as well as to an inflammatory response (Figure 5) ${ }^{72,162,164,215}$ Exactly how A $\beta$ protein or altered processing of APP would result into the entire neurodegenerative cascade is a matter of intense research and scientific debate (for review see ${ }^{164,215}$ ). The main issue herein is which molecule( $s$ ) in the entire $A \beta$ cascade is (are) responsible for dysfunction and death of neurons and synapses. ${ }^{154}$ According to the original $A \beta$ cascade hypothesis, extracellular aggregations of fibrillar $A \beta$ would be responsible for neuronal dysfunction and loss. Several reports in the literature have suggested that extracellular aggregations of fibrillar $A \beta$ are responsible for neurodegeneration and death of neurons, ${ }^{217}$ raising the theory that the formation of extracellular $A \beta 40 / 42$ aggregations form the crucial event in $A D$. Studies on human and animal brains have indeed provided evidence that extracellular neuritic plaques are associated with a substantiall activation of microglial cells ${ }^{218,196}$ and astrocytes. ${ }^{21,220}$ Neuritic plaques have furthermore been shown to affect surrounding neurites in vivo, ${ }^{221,222}$ and fibrillar $A \beta$ aggregates have been shown to display neurotoxic effects in vitro. ${ }^{223,224}$ Nonetheless, it has remained unclear whether $A \beta$-containing neuritic plaques are actually associated with neuronal cell death in vivo. Several studies with APP transgenic mice, which have abundant age-related plaque formation, have not led to convincing evidence for plaque-associated neurotoxicity. ${ }^{180,216}$

On the basis of recent studies which suggested that oligomeric extracellular species of $A \beta$ protein, rather than the fibrillar forms of $A \beta$, induced neurotoxicity in vitro, ${ }^{223}$ focus has shifted towards oligomeric forms of $A \beta$ as being the culprit in neurotoxicity. ${ }^{72,155}$ Oligomeric $A \beta$ species are complexes of a small number of $A \beta$ peptides. These complexes are mainly soluble and have been shown to induce various synaptic alterations. ${ }^{155}$ They can exist both extra- and intracellularly and are difficult to detect with immunohistochemical techniques. Again, actual prove that soluble oligomeric species of $A \beta$ are connected to neuron loss in vivo is not at hand. Given that $A \beta$ peptides are generated intracellularly (e.g. in plasma membranes and in membranes of the secretory/endosomal system) scientists have attempted to identify $\mathrm{A} \beta$ species within neurons, which turned out to be rather difficult. Very recently, $A \beta$ species have been detected within neurons in the brains of $\mathrm{AD}$ patients and not in controls, ${ }^{226}$ pointing to a potentially important role for intraneuronal species of $A \beta$.

Besides the putative neurotoxic properties of A $\beta$, mutant APP itself or APP fragments after $\beta$-secretase cleavage have also been suggested to induce neurotoxicity. Several reports in the literature for example, have claimed that the C99 fragment of APP induces neuron loss. 227.221 To further complicate the issue, another recent study indicated that mutant PS 1 might be responsible for neuron loss. ${ }^{229}$ It thus remains to be clearly established which molecule(s) is (are) connected with age-related loss of neurons in vivo. The major candidates are summarized in Figure 6. An important confounding factor in most of the discussed studies is that quantification of neuronal numbers (to asses reductions in neuronal numbers) was carried out with conventional quantitative methods which are subjected to considerable bias and therefore do not answer the research questions accurately. ${ }^{140,230}$ Only a limited number of studies was carried out with appropriate 


\section{Intraduction}

methodology in this respect, i.e. modern design-based stereology which allows for precise quantification of the total numbers of neurons and possible changes thereof. ${ }^{140,230}$

The issues raised above on the identification of the molecules responsible for age-related loss of neurons in $\mathrm{AD}$ are also applicable for the identification of the molecules responsible for age-related loss of synapses. ${ }^{155: 231}$. The high importance of synaptic alterations for AD pathogenesis is based on the observations that synaptic alterations precede frank signs of neuron loss in $\mathrm{AD}$ pathogenesis, ${ }^{\text {ss }}$ and that loss of synapses correlates well with cognitive decline in $\mathrm{AD}$ patients. ${ }^{232}$ The identification of the molecules responsible for age-related synapse loss in $\mathrm{AD}$ thus also awaits elucidation.

The pathogenesis of sporadic $\mathrm{AD}$ has been proposed to largely overlap with that of familial $\mathrm{AD}$, although the influence of aging and the $A$ poE-genotype are much more pronounced in sporadic AD. For the pathogenesis of sporadic AD, where specific mutations in APP and PS cannot account for the pathogenesis, recent evidence may show out to be of high relevance. These studies suggest that age-related oxidative stress mediates alternate APP processing towards $A \beta$ production ${ }^{253}$ that aging is associated with higher levels of BACE activity, ${ }^{234}$ and that aging is associated with a reduced neprilysin activity. ${ }^{235}$ The ApoE4 genotype has furthermore been reported to enhance $A B$ generation and increase oxidative stress although the underlying mechanism remains largely unclear. ${ }^{236}$

Despite the debates about the exact molecules responsible for neuronal and synaptic loss and the exact temporal sequence of the $A \beta$ cascade, evidence in fawor of the $A \beta$ cascade hypothesis is accumulating. ${ }^{162,164}$ As a result, the $A \beta$ cascade hypothesis is currently considered to be the main hypothesis on AD pathogenesis. ${ }^{72,162,164}$ Nonetheless, the $A \beta$ cascade hypothesis has remained controversial. One reason for this controversy is the lack of clear evidence of neuron loss in transgenic mice with abundant $A \beta$ formation. ${ }^{71}$ A second reason is the observation that the burden of neuritic plaques does not correlate with the clinical phenotype in $A D$ patients whereas occurrence of NFT and reductions in neuronal or synaptic numbers do ${ }^{73_{2}, 37}$ In alternative hypotheses on AD pathogenesis, tau protein abnormalities, ${ }^{238,239}$ heavy metals, ${ }^{240,241}$ vascular factors, ${ }^{242}$ and disturbed cholesterol homeostasis ${ }^{2431}$ have been proposed as central players. It should be noted that these hypotheses are alternative but not mutually exclusive. When appropriately used and interpreted with caution, animal models can be very useful in deciphering the contributions of proposed molecules and mechanisms.

In summary, although several genetic, molecular and biological investigations argue for the $A \beta$ cascade hypothesis, this hypothesis and its temporal sequence of events involved remain to be appropriately tested in wivo. Ultimately, the complex pathogenetic changes involved in AD result in neuritic dystrophy, loss of neurons and synapses and an activation of the immune system. 


\section{QUESTIONS AND HYPOTHESES ADDRESSED IN THIS THESIS}

i) The development of modern design-based stereology has prompted many neuroscientists (especially those working on alterations of neuron numbers) to use this methodology in investigations of neuronal death/loss. However, two important questions have remained unaddressed in the use of stereology. Does the analysis of sets of sections systematically and randomly sampled spanning the entire brain regions of interest (SRS series) per animal lead to other results than the analysis of one single section per animal? Can groups of animals show different mean total numbers of neurons but similar mean neuronal densities, which would limit the impact of neuronal density data in investigations of neuronal death/loss? To address this question, quantifications of neuron numbers and regional volumes were performed on SRS series and the obtained results were compared to data obtained by parallel analyses on a single "representative" section per animal. I hypothesized that data obtained by analyzing SRS series would substantially differ from data obtained by analyzing a single "representative" section per animal and that therefore conclusions based on these results differ as well. Furthermore, I hypothesized that results analyzed and expressed as total numbers of neurons can substantially differ from results analyzed and expressed as neuronal densities and may thereby lead to different conclusions on the same material. These hypotheses were tested in the study described in Chapter 2.

ii) The mechanisms which underlie the vulnerability of selective types of neurons in the aging brain remain largely unknown. Previous studies have shown a striking cell-type-specificity of age-related decline in the rate of nDNA repair during aging in the mouse brain. In Section 2.3. of this Chapter and in Chapter 3, I hypothesized that types of neuron with an age-related decline in the rate of nDNA repair show an accumulation of unrepaired nDNA damage during aging without an age-related loss of neurons whereas types of neuron without an age-related decline in the rate of nDNA repair show no accumulation of unrepaired nDNA damage during aging but do show an age-related loss of neurons. This hypothesis was tested for the first time in a controlled study on the same species, i.e., a cohort of aging mice of the same strain was investigated cell-type-specifically for age-related accumulation of unrepaired nDNA damage and age-related reductions in numbers of neurons. In Chapter 4 the study is described to test the hypothesis on four distinct types of neurons in the aging mouse brain, i.e. hippocampal pyramidal cells, hippocampal granule cells, cerebellar granule cells and cerebellar Purkinje cells.

iii) A major line of evidence has indicated that inereased production of free radicals and oxidative stress are central events in aging. ${ }^{2}$ Current evidence on the role of oxidative stress in aging and $\mathrm{AD}$ and the potential value of the use of endogenous and exogenous 
antioxidants as a preventative strategy for $\mathrm{AD}$ are discussed in Chapter 5 . Another strategy, caloric restriction, has been known for years to extend mean and maximum life span in a variety of species, allhough little is known about the exact effects of caloric restriction on the aging process in the brain, and on potential differential effects of caloric restriction on different brain regions and types of neurons in the brain during aging? On the basis of these issues, I hypothesized that a combination of exogenous and endogenous antioxidants with caloric restriction is a good strategy to attenuate age-related alterations in the brain. Specifically, I hypothesized that upregulation of an endogenous antioxidant (by transgenic overexpression of human $\mathrm{Cu} / \mathrm{Zn}$-superoxide dismutase in mice) together with a diet restricted in calories and enriched in exogenous antioxidants would attenuate age-related alterations in the hippocampus. Chapter 6 describes the study to test this hypothesis on age-related morphologic and molecular alterations in the mouse hippocampus.

iv) Despite general agreement that the $A \beta$ cascade hypothesis is the main one for $A D$ pathogenesis, it remains unclear whether any of the molecules - and if so which - mentioned in the cascade is responsible for age-related loss of neurons and synapses in vivo. I hypothesized that intraneuronal $A \beta$ rather than the other candidates (Figure 6) is connected with age-related loss of hippocampal neurons and synaptophysin-immunoreactive-presynaptic boutons. With the aim to assess age-related effects of the mentioned candidates (Figure 6), a systematic investigation was carried out to find out which molecules of the A $\beta$ pathway are involved in synapse and neuron loss. Chapter 7 focuses on the question whether neuronal expression of $C 99$ fragment results in age-related hippocampal neuron and synapse loss, Chapters 8 on the question whether extracellular $A \beta$ aggregations in the form of plaques, intraneuronal A $\beta$ or mutant PS1 result in age-related hippocampal neuron loss. Next, Chapter 9 focuses on the question whether mutant APP, mutant PS1, extracellular A $\beta$ aggregations or other A $\beta$-dependent events are associated with age-related synapse loss. I hypothesized that the C99 fragment of APP, mutant APP itself and mutant PSI itself do not result into loss of hippocampal neurons or synapses, whereas both extracellular $A \beta$ aggregations and intracellular $A \beta$ do play important roles in hippocampal neuron and synapse loss. The corresponding investigations were carried out with a set of novel transgenic mice.

v) As mentioned in section 3.6, neuropathologic alterations in $A D$ affect selective regions and types of neurons such as pyramidal neurons in the neoortex and hippocampus. These same regions and types of neurons are known to be affected in normal aging, although to a lesser degree. From this similarity the question arises whether the degenerative processes occurring during normal aging are the same as those occuring in $\mathrm{AD}$ ? In this respect, I hypothesized that degenerative processes that occur during aging set the stage for degenerative events involved in AD pathogenesis, but that the actual cellular mechanism which underlie AD are different than those which underlie aging. More specifically, I hypothesized that aging is associated with increased oxidative stress, accumulation of DNA damage, and moderate synaptic disturbances, that these age-related events are the 'sine-qua-non' for $\mathrm{AD}$ pathogenesis but that the neurode- 
generative events in $\mathrm{AD}$ far surpass and are partly different from those in aging. In particular, I hypothesize that alternate processing of APP, intraneuronal accumulation of $A \beta$ within the endolysosomal system with subsequent disturbances in cellular function and viabilty are events that are not substantially involved in normal aging but do play crucial roles in AD. These hypotheses were tested in different experiments which are described in several chapters throughout this thesis. The results from the experiments testing these hypotheses are discussed in Chapter 10.

\section{REFERENCES}

1. Barja G: Free radicals and aging. Trends Neurosci 2004, 27:595-600

2. Kirkwood TB, Austad SN: Why do we age? Nature 2000, 408:233-238.

3. Andersen JK: Oxidative stress in neurodegeneration: cause or consequence? Nat Med 2004, 10 Suppl:S1825

4. Mattson MP, Chan SL, Duan W: Modification of brain aging and meurodegenerative disorders by genes, diet, and behavior. Physiol Rev 2002, 82:637-672

5. Mattson MP, Duan W, Chan SL, Cheng A, Haughey N, Gary DS, Guo Z, Lee J, Furukawa K: Neuroprotective and neurorestorative signal transduction mechanisms in brain aging: modification by genes, diet and behavior. Neurobiol Aging 2002, 23:695

6. Harman D: Aging: overview. Ann N Y Acad Sci 2001, 928:1-21

7. Droge W: Free radicals in the physiological control of cell function. Physiol Rev 2002, 82:47-95

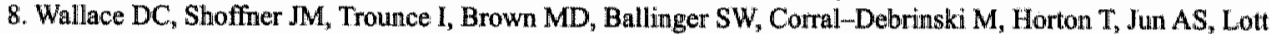
MT: Mitochondrial DNA mutations in human degenerative diseases and aging. Biochim Biophys Acta 1995, 1271:141-151

9. Wallace DC: Mitochondrial diseases in man and mouse. Science $1999,283: 1482-1488$

10. Wright $A F$, Jacobson SG, Cideciyan AV, Roman AJ, Shu X, Vlachantoni $D$, Mclnnes RR, Riemersma RA: Lifespan and mitochondrial control of neurodegeneration. Nat Genet 2004, 36:1153-1158

11. Drew B, Phaneuf S, Dirks A, Selman C, Gredilla R, Lezza A, Barja G, Leeuwenburgh C: Effects of aging and calloric restriction on mitochondrial energy production in gastrocnemius muscle and heart. Am J Physiol Regul Integr Comp Physiol 2003, 284:R474-480

12. Ward WF: Protein degradation in the aging organism. Prog Mol Subcell Biol 2002, 29:35-42

13. van Leeuwen FW, Gerez L, Benne R, Hol EM: +1 Proteins and aging. Int J Biochem Cell Biol 2002, 34:15021505

14. Schmitz C, Axmacher B, Zunker U, Korr H: Age-related changes of DNA repair and mitochondrial DNA synthesis in the mouse brain. Acta Neuropathol (Berl) 1999, 97:71-81.

15. Schmitz C, Materne $S$, Korr H: Cell-Type-Specific Differences in Age-Related Changes of DNA Repair in the Mouse Brain - Molecular Basis for a New Approach to Understand the Selectiwe Neuronal Vulnerability in Alzheimer's Disease. J Alzheimers Dis 1999, 1:387-407

16. Lu T, Pan Y, Kao SY, Li C, Kohane I, Chan J, Yankner BA: Gene regulation and DNA damage in the ageing human brain. Nature 2004, 429:883-891

17. Corral-Debrinski M, Horton T, Lott MT, Shoffner JM, McKee AC, Beal MF, Graluam BH, Wallace DC: Marked changes in mitochondrial DNA deletion levels in Alzheimer brains. Genomics 1994, 23:471-476

18. Mattson MP, Pedersen WA, Duan W, Culmsee C, Camandola S: Cellular and molecular mechanisms underlying perturbed energy metabolism and neuronal degeneration in Alzheimer"s and Parkinson"s diseases. Ann N Y Acad Sci 1999, 893:154-175

19. Mattson MP: Neuroprotective signaling and the aging brain: take away my food and let me run. Brain Res $2000,886: 47-53$

20. Lee CK, Weindruch R, Prolla TA: Gene-expression profile of the ageing brain in mice. Nat Genet 2000 , 25:294-297

21. Mattson MP: Calcium as sculptor and destroyer of neural circuitry. Exp Gerontol 1992, 27:29-49

22. Jin LW, Saitoh T: Changes in protein kinases in brain aging and Alzheimer's disease. Implications for drug therapy. Duugs Aging 1995, 6:136-149

23. Suh $Y$ : Cell signaling in aging and apoptosis. Mech Ageing Dev 2002, 123:881-890

24. Suh Y, Lee KA, Kim WH, Han BG, Vijg J, Park SC: Aging alters the apoptotic response to genotoxic stress. Nat Med 2002, 8:3-4 
25. Brum UT, Teman A: The mitochondrial-lysosomal axis theory of aging accumulation of damaged milochondrig a result of imperfect antophagocytosis. Eur ] Bichem 2002, 269:1996-2002

26. Bossy-Wetwel $E_{\text {; }}$ Schwarzentacther $R$, Lipton SA: Molecular pathways to neurodegeneration. Nat Med 2004, $105 \operatorname{mpp} .52-9$

27. Keller JN, Dimayuga E, Chen Q, Thorpe J, Gee J, Ding Q, Autophagy, proteasomes, lipofuscin, and oxidative stress the aging brain. Int J Biochem Cell Biol 2004, 36.2376-2391

28. Keller JN, Gee J, Ding Q: The proteasome in brain aging. Ageing Res Rew 2002, 1:279-293

29. Morrison $\mathrm{JH}$, Hof PR: Selectiwe vulnerability of corticocortical and hippocampal circuits in aging and Alzheimer ${ }^{*}$ disease. Prog Brain Res 2002, 136:467-486

30. Mielke R, Kessler J, Szelles B, Herholz K, Wienhard K, Heiss WD; Normal and pathological aging-findings of positron-emission-tomography. J Neural Transm 1998, 105:821-837

31. Tisserand DJ, Pruessner JC Samz Arigita EJ, van Boxtel MP, Evans AC, Jolles I, Uylings HB: Regional frontal cortical volumes decrease differentially in aging: an MRil study to compare volumetric approaches and voxel-brased morphometry. Neuroinage 2002, 17:657-669

32. Mandavilli BS, Rao KS: Neurons in the cerebral cortex are most susceptible to DNA-damage in aging rat brain. Biochem Mol Biol Int 1996, 40:507-514

33. Giamakopoulos $\mathrm{P}$, Gold $\mathrm{G}$, Michel JP, Bouras $\mathrm{C}$ : Cellular wulnerability im brain aging and Alzheimer's disease. Clinical correlates and molecular background. Ann Med Interne (Paris) 1998, 149:187-191

34. Hof PR, Morrison JH: The aging brain: morphomolecular senescence of cortical circuits. Trends Neurosci $2004,27: 607-613$

35. Ashok BT, Ali R: The aging paradox: free radical theory of aging. Exp Gerontol 1999, 34:293-303

36. Finkel T, Holbrook NJ: Oxidants, oxidative stress and the biology of ageing. Nature 2000, 408:239-247.

37. Knight IA: The biochemistry of aging. Adv Clin Chem 2000, 35:1-62

38. Meydani M, Lipman RD, Han SN, Wu D, Beharka A, Martin KR, Bronson R, Cao G, Smith D, Meydani SN: The effect of long-term dietary supplementation with antioxidants. Ann N Y Acad Sci 1998, 854:352-360

39. Melov $S$, Coskun $P$, Patel M, Tuinstra $\mathbb{R}$, Cottrell B, Jun AS, Zastawny TH, Dizdaroglu M, Goodman SI, Huang TT, Miziorko H, Epstein CJ, Wallace DC: Mitochondrial disease in superoxide dismutase 2 mutant mice. Proc Natl Acad Sci U S A 1999, 96:846-851

40. Van Remmen $H_{\text {, Ikeno }}$, Hamilton M, Pahlavani M, Wolf N, Thorpe SR, Alderson NL, Baynes JW, Epstein CI, Huang TT, Nelson J, Strong R, Richardson A: Life-long reduction in MnSOD activity results in increased DNA damage and higher incidence of cancer but does not accelerate aging. Physiol Genomics 2003, 16:29 37

41. Kawase $M$, Murakami $K$, Fujimura $M_{y}$ Morita-Fujimura $Y$, Gasche $Y$, Kondo $T$, Scott RW, Chan PH: Exacerbation of delayed cell injury after transient global ischemia in mutani mice with CuZn superoxide dismuttase deficiency. Stroke 1999, 30:1962-1968

42. Maier CM, Chan PH: Role of superoxide dismutases in oxidative damage and neurodegenerative disorders. Neuroscientist 2002, 8:323-334

43. Melow S, Doctrow SR, Schneider JA, Haberson J, Patel M, Coskun PE, Huffman K, Wallace DC, Malfroy B. Lifespan extension and rescue of spongiform encephalopathy in superoxide dismutase 2 nullizygous mice treated with superoxide dismutase-catalase mimetics. J Neurosci 2001, 21:8348-8353.

44. Liu J, Attmna $H_{3}$ Kuratstune $H_{3}$ Ames BN: Delaying brain mitochondrial decay and aging with mitochondrial antioxidants and metabolites. Ann N Y Acad Sci 2002, 959:133-166

45. Liu J Killilea DW, Ames $B N$ : Age-associated mitochondrial oxidative decay: improvement of carnitine acety/transferase substrate-binding affinity and activity in brain by feeding old rats acetyl-L - carnitine and/or R-alplua-lipoic acid. Proc Natl Acad Sci U S A 2002,99:1876-1881

46. Sohall RS, Mockett $\mathrm{RJ}_{n}$ Ort WC. Mechanisms of aging: an appraisal of the oxidatiwe stress hypothesis. Free Radic Biol Med 2002, 33:575-586

47. OrT WC, Solual RS: Extension of life-span by overexpression of superoxide dismutase and catalase in Drosophila melamogaster. Science 1994, 263:1128-1130

48. Aigaki T, Seong KH. Matsuo T: Longevity determination genes in Drosophila melanogaster. Mech Ageing Dev 2002, 123:1531-154!

49. Rogina B, Helfand SL: Cu, Zn superoxide dismutase deficiency accelerates the time course of an age-related marker in Drosophila melanogaster. Biogerontology 2000, 1:163-169

50. Coling DE, Yu KC, Somand D, Satar B, Bai U, Huang TT, Seidman MD, Epstein CJ, Mhatre AN, Lalwani AK: Effect of SODI overexpression on age- and noise-related hearing loss. Free Radic Biol Med 2003 , 34:873-880

51. On WC, Sohal RS: Does owerexpression of Cu,Zn-SOD extend life span in Drosophila melanogaster? Exp Gerontol 2003, $38: 227,230$

52. Cardozo-Pelaez F, Song S, Parthasarathy A, Epstein CJ, Sanchez-Ramos J: Attenuation of age-dependent oxidative danmge to DNA and protein in brainstem of $\mathrm{Tg}$ Cu/Zn SOD mice. Neurobiol Aging 1998, 19:311316 
53. Galli RL, Shukitt-Hale B, Youdim KA, Joseph JA: Fruit polyphenolios and brain aging muthitional interventions tangeting age-related neuronal and behavional deficits. Am $\mathbb{N}$ Y Acod Soi 2002, 959:128-132

54. Cotman CW, Head $\mathbb{E}$, Muggenburg BA, Zicker S, Milgram NW. Brain aging in the caninc: diet enriched in antioxidants reduces cognitive dysfunction. Neurobiol Aging 2002, 23:809-818

55. MeCay CM, Cowell MF, Maynard A: The effect of retarded growth upon the length of lifespan and upon ultimate body size. I Nutrition 1935:63-79

56. Barrows CH, Kokkonen GC: Diet and hife extensions in amimall model systems. Age $1978,1: 131-143$

57. Weindruch $R$, Walford RL, Fligiel $S$, Guthrie $D$ : The netardation of aging in mice by dietary restriction: longevity, cancer, immunity and hifetime energy intake. J Nurr 1986, $116.641-654$

58. Mattson MP, Duan W, Lee J, Guo Z: Suppression of brain aging and meurodegenerative disorders by dietary restriction and environmental enrichment: molecular mechawsms. Medh Ageing Dev 2001, 122:757 778

59. Sohal RS, Weindrach R: Oxidative stress, caloric restriction, and aging. Science 1996, 273:59-63

60. Rao KS: Dietary calorie restriction, DNA-repair and brain aging. Mol Cell Biochem 2003, 253:313-318

61. Shi L, Poe BH, Constance Linville M, Sonntag WE, Brunso-Bechtold JK: Caloric restricted male rats demonstrate fewer synapses in layer 2 of sensorimotor contex. Brain Res $2002,931,32 \ldots 40$

62. Obin M, Halbleib M, Lipman $R$, Camoll $K$, Taylor A, Bronson R: Calorie restriction increases light-dependent photoreceptor cell loss in the neural retina of fischer 344 rats. Neurobiol Aging 2000, 21:639-645

63. Scarmeas $\mathrm{N}$, Levy $G$, Tang MX, Manly J, Stem $Y$ : Influence of leisure activity on the incidence of Alzheimer"s disease. Neurology $2001,57 n 2236-2242$

64. Lindsay J, Laurin D, Verreault R, Hebert R, Helliwell B, Hill GB, McDowell I: Risk thotors for Alzheimer's disease: a prospective analysis from the Canadian Study of Health and Aging. Am J Epideniol 2002, 156:445453

65. Kawas C, Resnick S, Morrison A, Brookmeyer $\mathbb{R}$, Corrada M, Zonderman A, Bacal C. Lingle DD, Metter $\mathbb{E}$ : A prospective study of estrogen replacement therapy and the risk of developing Alzheimer's disense: the Baltumore Longitudinal Study of Aging. Neurology 1997, 48:1517-1521

66. Baldereschi M, Di Carlo A, Lepore: V, Bracco L, Maggi S, Grigoletto F, Scarlato G, Amaducoi L: Estrogenreplacement therapy' and Alzheimer's disease in the Italian Longitudinal Study on Aging. Neurology 1998 , 50:996-11002

67. Waring SC, Rocca WA, Petersen RC, O'Brien PC, Tangalos EG, Kokmen E: Postmenopausal estrogen replacement therapy and risk of $A D$ : a population-based study. Neurology 1999, 52:965-970

68. Woolley CS: Estrogen-mediated structural and functional symaptic plasticity in the female rat hippocampus. Horm Behav 1998, 34:140-148

69. Alzheimer A: Ueber eine eigenartige Erkrankung der Hirnrinde. Allg Zschr Psych 1907, 64:146 148

70. Kraepelin E: Psychiatrie. Ein lehrbuch für Studierende und Årtze. Leipzig, Verlag, 1910

71. Mudher A, Lovestone S: Alzheimer's disease-do tauists and baptists finally shake hands? Trends Neurosci $2002,25: 22-26$

72. Selkoe DJ: Alzheimer's disease: genes, proteins, and therapy. Physiol Rev 2001, 81:741-766.

73. Gianmakopoulos P, Hermann FR, Bussiere T, Bouras C, Kovari E, Perl DP, Morrison JH, Gold G, Hof PR: Tangle and neuron numbers, but mot amyloid load, predict cognitive status in Alzheimer's disease. Neurology $2003,60: 1495-1500$

74. Cummings IL: Alzheimer's disease. N Engl J Med 2004, 351:56-67

75. Diagnostic and statistical manual of mental disorders, 4th ed.. DSM-IV, American Fsychiatric Association, 1994

76. Kawas CH: Clinical practice. Early Alzheimer's disease. N Engl J Med 2003, 349:1056-1063

77. McKhann G, Drachman D, Folstein M, Katzman R, Price D, Stadlan EM: Clinical diagnosisg of Alzheimer discase: report of the NINCDS-ADRDA Work Group under the auspices of Departinent of Health and Human Services Task Force on Alzheimer"s Disease. Neurology 1984, 34:939-944

78. Cummings JL, Cole G: Alzheimer disease. Jama 2002, 287:2335-2338.

79. Health Council of the Netherlands: Dementia. 2002:publication no. 2002/2004E.

80. Jorm AF: Cross-mational comparisons of the occurrence of Alzheimer ${ }^{8}$ and vascular dementias. Eur Arch Psychiatry Clin Neurosei $1991,240: 218-222$

81. Breteler MM, Claus JJ, van Duijn CM, Laumer LJ, Hofman A: Epidemiology of Alahoimer's tisease. Epidemiol Rev 1992, 14:59-82

82. Bowirrat A, Treves TA, Friedland RP, Korczyn AD: Prevalence of Alzheimer's type dementia in an elderly Arab population. Eur J Neurol 2001, 8:119-123

83. Stevens ' $T$, Livingston $G$, Kitchen $G$, Manela M, Walker $Z$, Katona $C$ : Islington study of dementia subtypes in the community. Br J Psychiatry 2002, 180:270-276

84. Dewachter I, Van Leuven F: Secretases as targets for the treatment of Alaheimer's disease: the prospects. Lancet Neurol 2002, 1:409-416

85. Mayeux R: Epidemiology of neurodegeneration. Annu Rev Neurosci 2003, 26:81-104 


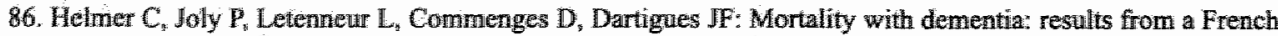
prospective community-based cohort. Am I Epidemiol 2001, 154:642-648

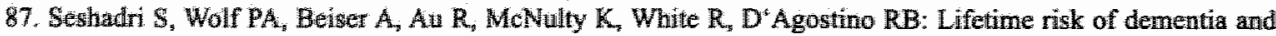
Alzheimer 8 disease. The impact of mortality on risk estimates in the Framingham 5 tudy. Neurology 1997 , 49:1498-1504

88. McDonnell J, Redekop WK, van der Roer N, Goes $\mathbb{E}$, Ruitenberg A, Busschibach JJ, Breteler MM, Rutten FF: The cost of treatment of Alzhemerts disease in The Netherlands: a regression-based sinulation model. Pharmatcoveonornics 2001, 19:379-390

89. Chartier-Harlin MC, Crawford F, Houlden $\mathrm{H}_{3}$ Warren $\mathrm{A}$, Hughes $\mathrm{D}$, Fidani L, Goate A, Rossor M, Roques $P$, Hardy $J_{\text {; }}$ et al.: Early-onset Alzheimer ${ }^{*}$ s disease caused by mutations at codon 717 of the beta-anryloid precursor protein gene Nature 1991, 353:844-846

90. Janssen JC. Beck JA, Campbell TA, Dickinson A, Fox NC, Harvey RJ Houlden $H$, Rossor MN, Collinge J: Early onset familial Alzheimer's disease: Mutation frequency in 31 families. Neurology 2003, 60:235-239.

91. St George-Hyslop PH, Tanzi RE, Polinsky RJ, Haines IL, Nee L, Watkins PC, Myers RH, Feldman RG, Pollen D, Drachman D, et al: The genetic defect causing familial Alzheimer"s disease maps on chromosome 21. Science 1987, 235:885 890

92. Schellenberg GD, Bird TD, Wijsman EM, On HT, Anderson L, Nemens E, White JA, Bonnycastle L, Weber JL, Alonso ME, et al.: Genetic línkage evidence for a familial Alzheimer"s disease locus on chromosome 14 Science 1992, 258:668-671

93. Van Broeckhoven C, Backhovens $\mathrm{H}_{\text {, Cruts }} \mathrm{M}_{\text {, De Winter }}$, Bruyland $\mathrm{M}$, Cras P, Martin JJ: Mapping of a gene predisposing to early-onset Alzheimer"s disease to chromosome 14q24.3. Nat Genet 1992, 2*335 339

94. St George-Hyslop P, Haines J, Rogaew E, Mortilla M, Vaula G, Pericalk-Vance M, Foncin JF, Montesi M, Bruni A, Sorbi S, al.; Genetic evidence for a novel familial Alzheimer's disease locus on chromosome 14 . Nat Genet 1992, 2:330-334

95. Levy-Lahad E, Wijsman EM, Nemens E, Anderson L, Goddard KA, Weber JL, Bird TD, Schellenberg GD: A familial Alzheimer's disease locus on chromosome 1. Science 1995, 269:970-973

96. Rogaew EJ, sherrington $R$, Rogaeva EA, Levesque $G_{y}$ Ikeda M, Liang Y, Chi H, Lin C, Holman K, Tsuda T, et al.: Familial Alzheimer's disease in kindreds with missense mutationts in a gene on chromosome 1 related to the Alzheimer's disease type 3 gene. Nature 1995, 376:775-778

97. Pericak-Vance MA, Bebout $\mathbf{L}$, Gaskell PC, Jr., Yamaoka $\mathbf{L H}$, Hung WY, Alberts MJ, Walker AP, Bartlett RJ, Haynes CA, Welsh KA, et al.: Linkage studies in familial Alzheimer disease: evidence for chromosome 19 linkage. Am I Hum Genet 1991, 48:1034-1050

98. Saunders AM, Strittmatter WJ, Sclimechel D, George-Hyslop PH, Pericak-Vance MA, Joo SH, Rosi BL, Gusella JF, Crapper-MacLachlan DR, Alberts $\mathrm{MJ}_{\text {, }}$ et al: : Association of apolipoprotein $\mathbb{E}$ allele epsilon 4 with late-onset familial and sporadic Alzheimer"s disease. Neurology 1993, 43:1467-1472

99. Strittmatter WJ, Saunders AM, Schmechel D, Pericak-Vance M, Enghild J, Salvesen GS, Roses AD: Apolipoprotein $\mathrm{E}^{*}$ high-avidity binding to beta-amyloid and increased frequency of type 4 allele in late-onset familial Alzheimer disease. Proc Natl Acad Sci U S A 1993, 90:1977-1981

100. Corder EH, Saunders AM, Strittmatter WJ, Schmechel DE, Gaskell PC, Small GW, Roses AD, Haines JL, Pericak-Vance MA: Gene dose of apolipoprotein E type 4 allele and the risk of Alzheimer's disease in Uate onset families. Science 1993, 261:921-923

101. Slooter AJ, Cruts M, Kalmijn S, Hofman A, Breteler MM, Van Broeckhoven C, van Duijn CM: Risk estimates of dementia by apolipoprotein $\mathrm{B}$ genotypes from a population-based incidence study: the Rotterdam Study. Arch Meurol 1998, 55:964-968

102. Stern $X$, Gurland $B$, Tatemich TK, Tang MX, Wilder D, Mayeux R: Infuence of education and occupation on the incidence of Alzheimer's disease. Jama 1994, 271:1004-1010

103. Hall KS, Gao S, Unverzagt FW, Hendrie HC: Low education and childhood rural residence: risk for Alzheimer's disease in African Americans. Neurology 2000,54,95,99

104. Moceri VM, Kukull WA, Emanual I, wan Belle G, Starr JR, Schellenberg GD, McCormick WC, Bowen JD, Teri L, Larson EB: Using census data and birth certificates to reconstruct the early-life socioeconomic environment and the relation to the development of Alzheimer's disease. Epidemiology 2001, 12:383-389

105. Guo Z, Cupples LA, Kurz A, Auerbach SH, Volicer L, Chui H, Green RC, Sadownick AD, Duara R, DeCarli C, Johnson K, Go RC, Growdon JH, Haines JL, Kukull WA, Farrer LA: Head injury and the risk of AD in the MIRAGE study. Neurology 2000, 54:1316-1323

106. Lott IT, Head E: Down syndrome and Alzheimer's disease: a link between development and aging. Ment Retard Dev Disabil Res Rew 2001, 7:172-178

107. Karlinsky H. Alzheimer's disease in Dowm's syndrome. A review. IAm Geriatr Soc 1986, 34:728-734

108. Schupf N, Kapell D, Lee JH, Ottman R, Mayeux R: Increased risk of Alzheimer's disease in mothers of adults with Down's syndrome. Lancet 1994, 344:353-356

109. Engelhart MJ, Geerlings MI, Ruitenberg A, van Swieten JC, Hofinan A, Witteman JC, Breteler MM; Dietary intake of antioxidants and risk of Alzheimer disease. Jama 2002, 287:3223-3229. 
110. Morris MC, Evans DA, Bienias JL, Tangney CC, Benmett DA, Agrgarwal N, Whisom RS, Schart PA: Dietiry intake of antioxidant mutrients and the risk of incident Alzheimer disease in biracial community study. Jama $2002,287: 3230-3237$.

111. Zandi PP, Anthony JC, Khachaturian AS, Stone SV, Gustafson D, Tschanz JT, Notton MC, Wellsh-Bohmer KA, Breitner JC: Reduced risk of Alzheimer disease in users of antwoxidant vitamin supplements: the $\mathrm{Cache}$ County Study. Arch Neurol 2004, 61:82-88

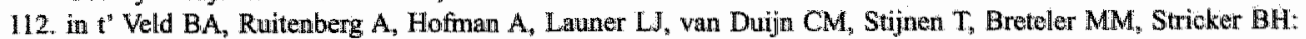
Nonsteroidal antimflammatory drugs and the risk of Alzheimer's disease. N Engl J Med 2001, 345:1515521

113. in "t Veld BA, Launer LJ, Hoes AW, Ott A, Hofman A, Bteteler MM, Stricker BH: NSAIDs and incident Alzheimer's disease. The Rotierdam Study Neurobiol Aging 1998, 19:607-611

114. Crisby M, Carlson LA, Winblad B: Statins in the prevention and treatment of Alzheimer disease. Allheimer Dis Assoc Disord 2002, 16:13/1-136

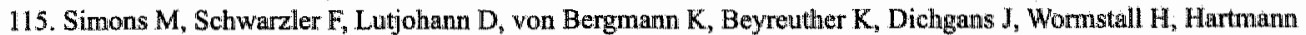
T, Schulz IB: Treatment with simvastatin in normocholesterolemic patients with Alzheimer"s disease: A $26-$ week randomized, placebo-controlled, double-blind trial. Ann Neurol 2002,52*346-350

116. Rockwood K, Kirkland S, Hogan DB, Macknight $\mathrm{C}$, Merry H, Verrenult $\mathrm{R}$, Wolfon C, McDowell I: Use of lipid-lowering agents, indication bias, and the risk of dementia in community-dwelling elderly people. Atroh Neurol 2002, 59:223-227

117. Henderson VW, Paganini-Hill A, Miller BL, Elble RJ, Reyes PF, Shoupe D, McCleary CA, Klein RA, Hake AM, Farlow MR: Estrogen for Alzheimer"s disease in women: randomized, double-blind, placebo-controlled trial. Neurology 2000, 54:295-301

118. Mulnard RA, Cotman CW, Kawas $C$, van Dyck CH, Sano M, Doody $R$, Koss E, Pfeiffer E, Jin $S$, Gamst $A$, Grundman $M$, Thomas $\mathbb{R}$, Thal $\mathrm{LJ}$ : Estrogen replacement therapy for treatment of mild to moderate Alzheimer disease: a randomized controlled trial. Alzheimen's Disease Cooperative Study. Jama 2000, 283:1007-1015

119. Breteler MM: Vascular risk factors for Alzheimer's disease: an epidemiologic perspective. Neurobiol Aging $2000,21: 153-160$

120. Ott A, Stolk RP, Hofman A, van Harskamp F, Grobbee DE, Breteler MM: Association of diabetes mellitus and dementia: the Rotterdam Study. Diabetologia 1996, 39:1392-1397

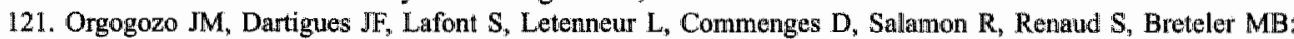
Wine consumption and dementia in the elderly: a prospective community study in the Bordeaux area. Rev Neurol (Paris) 1997, 153:185-192

122. Merchant $C$, Tang MX, Albert S, Manly $I$, Stern $Y$, Mayeux $R$ : The influence of smoking on the risk of Alzheimer's disease. Neurology 1999, 52:1408-1412

123. Ott A, Slooter AJ, Hofman A, van Harskamp F, Witteman JC, Van Broeckhoven C, van Duijn CM, Breteler MM: Smoking and risk of dementia and Alzhejmer's disease in a population-based cohort study: the Rotterdam Study. Lancet 1998, 351:1840-1843

124. Dickson DW: Neuropathology of Alzheimer's disease and other dementias. Clin Geriatr Med 2001, 17:209228

125. Dickson DW: The pathogenesis of senile plaques. J Neuropathol Exp Neurol 1997, 56:321-339

1126. Jarrett JT, Berger EP, Lansbury PT, Jr." The carboxy terminus of the beta anyloid protein is critical for the seeding of amyloid formation: implications for the pathogenes is of Alzheinner's disease. Biochemistry 1993 , $32: 4693-4697$

127. Dickson DW, Sinicropi S, Yen SH, Ko LW, Mattiace LA, Bucala R, Vlassara H: Olycation and microglial reaction in lesions of Alzheimer's disease. Neurobiol Aging 1996, 17:733-743

128. Iwatsubo $T$, Odaka $A$, Suzuki $N$, Mizusawa $H$. Nukina $N$, Ihara $Y$ : Visualiztation of A beta $42(43)$ and A beta 40 in senile plaques with end-specific $A$ beta monoclonals: evidence that an initially deposited species is $A$ beta $42(43)$. Neuron $1994,13,45-53$

129. Iwatsubo T, Mann DM, Odaka A, Suzuki N, Ihara Y: Amyloid beta protelin (A beta) deposition: A beta 42(43) precedes A beta 40 in Down syndrome. Ann Neurol 1995, 37:294-299

130. Gowing $E_{i}$ Roher AE, Woods AS, Cotter RJ, Chaney M, Little SP, Ball MU: Chemical characterization of A beta 17-42 peptide, a component of diffuse amyloid deposits of Alzheimer disease. J Biol Chem 1994, 269:10987-10990

131. Rhodin JA, Thomas T: A vascular connection to Alzheimer's disease. Microcirculation 2001, 8,207-220

132. Suzuki N, Iwatsubo T, Odaka A, Ishibashi Y, Kitada C, Thara Y: High tissue contenl of soluble buta 1.40 is linked to cerebral amyloid angiopathy. Am J Pathol 1994, 145:452-460

133. Revesz T, Ghiso J, Lashley T, Plant G, Rostagno A, Frangione B, Holton JL: Cerebral amyloid angiopathies: a pathologic, biochemical, and genetic view. J Neuropathol Exp Neurol 2003,62:885,898

134. Ghiso J, Frangione B: Cerebral amyloidosis, amyloid angiopathy, and their relationship to stroke and dementia. Alzheimers Dis 2001, 3:65-73 


\section{Intrōtuction}

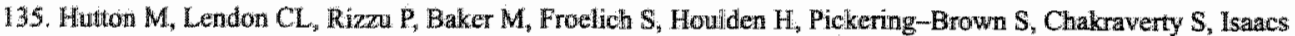
A. Grover A, Hackett J, Adamson J, Lincoln 3 , Dickson D, Davies P, Petersen RC, Stevens M, de Graaff E,

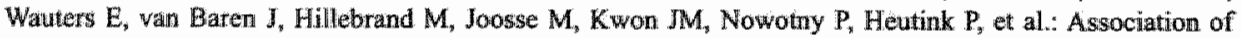
missense and $5^{5}$-splice-site mutations in tuw wh the inherited dementia FTDP-17. Nattre 1998, 393,702705

136. Illenberger $\mathrm{S}$, Zhengm Fischhofer $\mathrm{Q}$. Preuss U, Stamer $\mathrm{K}$, Baumann $\mathrm{K}$, Trinczek B, Biemat J, Godemann R, Mandelkow EM, Mandelkow E: The endogenous and cell cycle-dependent phosphorylation of tau protein in Ifving cells: implications for Alzheimer"s disease. Mol Biol Cell 1998, 9:1495-1512

137. Mandelkow E, Song YH, Schweers O, Marx A, Mandelkow EM: On the structure of microtubules, tau, and paired helical flaments. Neurobiol Aging 1995, 16:347-354

138. Bussiere $T$, Gold $\mathrm{G}$, Kovari $\mathrm{E}$, Giannakopoulos $\mathrm{P}$, Bouras $\mathrm{C}$, Perl DP, Morrison JH, Hof PR: Stereologic analysis of neurofibrillary tangle formation in prefrontal cortex area 9 in aging and Altheimer's disease. Meuroscience $2003,117: 577-592$

1.39. Hof PR, Cox $K$, Morrison IH: Quantitative analysis of a vulnerable subset of pyramidal neurons in Alzheimer"s disease: I. Superior frontal and inferior temporal cortex. I Comp Neurol 1990, 301:44-54

140. Sclinitz C, Hof PR: Recommendations for straightfonward and rigorous methods of counting neurons based on a computer simulation approach. J Chem Neuroanat 2000, 20:93-114

141. Schmitz C: Towards the use of state-of-the-ant stereology in experimental gerontology. Exp Gerontol 2000 , $35: 429-431$

142. West MJ, Coleman PD, Flood DG, Troncoso JC: Differences in the pattern of hippocampal neuronal loss in normal ageing and Alzheimer"s disease. Lancet 1994, 344:769-772

143. West MJ, Kawas CH, Martin LJ, Troncosio JC: The CAl region of the human hippocampus is a hot spot in Alzheimer's disease. Ann N Y Acad Sci 2000, 908:255-259

144. West MJ, Kawas CH, Stewart WF, Rudow GL, Troncoso JC: Hippocampal neurons in prewelinical Alzheimer"s disterse. Neurobilol Aging 2004, 25:1205-1212

145. Price JL, Ko Al, Wade MJ, Tsou SK, McKeel DW, Morris JC: Neuron number in the entorhinal cortex and C.A1 in preclinical Alzheimer disease. Arch Neurol 2001, 58:1395 1402

146. Bussiere T, Giannakopoulos P, Bouras C, Perl DP, Morrison JH, Hof PR: Progressive degeneration of nomphosphorylated neurofilament protein-enriched pyramidal neurons predicts cognitive impaiment in Alzheimer's disease: stereologic analysis of prefrontal cortex area 9. J Comp Neurol 2003, 463:281-302

147. Hof $P R$, Bussiere $T$, Gold $G$, Kovan $E$, Gianmakopoulos $P$, Bouras $C$, Perl DP, Morrison JH: Stereologic evidence for persistence of viable neurons in layer II of the entorhinal cortex and the CAI field in Alzheimer disease. J Neuropatholl Exp Neurol 2003, 62:55-67

148. Gonez-Isla T, Price JL, McKeel DW, Jr, Morris JC, Growdon JH, Hyman BT: Profound loss of layer M entorhinal cortex neurons occurs in very mild Alzheimer's disease. J Neurosci 1996, 16:4491-4500

149. Rossler M, Zarski R, Bohl J, Ohm TG: Stage-dependent and sector-specific neuronal loss in hippocampus during Alzheimar's disease. Acta Neuropathol (Berl) 2002, $103: 363-369$

150. Meier-Ruge W, Ulrich J, Stahelin HB: Morphometric investigation of nerve cells, neuropil and senile plaques in senile dementia of the Alzheimer type. Arch Gerontol Geriatr 1985, 4:219-229

151. Scott SA: Dendritic atrophy and remodeling of amygdaloid neurons in Alzheimer's disease. Dementia 1993, $4: 264-272$

152. Alendt $\mathrm{T}, \mathrm{Z}$ vegintseva $\mathrm{HG}$, Leontovich $\mathrm{TA}$ : Dendritic changes in the basal nucleus of Meynert and in the diagonal band nucleus in Altheimer"s disease-a quantitatiwe Golgi investigation. Neuroscience 1986 , $19: 1265-1278$

153. Arendt T: Alzheimer's disease as a disonder of mechanisms underlying structural brain self-organization. Neuroscience 2001, 102;723-765

154. Small DH, Mok SS, Bornstein JC, Alzheimer's disease and Abeta toxicity: from top to bottom. Nat Rev Neurosci $2001,2: 595-598$

155. Selkoe DJ: Alzheimer's disease is a synaptic failure. Science 2002, 298:789-791

156. Davies CA, Mann DM, Sumpter PQ, Yates PO: A quantitative morphometric analysis of the neuronal and synaptic content of the frontal and temporal cortex in patients with Alzheimer"s disease. J Neurol Sci 1987 , $78: 1.51-164$

157. Smith TD, Adams MM, Gallagher M, Morrison JH, Rapp PR: Circuit-specific alterations in hippocampal symaptophysin immunoreactivity predict spatial learning impainment in aged rats. I Neurosci 2000, 20:65876593

158. Motrison JH, Hof PR: Life and death of neurons in the aging brain. Science 1997, 278:412-419.

159. Gazzaley AH, Siegel SJ, Kordower JH, Mufson EJ, Morrison JH: Circuit-specific alterations of N-methylD-aspartate receptor subunit $\mathbb{1}$ in the dentate gyrus of aged monkeys. Proc Natl Acad Sci U S A 1996, 93:31213125

160. Braak H, Braak E: Staging of Alzheimer's disease-related neurofibrillary changes. Neurobiol Aging 1995 , $16: 271-278$; discussion $278-284$. 
161. Mirm SS, Heyman A, McKeel D, Sumi SM, Crain BJ, Brownlee LM, Vogel PS, Hughes JP, wan Belle O, Barig L: The Consortium to Erstablish a Registry for Azheimer's Disease (CERAD). Part I. Standardization af the nearopathologic assessment of Alzheimer"s disense. Neurology $1991,411,479-486$

162. Citron M: Strategies for disewse modification in Alzheimer's disease. Nat Rev Neurosci 2004, 5:677-685

163. Hardy J: Amyloid, the presenilins and Alzheimer's disease. Trends Neunosel 1997, 20:154-159.

164. Hardy J, Selkoe DJ: The amyloid hypothesis of Alzheimer's disease: progerss and problems on the road to therapeutics. Science $2002,297: 353-356$

165. Dickson DW: Building a more perfect beast: APP transgenic mice with neuronal loss. Am J Pathol 2004, 164:1143-1146

166. Wasco W, Bupp K, Magendantz M, Gusella JF, Tanzi RE, Solomon F: Identification of a nouse brain cDNA that encodes a protein related to the Alzheimer disease-alssociated anyloid beta protein prectrsor. Proc Nat Acad Sci U S A 1992, 89:10758-10762

167. Slunt HH, Thinakaran G, Von Koch C, Lo AC, Tanzi RE, Sisodia SS: Expression of a wbiquitous, crossreactive homologue of the mouse beta anyloid precursor protein (APP). J Biol Chem 1994, 269:2637-2644

168. Selkoe DJ, Podlisny MB, Joachim CL, Vickers EA, Lee G, Fritz LC, Oltersdorf T: Beta amyloid precursor protein of Alzheimer disease occurs as 110- to 135-kilodlalton membrane-associated proteins in neural and nonneural tissues. Proc Nat Acad Sci U S A 1988, 85:7341-7345

169. Hung AY, Selkoe DJ: Selective ectodomain phosphorylation and regulated cleavage of beta-amyloid precursor protein. Embo J 1994, 13:534-542

170. Weidemann A, Konig G, Bunke D, Fischer P, Salbaum JM, Masters CL, Beyreuthei K: Identification, biogenesis, and localization of precursors of Alzheimer's disease A4 amyloid protein. Cell 1989, 57:115-126

171. Walter J, Capell A, Hung AY, Langen H, Schnolzer M, Thinakaran G, Sisodia SS, Selkoe DJ, Hagss C: Ectodomain phosphorylation of beta-amyloid precursor protein at two distinct cellular locations. J Biol Chem $1997,272: 1896-1903$

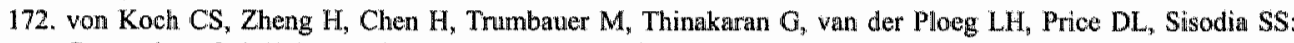
Generation of APLP2 KO mice and early postnatal lethality in APLP2/APP double KO mice. Neurobiol Aging $1997,18: 661-669$

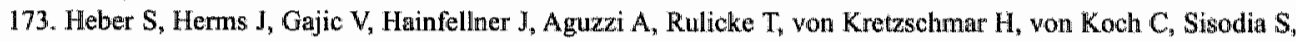
Tremml P, Lipp HP, Wolfer DP, Muller U: Mice with combined gene knock-outs reveal essential and partially redundant functions of amyloid precursor protein family members. I Neurosei 2000, 20:7951-7963

174. Muller U, Heber S, Anliker B, Sisodia SS, Herms J: Abnormal brain development in mice deficient in all three APP/APLP-family nembers. Soc Neurosei 2001 : Program no. 355.310

175. Koo EH: The beta-anyloid precursor protein (APP) and Alzheimer's disease: does the tail wag the dog? Traffic 2002, 3:763-770

176. Mucke L, Abraham CR, Masliah E: Neurotrophic and neuroprotective effects of hAPP in transgenic mice. Ann N Y Acad Sci 1996, 777:82-88

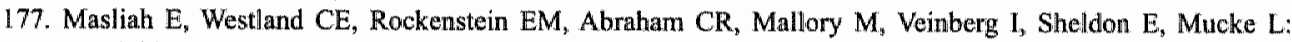
Amyloid precursor proteins protect neurons of transgenic mice against acute and chronic excitotoxic injuries in wivo. Neuroscience $1997,78: 135-146$

178. Panegyres PK: The functions of the amyloid precursor proteingene. Rev Neurosci $2001,12: 1-39$

179. Mucke $\mathbb{L}$, Masliah E, Johnson WB, Ruppe MD, Alford M, Rockenstein EM, Forss-Petter S, Pietropaolo M, Mallory M, Abrahan CR: Synaptotrophic effects of human amyloid beta protein precursors in the cortex of transgenic mice. Brain Res 1994, 666:151-167

180. Takeuchi A, Irizarry MC, Duff K, Saido TC, Hsiao Ashe K, Hasegawa M, Mann DM, Hyman BT, Iwatsubo T: Age-related amyloid beta deposition in transgenic mice overexpressing both Alzheimer mutant presinitin 1 and amyloid beta precursor protein Swedish mutant is not associated with global meuronal loss. Am I Pathol $2000,157: 331-339$

181. Seabrook GR, Smith DW, Bowery BJ, Easter A, Reynolds T, Fitzjohn SM, Morton RA, Zheng H, Dawson GR, Sirinathsinghji $\mathrm{DH}$, Davies $\mathrm{CH}$, Collingridge GL, Hill RG: Mechanisms contributing to the deficits in hippocampal synaptic plasticity in mice lacking amyloid precursor protein. Newropharmacology 1999 , $38: 349-359$

182. Esch FS, Keim PS, Beatie EC, Blacher RW, Culwell AR, Oltersdorf T, McClure D, Ward PJ: Cleavage of amyloid beta peptide during constitutive processing of its precursor. Science $1990,248,1122-1124$

183. Sisodia SS, Koo EH, Beyreuther K, Unterbeck A, Price DL: Evidence that beta-amyloid protein in Alzheimer"s disease is not deriwed by nomal processing. Sclience $1990,248: 492-495$

184. Lammich S, Kojro E, Postima R, Gilbert S, Pfeiffer R, Jasionowski M, Haass C, Fahrenholz F: Constitutive and regulated alpha-secretase cleavage of Alzheimer's amylloid precursor protein by a disintegrin metalloprotease. Proc Natl Acad Sci U S A 1999, 96:3922 3927

185. Seubert $P$, Oltersdorf $T$, Lee $M_{G}$, Barbour R, Blomquist $C_{3}$ Davis DL, Bryant $K$, fritz LC, Galasko D, Thal $\mathrm{LI}$, et al: Secretion of beta anyloid precursor protein cleaved at the amino terminus of the beta-amyloid peptide. Nature 1993, 361:260-263 
186. Sintha \$, Andergon JP, Earbow R, Basi GS, Caccavello R, Davis D, Doan M, Dovey HF, Frigon N, Hong J, Jacobson-Croak K, Jewet N, Keim P, Knops J, Lieberburg I, Power M, Tan H, Tatsuno G, Tung J, Schenk D,

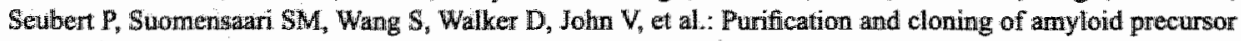
protein beta-3ecratase from human brain. Nature $1999,402: 537-540$

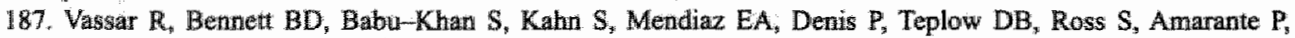

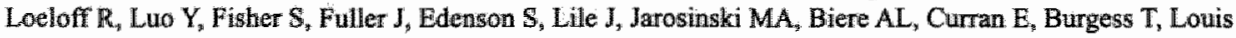
$\sqrt{ } C_{3}$ Collins $F$, Treanor $J$, Rogers $G$, Citron M: Beta-secretase cleawage of Alzheimer"s amyloid precursor protein by the transmembrane aspartic protease BACE. Science 1999, 286:735-741

188. De Strooper B: Aph-1, Per-2, and Nicastrin with Presenilin genterate an active gamma Secretase complex. Neuran $2003,38.9-12$

189. Anmant W, De Strooper B: A cell biological perspective on Alzheimer"s disease. Armu Rev Cell Dev Biol $2002,18 * 25-51$

190. Citron $M$, Diehl TS, Gordon $G$, Biere AL, Seubert $P$, Selkoe DJ: Evidence that the 42- and 40-amino acid forms of amyloid beta protein are generated from the beta-amyloid precursor protein by different protease activities Proc Natl Acad Sci U S A 1996, 93:13170-13175

191. Haass C, Schlossmacher MG, Hung AY, Vigo-Pelfrey C, Mellon A, Ostaszewski BL, Lieberburg I, Koo EH, Schenk D, Teplow DB, al.: Amyloid beta-peptide is produced by cultured cells during nomal metabolism. Ninure 1992, 359:322-325

192. Seubert P, Vigo-Pelfrey $C_{x}$ Esch F, Lee $M$, Dovey $H$, Davis $D$, Simha $S$, Schlosismacher $M$, Whaley J, 5 windlehurst $\mathrm{C}$, et al, : Isolation and quantification of soluble Alzheimer's beta-peptide from biologicall fluids. Nature 1992, 359:325-327

193. Haass C, Koo EH, Mellon A, Hung AY, Selkoe DJ: Targeting of cell-surface beta-amyloid precursor protein to lysosomes: alternatiwe processing into amyloid-bearing fragments. Nature 1992, 357:500-503

194. Sisodia SS. Betamamyloid precursor protein cleavage by a membrane-bound protease. Proc Natl Acad Sci U S A $1992,89: 6075-6079$

195. De Strooper B, Umans L, Van Leuven F, Van Den Berghe H: Study of the synthesis and secretion of normal and artificial mutants of murine amyloid precursor protein (APP): cleavage of APP occurs in a late compartment of the default secretion pathway. J Cell Biol 1993, 121:295-304

196. Hawss C, Lemere CA, Capell A, Citron M, Seubert P, Schenk D, Lannfelt L, Selkoe DJ: The Swedish mutation causes early-onset Alzheimer"s disease by beta--secretase cleavage within the secretory pathway. Nat Med $1995,1: 1291-1296$

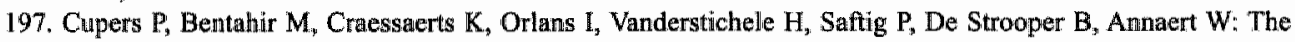
discrepancy between presenilin subcellular localization and gamma-secietase processitng of amyloid precursor protein. J Cell Biol 2001, 154:731-740

198. Koo EH, Squazzo SL: Evidence that production and release of amyloid beta-protein involwes the endocytic pathway. J Biol Chern 1994, 269:17386-17389

199. Perez RG, Soriano S, Hayes JD, Ostaszewski B, Xia W, Selkoe DJ, Chen X, Stokin GB, Koo EH: Mutagenesis identifies new signals for beta-amyloid precursor protein endocytosis, turnover, and the generation of secreted fragments, including Abeta42. J Biol Chem 1999, 274:18851-18856

200. Koo EH, Sisodia SS, Archer DR, Martin LJ, Weidemann A, Beyreuther K, Fischer P, Masters CL, Price DL: Precursor of amyloid protein in Alzheimer discase undergoes fast anterograde axonal transport. Proc Natl Acad Sci U S A 1990, 87:1561-1565

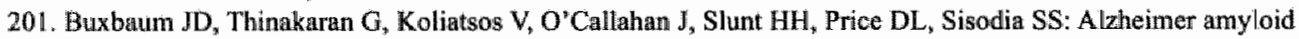
protein precursor in the rat hippocampus: transport and processing through the perforant path. J Neurosci $1998,18: 9629-9637$

202. Yamazaki T, Selkoe DJ, Koo EH: Trafficking of cell surface beta-amyloid precursor protein: retrograde and transoytotic transport in cultured neurons. J Cell Biol 1995, 129:431-442

203. Selkoe DJ" Clearing, the brain's anyloid cobwebs. Neuron $2001,32: 177-180$

204. Carson JA, Tumer AJ: Beta-anylloid catabolism: roles for neprilysin (NEP) and other metallopeptidases? J Neurochem $2002,81: 1-8$

205. Tumer PR, Q'Connor $\mathrm{K}$, Tate WP, Abrabam WC: Roles of amyloid precursor protein and its fragments in regulating neural activity, plasticity and memory. Prog Neurobiol 2003, 70:1-32

206. Ebinu JO, Yankner BA: A RIP tide in neuronal signal transduction. Neuron 2002, 34:499-502

207. Zhang J, Kang DE, Xía W, Okochi M, Mori H, Selkoe DJ, Koo EH: Subcellular distribution and tumover of presenilins in transfected cellis. J Biol Chem 1998, 273:1243,6-12442

208. McGuire SE, Davis RL: Presenilin-I and memories of the forebrain. Neurom 2001, 32;763-765

209. Wines-Samuelson $M$, Handler $M$, Shen J: Role of presenilin-1 in cortical lamination and survival of CajallRetzius neurons. Dev Biol 2005, 277:332-346

210. Lafontaine MA, Mattson MP, Butterfield DA: Oxidative stress in synaptosomal proteins from mutant ptesenilin-1 knock-in mice: implications for familial Alzheimer's disease. Neurochem Res 2002, 27:417421 
211. Mattson MP, Chan SL, Camandola S: Presenilin mutations and calcium signaling defects in the nervous and immune systems. Bioessays 2001, 23:733-744.

212. Duff K, Eckman $C$, Zehr C, Yu X, Prada CM, Perez-tur I. Hutton M, Buee L, Harigaya Y, Wager D, Morgan D, Gordon MN, Holcomb L, Refolo L, Zenk B, Hardy I, Younkin S: Increased anyloid-beta42(43) in brains of mice expressing mutant presenillin 1 . Nature $1996,383: 710-713$.

213. Wittenburg N, Eimer S, Lakowski B, Rohrig S, Rudolph $C$, Baumeister R. Presenilin is required for proper morphology and function of neurons in C. elegans. Nature 2000, 406:306-309

214. Presente A, Boylles RS, Serway CN, de Belle IS, Andres AJ: Notch is required for long-tem memory in Drosophila. Proc Natl Acad Sci U S A 2004, 101:1764-1768

215. Wirths $\mathrm{O}$, Multhaup $\mathrm{G}$, Bayer TA: A modifed beta-amyloid hypothesis: intraneuronal accumulation of the beta-anyloid pepticle - the first step of a fatal cascade. I Neurochem $2004,91: 513-520$

216. Robinson SR, Bishop GM: The search for an amyloid solution. Science 2002, 298:962-964

217. Hardy J, Allsop D: Amyloid deposition as the central event in the aetiology of Allheimer's discase. Thends Pharmacol Sci $1991,12 * 383-388$

218. Arends YM, Duyckaerts C, Rozemuller JM, Eikelenboom P, Hauw JJ: Microglia, amyloid and dementia in alzheimer disease. A correlative study. Neurobiol Aging 2000, 21:39-47

219. Mrak RE, Griffinbc WS: The role of activated astrocytes and of the neurotrophic cytokine S100B in the pathogenesis of Alzheimer"s disease. Neurobiol Aging 2001, 22:915-922

220. Ell Khoury J, Hickman SE, Thomas CA, Loike JD, Silverstein SC: Microglia, scavenger neceptors, and the pathogenesis of Alzheimer's disease. Neurobiol Aging 1998, 19:S81-84

221. Knowles RB, Wyart C, Buldyrev SV, Cruz L, Urbanc B, Hasselmo ME, Stanley HE, Hyman BT: Plaqueinduced neurite abnornalities: implications for disruption of neural networks in Alzheimer"s disease. Proc Natl Acad Sci U S A 1999, 96:5274-5279

222. Le R, Cruz L, Urbanc B, Knowles RB, Msiao-Ashe K, Duff K, Irizarry MC, Stanley HE, Hyman BT; Plaqueinduced abnomalities in neurite geometry in transgenic models of Alzheimer disease: implications for neural system disruption. J Neuropathol Exp Neurol 2001,60:753-758

223. Lorenzo A, Yankner BA: Beta-amyloid neurotoxicity requires fibril formation and is inhibited by congo red. Proc Natl Acad Sci U S A 1994, $91: 12243-12247$

224. Pike CJ, Walencewicz-Wasserman AJ, Kosmoski J, Cribbs DH, Glabe CG, Cotman CW: Structure-activity anallyses of beta-amyloid peptides: contributions of the beta $25-35$ region to aggregation and neurotoxicity. J Neurochem 1995, 64:253-265

225. Kim HI, Chae SC, Lee DK, Chromy B, Lee SC, Park YC, Klein WL, Krafft GA, Hong ST: Selective neuronal degeneration induced by soluble oligomeric amyloid beta protein. Faseb J 2003, 17:118-120

226. Grouras GK, Tsai J, Nashund J, Vincent B, Edgar M, Checler F, Greenfield JP, Haroutunian V, Buxbaum JD, $\mathrm{Xu} H$, Greengard $\mathrm{P}_{3}$ Relkin NR: Intraneuronal Abeta 42 accumulation in human brain. Am 1 Pathol 2000, $156: 15-20$

227. Berger-Sweeney J, McPhie DL, Arters JA, Greenan J, Oster-Granite ML, Neve RL: Impairments in learning and memory accompanied by neurodegeneration in mice transgemic for the carboxyl-terminus of the amyloid precursor protein. Brain Res Mol Brain Res 1999, 66:150-162

228. Oster-Granite ML, McPhie DL, Greenan J, Newe RL: Age-dependent neuronal and synaptic degeneration in mice transigenic for the $C$ terminus of the anyloid precursor protein. J Neurosci 1996, 16:6732-6741

229. Chu DH, Tanahashi H, Ozawa K, Keda S, Checher F, Ueda O, Suzuki H. Araki W, Inoue H, Shimotani $\mathrm{K}$, Takahashi $\mathrm{K}$, Gallyas $\mathbb{F}$, Tabira $T$. Transgenic mice with Alzheimer presenilin 1 mutations show accelerated meurodegeneration without amylloid plaque formation. Nat Med 1999, 5:560-564

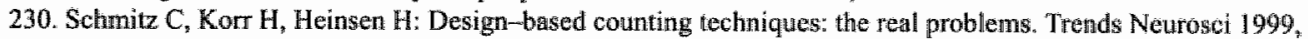
$22 \cdot 345-346$

231. Mattson MP, Gary DS, Chan SL, Duan W: Perturbed endoplasmic reticulum function, synaptic apoptosis and the pathogenesis of Alzheimer"s disease. Biochem Soc Symp 2001:151-162

232. DeKosky ST, Scheff SW: Symapse loss in frontal contex biopsies in Alzheimer's disease: correldion with cognitive severity. Ann Neurol 1990, 27,457-464

233. Multhaup $G_{,}$Scheuermann $S_{3}$, Schlicksupp $A$, Simons $A$, Strauss $M$, Kemmling $A$, Oehler $C$, Cappai $R$, Pipkorn R, Bayer TA: Possible mechanisms of APP-mediated oxidative stress in Alzheimer"s diacase. Frie Radic Biol Med 2002, 33:45-51

234. Fukumoto H, Rosene DL, Moss MB, Raju S, Hyman BT, Irizarry MC: Beta-secretase activity increases with aging in human, monkey, and mouse brain. Am J Pathol 2004, 164:719.725

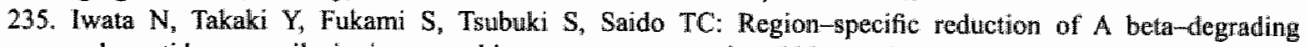
endopeptidase, neprilysin, in mouse hippocampus upon aging. J Neurosci Res 2002, 70:493-500

236. Tomiyama $T_{n}$ Corder EH, Mori $\mathrm{H}$ : Molecular pathogenesis of apolipoprotein E-mediated amyloidosis in late-onset Alzheimer's disease. Cell Mol Life Sci 1999, 56:268-279

237. Lassmann H, Fischer P, Jellinger K: Symaptic pathology of Alzheimer's disease. Anu $\mathbb{N}$ Y Acad Sci 1993, 695-59-64 
238. Mandelkow EM, Mandelkow E: Tau in Alzheimer's disease. Trends Cell Biol 1998, 8:425-427

239. Gold M. Tau therapeutics for Altheimer's disease: the promise and the challenges. J Mol Neurosci 2002 , $19.331-334$

240. Constantudis I: Hypothes is regarding amyloid and zinc in the pathogenesis of Alzheimer disease: potential for preventive intervention. Alahemer Dis Assoc Disord 1991, 5:31-35

241. Carpenter DO. Effects of metals on the nerwous system of humans and animals. Int J Occup Med Environ Health $2001,14: 209-218$

242. de lat Torie JC: Alzheimer"s disease: how does it start? J Alzheimers Dis 2002, 4:497-512

243. Koudinow AR; Berezov TT, Koudinova NV: Cholesterol and Alzheimer's disease: is there a link? Neurology $2002,58,11$. 


\section{Chapter 2}

\section{Prenatal protracted irradiation at very low dose rate induces severe neuronal loss in rat hippocampus and cerebellum}

Neuroscience, 2005; 130(4): 935-948

Christoph Schmitz, Maren Born, Peter Dolezel, Bart P.F. Rutten, Louis de Saint-Georges,

Patrick R. Hof, Hubert Korr 


\section{ABSTRACT}

Prenatal irradiation is known to damage the developing brain. However, little is known about the consequences of very low dose rate prenatal protracted irradiation over several days on neuron numbers in the offspring brain, and on wolumes of the corresponding brain regions. Pregnant Wistar rats were exposed either to a protracted gamma irradiation from embryonic day (E) 13 to E16 $(0.7 \mathrm{mGy} / \mathrm{min}$; total cumulative dose approximately $3 \mathrm{~Gy})$ or were sham-irradiated. Thirty months old male and female offspring were then analyzed for alterations in hippocampal and cerebellar morphology. Using design-based stereology and the analysis of sets of sections systematically and randomly sampled to span the entire brain region of interest, a statistically significant decrease in numbers of hippocampal pyramidal and granule cells as well as of cerebellar Purkinje and granule cells (approximately 50\%) was found in male and female irradiated offspring. The volumes of these brain regions were comparably altered. The analysis of only a "representative" section per animal yielded mostly non-significant trends. Evaluation of neuron densities showed no differences between prenatally irradiated and sham-irradiated offspring. Most importantly, very low dose rate prenatal protracted gamma irradiation did not result in the same morphologic alterations in the offspring brain as previously observed after prenatal single irradiation such as derangement of the laminar structure of pyramidal cells within the hippocampus or malformation of cerebellar lobules.

\section{INTRODUCTION}

Lesions of the central nervous system are a common finding in offspring following prenatal exposure to ionizing radiation. ${ }^{1-3}$ Severity of damage and vulnerability to radiation are a function of dose, dose rate and gestational age of exposure ${ }^{46}$ For example, single $\mathrm{X}$-irradiation with high dose rates (i.e., application of doses higher than 1 Gy within a few minutes) leads to dramatic effects on brain integrity. ${ }^{7-9}$ Single prenatal low-dose $X$-irradiation (i.e., single $\mathrm{X}$-irradiation with application of doses lower than $\mathbb{1}$ Gy within a few minutes) results in more discrete alterations in postnatal brain morphology such as clusters of pyknotic neurons scattered amongst normal hippocampal neurons, ${ }^{9}$ delayed loss of hippocampal pyramidal cells during adulthood 10 or discrete alterations in the spatial arrangement of cortical pyramidal cells." Studies employing fractionated irradiation (i.e., two or more irradiation sessions during pregnancy, with application of doses higher or lower than $1 \mathrm{~Gy}$ within a few minutes each) were either focused on exposure during early gestational periods, ${ }^{12}$ on structural brain anomalies expressed prenatally or early postnatally, ${ }^{1-15}$ or on the comparison between a single high-dose irradiation and two doses a few hours apart with the same total cumulative dose. ${ }^{16}$ In contrast, the consequences of prenatal protracted application of ionizing radiation at constant, very low dose rate over several days on the developing brain remain poorly known. Few alterations have been documented, such as slightly reduced brain weight or a reduction in the volume of the cingulum bundle. ${ }^{17}$ This limited knowledge about effects of very low dose rate prenatal protracted irradiation (VLDRPP irradiation) on the brain, however, stands in contrast to the potential social relevance of this kind of radiation particularly in relation to issues as varied as the future of nuclear power, manned space exploration, and radiological terrorism. ${ }^{18}$ 
The aim of this study was to assess for the first time long-term effects of VLDRPP irradiation on neuron numbers and regional volumes within the offspring" brain. Pregnant rats were irradiated from embryonic day (E) 33 to E 16 , which is in the period during which both the hippocampal pyramidal cells and cerebellar Purkinje cells begin to differentiate in the rat brain. ${ }^{6.9920}$ Both cell types play an important role in normal brain development and maturation, and at least the cerebellar Purkinje cells may have an inductive effect on the development of the cerebellar granule cells which are generated postnatally. ${ }^{21-23}$ VLDRPP irradiation was carried out at a dose rate of $0.7 \mathrm{mGy} / \mathrm{min}$ (total cumulative dose $3 \mathrm{~Gy}$ ). A comparable dose rate and total cumulative dose ( $1 \mathrm{mG} / \mathrm{min}$ for $25 \mathrm{~h}$; total cumulative dose $1.5 \mathrm{~Gy}$ ) was recently applied to human cells $i n$ vitro in a study assessing the risk of space crews by space irradiation, ${ }^{24}$ to give an example.

In addition, this study addressed a methodological question, i.e., to which extent analyses of neuron numbers and regional volumes within the brain depend on the selection of sections to be analyzed. To do so the quantifications were performed using design-based stereology, and sets of sections systematically and randomly sampled spanning the entire brain regions of interest (SRS series) were analyzed (for review see ref. 25). The obtained results were compared to data obtained by parallel analyses on a single "representative" section per animal. Furthermore, alterations in neuron numbers were compared to alterations in neuron densities.

\section{MATERIALS AND METHODS}

\section{Animals and VLDRPP irradiation}

Ten timed pregnant Wistar rats were kept at the Department of Radiobiology of the Belgian Nuclear Research Centre (SCK-CEN, Mol, Belgium; air-conditioned rooms, $20^{\circ} \mathrm{C}$, $60 \%$ relative humidity, 12:12 hours light:dark cycle with artificial lights on at 6:00 a.m., ad libitum access to water and standard laboratory chow). From E13 to E16 (EO: mating between 06.00 and 08.30 p.m.), five animals were subjected in a bunker to VLDR protracted irradiation under the following conditions: cobalt-60 gamma source without filters; 72 hours protracted irradiation; average expected dose rate $0.7 \mathrm{mGy} / \mathrm{min}$ (average expected total cumulative dose $3 \mathrm{~Gy}$ ); cages placed in a panoramic configuration (i.e., on a circle) with the source at the center position; distance between cages and source $139 \mathrm{~cm}$; air-conditioned room, $21 \pm 1^{\circ} \mathrm{C}, 60 \%$ relative humidity; lights off during the whole exposure except of a red light from an alarm system; ad libitum access to water and standard laboratory chow; animals were free to move in their cages. Each cage was equipped with two lithium fluoride TLD 700 dosemeters (Thermo Electron, Beenham, UK), one fixed on the front wall (i.e., the cage wall facing the source) and one on the back wall. Recorded values were $4.66 \pm 0.14$ Gy (front wall; mean \pm S.E.M.) and $2.65 \pm 0.05$ Gy (back wall). The remaining five animals were kept in the neighbouring room under identical conditions but were not urradiated (sham-irradiation). Birth of pups took place at E22. Immediately after birth, the number of pups per mother was reduced to 10 , and weaning took place at postnatal day 25 . For the present study, a total of 20 offsprings (one male and one female offspring per dam) were kept at SCK-CEN, and were observed for the development of tumors until they reached the 
age of 30 months. All investigations were carried out in strict accordance with the European Communities Council Directive of 24 November $1986(86 / 609 / \mathrm{EEC})$.

\section{Histology}

At 30 months of age, the 20 offsprings were anesthetized at SCK-CEN with chloral hydrate ( $10 \%$ aqueous solution, $0.005 \mathrm{ml} / \mathrm{g}$ body weight, intraperitoneal injection), and were sacrificed 5 minutes later by intracardial perfusion-fixation $(250 \mathrm{ml}$ phosphate buffered saline solution [PBS; $\mathrm{pH} 7.4,37^{\circ} \mathrm{C}$, followed by $250 \mathrm{ml}$ formalin solution $\left[10 \%, 4^{\circ} \mathrm{C}\right]$ ). The brains were removed from the skulls and postfixed for 10 days in $10 \%$ formalin solution at $4^{\circ} \mathrm{C}$. Then, they were sent to the Department of Anatomy and Cell Blology, RWTH Aachen University (Aachen, Germany) where they were hemisected exactly in the mediosagittal line. The left cerebellum and brainstem were separated from the rest of the brain by a cut in the coronal plane. Both tissue blocks (left cerebellar half, rest of the left brain half) were cryoprotected in sucrose solution $(10 \%, 20 \%$ and finally $30 \%$ sucrose in $0.1 \mathrm{M}$ Tris-HCl buffer, $2 \times 12$ hours per solution; $4^{\circ} \mathrm{C}$ ), and were frozen in Tissue-tek (Sakura Finetek Europe, Zoeterwoude, The Netherlands). Blocks were stored at $-70^{\circ} \mathrm{C}$ until further processing. Blocks containing the left cerebellar half were exhaustively cut into serial, $100 \mu \mathrm{m}$-thick sagittal sections on a cryostat (type HM 500 OMV, Microm, Walldorf, Germany) using $80 \mathrm{~mm}$ disposable steel blades (type C35, Feather, Japan). Blocks containing the rest of the left brain half were exhaustively cut into serial, $100 \mu \mathrm{m}$-thick horizontal sections. Every third section was selected with a random start, mounted on gelatinized glass slides, dried, defatted with Triton X-100 $(0.025 \%, 20$ minutes; Merck, Darmstadt, Germany), and stained with cresyl violet $(0.01 \%, 20$ minutes $)$. Slides were coverslipped using DePeX (Serva, Heidelberg, Germany).

\section{Stereologic Analysis}

For the hippocampus the following parameters were analyzed on a SRS series of sections spanning the entire left hippocampus: volumes of the granule cell layer and the pyramidal cell layer (CAl-3), total numbers and densities of granule cells and pyramidal cells (CAI-3), and the ratio between the number of granule cells and the number of pyramidal cells. In one parallel analysis the following parameters were analyzed on one "representative" section per animal each, with the section showing the largest total projection area of the hippocampal cell layers (dentate gyrus plus CA1-3 fields) as "representative section" (referred to as hippocampal largest projection area section thereafter): projection areas of the granule cell layer and the pyramidal cell layer (CA 1-3), and numbers and densities of granule cells and pyramidal cells (CAl-3). In another parallel analysis these parameters were analyzed on the section through the mid body of the left hippocampus as "representative section" of each animal (referred to as hippocampal midbody section thereafter).

Analysis of the cerebellum on a SRS series of sections spanning the entire left cerebellar half comprised the following parameters: volumes of the white matter, granule cell layer and molecular layer, total number of Purkinje cells, total number and density of granule cells, and 


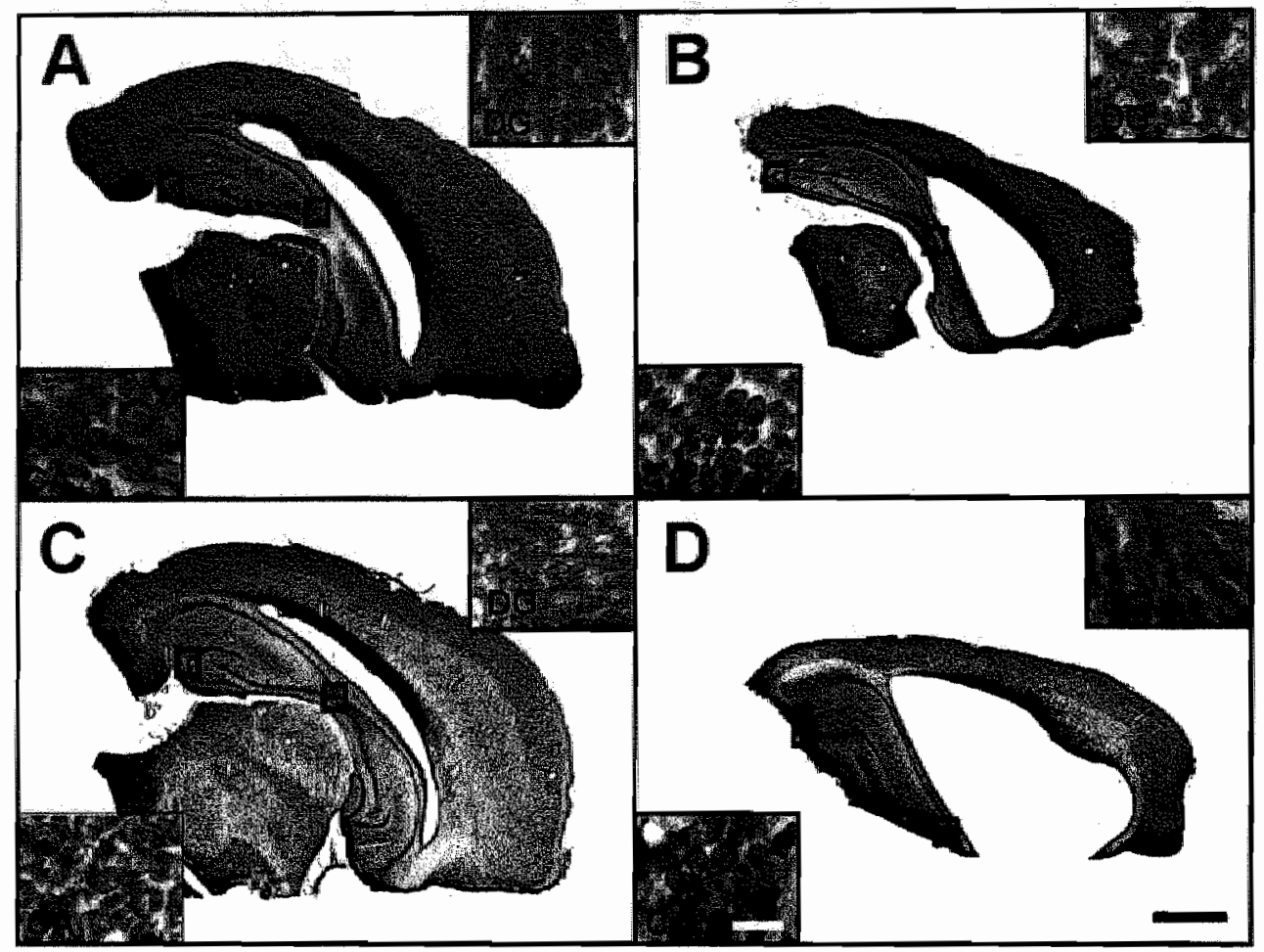

Figure 1. Low-power photomicrographs of 100 um thick horizontal sections from the leff brain half of male (A.B) and

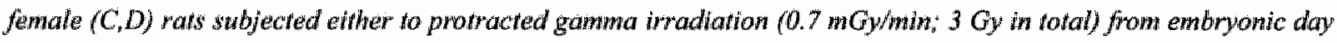
(E) 13 to E IO (B,D), or to shapy-irradiation (A,C). Sections were srained with cresyl wiole and show the mid-body of the laft hippocampus (scale bar $=1.5 \mathrm{~mm}$ ). Note the smaller size of the hippocampus and the cerebral cortex as well as the larger vertictes, in the prenatally irradiated animals compared to the sham-impadiated ones. The insets show high-power phonomicrographs of the pyramidal cell layers (CA3 field) and the gramule cell layers (dentate gyrus; DG). and awe nepresenfative of the magnification at whick the steneologic estimates were obianed (scale bar $=15$, small squares indicate the positions at which the insets were taken. Note the similar size, shape, distribution and densily of the newrons anong the prenatally irradiated and the sham-irradiated animals 


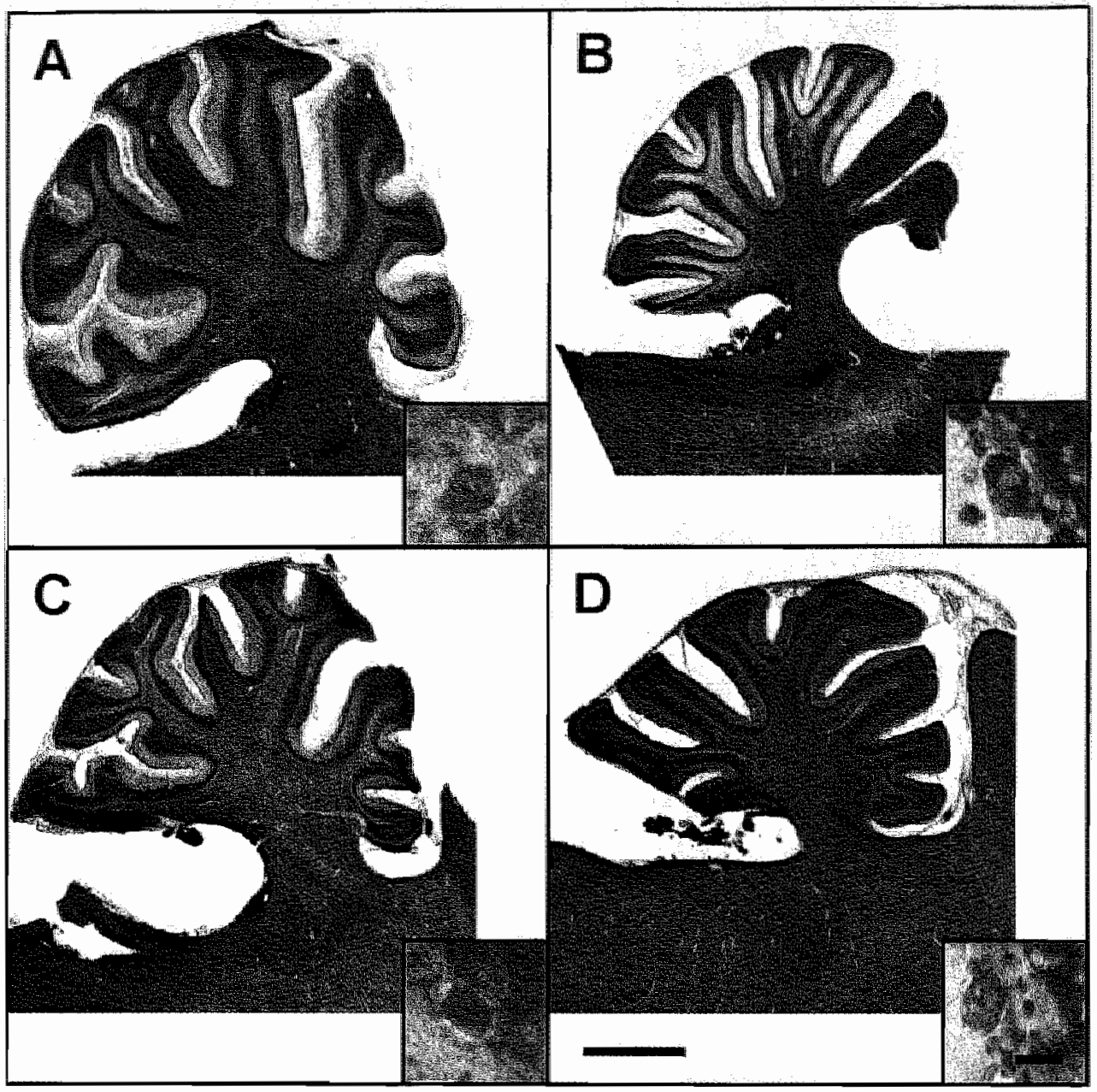

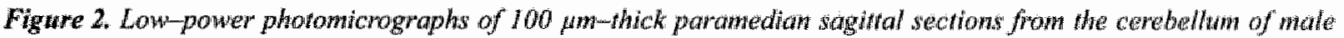
$(A, B)$ and female $(C, D)$ rats swbjected either to protracted ganma irradiation $(0.7 \mathrm{~m} G \mathrm{~g} / \mathrm{min} ; 3 \mathrm{~Gy}$ in total) from embromic day (E) 13 to $E$ I6 (B,D), or to sham-irradiation (A, C). Sections were stained with cresyl wolet and show the same parasagittal level in cerebellum and brainstem (scale bar $=1.5 \mathrm{~mm}$ ). Note the smaller size of the certbellum of the prematally irradiated animal compared to the shann-irradiated one, as well as the smaller size of the cerebellum of the sham-irradiated female rat compared to the sham-irradiated male. Interestingly, prenatal irradiation affected the branching pattern, but not the mumbers, of the cerebellar lobules. The insets show high-power photonticrographs of the border zone between the molecular layer (on the left), the Purkinje cell layer (middle, and the granule cell layer (on the right), and are representarive of the magnification at which the stereologic estimates were obtained (scale bar $=15 \mu \mathrm{m}$ ). Note the similar size, shape, distribution and density of the newrons among the prenatally irradiated and the sham-irradiated animals. 

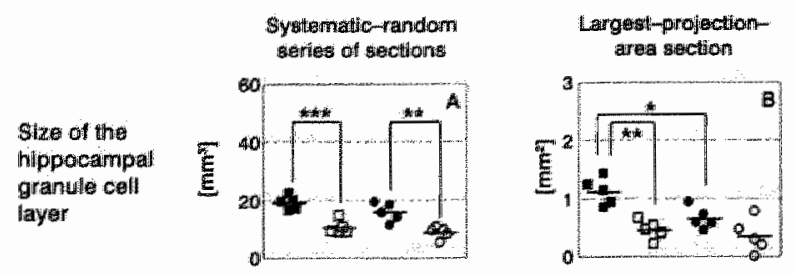

Mid-body section

Size of the hilppocampa giranule cell laystr

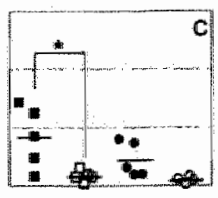

Size of the hippocampal pyramidal cell layer $\left(C A_{1} t-3\right)$
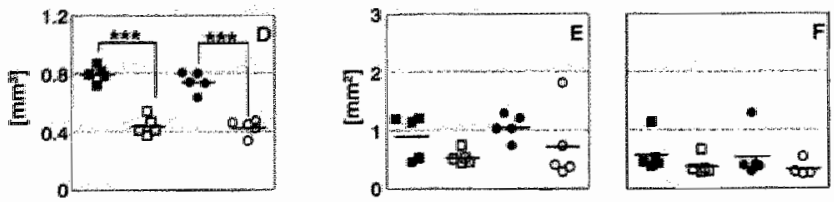

\section{Number of hippocampal granule cells}
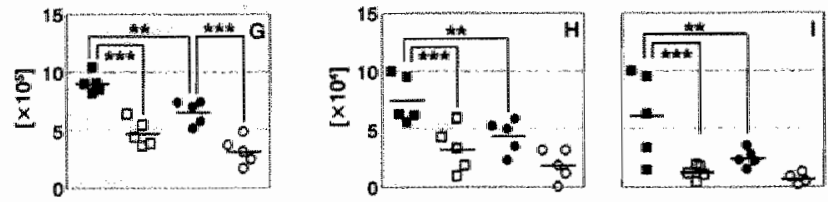

Density of hippocampal granule cells
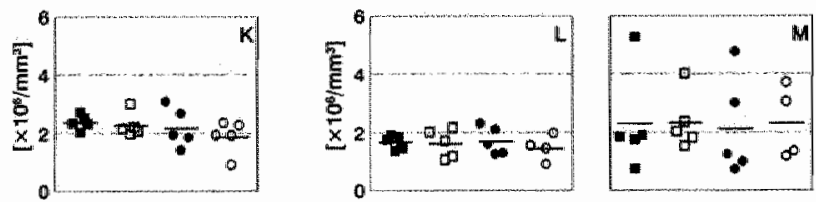

Number of hippocampal pyramidal cells (CA1-3)
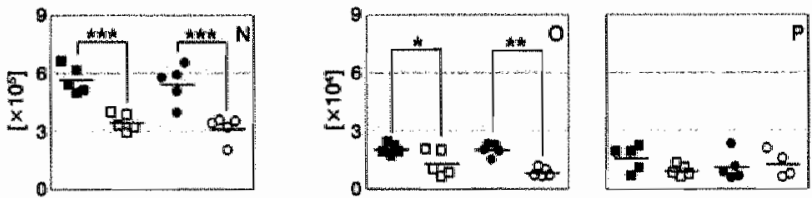

Density of hippocampal pyramidal cells (CANI-3)
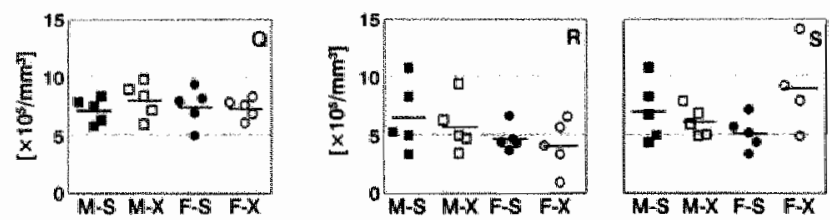

Figure 3. Results of the stereologic investigations in the hippocampus. Analysis of male (squares; " $M$ " in $Q, R$, S) and female (circles; 'F" in $Q, R, S$ ) rats subjected to prenatal gamma-irradiation (open squares and circles; ' $X$ ' in $Q, R, S$ ) or to sham-inradiation (black squares and circles; "S' in Q. $R$. S). Data were obtained by analyzing a systematic-random series of horizontal sections spanming the entire left hippocampus (column on the left), by analyzing a horizontal section of the left hippocampus showing the langest total area of hippocampal cell layers (dentate gyrus [DG] phus CAI-3) in each awimal (columm in the middle), or by analyzing a horizontal section through the mid body of the left hippocampus. in each animal (column on the right) in five animals per group. Data are shown as individual values and means per group (lines), and are given as volumes in $A$ and $D$, projection areas in $B, C, E$ and $F$, total mumbers of weurons in $G$ and $N$, numbers of neurons per section in $H, I, O$ and $P$, and numbers of neurons per unit volume in $K, L, M, Q, R$ and S. ANOVAs revealed significant differences between the groups in $A, B, D, G, H, N, O(p<0.001), I(p=0.003)$ and $C$ $(p=0.011)$. The $p$ waltes from the corresponding post-hoc Bonferronis multiple comparison tests are provided as * ( $p$ $<0.05) * *(p<0.01)$, or *** ( $(p<0.001)$ in $A, B, C, D, G, H, I, N$ and $O$. ANOVAs did not show significant differences between the groups in $E, F, K, L, M_{n} P, Q$ R and $S(p>0.05)$. 
the ratio between the number of granule cells and the number of Purkinje cells. As for the hippocampus parallel analyses were performed on one "representative" section per animal each, with either the section showing the largest total cerebellar projection area (referred to as cerebellar largest total projection area section thereafter) or the first paramedian sagittal section of the left cerebellar half (referred to as cerebellar first paramedian section thereafter) as "representative section". In these parallel analyses the following parameters were investigated: projection areas of the white matter, granule cell layer and molecular layer, numbers of Purkinje and granule cells, and density of granule cells.

The hippocampal. midbody section and the cerebellar first paramedian section in each animal were selected by microscopic pilot inspection of all sections of the corresponding SRS series of sections. The hippocampal largest projection area section and the cerebellar largest total projection area section in each animal were selected after evaluating these parameters for all sections of the corresponding SRS series of sections. Stereologic analyses were performed at the Department of Anatomy and Cell Biology, RWTH Aachen University (Aachen, Germany) with a stereology workstation, consisting of a modified light microscope (BX50; Olympus, Tokyo, Japan), Olympus UPلanApo objectives (20×, NA $=0.70 ; 40 \times$, oil, NA $=1.00 ; 100 \times$, oil, NA $=1.35$ ), motorized specimen stage for automatic sampling (Märzhäuser, Wetzlar, Germany), electronic microcator (Heidenhain, Traunreut, Germany), CCD colour video camera (JAI, Glostrup, Denmark), PCs with frame grabber boards (Screen Machine II, Fast Multimedia, Munich, Germany; or Flashpoint Intrigue light, Integral Technologies, Indianapolis, IN), stereology software (C.A.S.T.-Grid, Olympus; StereoInvestigator, MicroBrightField, Williston, VT), and a 17" television screen monitor. Projection areas of hippocampal cell layers were investigated by tracing the boundaries of these layers on video images displayed on the computer, whereas projection areas of cerebellar layers were analyzed by point counting methods. From the obtained data and the corresponding average actual section thickness after histologic processing (measured with the electronic microcator), the volumes of hippocampal granule cell layer and pyramidal cell layer (CAl-3) and of cerebellar white matter, granule cell layer and molecular layer were calculated using Cavalieri's principle. ${ }^{26}$ The variability of the estimated volumes of the cerebellar layers was assessed with the method described by Garcia-finana et al ${ }^{27}$ for estimates of volumes based on traced boundaries a procedure to predict precisely the $\mathrm{CE}$ is currently not available (see ${ }^{25}$ for details).

Neuron numbers were estimated with the optical fractionator. ${ }^{25,28-30}$ All neurons whose nucleus top came into focus within unbiased virtual counting spaces distributed in a systematic-random fashion throughout the brain regions of interest were counted. ${ }^{25}$ Estimated numbers of neurons per section and estimated total numbers of neurons per brain half were calculated from the numbers of counted neurons per section (or per brain half, respectively) and the corresponding sampling probabilities. For estimates of the number of neurons per section the section sampling fraction (ssf) was 1 , whereas ssf was 3 when calculating estimated total numbers of neurons per brain half as every third section was selected for analysis. . $5.28-30^{2}$

Estimates of section-specific neuronal densities were calculated by dividing the number of neurons in a given cell layer by the product of the projection area of this cell layer and the 
actual section thickness of the corresponding section after histologic processing. Estimates of global neuronal densities were calculated by dividing the total number of neurons of a given cell type by the total wolume of the corresponding cell layer. As it was not possible to delineate exactly the boundaries of the cerebellar Purkinje cell layer in the rat brain, estimates of Purkinje cell densities were not calculated. Finally, for each investigated brain region the individual frequency distributions of the number of neurons per unbiased wirtual counting frames were calculated, as well as the corresponding mean group data. Details on the counting procedures are summarized in Appendix. To control for litter effects, the ratios of the individual results for male and female offsprings of a given dam were calculated (only in the case of results obtained from a SRS series of sections).

\section{Statistical analysis}

For each group of animals, mean and standard error of the mean were calculated for all investigated parameters. Comparisons between groups were performed with one-way analysis of variance (ANOVA), followed by post-hoc Bonferroni's multiple comparison tests for pairwise comparisons. Differences in mean ratios of the individual results for male and female offsprings of a given dam between prenatally irradiated and prenatally sham-irradiated animals were tested with Student's unpaired $t$ test. Statistical significance was established at $\mathrm{p}<0.05$. All calculations were performed using GraphPad Prism (Version 4.00 for Windows, GraphPad Software, San Diego, CA).

\section{Photography}

All photomicrographs were produced by digital photography using an Olympus U-CMAD-2 digital camera attached to an Olympus AX 70 microscope and image analysis software software (analySIS; Imaging System, Münster, Germany). The final figures were constructed using Corel Photo-Paint w. 11 and Corel Draw v. 11. Only minor adjustments of contrast and brightness were made, which in no case altered the appearance of the original materials.

\section{RESULTS}

\section{Histology}

The brains of prenatally irradiated animals were smaller than the brains of prenatally sham-irradiated ones with smaller size of cortex, hippocampus, midbrain and cerebellum. Furthermore, the prenatally irradiated animals had considerably larger lateral ventricles than the prenatally sham-irradiated ones. In spite of the considerable decrease in size, the neocortex, hippocampus and cerebellum of the prenatally irradiated animals did not show obvious alterations in cytoarchitecture compared to the prenatally sham-irradiated animals. In addition, the prenatally irradiated animals showed alterations in the branching pattern, but not in the number, of the cerebellar lobules (Figs. 1 and 2). None of the investigated animals developed brain tumors (identified by histology in the course of the investigations) or other tumors evident at routine inspection following perfusion-fixation, respectively. 
Hippocampus

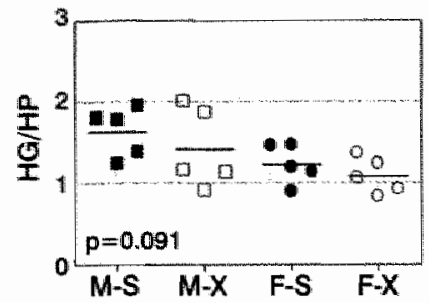

Cerebellum

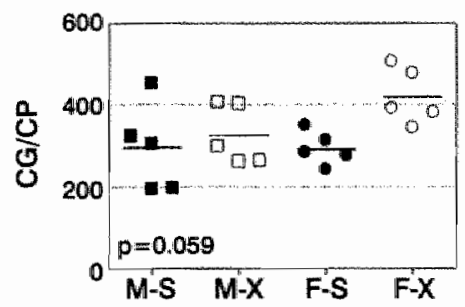

Figure 4. Ratios of total neuron mumbers in hippocanows and cerbbllum.

Data are shown as iwdividual wahies and means per group (hives). $H G$, hippacampal granule cells; HP. hippocampal piramidal alls; $C G$. cerebellar granule cells; CP, cerebellar Pukinje cells. M-S, male rats subjected to prenatal sham-irradiation; $M-X$, male rats subjected to prenatal irradiation; F-S, female rats subjected to prenatal shown-ilriadiation: F-X, female rats stbjected to prenatal irradiation

\section{Stereologic analysis of the left hippocampus}

When analyzing an SRS series of sections spanning the entire left hippocampus per animal, the following results were obtained: rats subjected to prenatal irradiation showed a statistically significant decrease in the mean volumes of both granule and pyramidal cell layers compared to the rats subjected to prenatal sham-irradiation (Figure 3A,D), as well as a significant decrease in the mean total numbers of both granule and pyramidal cells (Figure $3 \mathrm{G}, \mathrm{N}$ ), independent of sex. In addition, the prenatally sham-irradiated female rats had on average significantly fewer granule cells than the prenatally sham-irradiated males (Figure 3G). In contrast to total numbers, the densities of both granule and pyramidal cells were unaffected by the prenatal irradiation (Figure $3 \mathrm{~K}, \mathrm{Q}$ ). The ratio between the number of granule cells and the number of pyramidal cells was 1.34 on average and showed no significant difference between the groups (Figure 4). The ratios of individual results for male and female offsprings of a given dam showed considerable differences among dams. However, there were no differences in mean values of these ratios between irradiated and sham-irradiated dams (Figure S] in Appendix). Compared with these SRS series of sections data, the corresponding hippocampal largest projection area sections (Figure 3B, E, H, L, O and R) indicated that only male rats subjected to prenatal irradiation had a significant decrease in the mean projection area of the granule cell layer and the mean number of granule cells compared to rats subjected to prenatal sham-irradiation (Figure 3B, H). Furthermore, prenatally sham-irradiated female rats had a significantly smaller mean projection area of the granule cell layer than prenatally sham-irradiated males (Figure 3B). Also, the irradiation-induced reduction in the mean projection area of the pyramidal cell layer did not reach statistical significance (Figure 3E). The hippocampal midbody section results showed major differences with the corresponding SRS series of sections results. Specifically, only male but not female rats subjected to prenatal irradiation showed a statistically significant decrease in the mean projection area of the granule cell layer and in the mean number of granule cells (Figure 3C, I). Furthermore, prenatal irradiation had no significant effect on both the mean pro- 


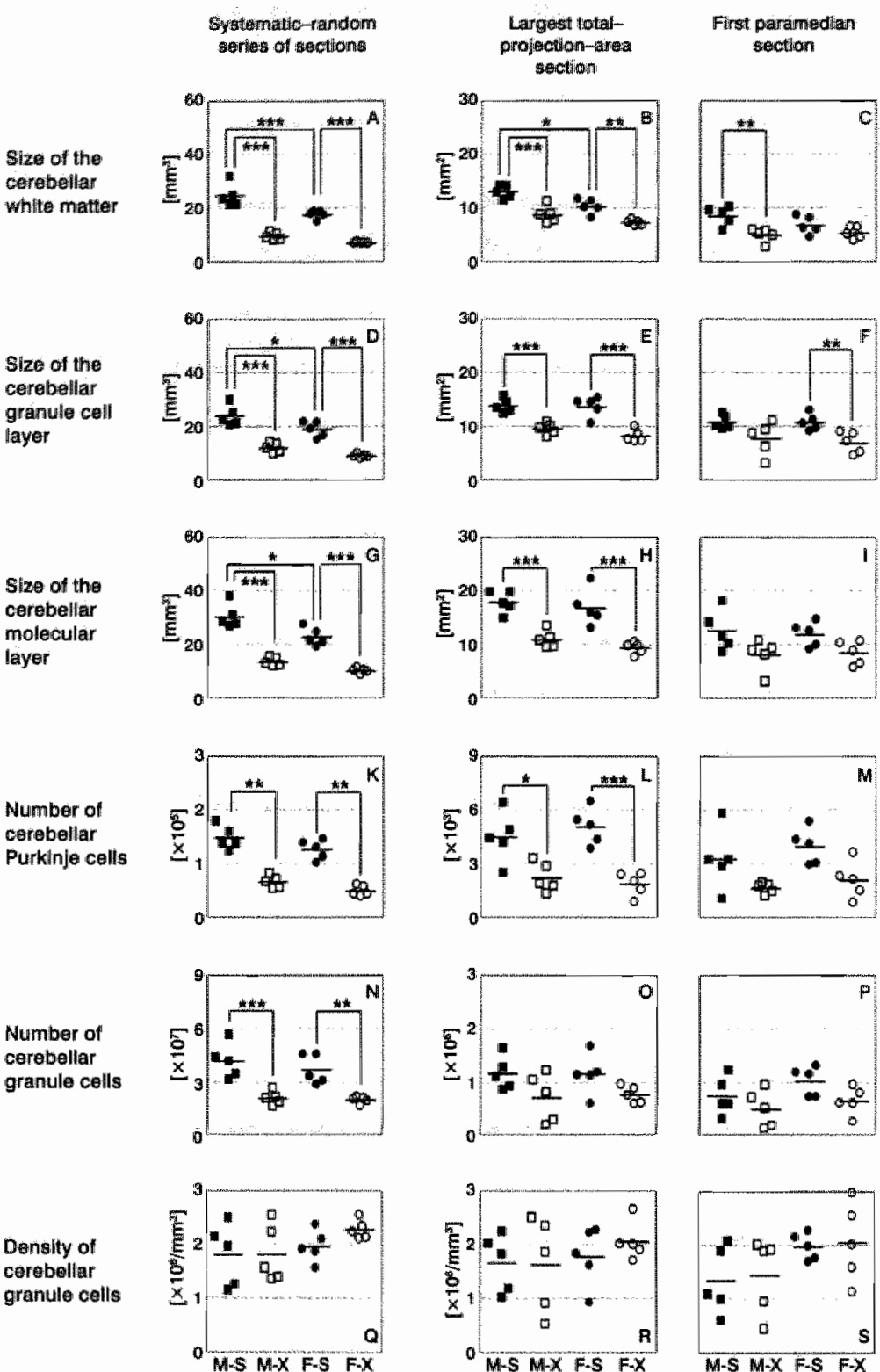

Figure 5. Results of the steneologic investigations in the cerebellum. Analysis of male (squares; "MN" in $Q, R, S)$ and female (cincles; ' $F$ ' in $Q, R, S$ ) rats subjected to prenatal gamma-irradiation (open squares and circles; ' $X$ ' in $Q, R$, S) or to sham-irradiation (black squares and circles; 'S' in $Q R, S$ ). Data were obtained by analyzing a systematic-random series of sagitral sections throtghout the left cerebellar half (column on the lefi), analyzing the first paramedian sagittal section of the left cerebellar half (column in the middle), or evaluating a sagittal section of the left cerebellar half showing the largest total cerebellar projection area (column on the right) in five amimals per group. Data are shown as individual values and means per group (lines), and are given as volumes in $A, D$ and $G$, projection areas in $B_{*} C, E_{s}, F$ $H$ and $l$, foral numbers of neurons in $K$ and $N$, numbers of neurons per section in $L, M, O$ and $P$, and numbers of neurons 
per whit volume in $Q$, R and $S$ ANOVAs revealed significant differences between the groups in $A, B, D, E, G, H, R, L$, and $N(p<0.001), C(p=0.006), F(p=0.017), M(p=0.018)$ and $I(p=0.046)$. The $p$ values frown the corresponding post hoc Bonferroni s multiple comparison tests are priwided as $*(p<0.05) * *(p<0.01)$, or *** $(p<0.001)$ in $A$ to $H, K, L$ and N. ANOVAs did not show significant differences berween the groups in 0 to $S(p>0.0 \mathrm{~s})$.

jection area of the pyramidal cell layer and the mean number of pyramidal cells (Figure 3F, P). Interestingly, female rats subjected to prenatal irradiation showed a substantial increase in the density of pyramidal cells compared to the female rats subjected to prenatal sham-irradiation. This effect however, was not statistically significant due to very high interindividual variation (Figure 3S).

\section{Stereologic analysis of the left cerebellar half}

In general, trends in irradiation-induced morphologic alterations comparable to those found in the hippocampus were obtained in the cerebellum when analyzing an SRS series of sections spanning the entire left cerebellar half per animal. Specifically, both male and female rats subjected to prenatal irradiation showed a significant decrease in the mean volumes of the white matter, granule cell layer and molecular layer compared to rats subjected to prenatal sham-irradiation (Figure 5A, D, G) as well as a significant decrease in the mean total numbers of both Purkinje and granule cells (Figure $5 \mathrm{~K}, \mathrm{~N}$ ). In addition, prenatally sham-irradiated female rats had significantly smaller mean volumes of the white matter, granule cell layer and molecular layer than prenatally sham-irradiated males (Figure $5 \mathrm{~A}, \mathrm{D}, \mathrm{G}$ ). The density of the granule cells was not affected by prenatal irradiation (Figure 5Q). The ratio between the number of granule cells and the number of Purkinje cells was 333 on average and showed no significant difference between the groups (Figure 4). As for the hippocampus, the ratios of individual results for male and female offsprings of a given dam showed considerable differences among the dams but no significant differences in mean values (Figure $\mathrm{S} 1$ in Appendix).

Compared with these SRS series of sections data, there was no significant difference in the mean number of granule cells between prenatally irradiated and prenatally sham-irradiated animals on the largest total projection area sections (Figure 50), as well as no significant difference in the mean projection areas of both granule cell layer and molecular layer between the prenatally sham-irradiated male and female rats (Figure 5E, H).

When the analysis was restricted to the first paramedian sagittal section of the left cerebellar half the results showed major differences with the corresponding data obtained by analysis of SRS sections spanning the entire left cerebellar half. Specifically, significant differences between prenatally irradiated and prenatally sham-irradiated rats were only found for male rats in the mean projection area of the cerebellar white matter (Figure 5C) and for female rats in the mean projection area of the cerebellar granule cell layer (Figure SF). Differences in mean numbers of cerebellar Purkinje and granule cells between prenatally irradiated and prenatally sham-irradiated animals did not reach statistical significance (Figure 5M, P). 


\section{DISCUSSION}

This is the first detailed investigation of the effects of VLDRPP irradiation on neuron number in the brain of offsprings using design-based steredogic methods. VLDRPP gamma irradiation of rats with a dose rate of $0.7 \mathrm{mGy} / \mathrm{min}$ from $\mathrm{E} 13$ to E16 (total cumulative dose $3 \mathrm{~Gy}$ ) resulted in a massive decrease in the total numbers of hippocampal and cerebellar neurons (approximately $50 \%$ on awerage) in male and female irradiated offspring, with comparable alterations in the volumes of these brain regions. The mean total numbers of hippocampal and cerebellar neurons of the prenatally sham-irradiated (i.e., control) animals (Figure 3 and 5), the mean ratio between the number of hippocampal granule cells and the number of hippocampal pyramidal cells (Figure 4) and the mean ratio between the number of cerebellar granule cells and the number of cerebellar Purkinje cells (Figure 4) of both prenatally irradiated and sham-irradiated animals were in line with several reports on neuron numbers in rats. ${ }^{31-38}$ This demonstrates the validity of the obtained results. Considerable differences among dams in ratios of individual results for male and female offsprings of a given dam (Figure S1) indicate that the observed effects were attributable to prenatal irradiation and did not represent litter effects (in case of litter effects the offsprings of a given dam would have shown similar effects, and the ratios of individual results for male and female offsprings of a given dam would have been similar among dams).

\section{Methodological considerations}

This study demonstrates remarkable differences between data obtained by analyzing sets of sections systematically and randomly sampled spanning the entire brain regions of interest (SRS series) and data obtained by analyzing a single "representative" section per animal. For both hippocampus and cerebellum the latter procedure resulted in less pronounced differences between the investigated groups of animals. In consequence, for many investigated parameters merely (non-significant) trends were observed when analyzing a "representative" section per animal, while the corresponding analysis of SRS series showed statistically significant differences between the groups. This was connected with a trend towards increased interindividual variability in the data obtained by analyzing a "representative" section per animal. The reason for this was most probably an increased intra-individual variability, that is, the variation of the individual data due to the limited number of analyzed sections (as shown in $29,39,40$ ). Interestingly, the largest projection area section results were in better concordance of the SRS series of sections results than the midbody section results (in case of the hippocampus) and the first paramedian section results (in case of the cerebellum, respectively). In one case (investigation of the size of the hippocampal granule cell layer) the midbody sections even showed a statistically significant difference between the prenatally sham-irradiated male and female rats, which was not found when SRS series of sections were investigated (Figure $3 \mathrm{~A}$ and $3 \mathrm{~B}$ ).

Finally, there was a striking difference between massive alterations in neuron numbers and an almost lack of alterations in neuron densities as a consequence of prenatal irradiation. This difference is due to the fact that prenatal irradiation resulted not only in neuron loss but also in a massive decrease in volume of the investigated brain regions. Note that the reverse situation has been described in the literature, with statistically significant reductions in neuron densities 
without concomitant alterations in neuron numbers due to increased volumes of the investigated brain regions. ${ }^{41-44}$ Thus, the data presented here show how results obtained using design -based stereology can be influenced by the selection of sections containing the brain region of interest, and how the outcome of studies can differ when focussing on neuron densities instead of neuron numbers. As already mentioned by West, ${ }^{45}$ the uncritical use and interpretation of neuron density data should be particularly disapproved. Furthermore, it might be useful to base estimates of the volume of brain regions and of neuron numbers on the analysis of sets of sections systematically and randomly sampled spanning the entire brain regions of interest, whenever possible.

\section{Differences between the effects of VLDRPP irradiation and single prenatal irradiation on the offsprings' brain}

Importantly, the VLDRPP irradiation protocol applied in the present study did not result in the same morphologic alterations in the offsprings' brain as previously observed after prenatal single irradiation with high dose rates. For example, we did not observe a derangement of the laminar structure of pyramidal cells within the hippocampus, as reported after single $\mathrm{X}$-irradiation of rats with a dose of $1.5 \mathrm{~Gy}$ on $\mathrm{E} 15^{46}$

Neither we found a four-layered 'lissencephalic' cortex as seen after single X-irradiation of rats with a dose of $2 \mathrm{~Gy}$ on $\mathrm{E} 16^{47}$ nor abnormal hippocampal and cerebellar cortical cellular patterns after single $\mathrm{X}$-irradiation of rats with a dose of $2 \mathrm{~Gy}$ on $\mathrm{E} 17,{ }^{48}$ or the formation of anteroposteriorly and horizontally directed cerebellar lobules, as opposed to the normal transverse arrangement, after single $\mathrm{X}$-irradiation of rats with a dose of $2 \mathrm{~Gy}$ on E16. Thus, the effects of VLDRPP irradiation on the developing brain differed from the effects of prenatal single irradiation with high dose rates.

\section{Effects of VLDRPP irradiation on the offsprings' brain}

To date few studies have focussed on the effects of VLDRPP irradiation on the offspring brain. Reyners et al. ${ }^{17}$ reported a statistically significant reduction in adult brain weight by $13 \%$ after VLDRPP gamma irradiation of rats with a dose rate of $0.1 \mathrm{mGy} / \mathrm{min}$ from $\mathrm{E} 12$ to $\mathrm{E} 16$ (total cumulative dose $0.56 \mathrm{~Gy}$ ), as well as by $7.3 \%$ after VLDRPP gamma irradiation with a dose rate of $0.1 \mathrm{mGy} / \mathrm{min}$ from E14 to E20 (total cumulative dose $0.8 \mathrm{~Gy}$ ). For the latter group of animals, Reyners et al. ${ }^{77}$ found also a significant $19 \%$ reduction in the volume of the cingulum bundle, potentially indicating neuron loss in the brain of the offsprings. Wang et al. ${ }^{49}$ subjected pregnant mice from E13 to E18 (corresponding to about E14.5 to E20.5 in rats ${ }^{50}$ ) to VLDRPP gamma irradiation with dose rates of $0.02,0.03$ or $0.056 \mathrm{mGy} / \mathrm{min}$, respectively (total cumulative dose $0.1,0.2$ or $0.4 \mathrm{~Gy}$, respectively) and found slight irradiation-induced alterations in various behavioral tasks in the adult offspring. However, the authors did not analyze the brains of these animals. In a study focussing on the migration of neuronal cells in the developing cerebral cortex, Hyodo-taguchi et al..$^{51}$ injected pregnant mice with bromodeoxyuridine (BrdU) on E14 and exposed them from E14 to E17 (corresponding to about E15.5 to E19 in rats ${ }^{50}$ ) to VLDRPP gamma irradiation with dose rates of $0.08,0.23$ or $0.71 \mathrm{mGy} / \mathrm{min}$, respectively (total. cumulative dose $0.3,0.9$ or $2.8 \mathrm{~Gy}$, respectively). VLDRPP irradiation with dose rates of 0.08 
mGy/min and $0.23 \mathrm{mGy} / \mathrm{min}$ had no significant effect on the migration of cortical neurons, whereas VLDRPP irradiation with $0.71 \mathrm{mGy} / \mathrm{min}$ resulled in delayed migration of cortical neurons during the embryonic period and significant differences in the distribution pattern of BrdULlabeled cells within the cerebral cortex relative to control animals at eight weeks of age. Furthermore, Hyodo-taguchi et al. ${ }^{51}$ observed in three-week-old animals subjected to VLDRPP irradiation with a dose rate of $0.71 \mathrm{mGy} / \mathrm{min}$ a significantly decreased number of BrdU labeled cells within the cerebral cortex (approximately $-40 \%$ on average compared to control animals). By contrast, in one-day old animals subjected to the same irradiation protocol the number of BrdU-labeled cells within the cerebral cortex showed no significant difference between prenatally irradiated and prenatally sham-irradiated animals. Hyodo-taguchi et al. ${ }^{51}$ interpreted this finding as suggestive of irradiation-induced neuron death during the postnatal maturation of the cerebral cortex. However, this interpretation should be considered with some caution since the analysis was performed on merely a few sections per animal (coronal brain sections covering the rostral portion of the hippocampus) without use of design-based stereologic methods. Furthermore, it cannot be excluded that the reduction in the number of BrdU-labeled cells in the study of Hyodo-taguchi et all. ${ }^{51}$ was at least in part caused by the fact that incorporation of BrdU into the DNA of mammalian cells may cause them to become more sensitive to the deleterious effects of ionizing radiation. ${ }^{52-54}$

Thus, the present data agree with previous reports using similar irradiation protocols but substantially expand our knowledge of the effects of VLDRPP irradiation on the offsprings" brain. It should be mentioned that in some studies injection of tritiated water into pregnant dams was used to induce protracted prenatal irradiation at low dose rates to the fetuses ${ }^{55-57}$ However, it is not possible to compare the results of these studies directly to the present data, since the fetuses are not irradiated at a constant dose rate after injection of tritiated water into pregnant dams. Rather, the dose rate in these conditions shows a fast increase within a few minutes, followed by an exponential decrease over several days. ${ }^{57}$

\section{Mechanisms of damage to the offsprings' brain by VLDRPP irradiation}

The VLDRPP irradiation protocol used in the present study resulted in a severe decrease in the numbers of hippocampal pyramidal cells and cerebellar Purkinje cells, whose final progenitors underwent division during the selected period of irradiation. ${ }^{6,19,20}$ Although not demonstrated by the present study, this suggests that the vulnerable period for both types of cells even to our VLDRPP irradiation protocol closely overlaps with the phase of division of their final progenitors, as is known to occur for prenatal single irradiation with high dose rates and short irradiation times. ${ }^{6.58,59}$ In this regard, data from Benekou et al ${ }^{60}$ and Bolaris et al. ${ }^{61}$ are particularly relevant. These authors exposed rats to prenatal single $X$-irradiation with doses of $0.1,0.2$ or 0.4 Gy on E15 or E17. Even after only 0.1 Gy the authors detected increased numbers of apoptotic as well as p53-immunoreactive cells, downregulation of $1 \mathrm{GF}-\mathrm{I}$, and a compensatory increase in the expression of IGF-II, BDNF, and NT-3 among proliferating, migratory and postmitotic neurons in the developing neuroepithelium. This indicates the occurrence of an X-irradiation-induced cell death by apoptosis with possible compensatory mechanisms in the developing rat brain (similar results were reported by Wang et al. ${ }^{49}$ ). Thus, it is possible that the VLDRPP irradiation 
protocol used here also caused apoptotic cell death of hippocampal pyramidal cells and cerebellar Purkinje cells in the developing brain. Whether this is related to alterations in the expression levels of p 53 and neurotrophic factors remains to be determined. Strikingly, we also observed a substantial decrease in the numbers of hippocampal and cerebellar granule cells, which are mostly generated postnatally. ${ }^{62,63}$ Thus, the vast majority of the final progenitors of these cells did not divide during the selected period of irradiation. One explanation may be that in this case, the progenitors of these cells were damaged by irradiation. This is supported by findings on the spontaneous neurological mutant mouse dreher. This mutant mouse shows during embryonic development a disruption of the rhombic lip, which is the source of cerebellar granule cell progenitors, ${ }^{64,65}$ as well as in postnatal animals a substantial decrease in the number of cerebellar granule cells. ${ }^{66}$ Another possibility may be irradiation-induced reductions in the amount of growth factors such as Bmp6, Bmp7 and Gdf7, i.e., peptide growth factors of the bone morphogenetic protein (BMP) family. Dorsal midline cells adjacent to the rhombic lip express Bmp6, Bmp7 and Gdf7 which are suggested to initiate the program of cerebelllar granule cell specification ${ }^{64}$ and have strong neurotrophic effects on cerebellar granule cells, ${ }^{67}$

On the other hand we did not found irradiation-induced alterations in the ratios between the number of hippocampal granule cells and the number of hippocampal pyramidal cells as well as between the number of cerebellar granule cells and the number of cerebellar Purkinje cells (Figure 4). Although this does not rule out the possibility that the early granule progenitor cell population was reduced by irradiation or the amount of growth factors was diminished, these unchanged ratios suggest that the decrease in the numbers of hippocampal and cerebellar granule cells is due to the absence of trophic support from their main postsynaptic targets, the hippocampal pyramidal cells and cerebellar Purkinje cells. At least for the cerebellum the regulation of the number of granule cells by a predetermined number of Purkinje cells in development has been established in a variety of experimental settings including mouse mutants, toxicologic damage, and prenatal irradiation. ${ }^{22,68-71}$ On the molecular level, sonic hedgehog (Shh) which is produced by Purkinje cells and is required for the proliferation of granule cell precursors plays an important role in this regulation. ${ }^{23,72,73}$ For hippocampal granule cells, the role of trophic support from postsynaptic targets in determining their number is less clear. On the one hand it is known that trophic support from postsynaptic targets is involved in determining neuron numbers in the limbic system as well. ${ }^{74}$ In this study, neonatal rats were subjected to $\mathrm{X}$-irradiation which reduced the number of hippocampal granule cells to $20 \%$ of control values.

The number of neurons in both the medial and lateral entorhinal cortices in X-irradiated animals appeared normal until postnatal day [P] 12, at which time a selective reduction in cell numbers became apparent. By P30, approximately $40 \%$ of the cells of origin of the perforant path were absent in $\mathrm{X}$-irradiated animals. ${ }^{74}$ The authors concluded that these cells were subject to retrograde transynaptic degeneration as a result of target removal. On the other hand, there is evidence for separate genetic determination of neuron numbers among hippocampal regions. ${ }^{75}$ Furthermore, prenatal ethanol exposure in rats has been shown to reduce the number of hippocampal pyramidal cells without affecting the number of hippocampal granule cells, clearly speaking against a major role of trophic support from postsynaptic targets in determining hippocampal granule cell number. ${ }^{76}$ On the molecular level, basic fibroblast growth factor 
(bFGF) has been shown to play an important role in determining the number of granule cells in the developing hippocampus. ${ }^{77}$ Whether there is also a role of Shi in this process remains to be determined. ${ }^{78}$ Interestingly, Shh is involved in adult hippocampal neurogenesis ${ }^{79,80}$ whereas bFGF seems to be not. ${ }^{77}$

Finally the question shall be discussed whether our prenatal irradiation protocol caused some accelerated postnatal and/or age-related cell loss in neurons that had been compromised by prenatal irradiation. Although this possibility cannot be completely ruled out, the unchanged ratios between the number of hippocampal granule cells and the number of hippocampal pyramidal cells as well as between the number of cerebellar granule cells and the number of cerebellar Purkinje cells in the 30-month-old animals do not support such postnatal and/or age-related effects. Accelerated postnatal loss of hippocampal neurons, which are under normal conditions not reduced in number during aging, ${ }^{37,81}$ has been observed only for hippocampal pyramidal cells but not for hippocampal granule cells after single prenatal low-dose $X$-irradiation. ${ }^{10}$ Furthermore, age-related loss of Purkinje cells has been well documented for the rodent cerebellum, ${ }^{82-85}$ whereas the number of cerebellar granule cells is not diminished during aging (Sturrock 1989, Rutten et al. 2003). ${ }^{82,85}$

In summary, VLDRPP irradiation of rats from E13 to E16 with a dose rate of $0.7 \mathrm{mGy} / \mathrm{min}$ had severe effects on numbers of cells whose final progenitors underwent division during the selected period of irradiation (hippocampal pyramidal and cerebellar Purkinje cells). This suggests that the vulnerable period for these cells closely overlaps with the phase of division of their final progenitors. However, irradiation also affected cells whose final progenitors underwent division after the selected period of irradiation (hippocampal and cerebellar granule cells). In this case reductions in neuron numbers resulted most probably from at least three different mechanisms, i.e., reductions in the number of granule cell progenitors earlier in development, reductions in the amount of growth factors and/or mitogens, and the absence of trophic support from postsynaptic targets. The present data are relevant in the context of the increasing interest in effects of very low dose rate protracted irradiation on the developing and adult organism (Brenner et al. 2003 ), in that they demonstrate that VLDRPP irradiation of rats from E13 to E16 with a dose rate of $0.7 \mathrm{mGy} / \mathrm{min}$ does result in a severe decrease in total numbers of hippocampal and cerebellar neurons in the offspring brain. Therefore the prenatal irradiation protocol applied in the present study shares an important feature with chronic low daily dose gamma irradiation of adult animals and humans that can lead to adverse health consequences. ${ }^{86,87}$

\section{REFERENCES}

1. Yarnazaki $\mathbb{N}$ : A review of the literature on the radiation dosage required to cause manifest central nervous system disturbances from in utero and postnatal exposure. Pediatrics 1966, 37:Suppl 37:877+

2. Kimler BF: Prenatal irradiation: a major concern for the developing brain. Int I Radiat Biol 1998, 73:423434

3. Streffer C, Shore R, Konermann G, Meadows A, Uma Devi P, Preston Withers J, Holm LE, Stather J, Mabuchi K, H R: Biological effects after prenatal irradiation (embryo and fetus). A report of the International Commission on Radiological Protection. Ann ICR.P 2003, 33:5-206

4. Hicks SP, D'Amato $\mathrm{CJ}$ : Effects of ionizing radiation on mammalian development. Advances in teratology. Edited by Woollam DHM. London, Logos Press, 1966, pp 195-243 
5. Sun $\mathrm{XZ}$, Inouye $\mathrm{M}$, Hayasaka $\mathrm{S}$, Takagishi $\mathrm{Y}$, Yamamura H: Effects of different doses of ganma-irradiation on the developing brain of mice. Environm Med 1995, 39:113-116

6. Li HP, Miki T, Gu H, Satriotono I, Mastumoto Y, Kuma H, Gonizalez D, Bedi KS, Swwalki H, Takenchi Y The effect of the timing of prenatal X-irradiation on Purkinje cell numbers in rat cerebellum. Brain Res Dev Brain Res 2002, 139:159-166

7. Norton S: Development of rat telencephalic neurons after prenatal X-irradiation. I Environ Sei Health C 1979, $13: 121-134$

8. Ferrer I: Experimentally induced cortical malformations in rats. Childs Nerv Syst 1993, 9:403-407

9. Brumi JE, Persaud TV, Huang W, Froese G: Postnatal development of the rat CNS following in utero exposure to a low dose of ionizing radiation. Exp Toxicol Pathol 1993, 45:223-231

10. Korr H, Thorsten Rohde H, Benders J, Dafotakis M, Grolms N, Schmitz C: Neuron loss during early adulfhood following prenatal low-dose X-irradiation in the mouse brain. Int $J$ Radiat Biol 2001, 77:567-580

11. Schmitz $C$, Grolms $N$, Hof $P R$, Boehringer $R$, Glaser $J$, Korr H: Altered spatial arrangement of layer $V$ pyramidal cells in the mouse brain following prenatal low-dose $X$-irradiation. A stereological study using a novel three-dimensional analysis method to estimate the nearest neighbor distance distributions of cells in thick sections. Cereb Cortex 2002, 12:954-960

12. Brent RL: The response of the 9 and one-half-day-old-rat embryo to variations in exposure rate of $150 \mathrm{~K}$ $X$-irradiation. Radiat Res 1971, 45:127-136

13. Brizzee $K R$, Jacobs $L A$, Kharetchki $X$ : Effects of total body $X$-irradiation in utero on early postnatal changes in neuron volumetric relationships and packing density in cerebral cortex. Radiat Res 1961, 14:96-103

14. Brizzee KR: Effects of Single and Fractionated Doses of Total Biody X-Irradiation in Utero on Growth of the Brain and its Parts. Nature 1964, 202:262-264

15. Brizzee KR, Jacobs LA, Bench CJ: Histologic effects of total-body X-irradiation in various dose fractionation patterns on fetal cerebral hernisphere. Radiat Res 1967, 31:415-429

16. Vidal-Pergola GM, Kimler BF, Norton S: Effect of in utero irradiation on the postnatal development, behavior, and brain structure of rats: dose fractionation with a 6-h interval. Radiat Res 1993, 134:369-374

17. Reyners $\mathrm{H}_{3}$ Gianfelici de Reyners $\mathrm{E}_{\mathrm{s}}$ Poortmans $\mathrm{F}$, Crametz $\mathrm{A}$, Coffigny $\mathrm{H}$, Maisin JR: Braïn atrophy after foetal exposure to very low doses of ionizing radiation. Int J Radiat Biol 1992, 62:619-626

18. Brenner DJ, Doll R, Goodhead DT, Hall EJ, Land CE, Little JB, Lubin JH, Preston DL, Preston RJ, Puskin JS, Ron E, Sachs RK, Samet JM, Setlow RB, Zaider M: Cancer risks attributable to low doses of ionizing radiation: assessing what we really know. Proc Natl Acad Sci U S A 2003, 100:13761-13766

19. Altman $J_{*}$ Bayer SA: Prenatal development of the cerebellar system in the rat. I. Cytogenesis and histogenesis of the deep nuclei and the cortex of the cerebellum. J Comp Neuroll 1978, 179:23-48

20. Bayer SA: Development of the hippocampal region in the rat. 1 . Neurogenesis examined with $3 \mathrm{H}$-thymidine autoradiography. J Comp Neurol 1980, 190:87-114

21. Altman J, Das GD: Post-natal origin of microneuromes in the rat brain. Nature 1965, 207:953-956

22. Vogel MW, Sunter K, Herrup K: Numerical matching between granule and Purkinje cells in lurcher chimeric mice: a hypothesis for the trophic rescue of granule cells from target-related cell death. I Neurosci 1989 , 9:3454-3462

23. Dahmane $\mathrm{N}$, Ruiz-i-Altaba A: Sonic hedgehog regulates the growth and patterning of the cerebellum. Development 1999, 126:3089-3100

24. Ohnishi $\mathbb{T}$, Takahashi $A_{*}$ Ohnishi K, Yonezawa M: Tumor suppresssor p53 résponse is blunted by low-dose radiation. Phys Med 2001, 17 Suppl 1:215-216

25. Schmitz C, Hof PR: Design-based stereology in neuroscience. Neuroscience 2005, 130:813-831

26. Cavalieri B: Geometrica Indivisibilibus Continuorum. Bononiae: Typis Clemetis Ferronij. 1635

27. Garcia-Finana M, Cruz-Orive LM, Mackay CE, Pakkenberg B, Roberts $\mathbb{N}$ : Comparison of MR imaging against physical sectioning to estimate the volume of human cerebral compartments. Neuroimage 2003, 18:505-516

28. West MJ, Slomianka L, Gundersen HJ: Unbiased stereological estimation of the total number of neurons in thesubdivisions of the rat hippocampus using the optical fractionator. Anat Rec 1991, 231:482-497

29. Schmitz C: Variation of fractionator estimates and its prediction. Anat Embryol 1998, 198:371-397

30. Schmitz C, Hof PR: Recommendations for straightforward and rigorous methods of counting neurons based on a computer simulation approach. J Chem Neuroanat 2000, 20:93-114

31. Hillman DE, Chen S: Vulnerability of cerebellar development in malnutrition-1. Quantitation of layer volume and neuron numbers. Neuroscience 1981, 6:1249-1262

32. Boss BD, Peterson GM, Cowan WM: On the number of neurons in the dentate gyrus of the rat. Brain Res $1985,338: 144-150$

33. Boss BD, Turlejski K, Stanfield BB, Cowan WM: On the numbers of neurons in fields CAI and CA3 of the hippocampus of Sprague-Dawley and Wistar rats. Brain Res 1987, 406:280-287

34. Harvey RJ, Napper RM: Quantitative study of granule and Purkinje cells in the cerebellar cortex of the rat. J Comp Neurol 1988, 274:151-157 
35. Korbo $L_{4}$ Andersen $B B$, Ladefoged $O$, Moller A: Total numbers of warious cell types in rat cerebellar cortex extimated using an unbiased stereological method. Brain Res $1993,609: 262-268$

36. Overgaard Larsen $J$, Tandrup $T$, Braendgaard $\mathrm{H}$ : The volume of Purkinje cellis decreases in the cerebellum of acrylamide-intoxicated rats, but no cells ane lost. Acta Neuropatholl (Berl) 1994, 88:307-312

37. Rasmussen $T$, Schliemanu $T$. Sorensen JC, Zimmer J, West MV: Memory impaired aged rats: no loss of prificipal hippocampal and subicular neurons. Neurobiol Aging 1996, 17:143-147.

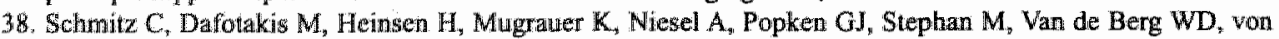
Horsten $\mathrm{S}_{\text {, Korr }} \mathrm{H}$ : Use of cryostat sections from snap-frozen nervous tissue for combining stereological estimates with histological, cellular, or molecular analyses on adjacent sections. J Chem Neuroanat 2000 , $20: 21-29$

39. Gundersen $\mathrm{HJ}$, Jensen EB: The efficiency of systematic sampling in stereology and its prediction. J Microsc $1987,1,47: 229-263$

40. Gumtinas-Lichius $\mathrm{O}$, Neis. WF: Comparison of enpirical and estimated efficiency in neuron counting by the fractionator method and in volume measurement by Cavalieri's method. Acta Stereol 1996, 15:131-139

41. Satorre J, Cano J, Reinoso-Suarez F: Stability of the neuronal population of the dorsal lateral geniculate nucleus (LGNd) of aged rats. Brain Res 1985, 339:375-377

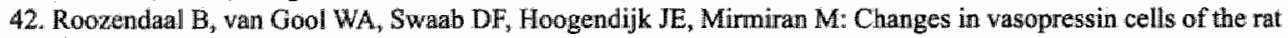
suprachiasmatic nucleus with aging. Brain Res 1987, 409:259-264

43. Sturrock RR: Stability of neuron number in the subthalamic and entopeduncular nuclei of the ageing mouse brain. J Anat 1991, 179:67 - 73

44. Altmad A, Spear PD: Effects of aging on the size, density, and number of rhesus monkey lateral geniculate neurons. J Comp Neurol 1993, 334:631-6443

45. West MJ: Stereological methods for estimating the total number of neurons and synapses: issues of precision and bias. Trends Neurosci 1999,22:51-61

46. Momosaki S, Sun $X Z$, Takai $N$, Hosoi $\mathbb{R}_{n}$ Inove $O$, Takahashi $S$ : Changes in histological construction and decrease in $3 H-Q N B$ binding in the rat brain after prenatal X-irradiation. I Radiat Res (Tokyo) 2002, 43:277282

47. Ferrer I, Alcantara S, Marti E: A four-layered 'lissencephalic' cortex induced by prenatal X-irradiation in the rat. Neuropathol Appl Neurobiol 1993, 19:74-81

48. Inouye $M$ : Cerebellar malformations in prenatally $X$-irradiated rats: quantitative analysis and detailed description. Teratology 1979, 20:353-364

49. Wang H, Chen D, Gao C, Zhou X: Effects of low level prenatal 60Co gamma-irradiation on postnatal growth and behavior in mice. Teratology 1993, 48:451-457

50. Kameyama Y: Low-dose radiation as an environmental agent affecting intrauterine development. Environm Med 1982, 26:1-15

51. Hyodo-taguchi $\mathrm{Y}$, Fushiki $\mathrm{S}$, Kinoshita $\mathrm{C}_{3}$ Ishikawa $\mathrm{Y}$, Hirobe T: Effects of continuous low-dose prenatal irradiation on neuronal migration in mouse cerebral cortex. J Radiat Res (Tokyo) 1997, 38:87-94

52. Djordjevic B, Szybalski W: Genetics of human cell lines. III. Incorporation of 5-bromo- and 5iododeoxyuridine into the deoxyribonucleic acid of human ells and its effect on radiation sensitivity. $J$ Exp Med 1960, 112:509-531

53. Miakis G, Kurtzman S, Pantelias G, Okayasu R: Mechanism of radiosensitization by halogenated pyrimidines: effect of BrdU on radiation induction of DNA and chromosome damage and its correlation with cell killing. Radiat Res 1989, 119:286-304

54. Hawkins RB: A microdosinetric-kinetic model for the sensitization of 79 cells to radiation by incorporation of bromodeoxyuridine. Radiat Res 2001, 155:698-702

55. Cahill DF, Yuile CL: Tritium: some effects of continuous exposure in utero on mammalian development. Radiat Res 1970, 44:727 737

56. Sun $\mathrm{XZ}$, Inouye $\mathrm{M}$, Yamamura $\mathrm{H}$, Fukui $\mathrm{Y}$ : Effects of prenatal treatment with tritiated water on the developing brailn in mouse. Int J Dev Neurosei 1997, 71:309-3113

57. Gaw WM, Wang B, Zhou XY: Effects of prenatal low-dose beta radiation from tritiated water on learning and memory in rats and their possible mechanisms. Radiat Res 1999, 1152:265-272

58. Hoshino $\mathrm{K}$ : Histiogenetic abnormalities of the brain caused by environmental factors: sensitive period for microcephaly. Cong Anon 1983, 23:415-423

59. Kameyama $Y$ : Factors in manifestation of developmental abnormalities of the central nerwous system by environmental agents. J Toxical Sci 1983, 8:91-103

60. Benekou A, Bolaris S, Kuzanis E, Bozas E, Philippidis H, Stylianopoulou F: In utero radiation-induced changes in growth factor levels in the developing rat brain. Int J Radiat Biol 2001, 77:83-93 
61. Bolaris S, Bozas E, Benckou A, Philippidis $\mathbb{H}$, Stylianopoulou F: In utero radiation-induced apoptosis and p53 gene expression in the developing rat brain. Int J Radiat Biol $2001,77: 71-81$

62. Altman $\mathrm{J}$ : Postnatal development of the cenebellar cortex in the rat. 3. Maturation of the components of the granular layer. J Comp Neurol 1972, 145,465-513

63. Schlessinger AR, Cowan WM, Gottlieb DI: An autoradiographic stuily of the time of orgin and the patem of granule cell migration in the dentate gyrus of the rat. J Conmp Neuroll $1975,159: 149-175$

64. Alder J, Cho NK, Hatten ME: Embryonic precursor cells from the rinombic lip are specified to a cerebellar granule neuron identity. Neuron 1996, 17:389-399

65. Alder J, Lee KJ, Jessell TM, Hatten ME: Generation of cerebellar gramule neurons in who by transplantation of BMP-treated neural progenitor cells. Nat Neurosei $1999,2: 535-540$

66. Millonig JH, Millen KJ, Hatten ME: The mouse Drelher gene Lmx la controls formation of the roof plate in the wertebrate CNS. Nature $2000,403: 764-769$

67. Yabe T, Samuels I, Schwartz JP: Bone morphogenetic proteins BMP 6 and BMP-7 have differential effects on survival and neurite outgrowth of cerebellar granule cell neurons. I Neurosci Res 2002, 68:161-168.

68. Wetts $\mathrm{R}$, Herrup $\mathrm{K}$ : Direct cortelation between Purkinje and granule cell number in the cerebella of lurcher chimeras and wild-type mice. Brain Res 1983, 312:41-47

69. Chen $S$, Hillman DE: Regulation of granule cell number by a predetermined number of Purkinje cells in devellopment. Brain Res Dev Brain Res 1989, 45:137-147

70. Ralcewicz TA, Persaud TV: Effects of prenatal exposure to low dose ionizing radiation on the development of the cerebellar cortex in the rat. Histol Histopathol 1995, 10.371-3.83

71. Goldowitz D, Hamre K: The cells and molecules that make a cerebellum. Trends Neurosci 1998, 21:375382

72. Wallace VA: Purkinje-cell-derived Sonic hedgehog regulates granule neuron precursor cell proliferation in the developing mouse cerebellum. Curr Biol 1999, 9:445-448

73. Wechsler-Reya RJ, Scott. MP: Control of neuronal precursor proliferation in the cerebellum by Sonic Hedgehog. Neuron 1999, 22:103-114

74. Lewis ER, Cotman CW: Factors specifying the development of synapse number in the rat dentate gyrus: effects of partial target loss. Brain Res 1980, 191:35-52

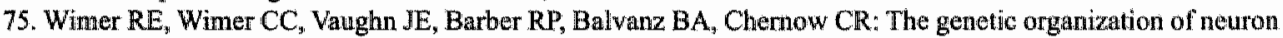
number in Ammon's homs of house mice. Brain Res 1976, 118:219-243

76. Barnes DE, Walker DW: Prenatal ethanol exposure permanently reduces the number of pyramidal netrons in rat hippocampus. Brain Res 1981, 227:333-340

77. Cheng Y, Black IB, DiCicco-Bloom E: Hippocampal gramule neuron production and population size are regulated by levels of bFGF. Eur J Neurasci $2002,15: 3-12$

78. Charytoniuk D, Porcel B, Rodriguez Gomez J, Faure $H$, Ruat $\mathrm{M}$, Traiffort E: Sonic Hedgehog signalling in the developing and adult brain. J Physiol Paris 2002, 96:9-16

79. Lai K, Kaspar BK, Gage FH, Schaffer DW: Sonic hedgehog regulates adult neural progenitor proliferation in witro and in wivo. Nat Neurosci $2003,6: 21-27$

80. Machold R, Hayashi S, Rutlin M, Muzumdar MD, Nery S, Corbin JG, Gritli-Linde A, Dellovade T, Portar IA, Rubin LL, Dudek H, McMahon AP, Fishell $\mathrm{G}$. Sonic hedgehog is required for progenitor cell maintenance in telencephalic stem cell niches. Neuron $2003,39: 937$ - 950

81. Rapp PR, Gallagher M: Preserved neuron number in the hippocampus of aged rats with spatial learning deficits. Proc Natl Acad Sci U S A 1996, 93:9926-9930

82. Sturrock RR: Changes in neuron number in the cerebellar cortex of the ageing mouse. I Hirnforsch 1989 , 30:499-503

83. Hadj-Sahraoui $N$, Frederic F, Zanjani $H$, Herrup $K$, Delhaye-Bouchaud $N$, Mariani J: Purkinje cell loss in heterozygous staggerer mutant mice during aging. Brain Res Dev Brain Res 1997, 98:1--8

84. Doulazmi M, Frederic F, Lemaigre-Dubreuil Y, Hadj-Sahraoui N, Delhaye-Bouchaud N, Mariani J: Cerebellar Purkinje cell loss during life span of the heterozygous staggerer mouse (Rora(-)/Rora(sg)) is gender-related. JComp Neurol 1999, 411:267-273

85. Rutten BPF, Kor H, Gerlach OHM, Oyen H., Steinbusch HWM, Schmitz C: The aging brain: less neurons could be better. The cerebellum. Sor Neurosei Abstr No 735162003

86. Carnes BA, Gavrilova N, Grahn D: Pathology effects at radiation doses below those causing increased mortality. Radiat Res 2002, 158:187-194

87. Seed TM, Inal C, Dobson ME, Ghose S, Hilyard E, Tolle D, Fritz TE: Accommodative responses to chronic irradiation: effects of dose, dose rate, and pharmacological response modifiers. Mil med 2002, 167..82--86. 


\section{APPENDIX}

\begin{tabular}{|c|c|c|c|c|c|c|}
\hline & $\mathrm{DG}$ & $\mathrm{CA} \perp-3$ & ML & PL & GL & WM \\
\hline $\bar{S}$ & 15 & 15 & 17 & 17 & 17 & 17 \\
\hline Obj. 1 & $20 x$ & $20 x$ & $20 x$ & - & $20 \times$ & $20 x$ \\
\hline$\sum S_{S m}$ & - & - & 118 & - & 101 & 73 \\
\hline$\sum p_{1}$ & - & - & 153 & - & 125 & 109 \\
\hline$\sum p_{t}$ & - & - & 1,630 & - & 1,341 & $1,24 \mathrm{C}$ \\
\hline$\overline{C E_{p D i}}$ & - & - & 0.018 & - & 0.029 & 0.023 \\
\hline Obj. 2 & $40 x$ & $40 x$ & - & $40 x$ & $100 x$ & - \\
\hline sla-x sla-y $[\mu \mathrm{m}]$ & 200 & 200 & - & 400 & 400 & 一 \\
\hline $\mathrm{a}\left[\mu \mathrm{m}^{2}\right]$ & 612 & 1,224 & - & 15 & 15 & - \\
\hline $\mathrm{h}[\mu \mathrm{m}]$ & 10 & 10 & - & 15 & 15 & - \\
\hline $\mathrm{d}[\mu \mathrm{m}]$ & 5 & 5 & - & 5 & 5 & 一 \\
\hline $\bar{t}[\mu \mathrm{m}]$ & 40.6 & 42.1 & 47.5 & 47.9 & 46.9 & 47.5 \\
\hline$\sum c s_{m b / p m}$ & 15 & 25 & - & 30 & 26 & - \\
\hline$\sum c s_{1}$ & 25 & 33 & - & 37 & 31 & - \\
\hline$\sum c s_{t}$ & 126 & 312 & - & 347 & 307 & - \\
\hline$\sum n_{m b / p m}$ & 102 & 86 & - & 110 & 89 & - \\
\hline$\sum m_{1}$ & 164 & 112 & - & 125 & 105 & - \\
\hline$\sum n_{t}$ & 775 & 1,074 & - & 1,188 & 996 & \\
\hline$C E_{n-1}$ & 0.039 & 0.032 & - & 0.031 & 0.033 & \\
\hline
\end{tabular}

Details of the stereologic estimation procedures. $\bar{S}$, average number of sections showing the corresponding brain region on systematically and randomly sampled series of sections spanning the entire left hippocampus or the left cerebellar half, respectively. DG, hippocampal dentate gyrus (and granule cells within this layer); CAl-3, hippocampal CA 1-3 field (and pyramidal cells within this layer); ML, cerebellar molecular layer; PL, cerebellar Purkinje cell layer (and cerebellar Purkinje cells); GL, cerebellar granule cell layer (and cerebellar granule cells); WM, cerebellar white matter. Obj. 1, objective used for identification of the boundaries of the layers (or for point counting, respectively); sla- $\mathrm{x}$ and sla-y; distance between the points for point counting in mutually orthogonal directions $x$ and $y$ (see Figure 1B in Schmitz and Hof $\left.{ }^{30}\right) ; \overline{\sum S_{S m}}$, average number of points counted in the corresponding layer within the first paramedian sagittal section of the left cerebellar half; $\overline{\sum p_{1}}$, average number of points counted 
in the corresponding layer within the section showing the largest total cerebellar projection area; $\sum p_{i}$, average number of points counted in the corresponding layer within the entire cerebelhum; $\overline{C E_{p I i}}$, average predicted coefficient of error of the estimated volumes using the prediction method described by Garcia-Finana et al. ${ }^{27} \mathrm{Obj} .2$, objective used for counting neurons; $\sin -\mathrm{x}$ and $\sin -\mathrm{y}$; distance between the unbiased virtual counting spaces in mutually orthogonal directions $\mathrm{x}$ and $\mathrm{y}$; $\mathrm{a}$ and $\mathrm{h}$, base and height of the unbiased virtual counting spaces; $\mathrm{d}$, depth within the section at which the unbiased virtual counting spaces were placed; $\bar{t}$, measured actual average section thickness after histologic processing; $\overline{\sum s_{p m b} p \text {; }}$; average sum of unbiased virtual counting spaces used for counting neurons in the corresponding layer within the section through the mid body of the left hippocampus (or within the first paramedian sagittal section of the left cerebellar half, respectively); $\overline{\sum s_{1}}$, average sum of unbiased virtual counting spaces used for counting neurons in the corresponding layer within the section showing the largest total area of the hippocampal cell layers (DG plus $\mathrm{CAl}-3$ ) (or within the section showing the largest total cerebellar projection area, respectively). $\overline{\sum c s_{i}}$, average sum of unbiased virtual counting spaces used for counting neurons in the corresponding layer within the entire hippocampus (or within the entire cerebellum); $\overline{\sum n_{m b / p m}}$; average number of neurons counted in the corresponding layer within the section through the mid-body of the left hippocampus (or within the first paramedian sagittal section of the left cerebellar half, respectively); $\overline{\sum n_{1}}$, average number of neurons counted in the corresponding layer within the section showing the largest total area of the hippocampal cell layers (DG plus CA1-3) (or within the section showing the largest total cerebellar projection area, respectively). $\sum n_{i}$, average number of neurons counted in the corresponding layer within the entire hippocampus (or within the entire cerebellum); $\overline{C E_{n-1}}$; average predicted coefficient of error of the estimated total numbers of neurons using the prediction method described by Schmitz ${ }^{29}$ and Schmitz and Hof. 

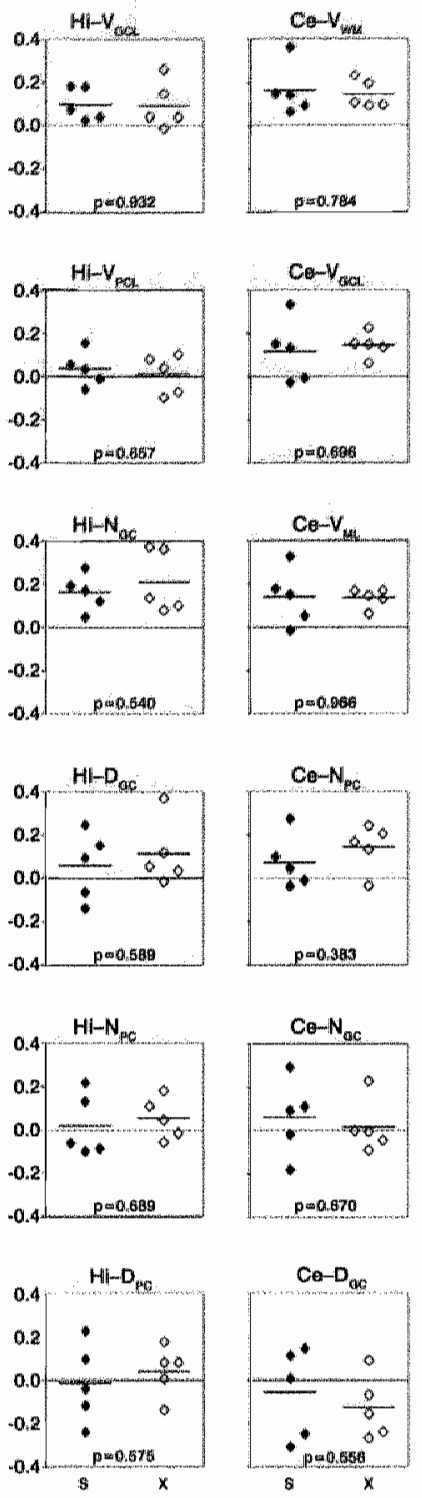

Figure S1. Ratios of individual results for male and female offsprings of a given dam. Analysis of rats subjected to prenatal irradiation (black diamonds) and prenatal sham-irradiation (open dianonds). Data were calculared as (male-female) / (male to femade)] and are shown as indiwidtual values and means per group (lines). Data were arranged in the same order as in Figure 3 and Figure 5. Hi- $W_{\text {cic }}$ wolume of the hippocampial granule cell layer. $\mathrm{Hi}_{\mathrm{i}} \mathrm{V}_{\mathrm{PC}}$, wolume of the hippocampal pyramidal cell loyer $(C A 1-3)$. Hi-N $\mathrm{NC}_{\text {o }}$ total number of hippocampal gramule cells. Hi- $D_{G C}$ density of hippocampal granule cells. Hi-NPC. 1otal number of hippocampal pyramidal cells $(C A I-3)$. $H i-D_{P G}$ density of hippocampal pyramidal cells $(\mathrm{CA} 1-3) . \mathrm{Ce}-V_{\text {whe }}$ wotume of the cerebellar white matter.

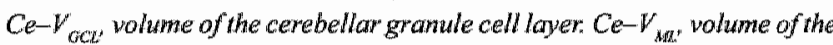
cerebellar molecular layer. $\mathrm{Ce}-N_{P C^{r}}$ total mumber of cerebellar Purkinje cells. Ce- $N_{G C}$ tonal number of cerebellar gramule cells. Ce- $D_{C C}$ density of cerebellar gramule cells. 


\section{Chapter 3}

\section{The aging brain: fewer neurons could be better}

Mechanisms of Ageing \& Development, 2003;124(3):349-355.

Bart P.F. Rutten, Hubert Korr,

Harry W.M. Steinbusch, Christoph Schmitz 


\section{ABSTRACT}

Molecular and cellular markers of age-related alterations in the brain vary significantly between different brain regions and between different types of neurons. In contrast to what had been thought for years, it has recently become clear that only specific types of neurons show an age-related loss of cells. Based on previous work we hypothesize that there is an interrelationship between two important processes in the aging brain: some types of neurons in the aging brain show an accumulation of unrepaired nuclear (n) nDNA damage since no cells are lost during aging. In contrast, other types of neurons show no accumulation of unrepaired nDNA damage since the cells with the greatest decline in nDNA repair capacity and the highest amount of $\mathrm{nDNA}$ damage are lost during aging. Most interestingly, the former types of neurons seem to correlate strongly with those types of neurons afflicted in age-related cognitive decline and in the selective neuronal vulnerability in Alzheimer's disease. Therefore, modulation of the $\mathrm{nDNA}$ damage response by stimulation of $\mathrm{nDNA}$ repair processes, or by elimination of neurons with a high amount of unrepaired nDNA damage in the aging brain, may lead to a functional improvement in networks of these types of neurons and to a better functioning of the aging brain in general. Ultimately, the implication of this strategy may lead to the prevention of Alzheimer's disease.

\section{INTRODUCTION}

Mammalian aging is an inevitable process associated with a general decline in physiological function, and with an increased incidence of degenerative diseases and cancer. Importantly, basic processes involved in aging of the central nervous system contribute to several prevalent neurodegenerative diseases like Alzheimer's disease (AD) and Parkinson's disease.' The aging brain is characterized by several age-related alterations. On the molecular and cellular level, an important aspect of the aging process of the brain is an increased production of free radicals and an accumulation of nuclear ( $\mathrm{n}$ ) and mitochondrial (mt) DNA damage. ${ }^{2 n^{3}}$ This is accompanied by an age-related decline in the amount of nDNA repair. ${ }^{3-5}$ On the functional level, the cognitive capacity of the aging brain declines gradually in the elderly individual. ${ }^{6}$, Neuropathological studies indicate that shrinkage of the brain, loss of neurons and the presence of specific intracelIular and extracellular protein aggregates are common age-related findings. ${ }^{*}$ However, it has been shown over the last years that markers of these age-related alterations vary significantly between different brain regions, as well as between different types of neurons, ${ }^{4,5},{ }^{9-12}$ As the brain consists of various types of neurons with different morphologic, physiologic and functional features, it is of great importance to investigate the aging brain in a cell type-specific manner. The number of studies assessing the regional variability and cell type-specific alterations in the aging brain, however, is very limited. In this article, several of these studies are reviewed. Based on this, a novel hypothesis concerning a better functioning of the aging brain in general is outlined. This hypothesis might also have implications for preventing the development of AD. 


\section{REGIONAL VARIABILITY OF DNA DAMAGE AND REPAIR IN THE AGING BRAIN}

In recent quantitative studies, the rates of spontaneous nDNA repair and mtDNA synthesis were analyzed for various cell types of the aging rodent brain.,13 The results of these studies indicated that the rate of mtDNA synthesis decreases in all investigated types of neurons during aging (Table 1, first column). However, a cell-type-specificity was found for the rate of spontaneous nDNA repair in the aging rodent brain. Purkinje cells in the cerebellum, mitral cells in the olfactory bulb, and the large neurons in the lateral vestibular nucleus did not show an age-related decline of the rate of spontaneous nDNA repair, whereas all other investigated types of projection neurons did (Table 1, second column). Importantly, age-related decline in the rate of $n$ DNA repair may result in an age-related accumulation of unrepaired nDNA damage and thus in cellular dysfunction. ${ }^{14}$ Other studies have shown a regional variability in the amount of unrepaired nDNA damage in the aging rodent brain," and the patterns found were compatible with the cell-type-specific findings concerning the rate of nDNA repair in the studies of Schmitz et al..$^{4,13}$ Specifically, the cerebellum exhibited a much lower amount of unrepaired nDNA damage than the neocortex and the hippocampus (Table 1, third column). Together these results clearly indicated a previously unknown regional variability in the processing of nDNA damage in the aging rodent brain.

In addition to the accumulation of unrepaired nDNA damage, aging is associated with an accumulation of mtDNA deletions. ${ }^{10}$ Interestingly, there are also region-specific differences in the amount of mtDNA deletions in the aging rodent brain. ${ }^{10}$ With particular respect to the human brain, certain brain regions such as the neocortex and the hippocampus exhibit large amounts of mtDNA deletions in aged individuals, whereas the cerebellum does not show this phenomenon (Table 1, fourth column). ${ }^{15-17}$

\section{RESPONSES TO NDNA DAMAGE}

The response to nDNA damage in eukaryotic cells can be divided into three components: recognition of nDNA damage, a period of damage assessment (enforced by checkpoints), and the activation and implementation of the appropiate response, i.e. nDNA repair or apoptosis. ${ }^{18,19}$ The mechanisms and proteins involved in nDNA damage recognition are poorly understood. Over the last years, however, several genes and proteins involved in these mechanisms have been identified. One of the identified proteins that seems to have a crucial role in sensing DNA damage is ATM (ataxia telangiectasia mutated ${ }^{20}$ ). This protein is involved in the detection of nDNA double strand breaks. In the context of nDNA damage, checkpoints in damage assessment establish barriers to prevent the perpetuation of injured genomes..$^{19}$ Thus, these checkpoints will allow the cell to attempt to repair the nDNA damage or to die by apoptosis. ATM, ATR (ataxia telangiectasia rad 3 related $^{21}$ ) and DNA-PK (DNA-dependent protein kinases ${ }^{22}$ ) seem to act as checkpoint sensors signaling to both cell-cycle and apoptosis machineries. Eventually, checkpoint activation can lead to 553 phosphorylation and activation which, subsequently, initiates cell cycle regulator proteins such as $\mathrm{p} 21$ and GADD $45,{ }^{19}$ or apoptotic activator proteins such as Bax and caspases. ${ }^{23}$ The decision whether or not to die by apoptosis is regulated by numerous 
"pro- and anti-apoptotic' proteins of which only a subset have been identified. Among the powerful anti-apoptotic proteins in the mammalian nervous system are the neurotrophins. These proteins bind to the TrkA-receptor on the cell membrane and activate the PI(3)K pathway (phospho-inositide 3-kinase ${ }^{24}$ ). Among the pro-apoptotic proteins, C-jun, Dp5, Bax, Bcl-xl, CD95, MDM2 and PERP have been identified. ${ }^{19}$ The major function of apoptosis is to remove cells that would hamper optimal function of the organism as a whole. The apoptosis process is designed to rapidly remove cells from tissues, tagging them for phagocytosis and recycling their constituent molecules. ${ }^{25}$ The role of the main effectors in the apoptotic machinery is played by the caspases. ${ }^{24}$ Caspases activate other proteins of the apoptotic machinery by cleavage, uncouple the catalytic and nDNA binding domains of poly-ADP-ribose polymerase, and activate a DNAse to fragment the nDNA molecules. ${ }^{24}$ By contrast, if the cell "chooses" to repair the $\mathrm{nDNA}$ damage, the machinery of $\mathrm{nDNA}$ repair is able to activate specific repair proteins according to the nature of the nDNA damage. 19,26 Double strand breaks can be repaired by homologous recombination or non-homologous end joining, whereas single strand damages can be repaired by nucleotide excision repair, base excision repair or mismatch repair. ${ }^{26}$ It should be noted that the mismatch repair pathway is connected to the cell cycle and therefore cannot be used by postmitotic cells such as neurons.

However, if nDNA repair mechanisms become insufficient to repair the damage during aging (due to decreased repair capacity or to an increased amount of nDNA damage), nDNA damage will remain unrepaired and will accumulate. This may result in cellular dysfunction. ${ }^{14}$ Interestingly, recent studies (not carried out on the nervous system) suggest that aging may also alter the apoptotic response to genotoxic stimuli. For example, Suh et al. showed that the apoptotic potential is dramatically reduced in aged murine hepatocytes after treatment with a genotoxic agent. ${ }^{27}$ On the basis of this result, the authors speculated that age-related down-regulation of apoptosis might provide the mechanism of the well documented increase in nDNA damage and mutations with age. As Suh et al. further indicate, ${ }^{27}$ it is highly tempting to speculate on the implications of these findings to the aging brain (although data obtained from cells, which can undergo mitosis, do not necessarily hold for postmitotic cells ${ }^{28}$ ). In this vein, we hypothesize that some neurons in the aging brain do not respond appropriately to nDNA damage, undergoing neither $\mathrm{nDNA}$ repair nor apoptosis. Considering the data summarized in Table 1, this might indeed be the case.

\section{REGIONAL VARIABILITY OF CELL LOSS IN THE AGING BRAIN}

It has been assumed in the neuroscience community for a long time that aging is associated with a loss of neurons throughout all regions of the brain, and that this loss of neurons would explain the functional decline of the brain during aging. ${ }^{29-31}$ Recent investigations, however, have provided convincing evidence that age--related loss of neurons in the mammalian brain clearly exhibits a regional and cell-type-specific variability (Table 1, fifth column). ${ }^{12,29,30,32}$ In this regard it should be noted that especially the application of state-of-the-art stereological methods has tremendously contributed to this shift in the knowledge concerning regional variability of neuronal loss in the aging brain. ${ }^{33,34}$ For example, Merrill et al. recently showed 
that the numbers of pyramidal cells in the entorhinal cortex and hippocampus are conserved even in aged rodents with behawioural deficits. ${ }^{35}$ As age-related cognitive decline of rodents is associated with disturbances of the neocortex and of the hippocampus, Merrill et al. concluded that age-related processes other than neuronal loss in the hippocampus are likelly to cause age-related cognitive deficits in rodents ${ }^{35}$ Importantly, a meta-amalysis of the current literature regarding cell-type-specific loss of neurons in the aging rodent brain indicated that specific types of neurons do show a substantial age-related loss of cells (Table 1 ; fifth column). For example, up to $30 \%$ of Purkinje cells in the human cerebellum are lost, ${ }^{36}$ and also a substantial amount of the mitrall cells in the olfactory bulb are lost during aging in the rodent brain ${ }^{37}$ Most interestingly, in the aging rodent brain there is a striking inverse correlation such that types of neurons showing no decline of the rate of spontaneous nDNA repair (with the implication of no increase in the amount of unrepaired $\mathrm{nDNA}$ damage) exhibit an age-related loss of cells, and types of neurons showing a decline in the rate of spontaneous $\mathrm{nDNA}$ repair do not show an age-related loss of cells (Table 1 , second vs. fifth column).

\section{CELL LOSS AS A POTENTIALLY PROTECTIVE MECHANISM IN THE AGING BRAIN}

Based on this inverse correlation we hypothesize that - at least in the aging rodent brain - cell loss is the basis of the apparent lack both of age-related decline in the rate of spontaneous nDNA repair and of age-related accumulation of unrepaired nDNA damage in certain types of

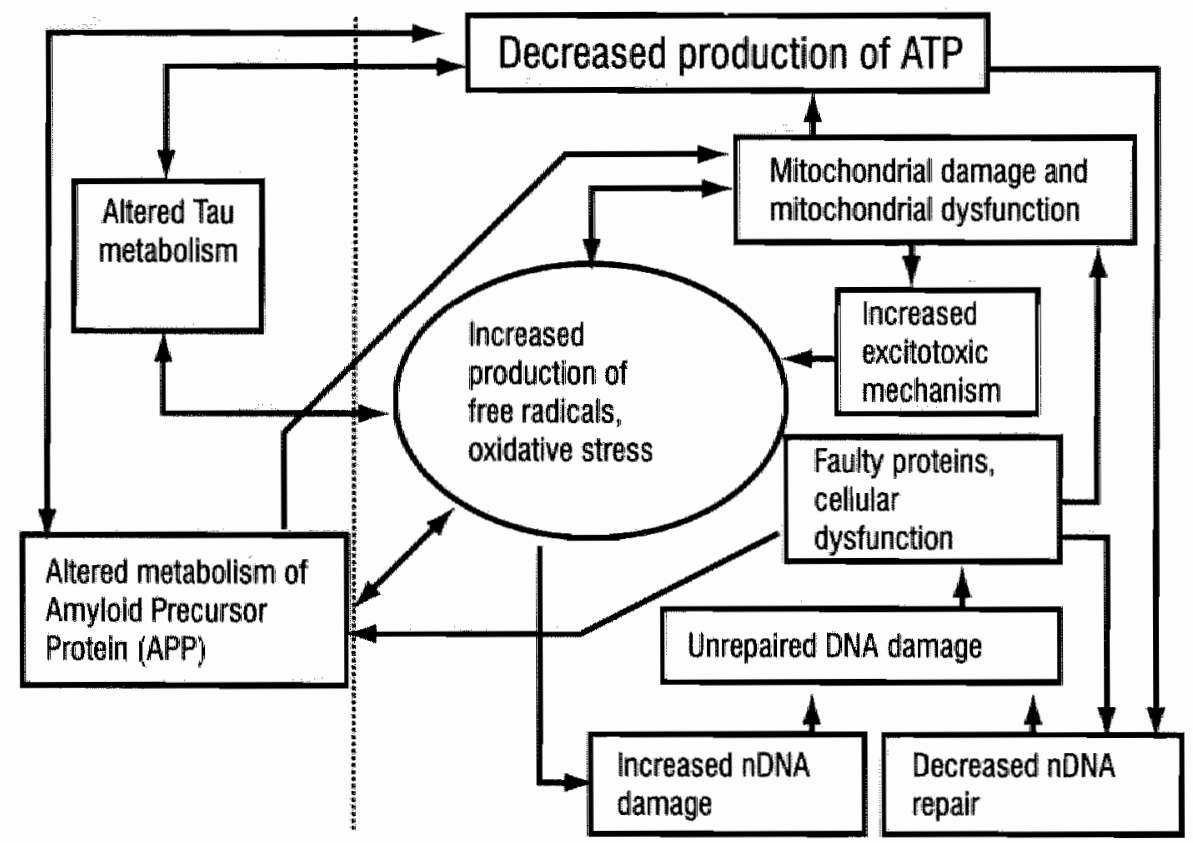

Figure 1. Short overview on some interactions between seweral molecular events involwed in brain aging (right part of the figure, i.e., right from the dotted line) and their interrelations with AD pathogenesis (left part of the figure). References for these interactions can abundantly be found in the literature. 
Table 1.

\begin{tabular}{|c|c|c|c|c|c|c|c|}
\hline Brain region & Type of neurons & 1 & 2 & 3 & 4 & 5 & 6 \\
\hline \multirow[t]{3}{*}{ Neocortex } & & & & + & + & & \\
\hline & All pyramidal cells & + & + & & & - & + \\
\hline & Layer V pyramidal cells & + & + & & & - & + \\
\hline \multirow[t]{3}{*}{ Hippocampus* } & & & & + & + & & \\
\hline & Granule cells & + & + & & & - & + \\
\hline & CA pyramidal cells & + & + & & & - & + \\
\hline
\end{tabular}

\section{Olfactory bulb**}

$$
\text { Mitral cells }
$$

$+\quad-$

\section{Cerebellum}

\section{Purkinje cells}

1: Age-related decline in mtDNA biosynthesis, . $^{3}$

2: Age-related decline in rate of $n$ DNA repair, ${ }^{13}$

3: Age-related accumulation unrepaired nDNA damage

4: Age-related accumulation of mDNA deletions"

5: Age-related loss of cells, ${ }^{4,3}$

6: NFT formation in $A D^{4,13}$

Note that CAI neurons develop NFT along with CA4 neurones but CA 2 neurones and to a certain extent CA3 neurans are relatively resistant to NFT formation. Additionally whilst granule cells in the dentate gyrus develop $N F T_{s}$ these are generally scattered and few in number.

With respect to the mitral cells of the olfactory butb (MC), one has to consider that conflicting data about NFT formation in these cells have been reported in the literature. Indeed in the paper by Kovacs et al. "sin abundancy of NFT formation in MC has been reported in AD. However, this stands in contrast to reports by Bresak et al." and Esiri et al. "s which have reported lack of NFT in MC in AD. Moreover, in the paper of Kovacs et al. ${ }^{\text {ST }}$ NFT formation in MC has also been described in controls not suffering from AD. This seems hardly to be compatible with the Bratk staging. in which NFT formation starts in the transentorhinal cortex, not in the olfactory bulb. Unfortumately, in the study by Kovacs et al. ${ }^{55}$ the formation of NFT in MC has not been investigated in the comtext of overall NFT" in the brain. In summary the auestion about NFT formation in MC in AD meeds further investigation. 
neurons. Conversely, we hypothesize that the lack of age-related cell loss is connected to both age-related decline in the rate of spontaneous $\mathrm{nDNA}$ repair and to age-related accumulation of unrepaired nDNA damage in of other types of neurons.

According to these hypotheses, neuronal dysfunction during aging is mainly connected to an accumulation of damaged macromolecules within certain specific types of neurons not having an appropriate cell death mechanism for highly damaged cells. Most importantly, age-related decline in cognitive function of rodents seems to be connected to the disturbed function of those types of neurons which do not show an age-related loss of cells (Merrill et al., 2001). This opens the possibility that the aging rodent brain does benefit from age-related loss of neurons. Recent studies have pointed to the fact that the pattern of cell loss in the aging human brain is very similar to the corresponding pattern in the aging rodent brain. 4

It is important to realize that even a substantial amount of neuronal loss does not necessarily needs to result in clinically detectable functional decline of certain brain regions or symptoms. For example, up to $60 \%$ of the dopaminergic neurons in the substantia nigra might be lost before overt symptoms appear in Parkinson's disease. ${ }^{38}$ Furthermore, substantial loss of cerebellar Purkinje cells has been reported in $\mathrm{AD},{ }^{39}$ but signs of cerebellar dysfunction are not early symptoms in AD.

Thus, the induction of an appropriate response to severe age-related nDNA damage, i.e., either effective repair of this nDNA damage or loss of the corresponding cells, might be a new strategy to prevent age-related functional decline of the human brain.

\section{AGE-RELATED CELL LOSS, NDNA DAMAGE, AND THE SELECTIVE NEURONAL VULNERABILITY IN AD}

Alzheimer's disease is a prevalent and devastating neurodegenerative disorder with a selective neuronal vulnerability of largely unknown origin. ${ }^{40,41}$ The neuropathological hallmarks of $A D$ comprise $\beta$-amyloid plaques and neurofibrillary tangles (NFT), consisting mainly of hyperphosphorylated tau protein. ${ }^{41}$ Importantly, NFT formation in AD exhibits a certain selectivity, i.e., distinct cell types and brain regions such as the enthorhinal cortex and the hippocampus are much more vulnerable than others. ${ }^{12,41}$ Several attempts have been made in the literature to explain this so-called selective neuronal vulnerability in $\mathrm{AD}_{,}^{42-49}$ but these explanations have remained unsatisfactory. The major risk factor for $\mathrm{AD}$ is aging, and several recent studies have indicated that the formation of the $\mathrm{AD}$ hallmarks is associated with the same deleterious molecular events which occur during aging. ${ }^{44,50,51}$ Figure 1 gives an overview of some of the most important processes involved in aging (right part of the figure) and in AD (right and left part). Interestingly, the same neuronal cell types and neural circuits that are devastated through 
degeneration in $\mathrm{AD}$ are particularly vulnerable to age-related molecular, biochenical and celLular alterations. ${ }^{12}$ For example, one of the very first events in $\mathrm{AD}$ seems to be an abnormally high amount of free radicals in the affected cells, which could be an early event leading towards the formation of NFT. ${ }^{52}$ Furthermore, there is a co-localization of truncated tau and nDNA fragmentation in $\mathrm{AD}$ neurons. ${ }^{53}$ Most interestingly, a meta-analysis of the literature indicated a striking correlation: the formation of NFT primarily occurs in those types of neurons which do not show an age-related cell loss (Table 1). ${ }^{4}$ For example, a significant number of Purkinje cells is lost in sporadic $\mathrm{AD},{ }^{39}$ exceeding the loss of Purkinje cells during aging. It is also known that Purkinje cells do not show formation of NFT in AD. Thus, although events involved in the aging process are also involved in $A D$, the extent of alterations in $A D$ exceeds the corresponding alterations in aging. As already mentioned, tangle-bearing neurons in $A D$ show a high degree of nDNA fragmentation. ${ }^{93-55}$ In the literature, this is discussed as reflecting an extraordinarily high amount of unrepaired nDNA damage within these cells rather than a sign of apoptosis. ${ }^{55}$ Furthermore, it has been speculated that the age-related accumulation of unrepaired nDNA damage could be one of the essential steps in the formation of NFT. ${ }^{53.54}$ Considering this speculation, it might be attractive to hypothesize that certain types of neurons are protected from the formation of NFT in AD by the physiological cell loss during aging. Obviously, the cell loss during aging should not be confused with the complex mechanism and pattern of pathological cell loss occurring in $\mathrm{AD}$, which likely involves a combination of several processes including $\beta$-amyloid plaque toxicity and age-related regional and cell-type-specific loss of neurons.

Nevertheless, the induction of an appropriate response to nDNA damage in all types of neurons by removing damaged neurons during the aging process in the brain, might be an attractive new strategy to prevent the formation of NFT in AD. According to our new hypothesis, future interventions aimed at the prevention of NFT formation in $\mathrm{AD}$ and aimed at preservation of brain function during aging should focus on the induction of an appropiate nDNA damage response by a selective removal of those neurons in the aging brain which show the highest amount of free radicals and nDNA damage. Further research on the mechanisms of the nDNA damage response during aging of the brain will therefore be of great interest. Obviously, the cell loss during aging should not be confused with the complex mechanism and pattern of pathological cell loss occurring in $\mathrm{AD}$, which likely involves a combination of several processes including $\beta$-amyloid plaque toxicity and age-related regional and cell-type-specific loss of neurons. Nevertheless, the induction of an appropriate response to nDNA damage in all types of neurons by removing damaged neurons during the aging process in the brain, might be an attractive new strategy to prevent the formation of NFT in AD. According to our new hypothesis, future interventions aimed at the prevention of NFT formation in $\mathrm{AD}$ and aimed at preservation of brain function during aging should focus on the induction of an appropriate nDNA damage response by a selective removal of those neurons in the aging brain which show the highest amount of free radicals and $\mathrm{nDNA}$ damage. Further research on the mechanisms of the nDNA damage response during aging of the brain will therefore be of great interest. 


\section{REFERENCES}

1. Maccioni $\mathrm{KB}_{\mathrm{s}}$, Munoz JP: Barbeito L: The molecular bases of Alzheimer"s disease and other neurodegenerative disorders. Arch Med Res 2001, 32:367-381.

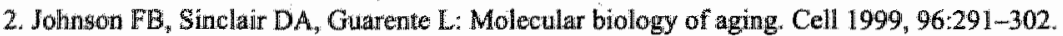

3. woil Zglinicki T, Pilger R, Sitte N: Accumulation of single-strand breaks is the major cause of telomere shortening in human fibroblasts. Free Radic Biol Med 2000, 28:64-74.

4. Schrnitz C, Korr H, Materne S: Cell-type-specific differences in age-related changes of DNA repair in the mouse brain - Molecular basis for a new approach to understand the selective neuronal vulnerability in Alzheimer"s disease. J Alz Dis 1999, 1:387-407

5. Schmitz C, Axmacher B, Zunker U, Korr H: Age-related changes of DNA repair and mitochondrial DNA synthesis in the mouse brain. Acta Neuropathol (Berl) 1999, 97:71-81

6. Petersen RC: Aging, mild cognitive impairment, and Alzheimer's disease. Neurol Clin 2000, 18:789-806.

7. Li SC, Lindenberger U, Sikstrom S: Aging cognition: from neuromodulation to representation. Trends Cogn Scil 2001, 5:479-486.

8. Schochet $\mathrm{SS}$, Jr.: Neuropathology of aging. Neurol Clin 1998, 16:569-580

9. Mandavilli BS, Rao KS: Neurons in the cerebrall cortex are most susceptible to DNA-damage in aging rat brain. Biochem Mol Biol lnt 1996, 40:507-514

10. Melov S, Hinerfeld D, Esposito L, Wallace DC: Multi-organ characterization of mitochondrial genomic rearrangements in ad libitum and caloric restricted mice show striking somatic mitochondrial DNA rearrangements with age. Wucleic Acids Res 1997, 25:974-982.

11. Lee CK, Weindruch R, Prolla TA: Gene-expression profile of the ageing brain in mice. Nat Genet 2000, 25:294-297.

12. Morrison JH, Hof PlR: Selective vulnerability of corticocortical and hippocampal circuits in aging and Alzheimer's disease. Prog Brain Res 2002, 136:467-486

13. Schmitz C, Axmacher B, Zunker U, Korr H: Age-related changes of DNA repair and mitochondrial DNA synthesis in the mouse brain. Acta Neuropathol (Berl) 1999, 97:71-81.

14. de Boer J, Andressoo JO, de Wit J, Huijmans J, Beems RB, van Steeg $H_{x}$, Weeda $G_{w}$ van der Horst GT, van Leeuwen W, Themmen AP, Meradji M, Hoeijmakers JH: Premature aging in mice deficient in DNA repair and transcription. Science 2002, 296:1276-1279

15. Cortal-Debrinski M, Horton T, Lott MT, Shoffner JM, McKee AC, Beal MF, Graham BH, Wallace DC: Marked changes in mitochondrial DNA deletion levels in Alzheimer brains. Genomics 1994, 23:471-476

16. Melov S, Schneider JA, Coskun PE, Bemnett DA, Wallace DC: Mitochondrial DNA rearrangements in aging human brain and in situ PCR of mtDNA. Neurobiol Aging 1999, 20:565-571.

17. Corral-Debrinski M, Horton T, Lott MT, Shoffner JM, Beal MF, Wallace DC: Mitochondrial DNA deletions in human brain: regional variability and increase with advanced age. Nat Genet 1992, 2:324-329

18. Lowndes NF, Murguia JR: Sensing and responding to DNA damage. Curr Opin Genet Dev 2000, 10:17-25.

19. Rich T, Allen RL, Wyllie AH: Defying death after DNA damage. Nature 2000, 407:777-783

20. Meyn MS: Ataxia-telangiectasia, cancer and the pathobiology of the ATM gene. Clin Genet 1999, 55:289 304

21. Hoekstra MF: Responses to DNA damage and regulation of cell cycle checkpoints by the ATM protein kinase family. Curr Opin Genet Dev 1997, 7:170-175

22. Smith GC, Jackson SP: The DNA-dependent protein kinase. Genes Dev 1999, 13:916-934

23. Morrison RS, Kinoshita Y: The role of p53 in neuronal cell death. Cell Death Differ 2000, 7:868-879

24. Yuan J, Yankner BA: Apoptosis in the nerwous system. Nature 2000, 407:802-809

25. Savill $J_{0}$ Fadok V: Corpse clearance defines the meaning of eell death. Nature 2000, 407:784-788

26. Hoeijmakers JH: Genome maintenance mechanisms for preventing cancer. Nature 2001, 411:366-374

27. Suh $\mathrm{Y}$, Lee KA, Kim WH, Han BG, Vijg J, Park SC: Aging alters the apoptotic response to genotoxic stress. Nat Med 2002, 8:3-4

28. MacCallum DE, Hupp TR, Midgley CA, Stuart D, Campbell SJ, Harper A, Walsh FS, Wright EG, Balmain A, Lane DP, Hall PA: The p53 response to ionising radiation in adult and developing murine tissues. Oncogene $1996,13: 2575-2587$

29. Wickelgren l: For the cortex neuron loss may be less than thought. Science 1996, 273,48-50

30. Wickelgren I: Is hippocampal cell death a myth? Science 1996, 271:1229-1230.

31. Victor M, Ropper AH: Principles of Neurology. New York, McGraw-Hill, 2001

32. Peters A, Mortison JH, Rosene DL, Hyman BT: Feature article: are nenrons lost from the primate cerebral cortex during normal aging? Cereb Cortex 1998, 8:295-300 
33. Rapp PR, Gallagher M: Preserved neuron number in the hippocampus of agod rats with spatial learning deficits. Proc Natl Acad Sci U S A 1996, 93:9926-9930

34. Long M, Mouton PR. Jucker M, Ingram DK: What counts in brain aging? Designmbased stereologteal analysis of cell number. J Gerontol A. Biol Sci Med Sci 1999,54:B407-417

35. Merrill DA, Chiba AA, Tuszynski MH: Conservation of neuronal number and size in the entorhinal cortex of behaviorally characterized aged rats. J Comp Neurol $2001,438.445-456$.

36. Tonvik $\mathrm{A}$, Torp $\mathrm{S}$, Lindboe CF: Atrophy of the cerebellar vermis in ageng. A morphometric and histologite study. INewrol Sci 1986,76:283-294.

37. Hinds JW, McNelly NA: Aging of the rat olfactory bulb: growth and atrophy of constituent layers and ohinges in size and number of mitral cells. J Comp Neurol 1977, 72:345-367

38. Pakkenberg $B_{*}$ Moller $A_{*}$ Gundersen HJ, Mouritzen Dam A. Pakkenberg $\mathbb{H}$ : The absolute number of nerve cells in substantia nigra in normal subjects and in patients with Parkinson's disease estimated with an unbiased stereological method. J Neurol Neurosurg Psychiatry 1991, 54:30-33

39. Wegiel J, Wisniewski HM, Dziewiatkowski J, Badmajew E, Tarnawski M, Reisberg B, Mlodzik B, De Leon MJ, Miller DC: Cerebellar atrophy in Alzheimer's disease-clinicopathological correlations. Brain Res 1999 , $818: 41-50$.

40. Morrison BM, Hof PR, Morrison JH: Determinants of neuronal vilnenability in neurodegenerative diseases. Ann Nevrol 1998, 44:S32-44.

41. Cummings JL, Cole $\mathrm{G}$ : Alzheimer disease. Jama 2002, 287:2335-2338.

42. Rapoport S1: Integrated phylogeny of the primate brain, with special reference to humans and their diseases. Brain Res Brain Res Rev 1990, 15:267-294

43. Amstrong DM, Ikonomovic MD, Sheffield R, Wenthold RJ: AMPA-selective glutanate receptor subtype immunoreactivity in the entorhinal contex of non-demented elderly and patients with Alzheimer"s disease. Brain Res 1994, 639:207-216

44. Harman D: Alzheimer's disease: a hypothesis on pathogenesis. Journal American Aging Association 2000 , $23 \cdot 147-161$

45. Fukuyama R, Hatampaa K, Rapoport SI, Chandrasekaran K: Gene expression of ND4, a subunit of complex I of oxidative phosphorylation in mitochondria, is decreased in temporal cortex of brains of Alzheimer"s disease patients. Brain Res 1996, 713:290-293

46. Sandbrink R, Masters CL, Beyreuther K: A.PP gene fannily. Alternative splicing generates functionally rellated isoforms. Ann N Y Acad Sci 1996,777:281-287

47. Allen DD, Galdzicki Z, Brining SK, Fukuyama R, Rapoport SI, Smith QR: Beta-amyloid induced increase in choline flux across PC12 cell membranes. Neurosci Lett 1997, 234:71-73

48. Gïbson GE, Calingasan NY, Baker H, Gandy S, Sheu KF: Importance of vascular changes in selective neurodegeneration with thiamine deficiency. Ann N Y Acad Sci 1997, 826:516r-519

49. Stein DJ, Buchsbaum MS, Hof $\mathrm{PR}_{n}$ Siegel BV, Jr, Shihabuddin L: Greater metabolic rate decreases in hippocampal formation and proisocortex than in neocortex in Alzheimer's disease. Neuropsychobiology 1998, $37: 10-19$

50. Chen M, Fernandez HL: Revisiting Alzheimer's Disease from a New Perspective: Can "Risk Factors" Play a Key Role? J Alzheimers Dis 2000, 2:97-108

51. Joseph J, Shukitt-Hale B, Denisova NA, Martin A, Perry G, Smith MA: Copernicus revisited: gimylotd beta in Alzheimer's disease. Neurobiol Aging 2001, 22:131-146.

52. Nunomura A, Perry G, Aliew G, Hirai K, Takeda A, Balraj EK, Jones PK, Ghanbari H, Wataya T, Shimohama S. Chiba S, Atwood CS, Petersen RB, Smith MA Oxidative damage is the earliest event in Alzheinmer disedase. J Neuropathol Exp Neurol 2001, 60:759-767.

53. Ugolini $\mathrm{G}$, Cattaneo A, Movak M: Com-locallization of truncated tau and DNA fragmentation in Alzheimer"s disease neurones. Neuroreport 1997, 8:3709-3712

54. Sheng JG, Mrak RE, Griffin WS: Progressive neuronal DNA damage associated with neurofibrillary langle formation in Alzheimer disease. J Neuropathol Exp Neurol 1998, 57:323-328.

55. Jellinger KA, Stadelmam $C$ : Problems of cell death in neurodegeneration and Alxheimer"s Digeasie. I Alzheimers Dis 2001, 3:31-40

56. Kovacs T, Caims NJ, Lantos PL: beta-amyloid deposition and neurofibrillary tangle formation in the olfactory bulb in ageing and Alzheimer's disease. Newropathol Appl Neurobiol 1999, 25:481-491.

57. Ohm TG, Braak H: Olfactory bulb changes in Alzheimer's disease. Acta Neuropathol (Berl) 1987, 73:365369

58. Esiri MM, Wilcock GK: The olfactory bulbs in Alzheimer's disease. I Neurol Neurosurg Psychiatry 1984 47:56-601. Cummings JL: Alzheimer"s disease. N Engl J Med 2004, 351:56m67 


\section{Chapter 4}

\section{The aging brain: accumulation of DNA damage or neuron loss?}

Submitted

Bart PF Rutten, Christoph Schmitz,

Oliver HH Gerlach, Hans M Oyen, Emmily Bueno de Mesquita,

Harry WM Steinbusch, Hubert Korr 


\section{ABSTRACT}

Age-related molecular and cellular alterations in the central nervous system are known to show selectivity for certain cell types and brain regions. Among them accumulation of unrepaired nuclear (n) DNA damage can lead to irreversible loss of genetic information content. In the present study on the aging mouse brain, we observed a substantial accumulation of unrepaired $\mathrm{nDNA}$ damage in hippocampal pyramidal and granule cells as well as in cerebellar granule cells but not in cerebellar Purkinje cells. The reverse pattern was found for age-related reductions in total number of neurons. Only the total number of cerebellar Purkinje cells was significantly reduced during aging whereas the total numbers of hippocampal pyramidal and granule cells as well as of cerebellar granule cells were not. This formerly unknown inverse relation between age-rellated accumulation of nDNA damage and age-related loss of neurons may reflect a fundamental process of aging in the central nervous system.

\section{INTRODUCTION}

Compelling evidence in the literature points to a central role of accumulated nuclear (n) DNA damage in the aging process of postmitotic cells such as neurons in the central nervous system (CNS). ${ }^{1}{ }^{2}$ However, the aging process does not affect the CNS uniform.ly. ${ }^{3}$ Rather various brain regions and types of neurons differ substantially in the amount of accumulated nDNA damage during aging ${ }^{4}$ For instance, it has been shown that nDNA damage accumulates to a higher amount in the hippocampus during aging than in the cerebellum. ${ }^{5}$ Furthermore, we have recently shown for the mouse brain that hippocampal pyramidal and granule cells were affected by an age-related decline in the amount of spontaneous nDNA repair whereas cerebellar Purkinje cells were not. ${ }^{9}$ Noticeably, other studies on mice have indicated an age-related reduction in the number of cerebellar Purkinje cells ${ }^{7,8}$ whereas no alterations in the numbers of hippocampal pyramidal and granule cells as well as in the number of cerebellar granule cells were found during aging. ${ }^{6,9}$ Furthermore, at least hippocampal pyramidal cells as well as cerebellar granule and Purkinje cells are not replenished with age by neuronal progenitor cells. ${ }^{10-12}$ Based on these findings we have hypothesized that neurons in the mammalian CNS show either age-related accumulation of nDNA damage, connected with age-related decline in the ability to properly repair $\mathrm{nDNA}$ damage, or an age-related reduction in number. The aim of the present study was to test this hypothesis for the aging mouse brain. For this aim, both the relative amount of nDNA single strand breaks and the total numbers of cells were measured for hippocampal pyramidal and granule cells as well as for cerebellar granule and Purkinje cells in adult and aged animals taken from the same cohort of mice aged under controlled conditions. 


\section{MATERIAL AND METHODS}

\section{Animals}

A cohort of $n=80$ male Han/NMRI mice was bred and housed under specified pathogen free conditions at the Institut für Versuchstierkunde, RWTH Aachen University, Aachen, Germany (four animals per cage, air-conditioned rooms, $20^{\circ} \mathrm{C}, 60 \%$ humidity, $12: 12 \mathrm{hr}$ light:dark cycle with artificial lights on at 6:00 a.m., ad libitum access to water and Altromin standard diet [Altromin, Lage, Germany]). All experiments and investigations were performed in accordance with German animal protection law. Of these mice, $n=56$ were allowed to die spontaneously

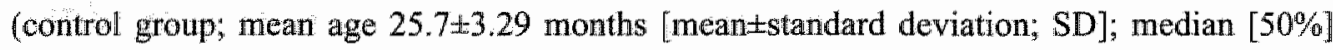
survival 26.1 months; maximum survival 30.3 months; data provided as requested for experimental aging research in ${ }^{12}$ ) (Fig. 1). The remaining mice were sacrificed at $11.3 \pm 0.8$ months of age ( $n=12$; "adult mice"; $100 \%$ survival of the control group) as well as at $27.8 \pm 0.3$ months of age ( $\mathrm{n}=12$; "aged mice"; $28 \%$ survival of the control group). Six adult and six aged mice were analyzed in a cell type specific manner in situ for the relative amount of nDNA single strand breaks with In Situ Nick Translation in combination with quantitative autoradiography. ${ }^{14}$ The remaining six adult and six aged mice were investigated with high-precision design-based stereology ${ }^{15-17}$ for total numbers of hippocampal pyramidal and granule cells as well as for cerebellar granule and Purkinje cells using the optical fractionator. ${ }^{15-17}$

\section{Analysis of the relative amount of nDNA single strand breaks}

$\mathrm{N}=6$ adult mice (mean age $=10.7 \pm 0.5$ months; mean $\pm \mathrm{SD}$ ) and $\mathrm{n}=6$ aged mice (mean age $=27.8 \pm 0.3$ months) were sacrificed by cervical dislocation. The brains were immediately dissected out and hemisected exactly in the midsagittal line. Right and left brain halves were embedded in Tissue-tek (Sakura Finetek Europe, Zoeterwoude, The Netherlands) and quickly frozen using a solution of aceton/dry ice at $-68^{\circ} \mathrm{C}$. The right brain halves were cut into $10 \mu \mathrm{m}$ thick frontal sections including the hippocampus or the cerebellum on a cryostat (type HM 500 OM; Microm, Walldorf, Germany). The sections were mounted on glass slides (SuperFrost Plus, Menzel, Braunschweig, Germany) and stored at $-70^{\circ} \mathrm{C}$ until further processing. The left brain halves were not used in the present study and were stored for future experiments.

The relative amount of nDNA single strand breaks was investigated by means of In Situ Nick Translation (ISNT), carried out using a slight modification of the protocol given by Maehara et al. [8]17 as described in Korr et al..$^{14}$ Briefly, sections were incubated for $60 \mathrm{~min}$ at $37^{\circ} \mathrm{C}$ with a reaction solution containing $50 \mathrm{mM}$ Tris-HCl-buffer $(\mathrm{pH} 7.5), 5 \mathrm{mM} \mathrm{MgCl}, 10 \mathrm{mM}$ 2-mercaptoethanol, $200 \mathrm{U} / \mathrm{ml}$ of E.coli DNA polymerase I (endonuclease-free, Boehringer, Mannheim, Germany), $10 \mu \mathrm{mol} / \mathrm{ml}$ each of dATP, dGTP, dCTP and dTTP (Boehringer) and $15 \mu 1\left[{ }^{3} \mathrm{H}\right] \mathrm{dTTP} / \mathrm{ml}(1.03 \mathrm{MBq} / \mathrm{ml}$; American Radiolabeled Chemicals Inc., St. Louis, MO). Incubation was carried out using special in-situ chambers consisting of small frames made of silicon (height $=1 \mathrm{~mm}$; comparable to customary adapters for in situ $\mathrm{PCR}$ ) and coverslips placed onto the slides. The reaction was terminated by washing the slides with $50 \mathrm{mM}$ Tri- $\mathrm{HCl}$ buffer ( $\mathrm{pH} 7.5$ ). Afterwards the sections were Feulgen stained, dipped into diluted Ilford K2 emulsion ( $3: 2$ with distilled water) at $42^{\circ} \mathrm{C}$, exposed for 5 days at $4^{\circ} \mathrm{C}$ and developed in 
Amidol ( $4 \mathrm{~min}, 18^{\circ} \mathrm{C}$ ). After poststaining with hematoxylin the awtoradiographs were covered with a coverslip using Entellan (Merck, Darmstadt, Germany).

Evaluation of the autoradiographs was carried out with a light microscope (Olympus BH-2 equipped with a $100 x$ oil Olympus UplanFl objective, $N A=1.30$ ). For each animal two randomly selected, non-adjacent coded autoradiographs showing the hippocampus as well as two autoradiographs showing the cerebellum were selected. On each section 50 randomly selected cell profiles of each of the following types of neurons were investigated regarding the number of autoradiographic silver grains over the nucleus: hippocampal pyramidal cells (area CA 1-3), hippocampal granule cells (dentate gyrus), cerebellar granule cells, and cerebellar Purkinje cells. Counting of silver grains of all types of neurons was performed by the same person blinded for the age of the mice. Background was corrected by investigating autoradiographs which were prepared in an identical manner as described above except for the application of DNA polymerase I. ${ }^{14}$ Furthermore, data were corrected for nuclear size, allowing direct comparisons between different cell types. ${ }^{14}$

\section{Analysis of total numbers of neurons}

$\mathrm{N}=6$ adult $(12-$ month-old) mice and $\mathrm{n}=6$ aged mice (mean age $=27.8 \pm 0.3$ months; mean $\pm \mathrm{SD}$ ) were anesthetized with chloral hydrate $(10 \%$ aqueous solution, $0.005 \mathrm{ml} / \mathrm{g}$ body weight, intraperitoneally) and were sacrificed by intracardial perfusion fixation with formalin solutions as previously described. ${ }^{13}$ After opening the skulls, the heads of the animals were postfixed in formalin solution for $24 \mathrm{~h}$ at $4^{\circ} \mathrm{C}$. Afterwards the brains were removed, hemisected exactly in the midsagittal line, and further fixed in formalin solution for 10 days at $4^{\circ} \mathrm{C}$. Both brain halves were cryoprotected in sucrose solution $(10 \%, 20 \%$ and finally $30 \%$ sucrose in $0.1 \mathrm{M} \mathrm{Tri}-\mathrm{HCl}$ buffer, $2 \times 12 \mathrm{~h}$ per solution; $4^{\circ} \mathrm{C}$ ), embedded in Tissue - tek (Sakura Finetek) and qü̈ckly frozen. Both brain halves were stored at $-70^{\circ} \mathrm{C}$. The left brain halves were not used in the present study and were stored for future experiments.

The right brain halves were entirely cut into serial, $30 \mu \mathrm{m}$ thick frontal sections on a cryostat (type HM 500 OMV, Microm). Every tenth section was collected, mounted on a glass slide (Superfrost Plus; Menzel), dried, defatted with Triton X-100 (0.025\%, 20 min; Merck), and stained with cresyl violet $(0.01 \%, 10 \mathrm{~min})$. Slides were dehydrated and coverslipped using DePeX (Serva, Heidelberg, Germany). On all sections showing the hippocampus, the granule and pyramidal cell layers were delineated as recently described. ${ }^{18}$ On all sections showing the cerebellum, the granule cell layer (including the Purkinje cell layer) was delineated. Delineations were carried out using a stereology workstation, consisting of a modified light microscope (Olympus BX50; Olympus, Tokyo, Japan), Olympus UplanApo objectives (10x, $\mathrm{NA}=0.40 ; 40 \times$, oil, $\mathrm{NA}=0.75 ; 100 \times$, oil, $\mathrm{NA}=1.35$ ), motorized specimen stage for automatic sampling (Ludl, Hawthorne, NY, USA), electronic microcator (Ludl), CCD color video camera. (Hitachi, Tokjo, Japan), PC (CoWoTec, Magdeburg, Germany) with framegrabber board, and. stereology software (Stereolnvestigator, MicroBrightField, Williston, VT, USA). Delineations were performed at a final magnification of $\times 360$ (i.e., using the $10 \times$ objective). Total numbers of neurons were investigated with the optical fractionator ${ }^{15-17,20}$ Quantifications of total numbers 
of every type of neuron were performed by the same person blinded for the age of the mice. All hippocampal pyramidal and granule cells as well as all cerebellar granule and Purkinje cells whose nucleus top came into focus within unbiased virtual counting spaces distributed in a systematic-random fashion throughout the brain regions of interest were counted. Estimated total numbers of neurons were calculated from the numbers of counted neurons and the corresponding sampling probabilities. Details on the counting procedures are summarized in Táble 1.

\section{Statistical analysis}

For each animal and type of neuron, the frequency distribution of the 100 obtained (uncorrected) numbers of autoradiographic silver grains was calculated, with bin width of one and the center of the first bin at zero. These frequency distributions were used to calculate age-specific, averaged frequency distributions of uncorrected numbers of autoradiographic silver grains for each type of neuron. For instance, the $\mathrm{n}=6$ adult mice showed the following frequencies of hippocampal pyramidal cells with a total of six autoradiographic silver grains over the nucleus: $14,6,16,8,10,18$.

Accordingly, the average frequency of hippocampal pyramidal cells in the brains from the adult mice with a total of six autoradiographic silver grains over the nucleus was 12 . These averaged frequency distributions of the adult mice were compared with the corresponding averaged frequency distributions of the aged mice using the Kolmogorov-Smirnov two sample test. Comparing averaged frequency distributions considered the fact that the $95 \%$ critical value (alpha $=0.05$ ) for the Kolmogorov-Smirnov two sample test depends on the number of data points (which was 200 when comparing 2 groups with 100 data points each). Statistical significance was established at $p<0.0125$, since four different types of neurons were investigated simultaneously. These calculations were performed using SPSS (Version 11.5 .0 for Windows; SPSS, Chicago, IL). Furthermore, for each group of mice and investigated type of neuron, mean and standard error of the mean were calculated for the mean autoradiographic silver grain number per nucleus (corrected for background and nuclear size) and the estimated total number

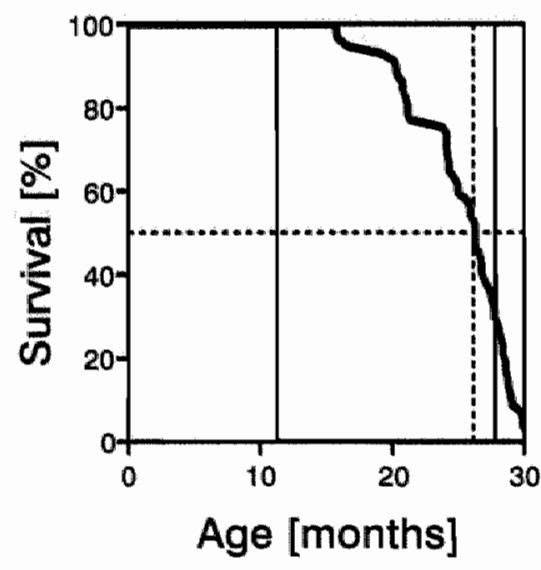

Figure 1. Survival curve of the mice who died spontaneously (contral group: $n=56$ ). The dashed vertical line indicates $50 \%$ survival of the cohort (26.1 months). The solid vertical lines indicate the time points at which adult mice (mean age 11.3 months) and aged mice (mean age 27.8 manths) were sacrificed for analysis. 

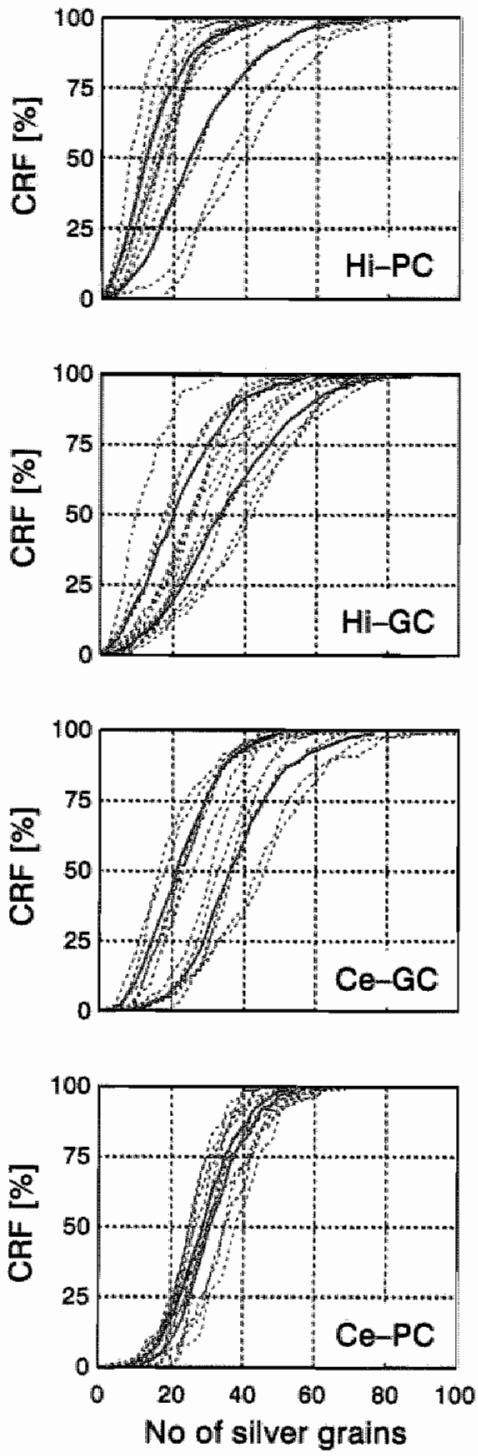

Figure 2. Comulated relative frequency (CRF) distributions of uncorrected numbers of autoradiographic silver grains frow adult mice (green limes) and aged wuce (ned lines). Dotted lines, inctividual frequency distributions: sollod lines; averaged" freguency distributions. $H-P C$, hippocampal pyramidal cells; Hi-GC, hippocampal gramule cells: $C \mathrm{GC}$ - cerebellar gramule cells; Ce PC cerebellar Purkinje cells 
The aging brailin: accumulation of dna damage or neuron loss

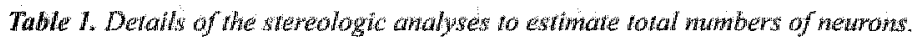

\begin{tabular}{|c|c|c|c|c|c|c|c|c|}
\hline Type of newron & ob] & $B\left(\mu m^{2}\right)$ & $H\left(\mu m^{2}\right)$ & $D(\mu m)$ & $t(\mu \mathrm{m})$ & EOD & $\mathbf{E Q}$ & CEpred $\{n \rrbracket$ \\
\hline $\mathrm{Hi}-\mathrm{PC}$ & $100 \mathrm{x}$ & 900 & 4 & 141 & 8.7 & 313 & 913 & 0.034 \\
\hline $\mathrm{Hi}-\mathrm{GC}$ & $100 x$ & 625 & 4 & 100 & 8.5 & 203 & 919 & 0.034 \\
\hline $\mathrm{Ce}-\mathrm{GC}$ & $100 x$ & 64 & 5 & 250 & 10.2 & 446 & 1.555 & 0.026 \\
\hline $\mathrm{Ce}-\mathrm{PC}$ & $40 x$ & 3,600 & 5 & 220 & 10.9 & 261 & 507 & 0.045 \\
\hline
\end{tabular}

Hi-PC, hippocampal pyramidal cells (CAI-3); Hi-GC, hippocampal granule cells; $C e-G C$; cerebellar granule cells; $C e-P C$, cerebellar Purkinje cells. Obj., objective used; $B$ and $H$, base and height of the unbiased virtual counting spaces; $D$, distance between the unbiased virtual coumting spaces in mutually orthogonal directions $x$ and $y ; t$, measured actual average section thickness after histological processing; $\Sigma O D$, average sum of unbiased virtual counting spaces used; $\Sigma Q$, average number of counted neurons; $C E_{\text {pred }}[n]$, average predicted coefficient of error of the estimated total numbers of neurons using the prediction method. ${ }^{15,16}$

of neurons. Comparisons between adult and aged animals were performed with two-tailed unpaired Student's $t$ test.

Statistical significance was established at $p<0.0125$, since four different types of neurons were investigated simultaneously. These calculations were performed using GraphPad Prism (Version 4.00 for Windows, GraphPad Software, San Diego, CA).

\section{RESUITS}

\section{Relative amount of nDNA single strand breaks}

For hippocampal pyramidal and granule cells as well as for cerebellar granule cells - but not for cerebellar Purkinje cells - statistically significantly different averaged frequency distributions of uncorrected numbers of autoradiographic silver grains were found when comparing adult with aged mice $(p<0.001$ for hippocampal pyramidal and granule cells as well as for cerebellar granule cells, $p=0.587$ for cerebellar Purkinje cells) (Figure 2). The cumulated relative frequency distributions of uncorrected numbers of autoradiographic silver grains of hippocampal pyramidal and granule cells as well as of cerebellar granule cells from the aged mice were shifted to the right compared with the corresponding frequency distributions from the adult animals (Figure 2). This indicated that the aged mice showed on average higher numbers of uncorrected autoradiographic silver grains per nucleus for hippocampal pyramidal and granule cells as well as for cerebellar granule cells, but not for cerebellar Purkinje cells. Analysis of autoradiographic silver grains corrected for background and nuclear size resulted in the same finding. The mean corrected number of autoradiographic silver grains of hippocampal pyramidal and granule cells 


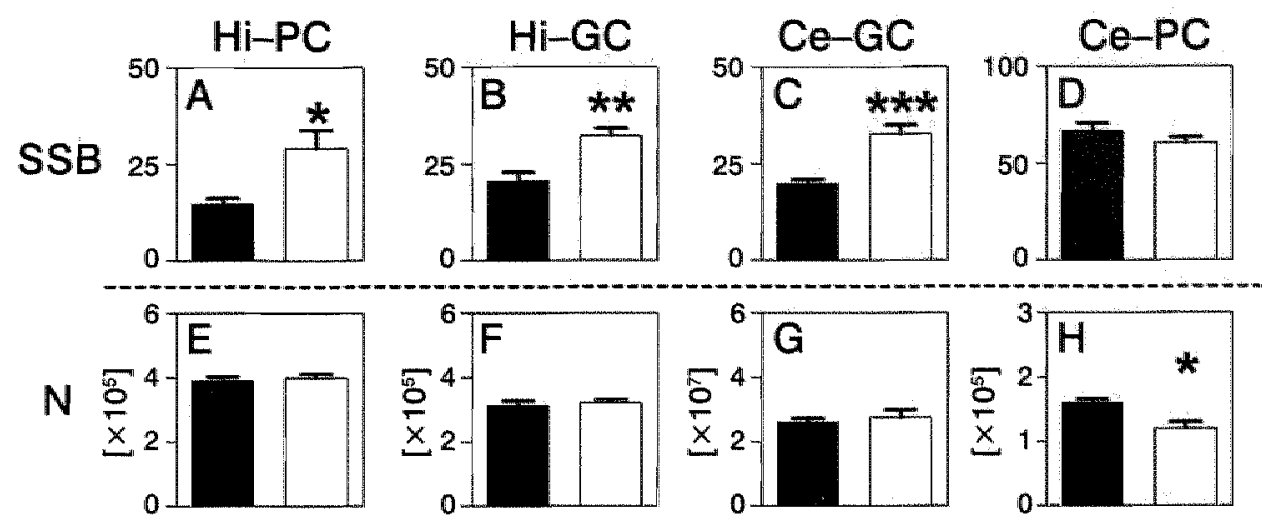

Figure 3 (A-D) Auloradiographic silver grain counts correcred for background and wiclear size [5], representing the relative amoum of unrepaired nDNA single strand breaks. (E-H) Total numbers of newrons $(N)$ in the brain of adult and aged mice. $(A, E)$, hippocampal pyramidal cells $[H i-P C],(B, F)$ hippocampal gramile cells $[H i-G C],(C, G)$. cerebellar granule cells $\sqrt{ } \mathrm{C}-\mathrm{GC}$ ]. (D, H) cerebellar Purkinje cells [Ce-PC]. Closed bars, adult animals; open bars, aged animals. Data are shown as mean $\pm S . E . M .{ }^{*}, p<0.0125 ; * *, p<0.005 ; * * *, p<0.001$ (resulss from mo-tailed umpaired Student's ( rest).

as well as of cerebellar granule cells was significantly higher in the aged mice than in the adult ones $(+97,6 \%$ for hippocampal pyramidal cells in area $\mathrm{CAl}-3, \mathrm{t}=3.141, \mathrm{p}=0.012 ;+57.4 \%$ for hippocampal granule cells, $t=3.804, p=0.004$; and $+65.3 \%$ for cerebellar granule cells, $t=4.938, p<0.001 ;$ Figure $3 \mathrm{~A}-\mathrm{C}$ ).

Importantly, cerebellam Purkinje cells showed the highest mean corrected number of autoradiographic silver grains of all investigated types of neurons but did not show differences in mean numbers between aged and adult mice $(\mathrm{t}=1.292, \mathrm{p}=0.225$; Figure $3 \mathrm{D})$. In summary, the autoradiographic analysis with In Situ Nick Translation demonstrated that cerebellar Purkinje cells had the highest relative amount of nDNA single strand breaks of all investigated types of neurons. However, age-related accumulation of nDNA single strand breaks was observed for hippocampal pyramidal and granule cells as well as for cerebellar granule cells, but not for cerebellar Purkinje cells.

\section{Total numbers of neurons}

The mean total numbers of hippocampal pyramidal and granulle cells as well as of cerebellar granule cells did not differ between adult and aged mice (hippocampal pyramidal cells: $t=0.635$, $p=0.539$, Figure 3E; hippocampal granule cells: $t=0.568, p=0.583$, Figure $3 F$; cerebellar granule cells: $t=0.603, p=0.560$, Figure $3 \mathrm{G}$ ). In contrast, the mean total number of cerebellar Purkinje cells was significantly reduced in the aged mice compared with the adult ones $(-25.2 \%$, $1=3.313, p=0.009$, Figure $3 \mathrm{H}$ ). 


\section{DISCUSSION}

The results of the present study are the first description of cell-type-specific alterations in the relative amount of nDNA single strand breaks in situ in the mouse brain during aging. Furthermore, we have estimated the total numbers of four different types of neurons with high-precision design-based stereology (optical fractionator) and found that only cerebellar Purkinje cells were reduced in number during aging. These results are in line with various reports on cell type specific neuron loss in the rodent brain during aging (for details see ${ }^{4}$ ) and they extend earlier reports on region-specific accumulation of nDNA damage in the rodent brain $^{4}$ in a cell type specific manner. It should be mentioned that, based on the selection of aged mice at $28 \%$ survival of the control group, the results of the present study were neither biased by the "survival-of-the-fittest" effect (which can be observed at approximatly $40 \%$ survival of a cohort; see, e.g., ${ }^{6}$ ) nor by the "oldest-of-the-old" effect (which can be observed at approximatly $10 \%$ survival of a cohort see, e.g., ${ }^{21}$ ).

Interestingly, our group recently showed an age-related decline in the rate of spontaneous nDNA repair in hippocampal pyramidal and granule cells but not in cerebellar Purkinje cells (data of cerebellar granule cells were not unequivocaly by using quantitative autoradiography after injection of tritiated thymidine on the same animal model (i.e., same mouse strain, identical housing conditions at the same animal facility, almost identical survival curve). ${ }^{6}$ Altogether these data point to the existence of the following, so far unknown correlation between $\mathrm{nDNA}$ damage, $\mathrm{nDNA}$ repair and neuron loss in the aging mammalian brain: certain types of neurons (such as hippocampal pyramidal and granule cells as well as cerebellar granule cells) suffer from age-related decline in the ability to properly repair nDNA damage, resulting in accumulation of $n D N A$ damage. However, these types of neurons are not reduced in number during aging. Other types of neurons (such as cerebellar Purkinje cells) are reduced in number during aging, and the remaining cells show no difference in the ability to properly repair nDNA damage compared with cells in young animals and, thus, no accumulation of nDNA damage.

Importantly, age-related accumulation of nDNA damage plays an important role in impaired protein synthesis, increased production of free radicals and the formation of protein aggregations during aging, ultimately leading to severe cellular dysfunction. ${ }^{2,22}$ Therefore, age-related accumulation of $\mathrm{nDNA}$ damage in selective types of neurons instead of proper repair of this damage or otherwise loss of the corresponding cells may play an important role in the neurobiology of the aging brain as well as in the well-known selective neurovulnerability in various neurodegenerative diseases. ${ }^{3,22}$ The correlation between nDNA damage, nDNA repair and neuron loss in the aging mammalian brain demonstrated in the present study leads to the hypothesis that selective types of neurons, such as cerebellar Purkinje cells, utilize certain mechanisms to eliminate cells with high amount of nDNA damage during aging whereas others do not. One might speculate that this occurs in connection with the fact that certain types of neurons (such as cerebellar Purkinje celis) show higher amounts of nDNA damage than other types of neurons (as demonstrated in Figure 3 by autoradiographic silver grains corrected for background and nuclear size); however, this speculation needs to be tested in future studies. Anyway it is important to note that in other organs than the brain, the apoptotic response to nDNA damage was recently 
found to be downregulated during aging. ${ }^{23}$ Accordingly it is tempting to speculate that distinct types of neurons are subjected to this downregulation of apoptotic response whereas other types of neurons are not. It will thus be important to identify cell-type-specific differences in the molecular machinery responsible for $\mathrm{nDNA}$ damage responses and to identify target molecules for modulating these responses. In summary, attenuation of age-related accumulation of $\mathrm{nDNA}$ damage in neurons may be reached through several strategies: diminishing age-related increase in the amount of nDNA damage by prevention of increased free radical production etc, enhancing the capacity to repair nDNA damage, or - when damage is beyond a certain threshold - by specifically eliminating neurons with high amount of unrepaired nDNA damage.

\section{REFERENCES}

1. Kirkwood TB, Austas SN. Why do we age? Nature 2000;408:223-38.

2. LuI T, Pan Y, Kao SY, Li C, Kohane I, Chan J, Yankner BA. Gene regulation and DNA damage in the ageing human brain. Nature 2004:429:883-91

3. Morrison JH, Hof PR. Selective vulnerability of corticocortical and hippocampal circuits in aging and Alzheimer's disease. Prog Brain Res 2002;136:467-86

4 Mandavilli BS, Rao KS. Neurons in the cerebral cortex are most susceptible to DNA-damage in aging rat brain. Biochem Mol Biol Int 1996;40:507-514

5. Rutten BP, Korr H, Steinbusch HW, Schmitz C. The aging brain: less neurons could be better. Mech Ageing Dev 2003;124:349-355

6. Schmitz C, Axmacher B, Zunker U, Korr H. Age-related changes of DNA repair and mitochondrial DNA synthesis in the mouse brain. Acta Neuropatholl 1999;97:71-81

7. Sturrock RR. Changes in neuron number in the cerebellar cortex of the ageing mouse. $J$ Hirnforsch 1989;30:499-503

8. Zanjani H, Lemaigre-Dubreuil Y, Tillakaratme NJ, Blokhin A, McMahon RP, Tobin AJ, Vogel MW, Mariani J. Cerebellar Purkinje cell loss in aging Hu-Bcl-2 transgenic mice. J Comp Neurol 2004;475:481-92

9. Rapp $\mathbb{P R}$, Gallagher M. Preserved neuron number in the hippocampus of aged rats with spatial learning deficits. Proc Natl Acad Sci U S A 1996;93:9926-30

10. Abrous DN, Koehl M, Le Moal M. Adult neurogenesis; from precursors to network and physiology. Physiol Rev 2005;85:523-69

11. Brazel CY, Rao MS. Aging and neuronal replacement. Ageing Res Rev 2004;3:465-83

12. Turlejski K, Djavadian R. Life-long stability of neurons: a century of research on neurogenesis, neuronal death and neuron quantification in adult CNS. Prog Brain Res $2002 ; 136: 39-65$

13. Mos J, Hollander CF. Analysis of survival deta on aging rat cohorts: pitfalls and some practical considerations. Mech Ageing Dev 1987;38:89-105

14. Korr H, Thorsten Rohde H, Benders J, Dafotakis M, Grolms N, Schmitz C. Neuron loss during eatly adulthood following prenatal low-dose X-irradiation in the mouse brain. Int J Radiat Biol 2001;77:567 80

15. Schmitz $\mathrm{C}$, Hof $\mathrm{PR}$. Recommendations for straightforward and rigorous methods of counting neurons based on a computer simulation approach. J Chem Neuroanat $2000 ; 20: 93-114$

16. Schmitz C, Hof PR. Design-based stereology in neuroscience. Neuroscience 2005;130,813-831

17. West MJ. New stereological methods for counting neurons. Neurobiol Aging 1993;14:275-85

18. Maehara $Y$, Anai H, Kusumoto $T$, Sakaguchi $Y$, Sugimachi $K$. Nick translation detection in situ of cellular DNA strand break induced by radiation. Am I Pathol 1989;134:7-10

19. Rutten BP, Wirths O, Van de Berg WD, Lichtenthaler SF, Vehoff J, Steinbusch HW, Korr H, Beyreuther K, Multhaup G, Bayer TA, Schmitz C. No alterations of hippocampal neuronal number and synaptic bouton number in a transgenic mouse model expressing the beta-cleaved $\mathrm{C}$-terminal APP fragment. Neurobiol Dis $2003: 12: 110-120$

20. Schmitz C. Variation of fractionator estimates and its prediction. Anat Embryol 1998;198:371-97

21. Gower AJ, Lamberty Y. The aged mouse as a model of cognitive decline with special emphasis on studies in NMRI mice. Behav Brain Res 1993;57:163-73

22. Lieber MR, Karanjawala ZE. Ageing, repetitive genomes and DNA damage. Nat Rev Mol Cell Biol $2004 ; 5: 69-75$

23. Suh Y, Lee KA, Kim WH, Han BG, Vijg J, Park SC. Aging alters the apoptotic response to genotoxic stress. Nat Med 2002;8:3-4. 


\section{Chapter 5}

\section{Antioxidants and Alzheimer's disease: from bench to bedside (and back again)}

Current Opinion in Clinical Nutrition and Metabolic Care, 2002, 5: 645-651

Bart P.F. Rutten, Harry W.M. Steinbusch,

Hubert Korr, Christoph Schmitz 


\section{ABSTRACT}

Purpose of review: Accumulating evidence from both animal and human studies indicates a major role for oxidative damage in the pathogenesis of Alzheimer's disease (AD), occuring even before symptoms arise and both $\beta$-amyloid containing plaques and neurofibrillary tangles are formed. This raises the possibility to prevent or at least slow down the progression of $A D$ by the use of antioxidants. In this review, we present recent studies on the association between oxidative stress and $A D$ pathology, and on the efficacy of dietary, exogeneous antioxidants to prevent or attenuate the progression of $A D$.

Recent findings: Recent prospective studies have indicated that dietary intake of several exogenous antioxidants is associated with a lower risk for $\mathrm{AD}$. This suggests that people at risk for developing $\mathrm{AD}$ or being in the early phases of this disease may benefit from intervention with exogeneous antioxidants. However, the clinical studies carried out so far do not provide the final answer to whether antioxidants are truly protective against AD.

Summary: There is compelling evidence that oxidative stress is involved in AD pathogenesis, and several lines of evidence indicate that administration of antioxidants may be useful in prevention and treatment of $\mathrm{AD}$. However, further clinical studies based on larger cohorts studied over a longer period of time are needed to test this hypothesis. Furthermore, for the future one might expect balanced upregulation of both exogenous and endogenous antioxidants as one of the best treatment strategies for preventing or at least slowing down the progression of $\mathrm{AD}$.

\section{INTRODUCTION}

Alzheimer's disease (AD) is a devastating neuropsychiatric disorder with a tremendous impact on the individual and on society in general. The disease is clinically manifested by a progressive dementia ${ }^{1}$ with concomitant behavioral and social problems. ${ }^{2}$ The neuropathologic hallmarks of $\mathrm{AD}$ are the formation of neuritic plaques containing $\mathrm{B}$-amyloid, neurofibrillary tangles (NFT) mainly consisting of paired helical filaments, and neurodegeneration, showing a selective neuronal vulnerability of largely unknown origin. ${ }^{3 *}$ Approximately 5\% of all AD cases have an early onset and are familial, based on mutations of either presenilin 1 (PS-1), presenilin 2 (PS-2) and/or the $\beta$-amyloid precursor protein (APP). ${ }^{4}$ By contrast, approximately $95 \%$ of all $\mathrm{AD}$ cases represent the sporadic or late onset form of the disease, not showing mutations of PS-1, PS-2 and/or APP. Aging as well as the apolipoprotein E4 (ApoE4) genotype have been shown to be the major risk factors for sporadic $\mathrm{AD} .^{3 *}$ Accumulating evidence indicates a major role of free radicals and oxidative stress in $\mathrm{AD}$ pathogenesis and pathophysiology. ${ }^{4 *, 6}$ Free radicals are highly reactive molecules either donating an electron to or extracting an electron from molecules. The most important free radicals are oxygen derivatives such as superoxide and hydrogen peroxide. ${ }^{7.8 * *}$ Antioxidants act by catalyzing the breakdown of oxidants or by scavenging oxidants with the aim to prevent damage to important molecules such as nucleic acids, proteins, lipids and sugars. $7,8 * *$ Oxidative stress can be defined as the imbalance between 


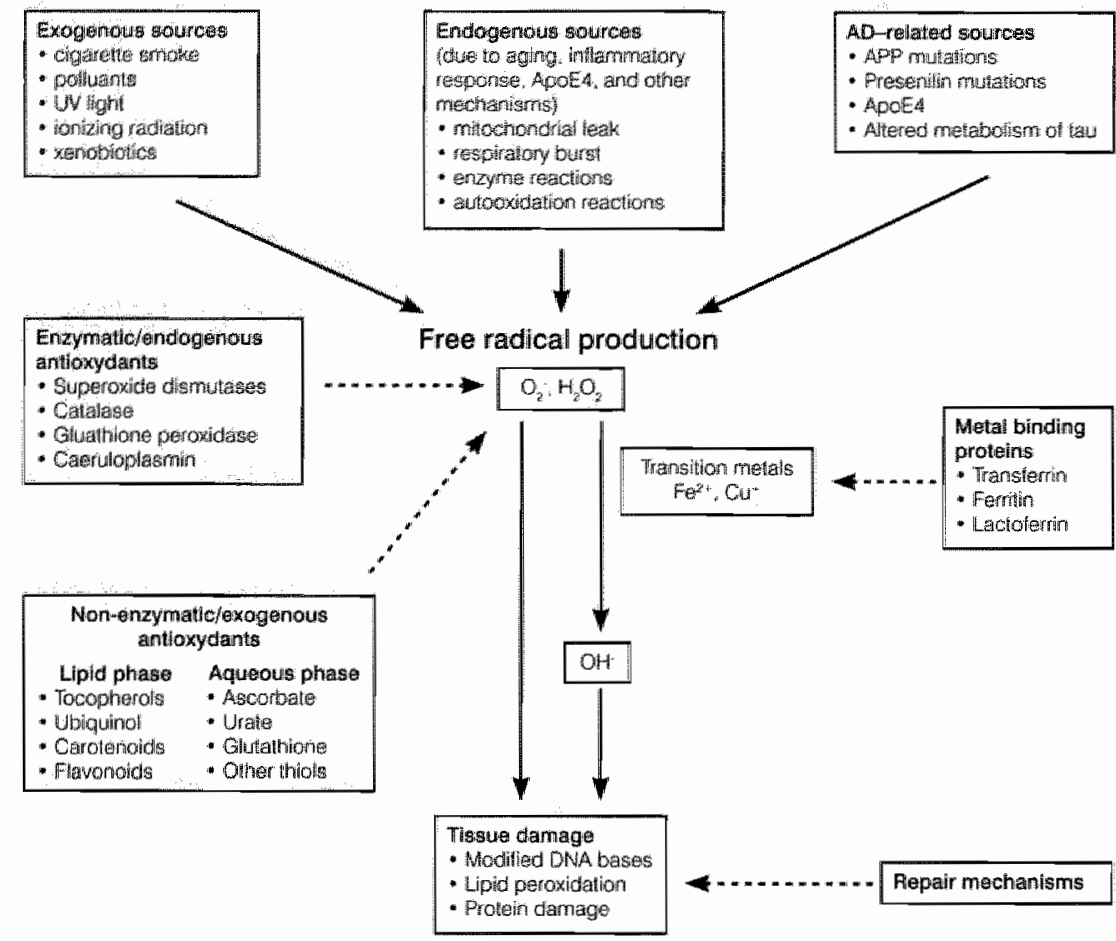

Figure 1. Major sources of free radicals in Atzheimer's discase, the consequences of free radical dannage, and the anti. oxidant defences against free radical attack. Generally, endogenous/enzynatic antioxidants catalyse the breakdown of free radical species, whereas nonenzynatic/erogenous anvioxidants react preferentially with free radicals by donatimg electrons. Transition metal binding prateins prevent the interaction of transition melals with hydrogen peroxide and superoxide producing highly reactive hydroxyl radicals. Among the repair mechanisms, DNA repair and mitochondrial renewal are the most powerfit.

oxidants and antioxidants in favor of oxidants. Neurons seem to be particularly vulnerable to oxidative stress due to the substantial amount of oxygen consumption by the brain, the low glutathione content and a high proportion of polyunsaturated fatty acids in neurons. ${ }^{5 *}$ Administration of antioxidants to $\mathrm{AD}$ patients or patients at risk for developing $\mathrm{AD}$ has therefore been proposed and limitedly tested as a preventative and therapeutic strategy to combat AD pathology. Here, we review recent studies concerning the association between oxidative stress and $\mathrm{AD}$ pathology and the efficacy of antioxidants in prevention and slowing down the progression of $\mathrm{AD}$. In addition, implications for future directions of research are discussed.

\section{OXIDATIVE STRESS IN AD}

A large body of evidence has indicated a major role of oxidative stress and oxidative damage in brains of $\mathrm{AD}$ patients, with the highest amount of oxidative damage in brain regions mostly affected by $A D$ pathology such as hippocampus and cortex. ${ }^{5 * 6,6,10}$ In this regard, both $\beta$-amyloid 
containing plaques ${ }^{17^{*}-13}$ and $\mathrm{NFT}^{14,15 *}$ seem to be closely associated with markers of oxidative stress. So far, the exact interrelations between $\beta$-amyloid containing plaques and NFT on one hand and the formation of oxidative damage in brains of AD patients on the other hand have not been established. ${ }^{12,15 *}$ However, a recent study has indicated that the increase in oxidative stress in vulnerable neurons precedes $\beta$-amyloid plague and NFT formation. ${ }^{16 * *}$

Among the markers of oxidative stress in brains of AD patients, oxidative damage to proteins has been observed in hippocampal tissue by elevated levels of carbonyls in nuclei of neurons and glial cells as well as in meuronal cytoplasm. ${ }^{17}$ Oxidative modifications of proteins in the presence of sugars may result in the formation of advanced glycation end products (ACEs). Several studies have indicated that AGEs are present in both NFT and senile plaques in AD. ${ }^{18,19}$ Furthermore, several studies have indicated oxidative damage to lipids in AD such as elevated levels of tran-4-hydroxy-2-hexenal (4-HNE) in cerebrospinal fiuid (CSF), acrolein in the amygdala and hippocampus/ parahippocampal gyrus, ${ }^{21} \mathrm{~F} 2$-isoprostanes in $\mathrm{CSF}$, ${ }^{22}$ and $\mathrm{F} 4-$ neuroprostanes in the cortex ${ }^{23}$ (see also ${ }^{24 *}$ ). In addition, elevated levels of 8-hydroxy-2"-deoxyguanosine (8-OHdG) indicating oxidative damage to DNA have been observed in CSF of AD patients. ${ }^{25}$ Oxidative damage to DNA in brains of AD patients might also be indicated by elevated levels of DNA strand breaks. ${ }^{26}$

In addition to studies having investigated oxidative damage to brain tissue or CSF in $A D$, recent studies have focused on signs of oxidative stress in non-neuronal tissue in AD. Mecocci and co-workers showed that lymphocytes of $A D$ patients exhibit elevated levels of 8-OHdG and decreased levels of antioxidative carotenoids as compared to healthy aged control subjects. ${ }^{27 k^{2}}$ Besides this, MoGrath and co-workers have investigated blood plasma of AD patients and have found elevated levels of 4-HNE but lower levels of ascorbate (vitamin C) compared to controls. ${ }^{28}$

As already mentioned, aging and the ApoE4 genotype are the major risk factors for sporadic AD. * Interestingly, both are associated with increased oxidative stress to the central nervous system. Aging is known to cause an increased production and amount of reactive oxygen species, and elevated markers of oxidative damage have extensively been documented in aged cells and tissues. ${ }^{29-31 * 32}$ Furthermore, Ramassamy and co-workers have recently shown that the ApoE4 genotype is associated with higher oxidative insults in specific brain regions of AD patients. ${ }^{3 *}$ In this regard, Lauderback and co-workers suggest a role for apolipoprotein $\mathrm{E}$ in antioxidative modulation of $\beta$-amylod toxicity, with the $\mathbb{E} 4$ allele being not as effective in this role as the other alleles of apolipoprotein $\mathbb{E}^{34}$

Several enzymatic and non-enzymatic antioxidants are present in biological tissue to prevent oxidative damage by free radicals and reactive oxygen species. ${ }^{7, * * *, 31 *}$ Enzymatic antioxidants are produced endogenously and catalyze the breakdown of free radicals and intermediate molecules (reactive oxygen species) usually in the intracellular environment. *** $^{*}$ Among these enzymatic antioxidants, superoxide dismutases metabolize superoxide anions - mainly produced during oxidative phosphorylation in mitochondria - to hydrogen peroxide. Subsequently, hydrogen peroxide is enzymatically processed by catalase and glutathione peroxidase to water. 
In the presence of iron and copper, however, hydrogen peroxide can also be processed via the Fenton reaction forming highly reactive hydroxyl radicals. Non-enzymatic antioxidants mainly act as scavenging agents in oxidative chain reactions. ${ }^{7,31 *}$ They can be divided into lipid phase chain breaking antioxidants such as tocopherols (among which is $\alpha$-tocopherol, vitamin E), carotenoids (among which is vitamin A), flavonoids and ubiquinone, and aqueous phase chain breaking antioxidants such as ascorbate, glutathione and uric acid ${ }^{8 * *}$. Additionally, other non-enzymatic antioxidants act by preventing the interaction of transition metals such as iron and copper with hydrogen peroxide and superoxide. These are the so-called metal binding proteins such as transferrin, ferritin, and lactoferrin. ${ }^{8 * *}$

To fully address the consequences of oxidative stress in $\mathrm{AD}$ pathogenesis, it would be attractive to search for altered levels of antioxidants in the brain of AD patients. Among the few studies published so far on this topic, Karelson and co-workers have found that elevated levels of lipid peroxidation in the inferior temporal lobe in $\mathrm{AD}$ correlate positively with levels of superoxide dismutase and catalase, but correlate negatively with total antioxidant capacity as measured by in vitro inhibition of standard linoleic acid peroxidation. ${ }^{3 *}$ These results suggest that there is an upregulation of endogenous antioxidants in affected regions in the $\mathrm{AD}$ brain to compensate for the increased amount of oxidants. This, however, is not sufficient to combat the increased amount of oxidants within these brain regions. In summary, there is compelling evidence that oxidative stress is involved in AD pathogenesis (see also ref. 36). Particularly, oxidative stress seems to play an important role in early phases of $A D$ even before the formation of $\beta$-amyloid containing neuritic plaques and NFT, as well as before the appearance of clinical symptoms. This raises the general possibility to act on oxidative damage in $A D$ by decreasing the amount of free radical formation as well as by scavenging free radicals before major damage occurs.

\section{EXPERIMENTAL STUDIES ON ANTIOXIDANTS IN VIVD}

Over the last years, many experimental studies have addressed the impact of increased levels of non-enzymatic/exogenous or enzymatic/endogenous antioxidants on oxidative damage to the central nervous system. Several rodent studies have indicated that dietary supplementation with exogenous antioxidants may decrease age-related lipid peroxidation in the cortex ${ }^{37}$ oxidative injury to synapses, ${ }^{38}$ and protein and RNA oxidation. ${ }^{39 *}$ Furthermore, dietary supplementation with exogenous antioxidants may prevent ischemia-related apoptosis in hippocampal neurons, ${ }^{40,41}$ and has been shown to attenuate ozone-induced memory deficits and lipid peroxidation in rats ${ }^{42}$ as well as cypermethrin-induced oxidative stress in rat brain and liver. ${ }^{43}$ Other studies have assessed the effects of upregulation of endogenous antioxidants, and have shown that overexpression of human cytosolic copper-zinc superoxide dismutase ( $\mathrm{Cu} / \mathrm{Zn}$ SOD) in transgenic mice may attenuate age-dependent oxidative damage in the brainstem ${ }^{44}$, 3-nitropropionic acid induced neurotoxicity ${ }^{45}$, and may improve cognitive functioning in aged rodents ${ }^{46}$. Another study has shown a rescue of homocystein induced endothelial dysfunction by overexpression of glutathione peroxidase in transgenic mice, which might be caused by improved NO- regulation. ${ }^{4 *}$ Moreover, superoxide dismutase and catalse mimetics have been shown to prolong the mean life span of Caenorhabditis elegans. ${ }^{48 *}$ However, one should keep 
in mind that an excessive upregulation of certain endogenous antioxidants without concomitant increase of other endogenous antioxidants (e.g., increase of $\mathrm{Cu} / \mathrm{Zn}$ SOD without increase of glutathione peroxidase) might also have deleterious effects. ${ }^{49.50}$

The use of mice transgenic for mutated human APP, PS-1 and PS-2 has been shown to be a valuable tool for modeling several aspects of $\mathrm{AD}$ pathology. ${ }^{51 *}$ For example, Matsuoka and co-workers have demonstrated that mice carrying mutant human APP and PS-1 develop $\beta$-amyloid deposits at 10-12 weeks of age and show several features of the human disease..$^{53 *}$ These mice have shown a strong association between fibrillar $\beta$-amyloid and oxidatively damaged proteins (by increased brain levels of 3-nitrotyrosine) and lipids (by increased brain levels of $4 \mathrm{HNE}$ ). Noteworthy, the levels of 3-nitrotyrosine and $4 \mathrm{HNE}$ increased in relation to age-associated increase in fibrillar amyloid load. ${ }^{52 *}$ Other mice transgenic for human APP and PS-1 mutations have exhibited elevated markers of brain lipid peroxidation even before the formation of $\beta$-amyloid containing plaques. $25^{\circ}, 53^{* *}$ However, only a limited number of studies have evaluated the effects of antioxidants in these AD models. A recent study by Lim and co-workers has shown that administration of the phenolic exogenous antioxidant curcumin to mice transgenic for mutant human APP developing $\beta$-amyloid plaques results in decreased oxidative brain damage and $\beta$-amyloid pathology. ${ }^{54 * *}$ Besides this, Pratico and co-workers have investigated transgenic mice overexpressing mutant human APP, fed with a diet enriched in aluminium. ${ }^{55 *}$ Compared to non-transgenic littermates fed with the same diet, these authors have found an increase in brain isoprostane levels in the transgenic mice, correlated to increased $\beta$-amyloid levels and accelerated plaque deposition. Administration of vitamin $E$ reversed this effect of aluminium, as demonstrated by a reduction of brain isoprostane levels in transgenic mice fed with both aluminium and vitamin $E .^{55 *} \beta$-amyloid levels and plaque deposition were also reduced in these animals.

In summary, several lines of evidence indicate that administration of antioxidants may be useful in prevention and treatment of $\mathrm{AD}$. In this respect, scavenging of free radicals by non-enzymatic/exogeneous antioxidants seems to be the most practical approach. This is due to the fact that many different non-enzymatic/exogenous antioxidants without major side effects are available, and there is currently no therapeutic approach known to increase levels of enzymatic/endogenous antioxidants in humans. However, among the most effective approaches might be a balanced increase of both non-enzymatic/exogenous and enzymatic/endogenous antioxidants.

\section{CLINICAL STUDIES ON ANTIOXIDANTS IN AD}

The encouraging findings in the experimental models discussed above have stimulated studies on humans testing the effects of non-enzymatic/exogeneous antioxidants in treating and preventing AD. Early studies on this topic carried out between 1989 to 1997 (reviewed in ${ }^{56-58}$ ) indeed provided preliminary evidence that antioxidants may have a protective effect against the development of $\mathrm{AD}$. In a recent Cochrane review the outcome of all unconfounded, double blind, randomized trials carried out up to June 2000 has been analyzed, in which treatment with 
vitamin E at any dose was compared with placebo for patients with Alzheimer's disease..$^{5 \%}$ Only one study (published by Sano and co-workers ${ }^{60}$ ) was identified as meeting the inclusion criteria for Cochrane analysis. In this study focussing on patients diagnosed as having mild to moderate $\mathrm{AD}$, a slower progression of $\mathrm{AD}$ in patients using vitamin $\mathrm{E}$ has been shown as compared to patients not using this antioxidant. In the corresponding Cochrane review it has been concluded that there is - albeit insufficient - evidence for an efficacy of vitamin $E$ in the treatment of people with AD, justifying further studies on this topic. ${ }^{59 *}$

Since oxidative stress seems to be involved in the earliest phases of $A D, 26 * *$ it is an attractive issue to focus therapeutic interventions on the early phases of this disease. Accordingly, very recently three studies on this topic have been published. First, Commenges and co-workers have inwestigated 1,367 initially non-demented french people above 65 years of age, and found - during a 5 year follow-up period - an inverse relation between intake of flavonoids and the risk of incident dementia (of which AD is one possible cause) " ${ }^{6 *}$ Second, Morris and co-workers have investigated the relationship between $A D$ incidence and intake of the antioxidant nutrients, vitamin $\mathrm{E}$, vitamin $\mathrm{C}$, and beta-carotene (the so-called Chicago Health and Aging Project $t^{(2 * *)}$ ). In this prospective, longitudinal study the authors have followed up 815 people of 65 years of age and older free of $\mathrm{AD}$ at baseline. On an average of 1.7 years after baseline, food frequency questionnaires were obtained, and incident $\mathrm{AD}$ cases as evaluated in clinical examinations according to standardized criteria were taken as main outcome measure. The results of this study indicate that only vitamin $\mathbb{E}$ from food, but not other antioxidants or vitamin $\mathrm{E}$ from supplements, may be associated with a reduced risk for $\mathrm{AD}{ }^{62 * *}$ Interestingly, the investigators observed this association only among individuals without ApoE4 genotype, suggesting that people with ApoE4 genotype may not be protected from $\mathrm{AD}$ by the use of vitamin $\mathrm{E}^{62 * * *}$ Third, Engelhart and co-workers have determined whether dietary intake of beta-carotene, flavonoids, vitamin $C$ and vitamin $E$ is related to the risk for $\mathrm{AD}$ in a large population based, prospective cohort study (the so-called Rotterdam study). ${ }^{6 * *}$ This study includes 5,396 participants who were at baseline at least 55 years old, non-institutionalized, dementia free and whose dietary assessment was reliable. Incidence of AD based on standardized criteria was the main outcome measure. The results, obtained after a mean follow-up of 6 years, indicate that high dietary intake of vitamins $\mathrm{C}$ and $\mathrm{E}$ was associated with a significantly lower risk for $\mathrm{AD}$. This relation was even more pronounced in current smokers, for whom intake of beta-carotene and flavonoids was also preventative. ${ }^{6 * *}$ In contrast to the Chicago Health and Aging Project, ${ }^{62 * * *}$ in the Rotterdam study the association between intake of antioxidants and AD risk did not vary between ApoE genotypes. ${ }^{63 *}$ This difference between the outcome of the Chicago Health and Aging Project ${ }^{62 * * *}$ and the Rotterdam study $y^{63 * *}$ might be due to the different sample sizes in these studies.

\section{CONCLUSIONS AND FUTURE DIRECTIONS}

There is compelling evidence that oxidative stress is involved in AD pathogenesis. Furthermore, several lines of evidence indicate that administration of antioxidants may be useful in prevention and treatment of AD. Recent prospective studies have indicated that dietary intake of several 
exogenous antioxidants is associated with a lower risk for $\mathrm{AD}$, suggesting that intervention with antioxidants might be beneficial in the early phases of AD or in people at risk for developing AD. However, the clinical studies carried out so far do not provide the final answer to whether antioxidants are truly protective against $A D$. Further intervention trials and observational investigations based on larger cohorts studied over a longer period of time are needed to test this hypothesis (see also ${ }^{* *}$ ). Nonetheless, the idea that non-enzymatic/exogenous antioxidants might have beneficial effects on AD pathogenesis makes sense, and it seens unlikely that diets with high antioxidant content would negatively affect brain aging.

In addition to further clinical studies, would it make sense to go back to the bench on this topic? To answer this question, one should consider that all clinical trials carried out so far have focussed only on administration of non-enzymatic/exogeneous antioxidants. As already mentioned, however, a balanced upregulation of both exogenous and endogenous antioxidants might be the one of the best treatment strategies for preventing or at least slowing down the progression of AD. Thus, this strategy of a balanced upregulation of both exogenous and endogenous antioxidants is currently under study in our and other laboratories, using transgenic mice overexpressing human endogenous antioxidants and fed with diets containing high levels of exogeneous antioxidants as experimental models. It is anticipated that the results of these experimental studies will have substantial impact on new clinical trials for preventing or at least slowing down the progression of $\mathrm{AD}$ in the near future.

\section{REFERENCES}

1. Petersen RC: Aging, mild cognitive impairment, and Alzheimer's disease. Neurol Clin 2000, 18:789-806.

2. Woods RT: Discovering the person with Alzheimer"s disease: cognitive, emotional and behavioural aspects. Aging Ment Health 2001, 5 Suppl 1:7-16.

*3. Cummings JL, Cole G: Alzheimer disease. J Amer Med Assoc 2002, 287:2335-2338. A concise review on the current status on Alzheimer's disease.

4. Selkoe DJ: Alzheimer's disease: genes, proteins, and therapy. Physiol Rev 2001, 81:741-766.

*5. Christen Y: Oxidative stress and Alzheimer disease. Am J Clin Nutr 2000, 71:621S-629S. A comprehensive overwiew on the evidence concerning the associations between oxidative stress and $A D$.

6. Pratico D, Delanty N: Oxidative injury in diseases of the central nervous system: focus on Alzheimer's disease. Am J Med 2000, 109:577-585.

7. Halliwell B, Gutteridge JMC: Pree Radicals in Biology and Medicine, 3rd edition, Oxford University Press, 1999.

**8. Young IS, Woodside JV: Antioxidants in health and disease. J Clin Pathol 2001, 54:176-86. An excellent overview on the basic chemistry of free radical formation and free radical induced damage, as well as on enzymatic and non-enzymatic antioxidants in health and disease.

9. Markesbery WR, Carney JM: Oxidative alterations in Alzheimer's disease. Brain Pathol 1999, 9:133-146.

10. Giasson BI, Ischiropoulos H, Lee VM, Trojanowski IQ: The relationship between oxidative/nitrative stress and pathological inclusions in Alzheimer's and Parkinson's diseases( 1 , 2). Free Radic Biol Med 2002, 32:1264 1275.

11. Butterfield DA, Drake J, Pocernich $C_{n}$ Castegna A: Evidence of oxidative damage in Alzheimer's diserase brain; central role for amyloid beta-peptide. Trends Mol Med 2001, 7:548-554. A up-to-date overview on evidence of phospholipid peroxidation and protein and DNA oxidation in AD brain, ws well as an comprehensive discussion of the potential role of $\beta$-amyloid in oxidative damage in $\mathrm{AD}$.

12. Kontush A: Amyloid-beta: an antioxidant that becomes a pro-axidant and critically contributes to Alzheimer" "s disease. Free Radic Biol Med 2001, 31:1120-1131.

13. Multhaup G, Scheuermann S, Schlicksupp A, et al: Possible mechanisms of APP-mediated oxidative stress in Alzheimer's disease (1,2). Free Radic Biol Med 2002, 33:45-51. 
14. Castellani RJ, Hamis PL, Sayre LM, et al: Active glycation in netirofibrillary pathology of Alzheimer disease: N(epsilon)-(carboxymethyl) lysine and hexitol lysine. Free Radic Biol Med 2001, 31:175-180.

*15. Smith MA, Drew KL, Nunomura $A_{\text {, }}$ et al: Amyloid-beta, tau alterations and mitochondrial dysfunction in Alzheimer disease: the chickens or the eggs? Neurochem Int 2002,40:527-531. In this innovative article, the authors question the notion that $\beta$-amyloid and NFT cause AD, and that attempts at therapeutic intervention should therefore be focused on preventing $\beta$-amyloid and NFT formation. The authors state that this rationale might be misguided since recent evidence suggests that $\beta$-amyloid and NFT formation not only occurs as by-products of the fundamental disease process but may also be protective.

**16. Nunomura $A$, Perry $G$, Aliev $G$, et al: Oxidative damage is the earliest event in Alzheimer disease. I Neuropathol Exp Neurol 2001, 60:759-767. An important article showing for the first time that increased oxidative damage is an early event in $\mathrm{AD}_{\text {* }}$.

17. Smith MA, Perry G, Richey PL, et al: Oxidative damage in Alzheimer"s. Nature 1996, 382:120-121.

18. Yan SD, Chen X, Schmidt AM, et al: Glycated tau protein in Alzheimer disease: a mechanism for induction of oxidant stress. Proc Natl Acad Sci U S A 1994, 91:7787-7791.

19. Smith MA, Sayre LM, Monnier VM, Perry G: Radical AGEing in Alzheimer's disease. Trends Neurosci 1995, 18:172-176.

20. Lowell MA, Ehmann WD, Mattson MP, Markesbery WR: Elevated 4-hydroxynonenal in ventricular fluid in Alzheimer's disease. Neurobiol Aging 1997, 18:457-461.

21. Lovell MA, Xie C, Markesbery WR: Acrolein is increased in Alzheimer's disease brain and is toxic to primary hippocampal cultures. Neurobiol Aging 2001, 22:187-194.

22. Montine TJ, Markesbery WR, Morrow JD, Roberts LJ 2nd: Cerebrospinal fluid F2-isoprostane levels are increased in Alzheimer's disease. Ann Neurol 1998, 44:410-413.

23. Nourooz-Zadeh J, Liu EH, Yhlen B, et al: F4-isoprostanes as specific marker of docosahexaenoic acid peroxidation in Alzheimer's disease. J Neurochem 1999, 72:734-740.

*24. Arltt S, Beisiegel U, Kontush A: Lipid peroxidation in neurodegeneration: new insights into Alzheimer"s disease. Curr Opin Lipidol 2002, 13:289-294. A comprehensive summary of the evidence concerning oxidative damage to lipids in Alzheimer's disease, illustrating the role of lipid peroxidation in the pathophysiological cascade of $\mathrm{AD}$.

25. Lovell MA, Markesbery WR: Ratio of 8-hydroxyguanine in intact DNA to free 8-hydroxyguanine is increased in Alzheimer disease ventricular cerebrospinal fluid. Arch Neurol 2001, 58:392-396.

26. Adamec E, Vonsattel JP, Nixon RA: DNA strand breaks in Alzheimer's disease. Brain Res 1999, 849:67-77.

*27. Mecocci P, Polidori MC, Cherubini A, et al: Lymphocyte oxidative DNA damage and plasma antioxidants in Alzheimer disease. Arch Neurol 2002, 59:794-798. This interesting study on non-neuronal tissue has included a large number of patients and has shown that in $\mathrm{AD}$ a condition of increased oxidative stress is related to a poor antioxidant status, which is not restricted to brains of $A D$ patients.

28. McGrath LT, McGleenon BM, Brennan S, et al: Increased oxidative stress in Alzheimer's disease as assessed with 4- hydroxynonenal but not malondialdehyde. Quart J Med 2001, 94:485-490.

29. Johnson FB, Sinclair DA, Guarente L: Molecular biology of aging. Cell 1999, 96:291-302.

30. Wallace DC: Mitochondrial diseases in man and mouse. Science 1999, 283:1482-1488.

*31. Finkel T, Holbrook NJ: Oxidants, oxidative stress and the biology of ageing. Nature 2000, 408:239-247. A comprehensive overview on the evidence that the production of oxidants, together with the ability of organisms to respond to oxidative stress, is intricately connected to aging and life span.

32. Harman D: Alzheimer"s disease: role of aging in pathogenesis. Ann N Y Acad Sci 2002, 959:384-395.

*33. Ramassamy C, Averill D, Beffert U, et al: Oxidative insults are associated with apolipoprotein $E$ genotype in Alzheimer's disease brain. Neurobiol Dis 2000,7:23-37. This innovative study has shown in animal models and in brains of $\mathrm{AD}$ patients that the E4 allele of apolipoprotein is associated with higher oxidative insults in $\mathrm{AD}$.

34. Lauderback CM, Kanski J, Hackett JM, et all: Apolipoprotein E modulates Alzheimer's Abeta(1-42)-induced oxidative damage to synaptosomes in an allele-specific manner. Brain Res 2002, 924:90-97.

*35. Karelson E, Bogdanovic N, Garlind A et al: The cerebrocortical areas in normal brain aging and in Alzheimer's disease: noticeable differences in the lipid peroxidation level and in antioxidant defense. Neurochem Res 2001 , 26:353-361. One of the few studies which has focused on regional differences in oxidative stress markers and on activities of individual antioxidants as well as on total antioxidant capacity in brains of normal aging people and in brains of $A D$ patients.

36. Grundman M: Vitamin E and Alzheimer disease. Am J Clin Nutr 2000, 71: 630S-636S.

37. O'Donnell E, Lynch MA: Dietary antioxidant supplementation reverses age-related meuronal changes. Neurobiol Aging 1998, 19:461-467.

38. Urano S, Asai $Y$, Makabe $S$, et al: Oxidative injury of synapse and alteration of antioxidative defense systems in rats, and its prevention by vitamin E. Eur I Biochem 1997, 245:64-70. 
39. Liu J, Head E, Gharib AM, et al: Memory loss in old rats is associated with brain mitochondrial decta and RNA/DNA oxidation: partial reversal by feeding acetyl-L-camitine andor R-8lpha-lipoic acid. Proc Nan Acad Sci U S A 2002, 99:2356-2361. This elegant study focusedi on behaviour well as on markers of oxidative stress in old rats fed with a special diet containing high levells of speeific antioxidants.

40. Tagami $M$, Yamagata $\mathrm{K}$, Ikeda $\mathrm{K}$, et al: Vitamin $\mathrm{E}$ prevents apoptosis in cortical neurons during bypoxia and oxygen reperfusion. Lab Invest 1998, 78:1415-1429.

41. Tagami M, Ikeda K, Yamagata $K$, al: Vitamin $E$ prevents apoptosis in hippocampal neurons caused by cerebral ischemia and reperfusion in stroke-prone spontaneously hypertensive rats. Lab linvest 1999, 79:609. 615.

42. Guerrero AL, Dorado-Martinez $C$, Rodriguez $A_{\text {, }}$ elt al: Effects of vitamin $E$ on azone-induced memory deficits and lipid peroxidation in rats. Neuroreport 1999, 10:1689-1692.

43. Giray B, Gurbay A, Hincal F* Cypernethrin--induced oxidative stress in rat brain and liver is prevented by vitamin $\mathrm{E}$ or allopurinal. Toxicoll Lett 2001, 118:139-146.

44. Cardozo-Pelaez $F$, Song $S$, Parthasarathy $A$, et al: Attenuation of age-dependent oxidative damage to DNA and protein in brainstem of Tg CuZn SOD mice. Neurobiol Aging 1998, 1.9:31.1-316.

45. Beal MF, Ferrante RJ, Henshaw $R$, et al: 3-Nitropropionic acid neurotoxicity is attenuated in copper/zinc superoxide dismutase transgenic mice. J Neurochem 1995, 65:919-922.

46. Socci DJ . Crandall BM, Arendash $G W$. Chronic antioxidant treatment improves the cognitive performance of aged rats. Brain Res 1995, 693:88-94.

447. Weiss N, Zhang YYY, Heydrick $S$, et al: Overexpression of cellular glutathione peroxidase rescues homocyst(e)ine-induced endothelial dysfunction. Proc Natl Acad Sci U S A 2001, 98:12503-12508. One of the few recent studies on the effects of overexpression of glutathione peroxidase in mice.

* 48. Melov S, Ravenscroft J, Malik S, et al: Extension of life-span with superoxide dismutase/catalase mimetics. Science $2000,289: 1567-1569$. This innovative study thas shown for the first time that administration of enzymatic antioxidants - small synthetic superoxide dismutase/catalase mimetics - to Caenorhabditis elegans can increase their mean life span.

49. de Haan JB, Cristimo F, Jannello RC, Kola 1: Cu/Zn-superoxide dismutase and glutathione peroxidase during aging. Biochem Mol Biol Int 1995, 35:1281-1297.

50. de Haan JB, Cristiano F, Iannello $\mathrm{R}$, et al: Elevation in the ratio of Cu/Zn-superoxide dismutase to glutathione peroxidase activity induces features of cellalar semescence and this effect is mediated by hydrogen peroxide. Hum Moll Genet 1996, 5:283-292.

*51. van Leuven F: Single and multiple transgenic mice as models for Alzheimer's disease. Prog Neurobiol 2000, 61:305-312. An excellent overview on the different transgenic mouse models for AD and an ellegant discussion concerning the perspectives of studying these models to define early biochemical and pathological aspects. which are not accessible in human AD patients.

452. Matsuoka Y, Picciano M, La Francois J, Duff K. Fibrillar beta-amyloid evolkes oxidative damage in a transgenic mouse model of Alzheimer's disease. Neuroscience 2001, 104:609-613. An elegant study on the association of fibrillar $\beta$-amyloid and oxidative damage in an animal model of AD.

* 53. Pratico D, Uryu K, Leight S, et al: Imcreased lipid peroxidation precedes anyloid plaque formation in an animal model of Alzheimer amyloidosis. J Neurosci 2001, 21:4183-4187. An excellent animal study showing that oxidative damage is inflicted in the early phases of AD pathogenesis.

*4. Lim GP, Chu T, Yang Fet al: The curry spice curcumin reduces oxidative damage and amylloid pathology in an Alzheimer transgenic mouse. I Neurosci $2001,21: 8370-8377$. In this innovative animal study, the authors have shown the benefit of administrating the exogenous antioxidant curcumin to reduce oxidative damage and AD pathology.

*55. Pratico D, Uryu K, Sung S, et al: Aluminum modulates brain amyloidosis through oxidative stress in APP transgenic mice. Faseb J 2002, 16:1138- 1140 . This recent study has shown that oxidative stress in a transgenic mouse model of $\mathrm{AD}$, modulated by aluminium, is attenuated by treatment with vitumin $\mathbb{E}$.

56. Pitchumoni SS, Doraiswamy PM: Current status of antioxidant therapy for Alzheimer"s Disease. J Am Geriatr Soc $1998,46: 1566-1572$.

57. Rosler M, Retz W, Thome $J_{3}$, Riederer P: Free radicals in Alzheimer's dementia: currently available therapeutic strategies. J Neural Transm Suppl 1998, 54:2 11 1-219.

58. Flynn BL, Ranno AE: Phamacologic management of Alzheimer disease, Part II: Antioxidants, antihypertensives, and ergoloid derivatives. Ann Pharmacother 1999, 33:188-197.

*59. Tabet N, Birks J, Grimley Evans J: Vitamin E for Alzheimer's disease. Cochrane Database Syst Rev $2000,4$. A comprehensive analysis and discussion of evidence-based studies on vitamin $E$ treatment in $A D$.

60. Sano M, Ernesto C, Thomas RG, et al: A controlled trial of selegiline, alpha-tocopherol, or both as treatment for Allzheimer"s disease. The Alzheimer's Disease Cooperative Study. N Engl J Med 1997, 336:1216-1222. 
61. Commenges $\mathrm{D}_{*}$ scotet $\mathrm{V}$, Renaud $\mathrm{S}$, al: Intake of flavonoids and rish af dementia. Eur J Epidemiol 2000 , 16.357-363. One of the first studies on the association between antioxidant intake and the risk of incipient demerntiat.

*62. Morris MC, Evans DA, Bicnias JL, et al: Dietary intake of antioxidam mutrients and the risk of incident Aldhemer disease in a biracial community study. J Amer Med Assoc 2002, 287:3230-3237. A very recent, prospective study investigating a large population for the association between dietary intake of antioxidants and the rish of incipient $A D$.

* 63. Engethart MU, Geerlings MI, Ruitenberg * al: Dietary intake of antioxidants and risk of Alzheimer disease. I Amer Med Assoc 2002, 287:3223-3229. Another very recent, prospective study investigating a population considerably larger than the population investigated by Morris and co-borkers [62], for the association of Hetary intake of antioxidants and the risk of incipient $\mathrm{AD}$.

*64. Folley DI, White LR. Dietary intake of antioxidant and risilk of Alzheimer Disease. J Amer Med Assoc 2002 , 287:326-3263. A comprehensive discussion on the studies by Morris and co-workers [62] and by Engelhart and co wworkers [63], pointing out directions for future clinical studies. 


\section{Chapter 6}

\section{Caloric restriction reduces nuclear DNA damage accumulation and age-related neuronal shrinkage in mouse hippocampus}

Submitted

Bart P.F. Rutten, Imke A.J. van Kooten, Dave van lersel, Hellen P.J. Steinbusch, Marjanne Markerink, Kohtaro Asayama, Hubert Korr, Harry W.M. Steinbusch, Christoph Schmitz. 
Aging of the brain is characterized by increased oxidative stress and accumulation of damage to macromolecules. Selective types of neurons, as hippocampal pyramidal and granule cells, are preferentially affected during aging. Our previous work on the mouse brain showed a significant age-related accumulation of unrepaired nDNA damage in hippocampal pyramidal and granule cells. Furthermore, we hypothesized that long term transgenic upregulation of $\mathrm{Cu} / \mathrm{Zn}$ superoxide dismutase (SOD1) and dietary restriction of calories combined with upregulation of exogenous antioxidants attenuate age-related alterations in the mouse hippocampus. To test this hypothesis the effects of a diet restricted in calories and enriched in antioxidants (CR diet), and the effects of upregulation of SOD1 were investigated on alterations in hippocampal volumes, numbers of hippocampal neurons and size of hippocampal neurons during aging as well as on accumulation of unrepaired nDNA damage in hippocampal neurons at high age. To this end, four cohorts of mice were generated depending on diet and genotype. Mice of these cohorts were sacrificed at 12 and 24 months of age. The hippocampus of these mice was investigated with design-based stereologic techniques to quantify volumes, numbers of neurons and size of neurons, and with In Situ Nick Translation to quantify the relative amount of unrepaired nDNA single strand breaks in situ. The results showed that CR diet extended mean and most probably also maximum lifespan, resulted in hippocampal volume loss and substantially attenuated age-related reductions in the size of hippocampal granule cells, while overexpression of normal SODI did not affect any investigated parameter. Most importantly, the CR diet led to substantial reductions in the amount of unrepaired nDNA damage in hippocampal neurons in 24 -month-old mice. CR was thus a more effective strategy to attenuate age-related alterations in hippocampal neurons of the mouse brain than upregulation of SOD1.

\section{INTRODUCTION}

Aging of the mammalian central nervous system is characterized by increased oxidative stress and accumulation of damage to macromolecules eventually leading to neuronal dysfunction. ${ }^{1-3}$ (see also Chapter 3 of this thesis). Evidence has been found that accumulation of nuclear (n) DNA damage plays a central role in age-related cellular dysfunction. ${ }^{3.4}$ During aging, relatively high levels of nDNA damage occur in promoter regions of genes with central roles in synaptic plasticity, vesicular transport and mitochondrial function in the human brain, at least in the cerebral cortex. ${ }^{4}$ Aging is known to particularly affect neurons forming hippocampal and cortical circuitries. ${ }^{5}$ Although there is no detectable loss of neurons in hippocampus or cerebral cortex during normal aging, ${ }^{3}$ neurons within these regions show high amounts of DNA damage ${ }^{3,6-8}$ and altered expression of genes involved in the response to DNA damage $e^{4}$ and in synaptic plasticity. ${ }^{5,910}$ During aging, accumulation of unrepaired nDNA damage and decline in the rate of $\mathrm{nDNA}$ repair occurs preferentially in cortical and hippocampal neurons (cf. Chapter 4 of this thesis). ${ }^{6,11,12}$ Accumulating evidence suggests that oxidative stress initiates age-related damage accumulation $\mathrm{n}^{\mathrm{1}, 13,14}$ and the use of antioxidants has therefore been proposed as an effective strategy to prevent or attenuate age-related processes in the brain ${ }^{15,16}$ (cf. Chapter 5 of this thesis). Dietary means can be employed to upregulate the amount of exogenous antioxidants, 
while transenic approaches can be used to upregulate endogenous enzymatic antioxidants. Interestingly, transgenic expression of normal human $\mathrm{Cu} / \mathrm{Zn}$ superoxide dismutase (SOD1), a main endogenous antioxidant scavenging superoxide anion, in mice has been shown to result in attenuation of age-related accimulation of oxidative damage to DNA and protein in the brain stem ${ }^{17}$ and can attenuate neurodegeneration after various forms of injury to the mammalian brain. ${ }^{18-21}$ However, direct proof that upregulation of endogenous antioxidants affects: age-related alterations in hippocampus is currently lacking. Besides the use of antioxidants, various age-related alterations such as age-related DNA damage in the brain can be attenuated by restricting dietary intake of callories, i.e. caloric restriction (CR). ${ }^{22,23} \mathrm{CR}$ is furthermore the only known strategy that prolongs mean and maximum life span in various animal species. 24,23 Molecular studies to assess the effects of CR and antioxidants were previously carried out on homogenates of entire brains or entire brain regions of laboratory animals which does not allow for cell-type-specific analyses. As different brain regions and types of neuron are known to be differently affected by aging (as explained in detail in Chapters 3 and 4 of this thesis), ${ }^{3,5}$ studies carried out on homogenates cannot assess the exact effects of caloric restriction or antioxidants on age-related alterations in those types of neurons that are most affected during aging. Based on these considerations we hypothesized that a diet restricted in calories and enriched in antioxidants as well as transgenic upregulation of human SOD1 influence age-related alterations in the mouse hippocampus. Four cohorts of mice were generated based on diet and genotype. Mice were sacrificed at 12 and 24 months of age and the brains of these mice were analyzed. The present study focused on the analysis of age-related alterations in hippocampal volumes, numbers of hippocampal neurons and size of hippocampal neurons with design-based stereologic techniques, and on alterations in levels of nDNA damage in hippocampal neurons at high age with In Situ Nick Translation, a molecular technique to quantify unrepaired nDNA single strands breaks in situ. ${ }^{26}$

\section{MATERIALS AND METHODS}

\section{Animals}

Breeder pairs consisting of male mice transgenic for normal human SOD ${ }^{27}$ on a C57BI6 background (SOD mice) and female wild type mice (C57B16) from the same colony were purchased from Jackson Laboratories (Bar Harbor, ME, USA; stock \#002629, hemizygous C57BL/6-tgN(SOD1)3Cj); and transported to the Central Animal Facilities, Maastricht University, Maastricht, the Netherlands. SOD mice express three times the normal level of SODl in blood, brain, and fibroblasts. ${ }^{27}$ Breeding procedures were carried out with hemizygous male SOD mice and wild type female mice for several generations. Offsprings were genotyped with standard PCR protocols. Breeding was performed until $n=120$ male hemizygous SOD mice and $n=120$ male wild type mice were available, with all of these mice born within a period of 12 weeks. After weaning on postnatal day $21 \mathrm{n}=60$ SOD mice and $n=60$ wild-type mice were fed with a control diet (described in the next paragraph; SOD-CD mice and WT-CD mice). The remaining $n=60$ SOD mice and $n=60$ wild-type mice were fed with a diet restricted in calories and enriched in antioxidants (also described in the next paragraph; SOD-CR mice and WT-CR mice). All mice were housed in individual cages under specified pathogen free conditions at the 
Central Animal Facilities, Maastricht University, Maastricht; The Netherlands. All experments were approved by the local Animal Ethical Committee and were performed in acoordance with the dutch animal protection law.

\section{Diets}

The control diet was a derivation from the "N/N85" diet described by Weindruch and colleagues $(1986)^{28}$, and the diet restricted in calories and enriched in antioxidants a derivation from the "N/R 50" diet described by these authors. ${ }^{28}$ The N/R50 diet contained $50 \%$ less calories than a normal mouse diet while the N/N85 diet contained $85 \%$ of normal caloric intake for mice to ensure complete consumption of diet pellets and adequate control over caloric intake ${ }^{28}$ Both diets were custom made by Altromin (Lage, Germany). Th the appendix of this study the composition of both diets is provided in detail.

The N/N85 diet was fed in portions of 3.0 to 3.2 grams on Mondays, Tuesdays, Wednesdays and Thursdays and in portions of 9.0 to 9.2 grams on Fridays according to Weindruch and colleagues (1986) ${ }^{28}$ The N/R50 diet was fed in portions of 3.0 to 3.2 grams on Mondays and Wednesdays and in portions of 6.0 to 6.4 grams on Fridays according to these authors. ${ }^{28}$

\section{Time points of investigations}

General health conditions and survival of the mice was inspected every other day. Body weight of the mice was recorded once per eight weeks during the entire life span of the mice. Mice were sacrificed and their brains analyzed at two time points (arrows in Figure 1A). At a mean age of 12 months, six mice per group were sacrificed by perfusion-fixation and their brains were used for immunohistochemical localization of human SOD1 as well as for design-based stereologic analysis of hippocampal volumes, numbers of hippocampal neurons in areas CA 1-2 and dentate gyrus (DG), and mean size of hippocampal neurons in areas CA1-2 and DG. At a mean age of 24 months (when approximately $80 \%$ of the SOD CD and WT-CD mice had spontaneously died), 11 mice per group were sacrificed. Six of these 11 mice per group were sacrificed by perfusion-fixation. The brains of these mice were processed and used for immunohistochemical localization of SODI as well as for design-based stereologic analyses of hippocampal volumes, numbers of neurons and mean neuronal size. The remaining five mice per group were sacrificed by cervical dislocation. The brains of these mice were processed and used for measurements of the relative amount of unrepaired nDNA single strand breaks (SSB) in hippocampal pyramidal and granule cells at 24 months of age.

\section{Tissue processing for immunohisto-chemistry and stereology}

A total of 48 mice ( 6 per group, 2 time points) were used for design-based stereologic analysis. These mice were sacrificed during intracardial perfusion-fixation with formalin solutions as previously described (cf. Chapter 4 of this thesis). ${ }^{29}$ After opening the skulls, the heads of the animals were post-fixed in formalin solution for $24 \mathrm{~h}$ at $4^{\circ} \mathrm{C}$. Afterwards the brains were removed, hemisected in the midsagittal line, and further fixed in formalin solution for 10 days 
at $4^{\circ} \mathrm{C}$. Left brain halves were cryoprotected in sucrose solution $(10 \%, 20 \%$ and finally $30 \%$ sucrose in $0.1 \mathrm{M} \mathrm{Tr}-\mathrm{HCl}$ buffer, $2 \times 12 \mathrm{~h}$ per solution; $4^{\circ} \mathrm{C}$ ), embedded in Tissue-tek(B) (Sakura Finetek), quickly frozen and stored at $-70^{\circ} \mathrm{C}$. Then they were entirely cut into serial, $30 \mu \mathrm{m}$ thick frontal sections on a cryostat (type HM 500 OMV, Microm). The right brain halwes were not used in the present study and were stored for future experiments.

\section{Immunohistochemical detection of human SOD1 in hippocampus}

One series of every tenth section through the hippocampus was collected for immuno-histochemical detection of SOD1 with anti human SODI antibody. ${ }^{30}$ SOD1 immunohistochemistry was carried out in a free floating manner according to standard protocols as previously described " Briefly, avidin-biotin immunoperoxidase labeling was conducted by incubating sections overnight with primary antibody (polyclonal anti-human SOD1 antibody, $30,32 \quad 1: 5,000$ ) at $4^{\circ} \mathrm{C}$ after rinsing and blocking endogenous peroxidase activity with $0.3 \% \mathrm{H}_{2} \mathrm{O}_{2}$ in $0.01 \mathrm{M}$ TBS. After incubation and rinsing with TBS and TBS-T, the sections were incubated in biotinylated seconday IgG antibodies (biotinyllated donkey anti-rabbit IgG 1:800; Jackson, West Grove, PA, USA) for 1.5 hours at room temperature (RT), followed by ABC-kit (90 min at RT; Vectastain, Burlingame, CA, USA). The sections were then simultaneously incubated in $3,3^{\prime}$ - Diaminobenzidine (Sigma, Uithoorn, The Netherlands) containing $0.03 \% \mathrm{H}_{2} \mathrm{O}_{2}$ in TBS for 10 min at RT. Sections were rinsed with TBS, mounted on gelatinized glass slides, dehydrated, cleared and coverslipped using DePeX (Serva, Heidelberg, Germany). Immunoreactivity in hippocampal area CA 1-2, and dentate gyrus was photographed using an Olympus BX 51 microscope (Olympus, Tokyo, Japan) with a 10x objective (Olympus), and a Hitachi HV-C.20A camera (Hitachi Kokusai Electronics, Tokyo, Japan) connected to a computer which stored the acquired images. All images were acquired under identical conditions. Final figures were constructed using Corel Draw Version 11.0 (Corel, Ottawa, Canada) and Adobe Photoshop Version 7.0 (Adobe, San Jose, CA, USA). No adjustments of contrast and brightness were made.

\section{Analysis of volume, numbers of neurons and mean size of neurons in the hippocampus}

Another series of every tenth section through the hippocampus was collected, mounted on glass slides (Superfrost Plus; Menzel, Braunschweig, Germany), dried, defatted with Triton X-100 $(0.025 \%, 20 \mathrm{~min} ;$ Merck), and stained with cresyl violet $(0.01 \%, 15 \mathrm{~min})$. Slides were dehydrated and coverslipped using DePeX (Serva, Heidelberg, Germany). All stereologic procedures were carried out using a stereology workstation, consisting of a modified light microscope (Olympus BX50; Olympus, Tokyo, Japan), Olympus UplanApo objectives (10×, NA $=0.40 ; 100 \times$, oil, NA = 1.35), motorized specimen stage for automatic sampling (Ludl, Hawthorne, NY, USA), electronic microcator (Ludl), CCD color video camera (Hitachi, Tokyo, Japan), PC (CoWoTec, Magdeburg, Germany) with framegrabber board and stereology software (StereoInvestigator, MicroBrightField, Williston, VT, USA) and 17 " television screen monitor (Eizo, Nanao, Japan). Delineations for volume measurement of the entire hippocampus, hippocampal gray matter, hippocanipal area CA $1-2$ and area DG were performed according to descriptions in the literature ${ }^{33}$ at a final magnification of $\times 360$ (i.e., using the $10 \times$ objective). From the obtained data, the mean volumes of the entire hippocampus, hippocampal gray matter, hippocampal white 
matter (defined as volume of the entire hippocampus minus volume occupied by gray matter), as well as of hippocampal area CA 1-2 and DG were calculated. Numbers of pyramidal cells in hippocampal area CAl-2, and granule cells in DG were estimated with the $100 \times$ oil objective and using the Optical Fractionator probe as previously described (cf. Chapters 2 and 4 of this thesis) ${ }^{34,35}$ Details on the stereological quantification of numbers are summarized in Table 1. Briefly, all pyramidal and granule cells whose nucleus top came into focus within unbiased virtual counting spaces distributed in a systematic-random fashion throughout the brain regions of interest were counted. Estimated numbers of neurons were calculated from the numbers of counted neurons and the corresponding sampling probabilities. The mean perikaryal size of pyramidal cells in hippocampal area CA 1-2 and granule cells in DG was estimated with the Nucleator probe ${ }^{36}$ on all cells counted during the Optical Fractionator procedure.

\section{Analysis of the relative amount of nuclear (n) DNA single strand breaks}

Five 24-month-old mice per group were used for the analysis of the relative amount of nuclear (n) DNA single strand breaks (SSB). These mice were sacrificed by cervical dislocation, the brains were immediately dissected out and hemisected in the midsagittal line. Right brain halves were embedded in Tissue-tek ${ }^{\circledast}$ (Sakura Finetek Europe, Zoeterwoude, The Netherlands) and quickly frozen using a solution of aceton/dry ice at $-68^{\circ} \mathrm{C}$. The right brain halves were cut into 10 $\mu \mathrm{m}$ thick sagittal sections including the hippocampus at a cryostat (type HM $500 \mathrm{OM}$; Microm, Walldorf, Germany). The sections were mounted on glass slides (SuperFrost Plus; Menzel) and stored at $-70^{\circ} \mathrm{C}$ until further processing. Left brain halves were dissected into multiple regions and quickly frozen using liquid nitrogen. These left brain halves were stored at $-70^{\circ} \mathrm{C}$ for future investigations. On sections of the right brain halves SSB was investigated by means of In Situ Nick Translation (ISNT). ISNT was carried out using a slight modification of the protocol given by Maehara et al. ${ }^{26}$ as described in Korr et al. ${ }^{29}$ Briefly, sections were incubated for 60 min at $37^{\circ} \mathrm{C}$ with a reaction solution containing $50 \mathrm{mM} \mathrm{Tri-HCl-buffer} \mathrm{(pH} \mathrm{7.5),} 5 \mathrm{mM} \mathrm{MgCl}, 10$ $\mathrm{mM}$ 2-mercaptoethanol, $200 \mathrm{U} / \mathrm{ml}$ of E.coli DNA polymerase I (endonuclease-free; Boehringer, Mannheim, Germany), $10 \mu \mathrm{mol} / \mathrm{ml}$ each of dATP, dGTP, dCTP and dTTP (Boehringer) and $15 \mu \mathrm{l}\left[{ }^{3} \mathrm{H}\right] \mathrm{dTTP} / \mathrm{ml}$ (1.03 MBq/ml; American Radiolabeled Chemicals Inc., St. Louis, MO). Incubation was carried out using special in-situ chambers consisting of small frames made of silicon (height $=1 \mathrm{~mm}$; comparable to customary adapters for In Situ PCR) and coverslips placed onto the slides. The reaction was terminated by washing the slides with $50 \mathrm{mM} \mathrm{Tri-HCl}$ buffer ( $\mathrm{pH} 7.5$ ). Afterwards the sections were Feulgen-stained, dipped into diluted llford $\mathrm{K} 2$ emulsion ( $3: 2$ with distilled water) at $42^{\circ} \mathrm{C}$, exposed 5 days at $4^{\circ} \mathrm{C}$ and developed in Amidol $\left(4 \mathrm{~min}, 18^{\circ} \mathrm{C}\right.$ ). After poststaining with hematoxylin the autoradiographs were covered with a coverslip using Entellan (Merck, Darmstadt, Germany). Evaluation of the autoradiographs was carried out with a light microscope (Olympus BH-2 equipped with a $100 \mathrm{x}$ oil Olympus UplanFl objective, $N A=1.30$ ). For each mouse, one coded autoradiograph showing the hippocampus was selected. On each section 100 consecutive cell profiles of both pyramidal cells in hippocampal area CA1-2 and granule cells in DG were investigated regarding the number of silver grains over the nucleus. Background was corrected by investigating autoradiographs which were prepared in an identical manner as described above but omitting the application of DNA polymerase $I^{29}$ Furthermore, data were corrected for nuclear size. ${ }^{29}$ From the obtained data mean grain numbers per nucleus were calculated for each type of neuron and animal. 


\section{Statistical analysis}

For each group of mice mean and standard error of the mean were calculated for all investigated parameters. The mean body weights of the mice were analyzed with non-linear regression analysis and extra-sum- of squared $F$ tests for nested models focusing on age-related changes in mean body welghts per group, and with two way analysis of variance at selected ages focusing on differences between groups due to diets and genotype. Data of hippocampal volumes, numbers of hippocampal neurons and mean size of hippocampal neurons were analyzed with multivariate analyses focusing on the effects of aging, diets and genotype. When significant differences were found, replicate means were compared with Bonferroni post hoc tests for pairwise comparison. Data of mean relative amounts of $\mathrm{nDNA}$ single strand breaks were analyzed with two-way analysis of variance. Statistical significance was established when p was found to be smaller than 0.05. All calculations were performed using SPSS (Version 12, SPSS Inc, Chicago, USA) and graphs were created using GraphPad Prism (Version 4.00 for Windows, GraphPad Software, San Diego, USA).

Table 1. Details of the stereologic analyses to estimate mumbers of neurans. $P C$, pyramidal cells in hippocampal area CA 1-2; GC, grawule cells: in hippocampal dentate gyrus (DG). Obj., objective used; B and H, base (am2) and height (Am2) of the whbiased virtinal counting spaces; Dx and Dy, distance between the unbiased virnal counting spaces in divections $x(\mu m)$ and $y$, respectively" $t$, measured actwal average section thickness after histological processing fam;

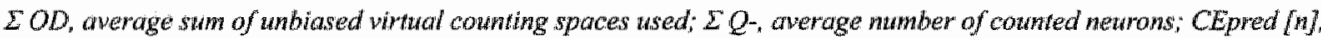

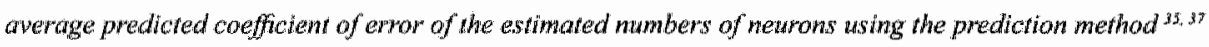

\begin{tabular}{lccccccccc} 
Type of neuron & Obj. & $\mathbf{B}$ & $\mathbf{H}$ & $\mathbf{D}_{\mathrm{x}}$ & $\mathbf{D}_{\mathbf{y}}$ & $\mathbf{t})$ & $\mathbf{\Sigma O D}$ & $\mathbf{\Sigma} \mathbf{C}$ & $\mathbf{C E}_{\text {pred }}[\mathbf{m}]$ \\
\hline PC, area CA 1-2 & $100 \mathrm{x}$ & 900 & 4 & 120 & 120 & 8.1 & 209 & 686 & 0.038 \\
GC, area DG & $100 \mathrm{x}$ & 324 & 4 & 100 & 100 & 7.8 & 172 & 726 & 0.037
\end{tabular}

\section{RESULTS}

\section{Increased S0D1 immunoreactivity throughout the hippocampus of SOD1 transgenic mice}

The intensity of human SOD 1 immunoreactivity was substantially increased in hippocampus of the SOD mice as compared to the wild-type mice (Figure 1). SOD1 immunoreactivity was detectable throughout the hippocampal neuropil and within the hippocampal pyramidal and granule cell layer of the dentate gyrus in the SOD mice (Figure $1 \mathrm{~B}, \mathrm{D}, \mathrm{F}$ and H). No differences in SOD 1 immunoreactivity were observed between the $S O D-C D$ mice and the SOD $-C R$ mice.

\section{Caloric restriction extended lifespan whereas overexpression of human SOD1 did not}

Mean lifespan was $22.9 \pm 4.7$ months for the WT-CD mice and $21.9 \pm 4.6$ months for the SOD-CD mice, while maximum lifespan was 27.3 months for the WT-CD mice and 26.5 months for the SOD-CD mice. There were no differences between the survival curves of the WT-CD mice and the SOD-CD mice (Figure 2A). Determination of the mean and maximum lifespan of the 

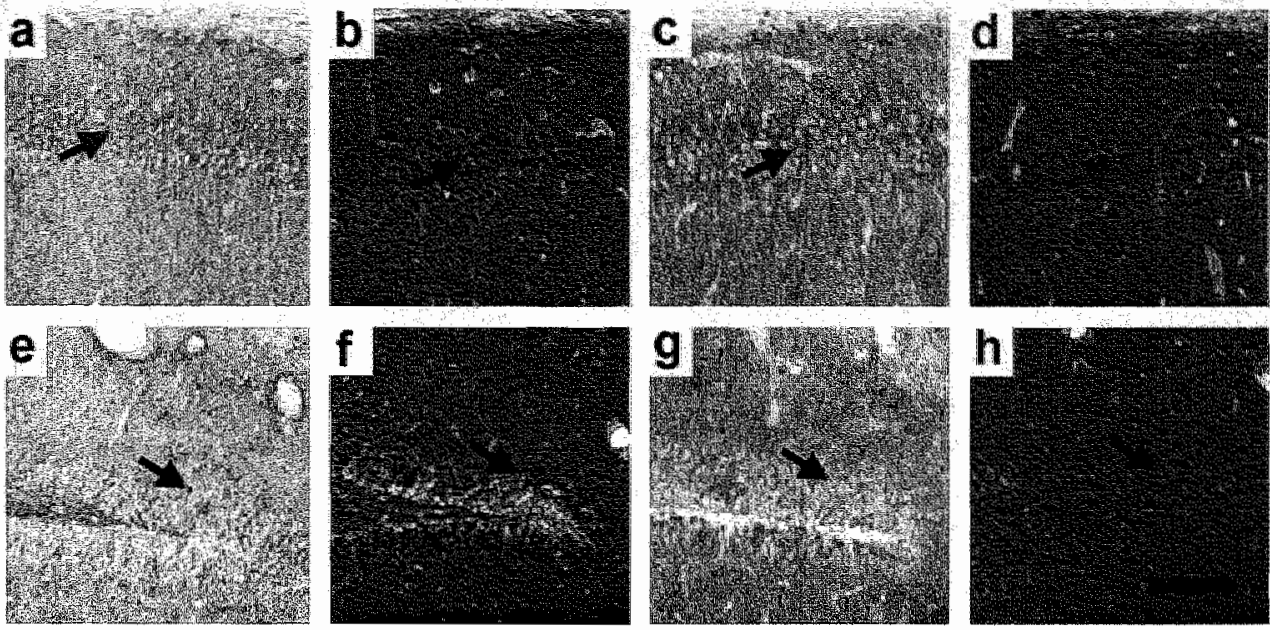

Figure 1. Immunohistochemical detection of human SODI in hippocompal area CA 1-2 (a to d) and dentate gyis

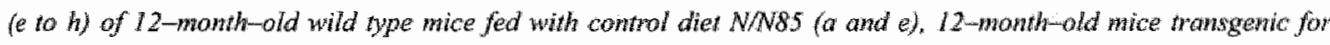
wormal human SODI fed with control diet N/N85 (b and f), 12-month-old wild type fed with calioric-nestrictedtantyoxidam-enriched diet N/RSO (c and g) and 12-monh-old mice manggentic for wormal hwmon SODI fed with caloric-

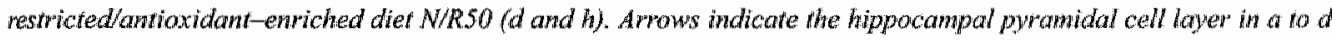
and the grawule cell layer in dentate gyrus in e to h. Note the moreased SODI immunoreactivity throwghow the gutgry

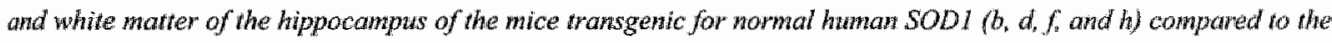
mild type mice $\left(a_{n} c, e_{1}\right.$ and $\left.g\right)$. Scale bar represents 100 um.
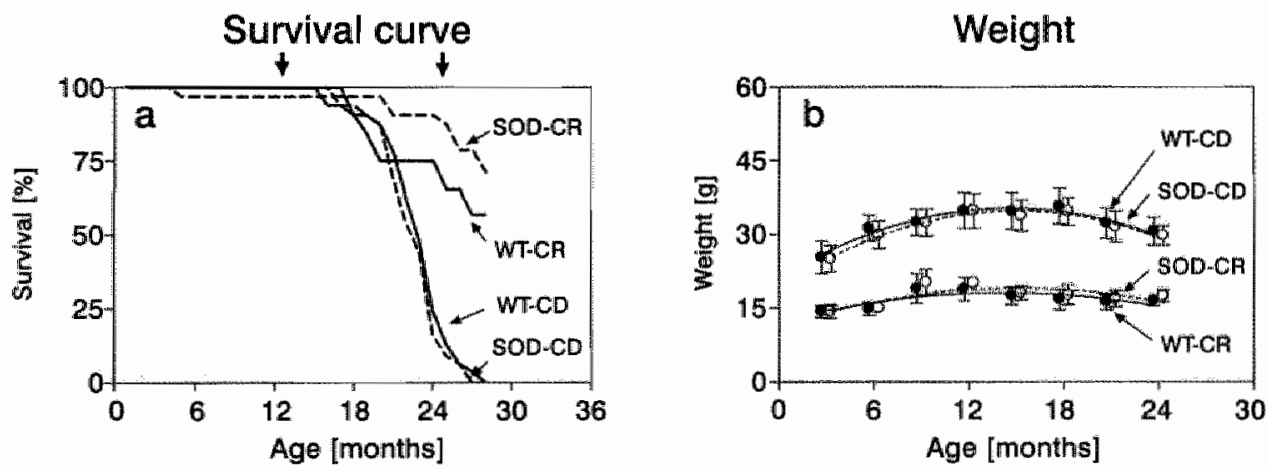

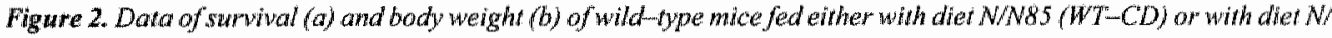
R50 (WT-CR) as well as of SOD transgenic mice fed either with diet N/N85 (SOD-CD) or with diet N/R5O (SOD-CR). Data in (b) are given as mean (dots) and standard errop of the mean (error bars) of the groups at iwterals of three months. Closed dors, mean body weights of whe WT mice; open dots mean body weighs of whe SOD mice. Lines in (b) indicate the weight carres of the WT-CD, SOD-CD, WT-CR and SOD-CR mice acconding ro second owder polynomial regression analysist. Arrows abowe graph a indicate the two age points at which mice were taken from she cohorts for analysis. Data in (a) are frow these mice of the cohorts which died spontaneourly: data in (b) are from all wice. 
WT-CR mice and the SOD-CR mice was not possible due to termination of the project at a mean age of the mice of 28 months. It should be noted that at 28 months of age, $56.8 \%$ of the WT-CR mice and the $78.8 \%$ of the SOD-CR mice were still alive, but $0 \%$ of the WT-CD mice and the SOD CD mice.

\section{Aging and caloric restriction influenced mean body weight}

Multivariate analysis showed that aging significantly affected mean body weight in all groups of mice $(\mathrm{p}<0.001$, Figure 2B). Non-linear regression analysis and extra-sum-of-squared-F-tests for nested models indicated that second order polynomial regression analysis was significantly better at describing the weight curves in all groups of mice than first order polynomial regression analysis ( $p<0.001$ for all groups; see Table 2 for $\mathrm{R}^{2}$ values of first order and second order polynomial regressions analysis).

Table 2. Details of non-linear regression analysis of the weight curves of wildt-1ype mice fed either with the N/N85 diet (WT-CD) or the N/R50 diet (WT-CR) as well as of SOD transigenic mice fed either with the N/N85 diet (SOD-CD) or the N/RSO diet (SOD-CR) as a function of age. 1st, $R 2$ walues of first onder polynomial regression analysis $O=$ $A+B \times X) ;$.nd, $R 2$ values of second order polynomial regression analysis $(Y=A+B \times X+C \times X 2) ; P, p$ values of extra-sum-of-squared $F$ tests for nested models comparing first order polynomial regression analysis of the weight curves with second order polynomial regression analysis (null hypothesis: first order polynomial regression analysis describes the weight curves better than second onder pohnomial regression analysis). P values smaller than 0.05 are shown in bold face.

\begin{tabular}{rrrrr} 
& WT-ND & SOD ND & WT-CR & SOD-CR \\
\hline $1^{\text {st }}$ & 0.249 & 0.279 & 0.050 & 0.080 \\
$2^{\text {nd }}$ & 0.488 & 0.517 & 0.265 & 0.363 \\
$P^{P}$ & $<0.001$ & $<0.001$ & $<0.001$ & $<0.001$
\end{tabular}

Table 3. P valwes of fmo-way analys of wariance of the effects of diet $(D)$ and genotype (G) and their inreraction ( $D^{*} G$ ) on the weigh of the mice at different ages. $P$ values smaller than 0.05 are depicted bold faced.

\begin{tabular}{cccc} 
Age [months] & $\mathrm{D}$ & $\mathrm{G}$ & $\mathrm{D} * \mathrm{G}$ \\
\hline 3 & $<0.001$ & 0.640 & 0.621 \\
6 & $<0.001$ & 0.007 & $<0.001$ \\
9 & $<0.001$ & 0.082 & 0.033 \\
12 & $<0.001$ & 0.043 & 0.022 \\
15 & $<0.001$ & 0.721 & 0.028 \\
18 & $<0.001$ & 0.668 & $<0.001$ \\
21 & $<0.001$ & 0.883 & 0.054 \\
24 & $<0.001$ & 0.963 & 0.010
\end{tabular}


Furthermore, the diet had significant influence on the mean body weight of the mice at all investigated ages ( $p<0.001$ at all time points; Figure 1B; Table 3). In addition, small but statistically significant effects of the genotype of the mice on the body weight of the mice were found at 6 months of age $(p=0.007$; Figure 1 ; Table 3$)$ and 9 months of age $(p=0.043$; Figure $1 B$; Table 3). The interaction between diet and genotype had significant effects on the body weight of the mice at $6,9,12,15,18$, and 21 months of age ( $\mathrm{p}$ values are given in Table 3 ).

\section{Aging and caloric restriction reduced hippocampal volumes}

Mean volumes of the entire hippocampus were significantly reduced as a result of aging $(\mathrm{p}=$ $0.003 ;-10.1 \%$; Figure $3 \mathrm{~A})$ and $\operatorname{diet}(\mathrm{p}=0.003 ;-10.0 \%)$ but not as a result of the genotype of the animals (all $\mathrm{p}$ values of multivariate analysis summarized in Table 4). Aging and diet furthermore influenced the mean volumes of the hippocampal gray matter and the hippocampal white matter irrespective of the genotype of the mice $(p=0.041,-7.3 \%$ for age effect on hippocampal gray matter; $p=0.002,-10.7 \%$, for age effect on hippocampal white matter; $p<0.001,-13.6 \%$ for diet effect on hippocampal grey matter; $\mathrm{p}=0.009,-9.1 \%$, for diet effect on hippocampal white matter; Figure $3 \mathrm{~B}$ and $3 \mathrm{C}$ ). Mean volumes of the hippocampal pyramidal cell layer $\mathrm{CA}$ $1-2$ and hippocampal granule cell layer DG were significantly reduced as a result of diet $(\mathrm{p}=$ $0.007,-14.0 \%$, for diet effects on hippocampal pyramidal cell layer CA $1-2 ; p=0.026,-11.3 \%$, for diet effects on hippocampal granule cell layer DG; Figure 3D and 3E) but not as a result of aging or the genotype of the mice. Post hoc tests showed that the age-related reductions in hippocampal volumes were not specific for a certain group of mice.

\section{Aging, caloric restriction and transgenic overexpression of SOD1 did not affect numbers of hippocampal neurons}

Numbers of hippocampal pyramidal cells in area CA 1-2 (Figure 3F) and granule cells in DG (Figure 3G) showed no alterations as result of aging, diet or genotype of the mice (p values are given in Table 4).

\section{Aging and caloric restriction influenced the size of hippocampal neurons}

The size of the pyramidal cells in area CA 1-2 was reduced as a result of diet $(p=0.039$; $-10.6 \%$; Figure $3 \mathrm{H}$ ), irrespective of age or the genotype of the mice. Post hoc tests showed that the diet-related reduction in size of hippocampal pyramidal cells in area CA $1-2$ was not specific for any group of mice. Age affected the size of hippocampal granule cells in area DG ( $p$ $<0.001 ;-16.7 \%$; Figure 3I) whereas diet or genotype did not. Post hoc tests showed that aging specifically resulted in reduced size of hippocampal granule cells in area DG in WT-CD mice and SOD-CD mice but not in WT-CR mice and SOD-CR mice. 

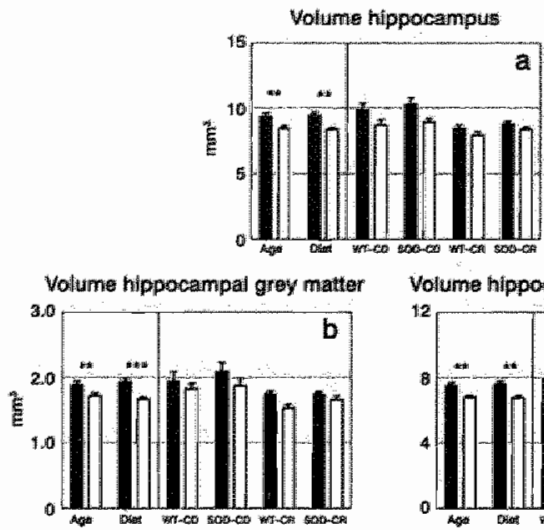

Volume inippocampat whine matler

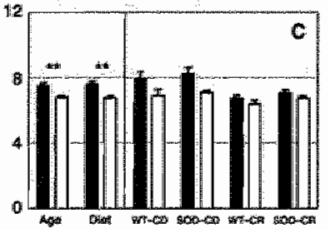

Wolumo pyramidial cill layer CA1-2

Volume granulle ceill layer DG
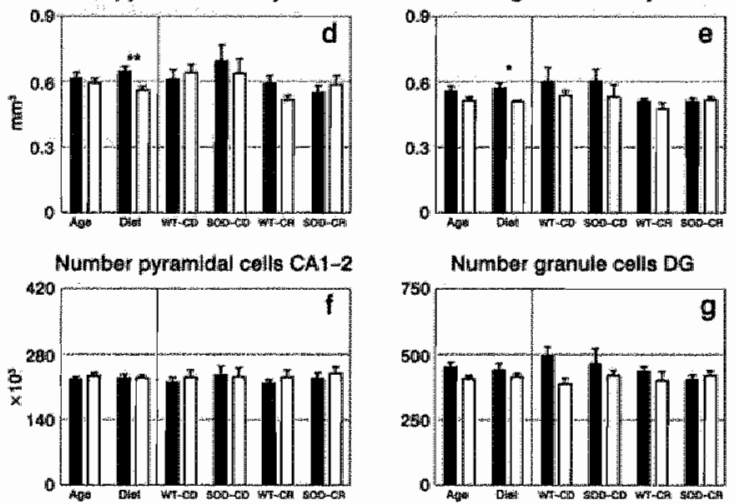

Size pyramidall cents C.A.1-2

Sizo granule cells DG
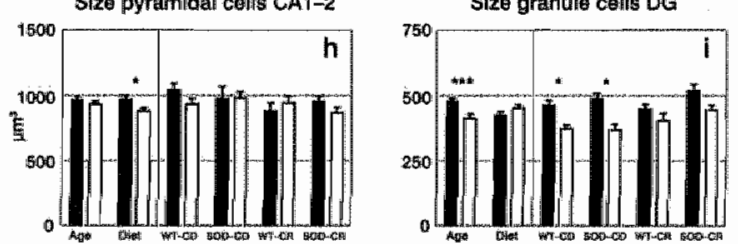

Figure 3. Wolume of the entire hippocampus (a), hippocampal gray matter (b), hippocampal white matter (c), hippocampal pyramidal cell layer area CA $1-2$ (d) and hippacampal granule cell layer dentare gyrus (DG) (e), number of pyramidal cells in anea $C A 1-2(1)$ and granule cells in area $D G(g)$ as well as size of the pyransidal cells in area $C A$ 1-2 (h) and gramule cells in area DG (i) of wild type mice fed either with diet N/N85 (WT-CD) or with diet N/R50 (WT-CR) as well as of SOD transgentic mice fed either with diet N/N85 (SOD-CD) or with diet N/R5O (SOD-CR). All graphs ane diwided into two parts by a vertical line for illustration purposes. Lefi parts of the graphs show mean and standard error of mean (SEMl of all investigated mice pooled for either age or diet. In case of Age closed bars represent 12-month-old mice and open bars 24-month-old wice; in case of Diet closed bars represent diet N/N85 and open bars diet N/R 50. Right parts of the graphs show mean and SEM of the individucal groups of mice. Here closed bars represent 12-month-old mice and open bars 24-months old mice. Data were analyzed with multivariate analysis, and differences were considtered significant when $p<0.05$. When significant differences were found in multivariate analysis. Bonferromi post-lests were performed to compare replicate means of 12-month-old mice wersws 24-month-old mice per individual group. P values are provided as * $(p<0.05) * *(p<0.01)$ or *** $(p<0.001)$ in the left parts of the graphs for significant differences in multivariate analysis and in the right parts of the graphs for significant differences in Bonferroni post-tests; all p values for multivariase analysis ane given in Table 4. 


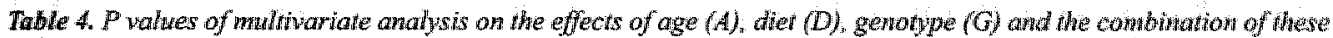

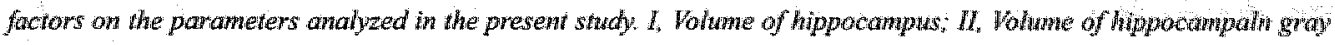

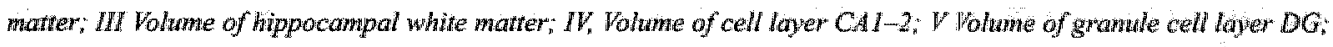
WI, number of pyramidal cells in area CA 1-2; VI, Number of gramule cells in DG; WII, Mean size of pyramidal Gells

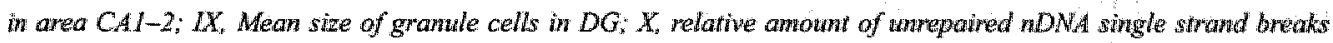

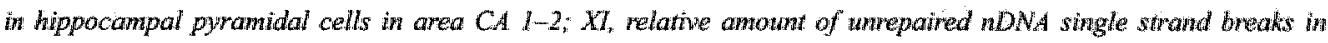
hippocampal granule cells in DG. P values smaller than 0.05 are depicted bold faced.

\begin{tabular}{rrrrrrrr} 
& \multicolumn{1}{c}{$\mathrm{A}$} & \multicolumn{1}{c}{$\mathrm{D}$} & $\mathrm{G}$ & $\mathrm{A} * \mathrm{D}$ & $\mathrm{A} * \mathrm{G}$ & $\mathrm{D} * \mathrm{G}$ & $\mathrm{A}^{*} \mathrm{D} \mathrm{G}^{*}$ \\
\hline I & 0.003 & 0.003 & 0.088 & 0.434 & 0.673 & 0.633 & 0.828 \\
II & 0.041 & $<0.001$ & 0.125 & 0.826 & 0.89 & 0.692 & 0.713 \\
III & 0.002 & 0.009 & 0.103 & 0.316 & 0.585 & 0.493 & 0.715 \\
IV & 0.779 & 0.007 & 0.193 & 0.554 & 0.697 & 0.524 & 0.300 \\
V & 0.174 & 0.026 & 0.518 & 0.534 & 0.751 & 0.684 & 0.907 \\
VI & 0.539 & 0.925 & 0.264 & 0.948 & 0.583 & 0.863 & 0.985 \\
VII & 0.082 & 0.274 & 0.808 & 0.289 & 0.245 & 0.913 & 0.649 \\
VIII & 0.063 & 0.039 & 0.362 & 0.947 & 0.455 & 0.569 & 0.181 \\
IX & $<0.001$ & 0.107 & 0.061 & 0.339 & 0.37 & 0.256 & 0.604 \\
X & & 0.005 & 0.771 & & & 0.3 & \\
XI & & $<0.001$ & 0.835 & & & 0.453 &
\end{tabular}

\section{Caloric restriction - but not overexpression of human SOD1 - reduced the relative amount of unrepaired nDNA single strand breaks}

The relative amount of unrepaired nDNA single strand breaks in hippocampal pyramidal cells in area CA $1-2$ was significantly reduced as a result of diet $(\mathrm{p}=0.005 ;-63.0 \%$; Figure $4 \mathrm{~A})$ but not as a result of genotype. Diet furthermore reduced the relative amount of unrepaired nDNA single strand breaks in hippocampal granule cells in area $\mathrm{DG}(p<0.001 ;-61.2 \% ;$ Figure $4 \mathrm{~B})$ while genotype did not (all $p$ values are given in Table 4).

\section{DISCUSSION}

In the present study we have shown that feeding mice with a certain diet restricted in calories and enriched in antioxidants (CR) resulted in substantial weight loss and extension of mean and maximum life span. We have furthermore shown that human SOD1 was expressed in the hippocampus of mice transgenic for human SOD1; an important prerequisite for testing effects of SOD1 on hippocampal neurons. The present study is the first high-precision stereologic study focusing on the effects of aging, caloric restriction (with a concomitant enrichment of antioxidants) and overexpression of SODI on the volumes of hippocampal regions, numbers of hippocampal neurons and their size in mice. We have shown that aging was associated with a reduced size of hippocampal granule cells and that caloric restriction attenuated age-related shrinkage of granule cells in mice. We have furthermore shown that CR was associated with 

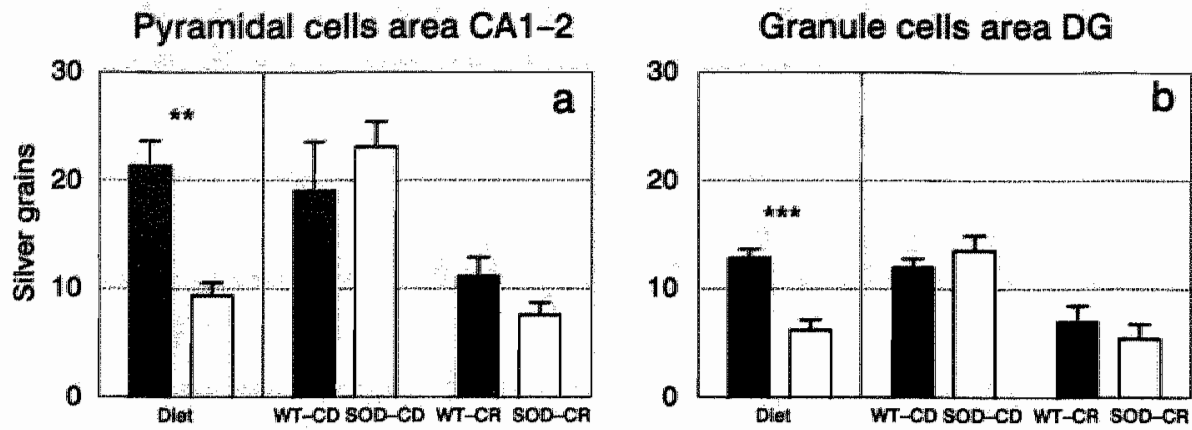

Figure 4. Relative amount of unrepaired nDNA single strand breaks (expressed as silver grains found in the analysis of autoradiographs) in hippocampial pyramidal cells in area CA 1-2 (a) and hippocampal gramule cells in area DG (b) of wild-iype mice fed either with diet N/N85 (WT-CD) or with diet N/R50 (WT-CR) as well as of SOD transgenic mice fed either with diet N/N85 (SOD-CD) or with diet N/R50 (SOD-CR) at 24 months of age. All graphs are divided into two parts by a vertical line for illustration purposes. Left parts of the graphs show mean and standard error of mean (SEM) of all investigated mice pooled for diet, right parts of the graphs show mean and SEM of the individual groups of mice Closed bars represent diet N/N85 and open bars diet N/R50. Data were analyzed with multivariate analysis, and differences were considered significant whem $p<0.05$. When significant differences were found in multivariate analysis, Bonferroni post-tests were performed to compare replicate means of wild-type mice versus SOD mice. $P$ values are provided as * $(p<0.05), *(p<0.01)$ or *** $(p<0.001)$ in the left parts of the graphs for significant differences in multivariate analysis and in the right parts of the graphs for significant differences in Bonferromi post-tests; all pvalues for multivariate analysis an given in Table 4.

hippocampal volume loss without concomitant loss of neurons. Moreover, our results show that CR substantially reduced the relative amount of unrepaired nDNA single strand breaks in hippocampal neurons of 24-month-old mice in vivo, whereas overexpression of human SOD1 did not.

\section{Caloric restriction but not overexpression of S0D1 increased mean and maximum lifespan of mice}

The finding that transgenic overexpression of SODI did not change mean or maximum lifespan of mice fed with control diet N/N85 implies that the level of SOD1 did not control lifespan in mice fed with this diet. Although exact data on mean and maximum life span of the WT-CR and the SOD-CR mice could not be established in the present study, the finding that $56.8 \%$ of the WT-CR mice and $78.8 \%$ of the SOD-CR mice were still alive at an age where all WT-CD mice and SOD-CD mice had died, indicates that mean and maximum life span were significantly increased as a result of CR. From an age of 18 months on, survival of the SOD-CR mice was always higher (at least up to 28 months of age) than survival of the WT-CR mice, suggesting that the combination of transgenic overexpression of SOD1 with CR had additive effects on survival of mice. It will be interesting to readdress this issue in future studies to establish mean and maximum life span of WT-CR mice and SOD-CR mice. 


\section{Age- and diet- related changes in body weight of mice}

The mean body weight of the mice subjected to $C R$ was significantly reduced during the entire life span (on average approximately $53 \%$ ) as compared with the mice fed with the control diet. This finding is fully in line with several reports in the literature. ${ }^{28}$ In contrast to this diet effect, we observed that overexpression of human SOD1 did not substantially affect the body weight of mice. Regression analysis furthermore showed that the weight curves of all groups of mice were best described with a second order polynomial regression curve, indicating that normal age-related regulation of body weight was not affected by $\mathrm{CR}$ or overexpression of human SOD1.

\section{Aging and caloric restriction reduced hippocampal volumes in mice}

The volumes of the entire hippocampus, hippocampal gray matter and hippocampal white matter of the investigated mice were significantly reduced as a result of aging. This finding, however, was only observed when a large number of animals was analyzed $(n=48$ in this study), and was not specifically observed in a certain individual group of mice. These results are in line with several studies describing age-related hippocampal volume loss in large cohorts of humans, ${ }^{38,39}$ although the authors of another study did not observe significant age-related hippocampal volume loss in humans. ${ }^{40}$

Our findings are the first showing that CR reduced the volume of the mouse hippocampus by approximately $10 \%$ (with $13.5 \%$ reduction in hippocampal gray matter and $9.1 \%$ reduction in hippocampal white matter). These findings are in line with a recent report of Markowska and colleagues describing that the volume of the putamen in rhesus monkeys under calloric restriction was approximately $16 \%$ smaller than in control monkeys. ${ }^{41}$ Although further research on the mechanisms underlying CR-induced volume loss is highly warranted, one could speculate that CR-induced stress and metabolic changes may necessitate strict control of the size of organs and brain regions. Although we did not measure brain weight and compared brain weight with body weight, it is noteworthy that the hippocampal volume of the WT-CR mice and SOD-CR mice was reduced by only $10 \%$ despite a $47 \%$ reduction in body weight, suggesting that brain weight and brain size are relatively conserved under $\mathrm{CR}$ conditions in mice.

\section{Aging, caloric restriction and overexpression of SOD1 did not result in hippocampal neuron loss in mice}

The results of the present study showed that overexpression of human SOD1 in mice did not alter numbers of hippocampal pyramidal cells in area CA1-2 and granule cells in DG. Moreover, our findings showed that aging did not change numbers of hippocampal pyramidal and granule cells, which is in line with several other studies in the literature on both rodents ${ }^{42,43}$ and human $s^{44,45}$. This finding furthermore confirmed that mechanisms responsible for age-related dysfunction of hippocampal neurons involve alterations at the subcellular level rather than mere loss of neurons. 
Our finding that CR did not alter numbers of pyramidal cells in hippocampal area CAI-2 and granule cells in the dentate gyrus are - to the best of our knowledge - the first indicating a preserved number of hippocampal neurons in mice subjected to CR. Previous studies have assessed the effects of caloric restriction on the retina in the rat. In this respect, Obin and colleagues observed that caloric restriction increased light-dependent photoreceptor cell loss during aging in rats, as measured by photoreceptor cell density analysis. ${ }^{46}$ On the other hand, Neufeld and Gachie recently showed that caloric restriction attenuated normal age-dependent loss of retinal ganglion cells as measured by density analyses. ${ }^{47}$ Because normal aging in the retina seems to be connected to loss of neurons while normal aging of the hippocampus is not, it is difficult to compare potential mechanisms underlying age-related and diet-related changes in numbers of neurons in the aging retina with those in the aging hippocampus. Moreover, the study by Obin and colleagues ${ }^{46}$ as well as the study by Neufeld and Gachie ${ }^{47}$ were carried out

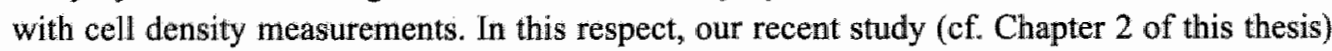
indicated that quantitative analyses of cell densities may not be indicative of alterations in cell densities. ${ }^{48}$ Analyses of neuronal densities were furthermore shown to result into incorrect data collection leading to false interpretation and conclusions, especially when the volume of the region of analysis was altered. ${ }^{4}$ The use of modern, design-based stereologic techniques (as used in the present study) allows however high precision quantification of numbers of neurons free of bias. ${ }^{49}$ Thus, the results of the studies by Obin and colleagues ${ }^{46}$ and Neufeld and Gachie ${ }^{47}$ may have been subject to bias, and it remains unclear whether caloric restriction attenuates or induces potential age-related loss of photoreceptor and ganglion cells in the retina.

The CR-induced volume loss observed in the present study was, most importantly, thus not accompanied by a loss of hippocampal neurons. Notably, CR-induced volume loss was largest in the hippocampal area CA1-2, and the pyramidal cells in CA1-2 showed a reduction in size as a result of CR. Therefore, our data argue that $C R$-induced volume loss of hippocampal area CA1-2 depended on reduced size of the pyramidal cells in this area. One could speculate that the reduced neuronal size of pyramidal cells in $C R$ mice potentially reflected reduced cellular metabolism.

\section{Age-related reduction in size of hippocampal granule cells in mice was attenuated by caloric restriction}

In the present study we observed an age-related reduction (about 16\%) in the size of hippocampal granule cells during aging. The dendritic tree of hippocampal granule cells is located in the hippocampal molecular layer where afferent axons from the entorhinal cortex teminate. Interestingly, the hippocampal molecular layer has been described as a hot spot in the aging brain $^{5}$ as it is preferentially affected by several age-related alterations such as reduced expression of the presynaptic marker synaptophysin, ${ }^{10}$ reduced expression of the NR-1 subunit of AMPA and NMDA receptors, ${ }^{30}$ reduced expression of Arc $-1^{51}$ (an immediate early gene which has been correlated with spike activity) and a reduced number of axospinous and axosomal synapses. ${ }^{52,53}$ One might therefore speculate that the observed age-related reduction in size of the granule cells reflects or is associated with some of these age-related alterations. Interestingly, the reduced size of the hippocampal granule cells during aging was only observed in CD mice 
but not in CR mice, suggesting that CR attenuated the normal age-related reduction in mean size of hippocampal granule cells in mice.

\section{Caloric restriction reduced nDNA damage in hippocampal pyramidal and granule cells in mice}

The relative amount of unrepaired nDNA single strand breaks in hippocampal pyramidal cells and in hippocampal granule cells was approximately $60 \%$ lower in the CR mice than in the CD mice. Previous studies have shown that CR reduced age-related increase of $8-O H D G$ levells $^{22}$ and age-related mitochondrial damage in brain. ${ }^{5455}$ Our findings are - to the best of our knowledge - the first showing that CR reduced the amount of unrepaired nDNA damage in hippocampal neurons. Attenuation of age-related accumalation of nDNA damage in neurons has been proposed to be achieved through several strategies: ${ }_{*}^{3}$ diminishing age-related increase in the amount of $\mathrm{nDNA}$ damage by prevention of increased free radical production etc, enhancing the capacity to repair nDNA damage, or - when damage is beyond a certain threshold - by specifically eliminating neurons with high amount of unrepaired nDNA damage (cf Chapter 3 and 4 of this thesis). In this respect, the preserved neuronal numbers in CR mice in the present study indicate that caloric restriction did not reduce nDNA damage in hippocampal neurons by eliminating neurons with high amounts of nDNA damage. Caloric restriction has been reported to reduce production of free radicals ${ }^{1}$ and to increase the activities of $\mathrm{nDNA}$ repair enzymes ${ }^{56}$ as well as to normalize the age-related decline in the rate of nDNA repair. ${ }^{57}$ On this basis one can argue that $C R$ reduced nDNA damage in hippocampal neurons by attenuation of oxidative stress and by enhancement of nDNA repair. Future studies will be employed to test these hypotheses.

\section{Methodologic consideration: volume loss of a certain brain region does not necessarily indicate neuron loss in this brain region}

Volume measurements of the present study indicated significant age-related and diet-related reductions in hippocampal volume. For instance, CR resulted in a $10 \%$ volume reduction of the hippocampus with an approximately $17 \%$ volume reduction in hippocampal cell layers. Importantly, the observed age-related and diet-rellated volume reductions were not associated with loss of neurons. Both aging and CR resulted however in significant cell-type-specific reductions in the mean perikaryal size of neurons. Thus, the observed loss of hippocampal volumes reflected reduced mean neuronal size and not a loss of neurons. This is a relevant observation as hippocampal volume loss in imaging studies is often interpreted as a sign of neurodegeneration and/or neuron loss ${ }^{58,99}$ For example, Driscoll and colleagues recently reported that impaired performance in hippocampal-dependent tasks of humans was correlated with hippocampal volume loss. ${ }^{59}$ Together with their observation of decreased hippocampal levels of $N$-acetyl-aspartate and creatine (i.e. neuronal metabolites detectable with non-invasive proton magnetic resonance spectroscopy) these authors interpreted their findings as implying neuronal loss and/or decreased neuronal density in the hippocampus during aging. ${ }^{59}$ Our findings show that this interpretation might be incorrect and advocate caution when interpreting results of imaging studies towards cellular processes. 
In summary, long term CR extended mean and most probably also maximum lifespan of mice, resulted in hippocanpal volume loss and abolished age-related reductions in the size of hippocampal granule cells, while overexpression of normal SOD1 did not affect any inwestigated parameter. Most importantly, $C R$ resulted in reduced levels of unrepaired nDNA damage in hippocampal neurons in aged mice. CR was thus a more effective strategy to attenuate age-related alterations in hippocampal neurons of the mouse brain than transgenic upregulation of SOD1.

\section{REFERENCES}

11. Barja G: Free radicals and aging. Trends Neurosei 2004, 27:595 -600

2. Johnson FB, Sinclair DA, Guarente L: Molecular biology of aging. Cell 1999, 96:291-302.

3. Rutten BP, Korr H, Steinbusch HW, Schmitz C: The aging brain: less meurons could be better. Mech Ageing Dev 2003, 124:349-355

4. Lu T, Pan Y, Kao SY, Li C, Kohane I, Chan J, Yankner BA: Gene regulation and DNA damage in the ageing buman brain. Nature 2004, 429:883-891

5. Hof PR, Morrison JH: The aging brain: morphomolecular senescence of cortical circuits. Trends Neurosci 2004, 27:607-613

6. Mandavilli BS, Rao KS: Neurons in the cerebral cortex are most susceptible to DNA-damage in aging rat brain. Biochem Mol Biol Int 1996, 40:507-5:14

7. Mecocei P, MacGarvey U, Kaufman AE, Koontz D, Shoffiner JM, Wallace DC, Beal MF: Oxidative damage to mitochondrial DNA shows marked age-dependent increases in human brain. Ann Neurol 1993, 34:609-616

8. Corral-Debrinski M, Horton T, Lott MT, Shoffner JM, Beal MF, Wallace DC: Mitochondrial DNA deletions in human brain: regional variability and increase with advanced age. Nat Genet 1992, 2:324-329

9. Gilman CP, Chan SL, Guo Z, Zhu X, Greig N, Mattson MP: p53 is present in synapses where it mediates mitochondrial dysfunction and synaptic degeneration in response to DNA damage, and oxidative and excitotoxic insults. Neuromolecular Med 2003, 3:159-172

10. Smith TD, Adams MM, Gallagher $\mathrm{M}_{n}$ Morrison $\mathrm{JH}_{s}$ Rapp I'R: Circuit-specific alterations in hippocampal synaptophysin immunoreactivity predict spatial learning impairment in aged rats. J Neurosci 2000, 20:658765.93

11. Schmitz C, Materne S, Korr H: Cell-type-Specific Differences in Age-related Changes of DNA. Repair in the Mouse Brain - Molecular Basis for a New Approach to Understand the Selective Neuronal Vulnerability in Alzheimer's Disease. J Alzheimers Dis 1999, 1:387-407

12. Schrmitz $\mathrm{C}$, Axmacher B, Zunker U, Korr H: Age related changes of DNA repair and mitochondrial DNA synthesis in the mouse brain. Acta Neuropathol (Berl) 1999, 97:71-81.

13. Hasty P, Campisi J, Hoeijmakers J, van Steeg H, Vijg J: Aging and genome maintenance: lessons from the mouse? Science 2003, 299:1355 1359

14. Busuttil RA, Rubio M, Dolle ME, Campisi J, Vijg J: Oxygen accelerates the accurtulation of mutations during the senescence and immortalization of murine cells in culture. Aging Cell 2003, 2:287-294

15. Fang $\mathrm{YZ}$, Yang $\mathrm{S}$, Wu G: Free radicals, antioxidants, and nutrition. Nutrition 2002, 18:872-879

16. Harman D: Aging: overview. Ann N Y Acad Sei 2001, 928:1-21.

17. Cardozo-Pelaez F, Song S, Parthasarathy A, Epstein CJ, Sanchez-Ramos J: Attenuation of age-dependent oxidative damage to DNA and protein in brainstem of Tg Cu/Zn SOD mice. Neurobiol Aging 1998, 19:311316

18. Maier CM, Chan PH: Role of superoxide dismutases in oxidative damage and neurodegenerative disorders. Neuroscientist 2002, 8:323-334

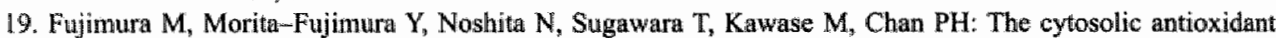
copper/zincmsuperoxide dismutase prevents the early release of mitochondrial cytochrome $\mathrm{c}$ in ischemic brain after transient focal cerebral ischemia in mice. J Neurosci 2000, 20:2817-2824

20. Nayak MS, Kita M, Marmor MF: Protection of rabbit retina from ischemic injury by superoxide dismutase and catalase. Invest Ophthalmol Vis Sci 1993, 34t:2018-2022

21. Chan $\mathrm{PH}_{n}$ Epstein CJ, Li Y, Huang TT, Carlson E, Kinouchi H, Yang G, Kamil H, Mikawa S, Kondo T, et al.: Transgenic mice and knockout mutants in the study of oxidative stress in brain injury. I Neurotrauma 1995, $12: 815-824$

22. Sohal RS, Agarwal S, Candas M, Forster MJ, Lal H: Effect of age and caloric restriction on DNA oxidative damage in different tissues of C57BL/6 mice. Mech Ageing Dev 1994, 76:215-224

23. Sohal RS, Weindruch R: Oxidative stress, caloric restriction, and aging. Science 1996, 273:59-63 


\section{Chapter $\mathrm{b}$}

24. Prolla TA, Mattson MP: Molecular mechanisms of brain aging and neurodegenerative disorders: lessons from dietary restriction. Trends Neurosei 2001, 24:S21-31

25. Mattson MP, Chan SL, Duan W: Modification of brain aging and neurodlegenerative disorders by genes, diet, and behavior. Physiol Rev 2002, 82:637-672

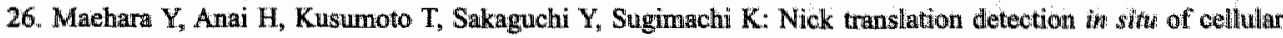
DNA strand break induced by radiation. Am I Pathol 1989, 134:7-10

27. Epstein CJ, Avraham KB, Lovett M, Smith S, Elroy-Stein O, Rotman G, Bry C, Groner Y: Transgenic mice with increased Cu/Zn-superoxide dismutase activity: animal model of dosage effects in Down syndrome. Proc Natl Acad Sci U S A 1987, 84:8044-8048

28. Weindruch $\mathrm{R}$, Walford $\mathrm{RL}$, Fligiel $\mathrm{S}$, Guthrie $\mathrm{D}$. The retardation of aging in mice by dietary restriction: longevity, cancer, immunity and lifetime energy intake. J Nutr 1986, 116:641-654

29. Korr $H$, Thorsten Rohde $H$, Benders J, Dafotakis $M_{,}$, Grolms N, Schmitz C: Neuron loss during early adulthood following prenatal llow-dose X-irradiation in the mouse brain. Int J Radiat Biol 2001, 77:567-580

30. Asayama K, Burr IM: Joint purification of mangano and cuprozinc superoxide dismutases from a single source-a simplified method. Anal Biochem 1984, 136:336-339

31. Rutten BP, Wirths O, Van de Berg WD, Lichtenthaler SF, Vehoff J, Steinbusch HW, Kor $\mathrm{H}_{*}$ Beyreuther $\mathrm{K}$, Multhaup G, Bayer TA, Schmitz C: No alterations of hippocampal neuronal number and synaptic bouton number in a transgenic mouse model expressing the beta-cleaved $C$-terminal APP fragment. Neurobiol Dis $2003,12: 110-120$

32. Shibata N, Asayama K, Hirano A, Kobayashi M: Immunohistochernical study on superoxide dismutases in spinal cords from autopsied patients with amyotrophic lateral sclerosis. Dev Neurosci $\rrbracket 996,18: 492-498$

33. Franklin KBJ, Paxinos, G.: The mouse brain in stereotaxic coordinates. San Diego, Academic Press, 1996

34. West MJ: New stereological methods for counting neurons. Neurobiol Aging 1993, 14:275-285

35. Schmitz C: Variation of fractionator estimates and its prediction. Anat Embryol (Berl) 1998, 198:371-397

36. Gundersen HJ, Bagger P, Bendtsen TF, Evans SM, Korbo L, Marcussen N, Moller A, Nielsen K, Nyengaard JR, Pakkenberg $B$, et al.: The new stereological toolls: disector, fractionator, nucleator and point sampled intercepts and their use in pathological research and diagnosis. Apmis 1988, 96:857-881

37. Schmitz C, Hof PR: Recommendations for straightforward and rigorous methods of counting neurons based on a computer simulation approach. J Chem Neuroanat 2000, 20:93-114

38. Jernigan TL, Archibald SL, Fennema-Notestine C, Gannst AC, Stout JC, Bonner J, Hesselink JR: Effects of age on tissues and regions of the cerebrum and cerebellum. Neurobiol Aging 2001, 22:581-594

39. Raz N, Lindenberger U, Rodrigue KM, Kennedy KM, Head D, Williamson A, Dahle C, Gerstorf D, Acker JD: Regional Brain Changes in Aging Healthy Adults: Generall Trends, Individual Differences and Modifiers. Cereb Cortex 2005

40. Sullivan EV, Marsh L, Pfefferbaum A: Preservation of hippocampal volume throughout adulthood in healthy men and women. Neurobiol Aging 2005, 26:1093-1098

41. Markowska AL: Life-long diet restriction failed to retard cognitive aging in Fischer-344 rats. Neurobiol Aging 1999, 20:177-189

42. Rasmussen T, Schliemann $T$, Sorensen $\mathrm{JC}_{\text {, }}$ Zinmer $J$, West MJ: Memory impaired aged rats: no loss of principal hippocampal and subicular neurons. Neurobiol Aging 1996, 17:143-147.

43. Rapp $P R$, Gallagher $M$ : Preserved neuron number in the hippocampus of aged rats with spatial leaming deficits. Proc Natl Acad Sci U S A 1996, 93:9926-9930

44. West MJ, Kawas $\mathrm{CH}$, Martin LJ, Troncoso JC: The CAl region of the human hippocampus is a hot spot in Alzheimer's disease. Ann N Y Acad Sci 2000, 908:255-259

45. West MJ, Kawas CH, Stewart WF, Rudow GL, Troncoso JC: Hippocampal neurons in pre-clinical Alzheimer's disease. Neurobiol Aging 2004, 25:1205-1212

46. Obin $\mathrm{M}_{n}$ Halbleib $\mathrm{M}$, Lipman R, Carroll $\mathrm{K}$, Taylor A, Bronson $\mathbb{R}$ : Calorie restriction increases light-dependent photoreceptor cell loss in the neural retina of fischer 344 rats. Neurobiol Aging 2000, 21:639-645

47. Neufeld $\mathrm{AH}_{3}$ Gachie EN: The inherent, age-dependent loss of retinal ganglion cells is related to the lifespan of the species. Neurobiol Aging 2003, 24:167-172

48. Schmitz C, Born M, Dolezel P, Rutten BP, de Saint-Georges L, Hof PR, Korr H: Prenatal protracted irradiation at wery low dose rate induces severe neuronal loss in rat hippocampus and cerebellum. Neuroscience 2005 , $130: 935-948$

49. Schmitz C, Hof PR: Design-based stereology in neuroscience. Neuroscience 2005, 130:813-831

50. Gazzaley AH, Siegel SJ, Kordower JH, Mufson EJ, Morrison JH: Circuit-specific alterations of N-methylD-aspartate receptor subunit 1 in the dentate gyrus of aged monkeys. Proc Natl Acad Sci U S A 1996, 93:31213125

51. Small SA, Chawla MK, Buonocore M, Rapp PR, Barnes CA: Imaging correlates of brain function in monkeys and rats isolates a hippocampal subregion differentially vulnerable to aging. Proc Natl Acad Sci U S A 2004, 101:7181-7186 


\section{Caloric restriction and owerexpression of sod}

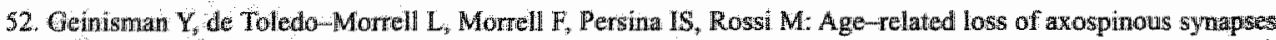
formed by two afferent gystems in the rat dentate gyriss as revenled by the unbiasied stereological dissector technigue Hippocampus 1992, 2:437-444

53. Ceinismar Y. Loss of axosomatic synapses in the dentate gyrus of aged rats. Bram Res $1979,168: 485-492$

54. Melow $\mathrm{S}$, Hinerfeld D, Esposito L, Wallace DC: Multi-organ characterization of mitochondmal genonit rearrangements in ad libium and caloric restricted mice show striking somatic mitochondrial DNA rearrargements with age. Wucleic Acids Res $1997,25974-982$

55. Cassano P. Lezza AM, Leeuwenburgh C, Cantatore P, Cadaleta MN: Measurement of the 4,834-bp mitochondrial DNA deletion level in aging rat liver and brain subjected or not to caloric restriction diet. Ann N Acad Sci 2004, 1019:269-273

56. Stuart JA, Kanahall B, Hogue BA, Souza-Pinto NC, Bohr VA: Mitochondrial and nuclear DNA base excision repair are affected differently by caloric restriction. Faseb J 2004, 18:595-597

57. Rao KS: Dietary calorie restriction, DNA-repair and brain aging. Mol Cell Biochem 2003, 253:313-318

\$8. Schuff N, Amend DL, Knowiton R, Norman D, Fein $\mathrm{G}_{3}$, Weiner MW: Age-related metabolite changes and volume loss in the hippocampus by magnetic resonance spectroscopy and imaging Neurobiol Aging 1999, $20: 279-285$

59. Driscoll 1, Harnilion DA, Petropoulos $H$, Yeo RA, Brooks WM, Baumgartner RN, Sutherland RJ: The aging hippocampus: cognitive, biochemical and structural findings. Cereb Cortex 2003, 13n 1344-1351 
Ingredient

Raw protein

Raw fat

Raw fiber

Raw ashe

Moisture

Dissaccharide

Polysaccharide

Usable energy Lysine

Methionine Cystine

Threonine

Tryptophan

Arginine

Histidine

Isoleutcine

Lewcine

Pherylalanine

Valine

Alanine

Asparagine

Glutamine

Glycine

Proline

Serine

Tyrosine

Vitamin A

Vitamin D3

Vitamin $\mathrm{E}$

Vitamin $\mathrm{K} 3$

Vitamin B

Vitamin $B 2$

Vitamin B6

Vitamin B12

Nicotinic acid

Panothenic acid

Follic acid

Biotin

Choline chloride

p-aminobenzoic acid

Inositol

Vitamin C

Calcium

Phosphorus

Magnesium

Sodium

Potassium

Sulfur

Chloride

Iron

Manganese Zinc

Copper lodide

Molybdenium Fluor

Selenium

Cobalt

Caproic acid

Lauric Acid

Myristine

Pentadecane

Palmitinic acid

Palmitoline

Margarine

Stearic acid

Oil acid

Linolec acid

Linolanic acid

Arachine
NN8S

$173,194.0$

$135,672.8$

$55,601.9$

$55,215.5$

$59,851.5$

$271,002.0$

$240,208.0$

$4,024.1$

$17,447.2$

$11,176.0$

$3,140.0$

$7,142.0$

$1,980.4$

$9,785.6$

$5,237.6$

$7,212.0$

$14,566.0$

$7,116.8$

$3,267.6$

$2,414.4$

$3,545.6$

$23,428.8$

$3,106.4$

$12,580.4$

$3,2.15 .2$

$9,228.0$

$17,250.0$

575.0

230.5

11.5

23.0

23.3

17.3

0.05

57.7

57.6

11.5

0.23

$1,161.5$

115.0

126.0

23.0

$9,388.2$

$7,361.0$

709.4

$2,476.0$

$7,245.9$

$2,040.0$

$3,640.8$

179.1

101.0

69.6

5.6

0.46

0.20

4.2

0.27

0.14

135.0

135.0

135.0

135.0

$16,470.0$

135.0

135.0

$3,240.0$

$31,185.0$

$73,845.0$

$3,645.0$

$1,215.0$
Nh50

unit

$\mathrm{mg} / \mathrm{kg}$

$135889.8 \mathrm{mg} / \mathrm{kg}$

$39659.5 \mathrm{mg} / \mathrm{kg}$

$100075.3 \mathrm{mg} / \mathrm{kg}$

$66271.0 \mathrm{mg} / \mathrm{kg}$

$182736.8 \mathrm{mg} / \mathrm{kg}$

$143495.0 \mathrm{mg} / \mathrm{kg}$

$3855.0 \mathrm{kcal} / \mathrm{kg}$

$30345.1 \mathrm{mg} / \mathrm{kg}$

$19897.9 \mathrm{mg} / \mathrm{kg}$

$5495.0 \mathrm{mg} / \mathrm{kg}$

$12507.3 \mathrm{mg} / \mathrm{kg}$

$3467.7 \mathrm{mg} / \mathrm{kg}$

$17133.4 \mathrm{mg} / \mathrm{kg}$

$9169.6 \mathrm{mg} / \mathrm{kg}$

$12630.2 \mathrm{mg} / \mathrm{kg}$

$25502.1 \mathrm{mg} / \mathrm{kg}$

$12462.1 \mathrm{mg} / \mathrm{kg}$

$5728.1 \mathrm{mg} / \mathrm{kg}$

$4235.1 \mathrm{mg} / \mathrm{kg}$

$6219.0 \mathrm{mg} / \mathrm{kg}$

$41026.1 \mathrm{mg} / \mathrm{kg}$

$5443.8 \mathrm{mg} / \mathrm{kg}$

$22022.1 \mathrm{mg} / \mathrm{kg}$

$9133.1 \mathrm{mg} / \mathrm{kg}$

$16154.8 \mathrm{mg} / \mathrm{kg}$

$31650.0 \quad \mathrm{IE} / \mathrm{kg}$

$1055.0 \quad 1 \mathrm{E} / \mathrm{kg}$

$374.8 \mathrm{mg} / \mathrm{kg}$

$21.1 \mathrm{mg} / \mathrm{kg}$

$42.3 \mathrm{mg} / \mathrm{kg}$

$42.8 \mathrm{mg} / \mathrm{kg}$

$31.7 \mathrm{mg} / \mathrm{kg}$

$0.08 \mathrm{mg} / \mathrm{kg}$

$105.8 \mathrm{mg} / \mathrm{kg}$

$105.7 \mathrm{mg} / \mathrm{kg}$

$21.1 \mathrm{mg} / \mathrm{kg}$

$0.40 \mathrm{mg} / \mathrm{kg}$

$2,130.1 \mathrm{mg} / \mathrm{kg}$

$211.0 \mathrm{mg} / \mathrm{kg}$

$230.3 \mathrm{mg} / \mathrm{kg}$

$42.2 \mathrm{mg} / \mathrm{kg}$

$16,839.0 \mathrm{mg} / \mathrm{kg}$

$13,596.3 \mathrm{mg} / \mathrm{kg}$

$1,21.7 .3 \mathrm{mg} / \mathrm{kg}$

4,437.0 $\mathrm{mg} / \mathrm{kg}$

$13,197.0 \mathrm{mg} / \mathrm{kg}$

$3,590.7 \mathrm{mg} / \mathrm{kg}$

$6,675.0 \mathrm{mg} / \mathrm{kg}$

$326.4 \mathrm{mg} / \mathrm{kg}$

$184.8 \mathrm{mg} / \mathrm{kg}$

$133.0 \mathrm{mg} / \mathrm{kg}$

$10.1 \mathrm{mg} / \mathrm{kg}$

$0.85 \mathrm{mg} / \mathrm{kg}$

$0.36 \mathrm{mg} / \mathrm{kg}$

$7.7 \mathrm{mg} / \mathrm{kg}$

$0.44 \mathrm{mg} / \mathrm{kg}$

$0.27 \mathrm{mg} / \mathrm{kg}$

$135.0 \mathrm{mg} / \mathrm{kg}$

$135.0 \mathrm{mg} / \mathrm{kg}$

$135.0 \mathrm{mg} / \mathrm{kg}$

$135.0 \mathrm{mg} / \mathrm{kg}$

$16,470.0 \mathrm{mg} / \mathrm{kg}$

$135.0 \mathrm{mg} / \mathrm{kg}$

$135.0 \mathrm{mg} / \mathrm{kg}$

$3,240.0 \mathrm{mg} / \mathrm{kg}$

$31,185.0 \quad \mathrm{mg} / \mathrm{kg}$

$73,845.0 \mathrm{mg} / \mathrm{kg}$

$3,645.0 \mathrm{mg} / \mathrm{kg}$

$1,215.0 \mathrm{mg} / \mathrm{kg}$ 


\title{
Chapter 7
}

\section{No alterations of hippocampal neuronal number}

\author{
and synaptic bouton number \\ in a transgenic mouse model expressing \\ the $\boldsymbol{\beta}$-cleaved $\mathrm{C}$-terminal APP fragment
}

Neurobiology of Disease, 2003; 12(2): 110-120

Bart P.F. Rutten, Oliver Wirths, Wilma D.d. Van de Berg, Stefan F. Lichtenthaler, Jochen Vehoff, Harry W.M. Steinbusch, Hubert Korr, Konrad Beyreuther, Gerd Multhaup,

Thomas A. Bayer, Christoph Schmitz 


\section{ABSTRACT}

Previous studies in the literature have resulted in conflicting reports on the potentiall neurotoxicity of the $\beta$-cleaved $A$ zheimer's disease $C$-terminal fragment $(\beta-C T F)$ of $\beta$-amyloid precursor protein in vivo. To re-address this question by use of state-of-the-art stereological techniques, we analyzed transgenic mice expressing human $\beta$-CTF with the $145 \mathrm{~F}$ mutation (SPA4CT) under control of the prion protein promoter. The transgene was expressed in hippocampus and cortex in large pyramidal neurons and in dentate gyrus granule cells. Proteolytic processing of $\beta-\mathrm{CTF}$ released $A \beta$. However, most of it remained uncleaved. Neurodegeneration was evaluated by investigating the numbers of hippocampal pyramidal and granulle neurons, as well as the number of synaptophysin-immunopositive presynaptic boutons in the hippocampus of 15-month-old SPA4CT mice with design-based stereological techniques. The analyses showed that a fourfold higher expression of the transgene compared to murine APP levels had no effect on the numbers of both neurons and synaptophysin-immunopositive presynaptic boutons. These data implicate that expression of $\beta$-CTF per se is not neurotoxic, and that other mechanisms are responsible for the neurotoxic events in Alzheimer's disease brain.

\section{INTRODUCTION}

Alzheimer's disease (AD) is characterized by the presence of extracellular amyloid plaques, vascular amylloid, neurofibrillary tangles, and neurodegeneration. The amyloid deposits in AD brains consist mainly of the 40 - to 42 -residue $\beta$-amyloid ( $A \beta$ peptides, ${ }^{1,2}$ which are derived in a two-step process by proteolytic cleavage from the larger $\beta$-amyloid precursor protein (APP) ${ }^{3}$. In the first step, $\beta$-secretase (BACE cleavage releases the truncated ectodomain of APP and generates $a \sim 12 \mathrm{kD} C$-terminal fragment $(\beta-\mathrm{CTF}$ or $\mathrm{C}-99) .{ }^{4}$ In the second step, $\beta-\mathrm{CTF}$ is processed by $\gamma$-secretase activity, generating $A \beta$ (for review see ref. 5). For $\gamma$-secretase activity, presenilin- (PS) 1 and PS-2 are required which are multipass transmembrane proteins. Alternatively, cleavage within the $A \beta$ domain of APP by $\alpha$-secretase activity releases a secreted form of APP, prevents the formation of $A \beta$ peptides and generates a $\sim 10 \mathrm{kD} C$-terminal fragnient $(\beta-C T F$ or $C-83$ ) (see ref. 5 for review). Point mutations of the APP gene have been identified in some families with a rare autosomal dominant form of early onset AD. ${ }^{6.7}$ A further subset of familial $A D$ cases is caused by mutations in the PS-1 gene on chromosome $14^{8}$ and the PS -2 gene on chromosome 1."10 The gain-of-function of PS mutations modifies APP processing and enhances the generation of $A \beta 42 .{ }^{11,12}$.

The role of $\beta-C T F$ in $A D$-related neurodegeneration has been controversially discussed in the literature. On one hand, it has been demonstrated in vitro that expression of full--length cDNA for human $\beta$-CTF is toxic in cultured neuronal and non-neuronal cell lines. ${ }^{13}$ Furthermore, it has recently been shown in vitro that $\beta-C$ TF can induce astrocytosis, suggesting a role of $\beta-C T F$ in promoting the production of proinflammatory mediators, nitric oxide, and subsequent reactive oxygen intermediates such as peroxynitrites by reactive astrocytes around senile plaques in AD. ${ }^{14}$ In addition, a recent in vitro study has suggested that the $C$-terminal $\beta$-secretase cleavage product of APP (i.e., $\beta-C T F$ ) - but not $A \beta$ - mediates apoptosis of neurons caused by mutations 
of the $\mathrm{APP}$ gene in early onset $\mathrm{AD} .{ }^{15}$ On the other hand, expression of $\mathrm{B}-\mathrm{CTF}$ in rat $\mathrm{PC1} 2$ cells resulted in a significantly decreased vulnerability to $\mathrm{H}_{2} \mathrm{O}_{2^{2}}{ }^{16}$ Two studies in vivo have suggested age-dependent neuronal and synaptic degeneration - accompanied by impaiments in learming and memory - in mice transgenic for the CTF of APP. ${ }^{17,18}$ In another study, however, neurodegeneration, gliosis, and reduced immunostaining for synaptophysin could only occasionally be abserved in a large sample of mice transgenic for the 99 -amino acid CTF of APP. ${ }^{19}$

The importance to understand the involvement of $\beta-\mathrm{CTF}$ in neurodegeneration and induction of astrocytosis is underlined by the fact that currently a major therapeutic strategy aims to decrease the production of $A \beta$ in $A D$ by inhibition of $\gamma$-secretase.,20,21 With respect to this strategy it could recently be demonstrated that adult mice deficient in neuron-specific PS-1 (PS $-1(n-/-))$ had strongly decreased levels of endogeneous brain amyloid peptides, concomitant with accumulation of endogeneous $\beta-\mathrm{CTF}^{22}$ Crossing PS-1(n-1-)-mice with mice transgenic for human mutant APP (APP[V7 17I]) resulted in double transgenic mice (APP [V717I] $\times$ PS1(n(-)) not showing amyloid pathology and impairment of long-term potentiation as known for APP[V7171] mice. However, APP[V7171] $\times$ PS1(n-/-) mice demonstrated cognitive deficits similar to APP [V 7 17I] mice, which were not seen in PS-1(n-/-) mice. ${ }^{22}$ The authors concluded that the use of $\gamma$-secretase inhibitors must be scrutinized further, considering potential neurotoxic effects of accumulating $\beta-$ CTF (see also ref. 23-24).

On this basis we have carried out a re-evaluation of the question whether or not accumulation of $\beta-$ CTF results in neurodegeneration (i.e., loss of synapses and/or loss of neurons) and gliosis in vivo. For doing so, we investigated - using state-of-the art stereological techniques - a transgenic mouse model expressing a construct with the APP signal peptide fused to the mutant I45F carboxyterminal 99 amino acids of APP under the control of the prion protein promoter. ${ }^{25}$ A detailed description of the construct used can be found in Lichtenthaler et al. ${ }^{26}$

\section{MATERIALS AND METHODS}

\section{Animals}

The transgene vector $\mathrm{pBS} / \mathrm{SPA} 4 \mathrm{CT}$ with a substitution of lle- 45 by phenylalanine was generated using the Quik Change Site Directed Mutagenesis Kit (Stratagene) as published previously.27 This artificial mutation generated abundant processing of the C-terminal domain of APP and was therefore used to generate transgenic mice. The SPA4CT construct ${ }^{28}$ contains the signal peptide (SP) of APP followed by leucine and glutamic ${ }^{28}$ acid and the C-terminal 99 amino acids of APP (A4CT). Expression is under the control of the prion protein ( $\mathrm{pPrPhg}$ ) promoter. A Notl/Sall fragment containing the promoter and mutated cDNA sequence was isolated, purified and microinjected into the pronuclei of fertilized eggs (C57BL/6 $\times$ DBA) according to standard methods. Founders were backcrossed to C57BL/6 mice. Control animals were littermates of the transgenics. Over the entire period of investigation, no differences in health, activity pattern and maintaining of a nommal dietary schedule were observed between transgenic and control animals. All experiments were performed according to the German animal protection law. 


\section{Western Blot Analysis}

Transgenic $(n=30)$ and control mice $(n=40)$ of ages between 3 and 20 months were sacrificed by cervical translocation, and the brains removed from the skulls. One hemisphere per animal was immersion-fixed by $4 \%$ buffered formalin at $4^{\circ} \mathrm{C}$ and paraffin-embedded for immunohistochemical analysis (described below), and the other hemisphere was snap-frozen for biochemical analysis.

Snap frozen brain halves were homogenized in lysis buffer $(120 \mathrm{mM} \mathrm{NaCl}$, $50 \mathrm{mM}$ Tris, $1 \%$ Triton $\mathrm{X}-100$ ) including complete protease inhibitor cocktail (Boehringer Mannheim, Germany). Cellular debris was remowed by centrifugation at $14.000 \mathrm{rpm}$ at $4^{\circ} \mathrm{C}$ for 25 min. The proteins were run on 10\% or 16\% Tris-tricine SD-polyacrylamide gels (Novex, San Diego; CA) and transferred to Hybond nitrocellulose membranes (Amersham Pharmacia Biotech, Little Chalfont, UK). Western blots were probed with monoclonal antibody W0-229 and polyclonal anti APP-CT antibody.30 For A $\beta$ detection the blotted membrane was heated in boiling phosphate buffered saline (PBS; $8.1 \mathrm{mM} \mathrm{Na} 2 \mathrm{HPO} 4,1.5 \mathrm{mM} \mathrm{KH}_{2} \mathrm{PO}_{4}, 137 \mathrm{mM} \mathrm{NaCl}$, and 2.7 $\mathrm{mM} \mathrm{KCl}, \mathrm{pH} 7.4$ ) for 5 min to enhance the signal and blocked with 5\% non-fat dry milk in PBS containing $0.05 \%$ Tween-20 for $1 \mathrm{~h}$. Afterwards, the primary antibody was added and incubated overnight at $4^{\circ} \mathrm{C}$. The bound antibodies were detected by horseradish peroxidase-conjugated anti-mouse or anti-rabbit IgG secondary antibodies (Amersham) followed by ECL detection system (Amersham) according to the manufacturer's instructions.

\section{Immunohistochemistry}

Immunohistochemistry was performed on $4 \mu \mathrm{m}$ thick paraffin sections according to standard protocols. In brief, sections were deparaffinized in xylene and rehydrated. Treatment with $1 \%$ $\mathrm{H}_{2} \mathrm{O}_{2}$ in methanol was applied to block endogenous peroxidase activity. Microwave heating treatment in $0.01 \mathrm{M}$ citrate buffer ( $\mathrm{pH} \mathrm{6.0}$ ) and pretreatment with $88 \%$ formic acid was performed in some sections and enhanced immunoreactivity. Sections were treated with fetal calf serum prior to the addition of the primary antibodies to block non-specific binding sites. This was followed by an overnight incubation with the primary antibodies at room temperature (RT). Staining was visualized using the $\mathrm{ABC}$ method, with a vectastain kit (Vector Laboratories, Burlingame, USA) and $0.3 \%$ diaminobenzidine (DAB) as chromogen. Counterstaining was carried out with hematoxylin. Immunohistochemistry was performed using the antibodies

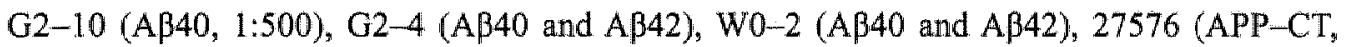
$1: 500)$ and anti-GFAP $\left(1: 400\right.$, DAKO) as described before. ${ }^{31,32}$

\section{Stereology}

Five male, 15-month-old transgenic mice and five male age-matched controls were used to investigate the total numbers of hippocampal pyramidal and granule cells, the volumes of the hippocampal pyramidal and granule cell layer, the vollume of the hippocampal white matter and the density of synaptophysin-immunopositive presynaptic boutons. The body weight of the transgenic mice was $45.6 \pm 1.21 \mathrm{~g}$ (mean $\pm \mathrm{SEM}$ ), and was $40.4 \pm 3.59 \mathrm{~g}$ for the control animals (unpaired t test: $p=0.207$ ). Mice were anesthetized with chloral hydrate (10\% aqueous solu- 


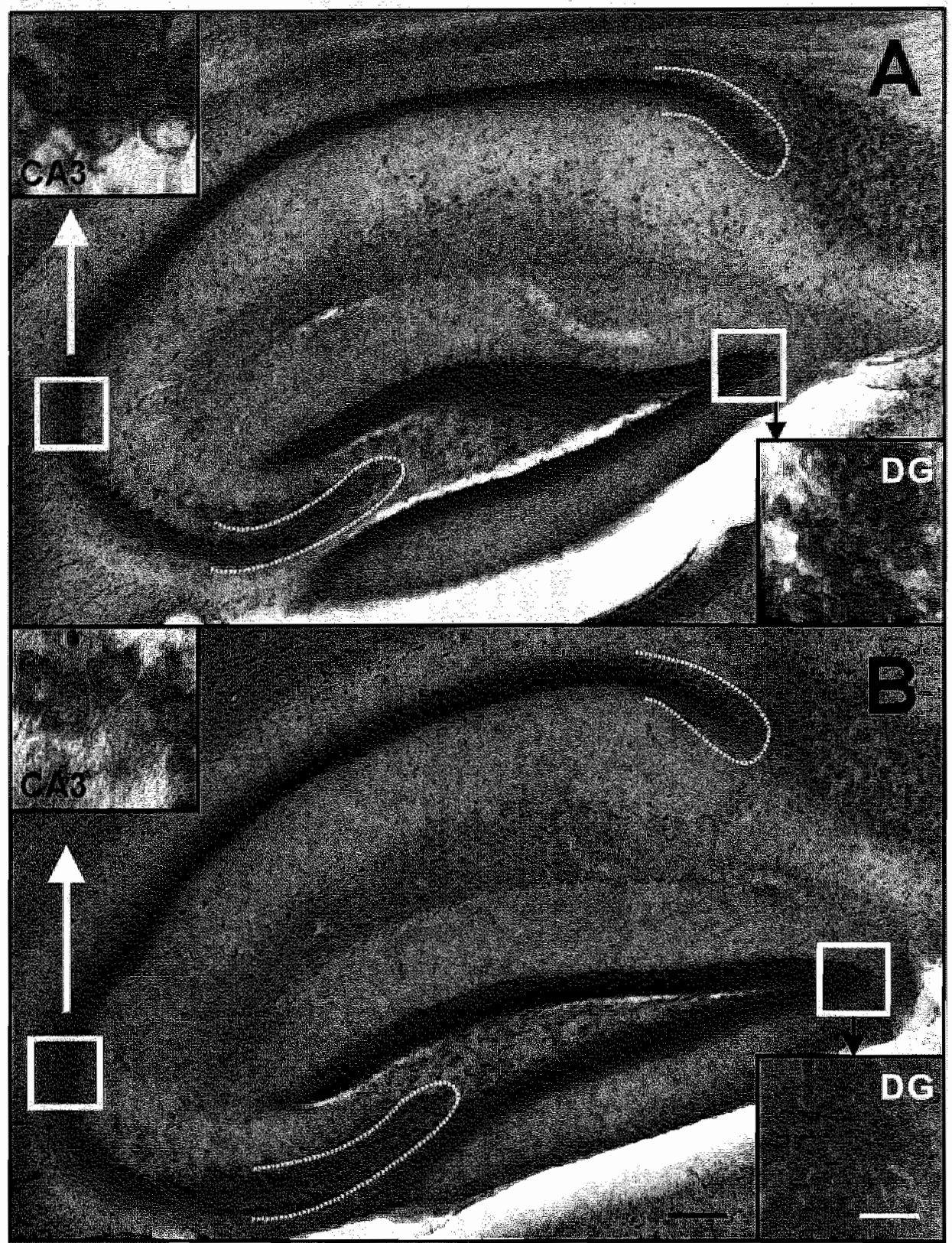

Figure 1. Representative low-power photownicrographs of loo um thick sagithal sections of the hipporampus of

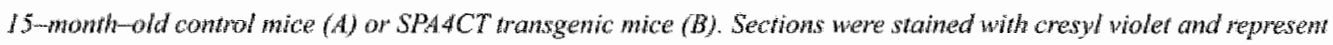

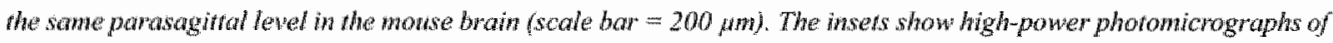

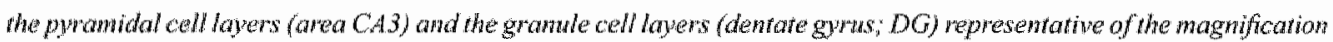
at which the sterelogrical extimates were made (scale bar $=15$ am). The small squares indicate the positions at which the inset photomicrogyphs were taken. The dofted limes indicate the boundaries of the hippocampal pyramidal cell

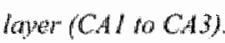




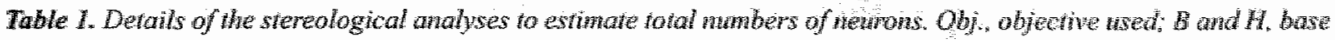

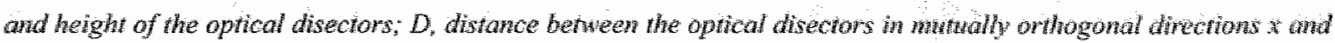

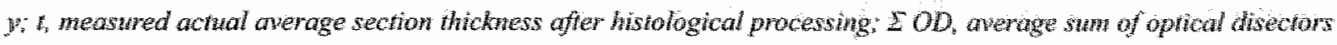

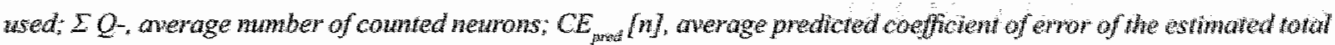
nuwbers of newrons using the prediction method described by Schnitz (1998) awd Schmitz and Hof (2000).

Type of neuron

Pyramidal cells (CA1-CA3) Granule cells (dentate gyrus)

$\begin{array}{ccc}\text { Obj } & 100 \times & 100 \times \\ \mathrm{B}\left(\mu \mathrm{m}^{2}\right) & 306.00 & 536.00 \\ \mathrm{H}\left(\mu \mathrm{m}^{2}\right) & 8 & 10 \\ \mathrm{D}(\mu \mathrm{m}) & 150 & 75 \\ \mathrm{t}(\mu \mathrm{m}) & 39.6 & 42.4 \\ \Sigma \mathrm{OD} & 420 & 758 \\ \Sigma \mathrm{Q}- & 345 & 2577 \\ \text { CEpred[n] } & 0.055 & 0.020\end{array}$

tion, $0.005 \mathrm{ml} / \mathrm{g}$ body weight, i.p.) and were sacrificed by intracardial perfusion fixation with formalin solutions as previously described.33-35 After opening the sculls, the heads of the animals were fixed in formalin solution for $24 \mathrm{~h}$ at $4^{\circ} \mathrm{C}$. Afterwards the brains were removed, halved in the mediosagittal line, and further fixed in formalin solution for 10 days at $4^{\circ} \mathrm{C}$. Both brain halves were then cryoprotected in sucrose solution $(10 \%, 20 \%$ and finally $30 \%$ sucrose in $0.1 \mathrm{M}$ Tris- $\mathrm{HCl}$ buffer, $2 \times 12 \mathrm{~h}$ per solution; $4^{\circ} \mathrm{C}$ ) and were frozen in Tissue-Tek (Sakura Finetek Europe, Zoeterwoude, The Netherlands). Both hemisheres were stored at $-70^{\circ} \mathrm{C}$ until further processing.

Left brain halves were used to investigate the total mumbers of hippocampal pyramidal and granule cells, as well as the volumes of the hippocampal pyramidal and granule cell layer. These hemisheres were entirely cut on a cryostat (Type HM 500 OMV, Microm, Walldorf, Germany) to serial, $100 \mu \mathrm{m}$ thick sagittal sections. Every third section was selected, mounted on gelatinized glass slides, dried and defatted with Triton X-100 (Merck, Darmstadt, Germany; $0.025 \%$, $20 \mathrm{~min})$ and stained with cresyl violet $\left(0.01 \%, 20 \mathrm{~min}\right.$; cf. ref $\left.^{34,35}\right)$. Slides were coverslipped using DePeX (Serva, Heidelberg, Germany).

Right brain halves were used to analyze the density of synajtophysin-immunopositive presynaptic boutons (SIPB). These brain halves were entirely cut on another cryostat (Leica CM 3050, Nussloch, Germany) into $30 \mu \mathrm{m}$ thick coronal sections. Every eighth section was selected and used for synaptophysin immunohistochemistry as previously described ${ }^{36}$ Briefly, tri-buffered saline (TBS, $0.01 \mathrm{M}$ ) with $0.2 \%$ Triton $\mathrm{X}-100$ (TBS-T) was used for washing and diluting antibodies. To minimize background staining, sections were pre-incubated in $5 \%$ normal goat serum (NGS; Sigma, Uithoorn, The Netherlands) at room temperature (RT) for $30 \mathrm{~min}$. NGS $(2.5 \%)$ was added to all solutions containing antibodies. A polyclonal antibody against synaptophysin (A0010, lot 019, Dako, Glostrup, Denmark) was used at a dilution 1:1000 overnight 


\section{Wo alterations in netiron or synaptic numbers in $\beta$-CTF mice}

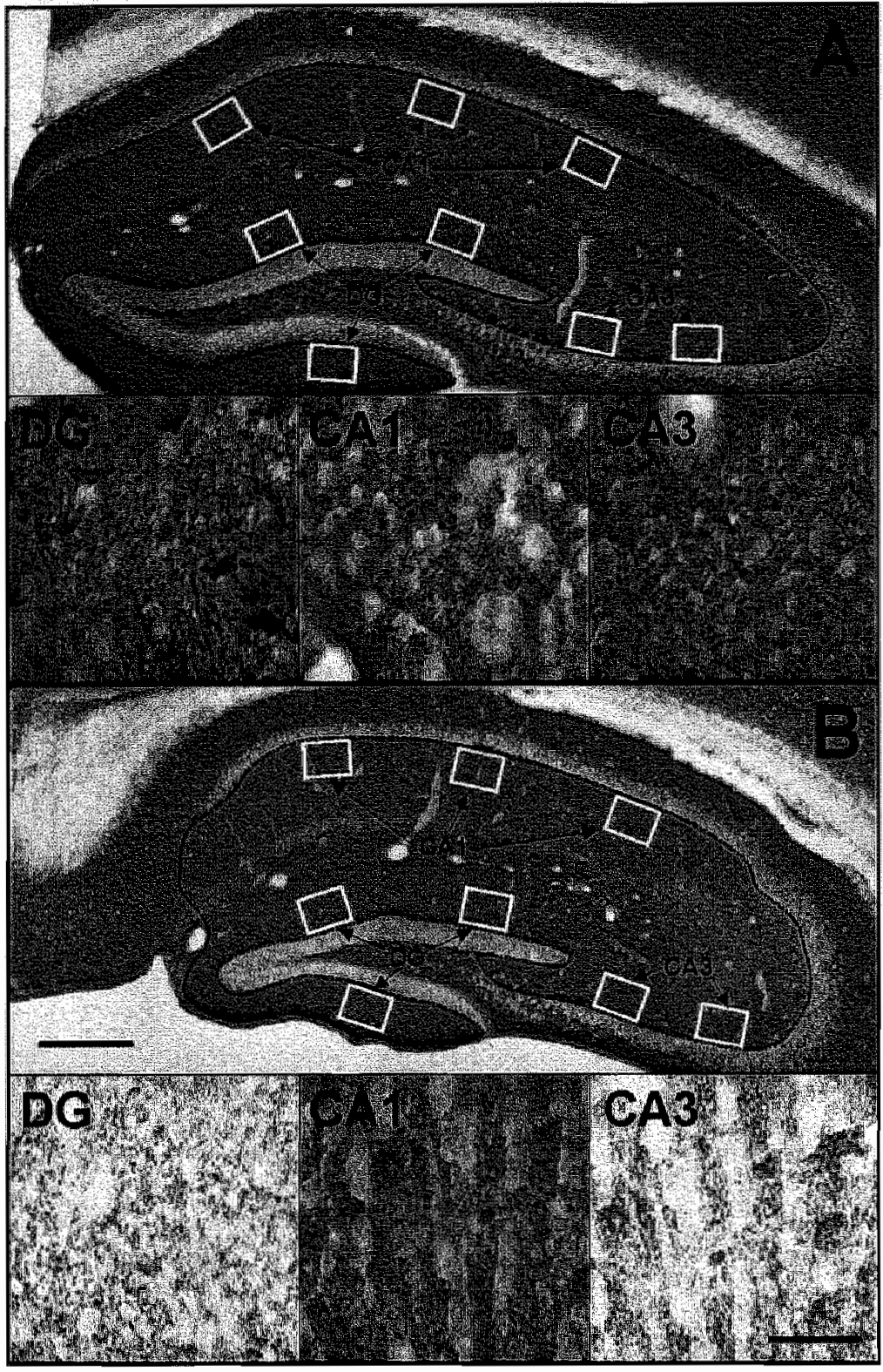

Figure 2. Representative low-power photomicrographs of $30 \mu \mathrm{m}$ thick coronal sections of the hippocampus of 15-month-old control mice (A) or SPA4CT transgenic mice (B). Sections were processed for synaptophysin immunohistochemistry using a polyolonal antibody against synaptophysin (A0010, Dako. Denwrark) and represent almost the same coronal level in the mouse brain (scale bar $=300 \mu \mathrm{m}$ ). Below the low-power photomicrographs, three highpower photomicrographs each are shown of the grawule cell layers (dentate gyrus; DG) and the pyramidal cell layers (areas CAI and CA3), representarive of the magnification at which the density of the synaptoplysin-immunopositive presynaptic bowtons was measured (scale bav $=15 \mu \mathrm{m}$ ). The swall squares indicate the positions at which the analyses were performed, as well as the high-power photomicrographs were laken. The dotted lines indicate the delineation of the hippocampal white matter. 
at $4^{\circ} \mathrm{C}$. After washing with TBS and TBS-T, the tissue was immersed in biotinylated goat anti-rabbit IgG (1:400, Jackson, West Grove, PA, USA) for $1.5 \mathrm{~h}$ at RT, followed by ABC-kit (1:800 for $90 \mathrm{~min}$; Vectastain, Burlingame, CA, USA). After washing with TBS and TBS-T, the sections were incubated in $0.3 \% 3,3^{\prime}-\mathrm{DAB}$ (Sigma) containing $0.03 \% \mathrm{H}_{2} \mathrm{O}_{2}$ in $\mathrm{TBS}-\mathrm{T}$ for 10 min at RT. Sections were washed with TBS, mounted on gelatinized glass slides, dehydrated, cleared and coverslipped using Permount (Merck, Amsterdam, The Netherlands).

On sections of the left brain halves, the pyramidal and gramule cell layers were delineated as depicted in Figure 1. No distinction was made between areas CA1 to CA3 (cf. ref 34). On sections of the right brain halves, the hippocampal white matter was delineated as depicted in Figure 2. Estimates of total numbers of neurons were carried out by means of the optical fractionator ${ }^{37-39}$ and a stereology workstation, consisting of a modified light microscope (type BX50; Olympus, Tokyo, Japan), Olympus UPlanApo objectives (10×, NA =0.40; 100x, oil, $\mathrm{NA}=1.35$ ), a motorized specimen stage for automatic sampling (Maerzhaeuser, Wetzlar, Germany), an electronic microcator (Heidenhain, Traunreut, Germany), a CCD colour video camera (IAI, Glostrup, Denmark), a PC (IBM, Portsmouth, England) with framegrabber board (type Screen Machine II, Fast Multimedia, Munich, Germany) and stereology software (C.A.S.T.-Grid, Olympus; StereoInvestigator, MicroBrightField, Inc., Colchester, VT, USA) and a 17" television screen monitor (IBM). Using the sagittal sections of the left brain halves, all hippocampal pyramidal (CA1 to CA3) and granule cells were counted which nuclear top came into focus within optical disectors systematically-randomly spaced throughout the delineated brain regions. Counting was performed at a final magnification of $\times 3,600$. In Table 1 all details of the counting procedure were summarized. Estimated total numbers of neurons were calculated from the number of counted neurons and the sampling probability. ${ }^{37-39}$

The same sections were used for investigating the volumes of the hippocampal pyramidal (CAl to CA3) and granule cell layer. This was done by delineating and measuring the projection areas of these brain regions on all analyzed sections using the described stereology work station at a final magnification of $\times 360$ (i.e., by using the $10 \times$ objective).

From the obtained data and the corresponding average actual section thickness after histologicall preparations (measured with the electronic microcator), total volumes were calculated by means of the Cavalieri"s principle ${ }^{40}$ considering overprojection. ${ }^{41}$ The hippocampal white matter volume was estimated on the synaptophysin-immunostained sections using the Cavalieri's principle as well. Since it was not possible to measure the average actual section thickness after histological preparations here, the original section thickness $(30 \mu \mathrm{m})$ was considered for calculating the volumes.

The coronal sections of the right brain halves were used to analyze the density of the SIPB. Three regions within the hippocampus were analyzed, i.e., CA1, CA3 and the dentate gyrus (DG). Within the regions $\mathrm{CA} \perp$ and $\mathrm{DG}$, three randomly chosen areas of the systematically-randomly sampled sections were evaluated each, while in $\mathrm{CA} 3$ two randomly chosen areas were evaluated 
as indicated in Figure 2. Five to seven sections per animal were analyzed, depending on the individual rostro-caudal extension of the hippocampus. The density of the SIPB was estimated as previously described. ${ }^{34}$, Briefly, an Olympus BH-2 microscope equipped with a $100 \times$ oil immersion planachromatic objective and a $10 \times$ projection lens was used. The microscope was equipped with a CCD video camera (Paes, Zoeterwoude, The Netherlands). Immunoreactive presynaptic boutons were detected by an image analysis system, slightly modified for detection of grayscale punctae (AnalysL-pro, Münster, Germany). All measurements were performed on a single focal plane. Shading error correction was performed before measurements to correct for irregularities in illumination of the microscopic fields. Three images per randomly chosen area were taken and stored. Background levels were equalized and the detection threshold was tested and kept at the same lewell for all samples. From these data, the mean SIPB density per $\mu \mathrm{m}^{2}$ was calculated. The synaptophysin-immunoreactivity was restricted to small punctae with a morphological appearance that was not apparently different between animals or groups.

\section{Statistical analysis}

For each group, mean and standard error of the mean were calculated for all investigated variables (i.e., total numbers of hippocampal pyramidal and granule cells, volumes of the hippocampal pyramidal and granule cell layers, volumes of the hippocampal white matter, and densities of the hippocampal SIPB). Comparisons between the groups were performed with the Student's two-tailed $t$ test. Statistical significance was established at $\mathrm{p}<0.05$. All calculations were performed using GraphPad Prism (Version 3.00 for Windows, GraphPad Software, San Diego, USA).

\section{RESULTS}

\section{Western blot analysis}

Total brain lysates of SPA4CT transgenic mice between 3 and 20 months, as well as agematched control mice, were analysed by Western blot, either with monoclonal antibody W0-2 (AB 5-8) or polyclonal anti A.P. .CT antibody. As expected, in brain lysates of mice bearing the human transgene, a significant amount of human $\beta$-CTF was detected with both antibodies. The polyclonal anti APP-CT antibody recognized both the murine and the human APP C-terminus. The $12-\mathrm{kDa}$ signal representing the human $\beta-\mathrm{CTF}$ was fourfold stronger than the endogenous murine $\beta-\mathrm{CTF}^{4}$, as analyzed by densitometry using computer-assisted imaging software (Quantity One, Bio-Rad) (Figure 3A). There was no detectable difference in the expression level of $\beta-C T F$ between transgenic and wildtype animals (Figure 3A). Levels of endogenous murine full-length APP, detected by Western blot with polyclonal anti APP-CT antibody, remained again unchanged in transgenic and control animals (Figure 3B). Analysis with the $W 0-2$ antibody which detects human $A \beta$, revealed that the transgenic animals expressed the $12 \mathrm{kDa}$ transgene, and additionally the $4 \mathrm{kDa} A \beta$ band generated by $\gamma$-secretase cleavage. No age-related changes in the expression level of the $\beta-C T F$ transgene or A $\beta$ levels were found (data not shown). Neither the transgene nor $A \beta$ were detected in brain lysates of non-transgenic control animals (Figure $3 \mathrm{C}$ ). 
A

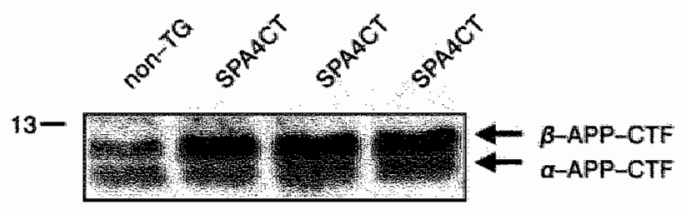

27576 (anti-APP CT)

B
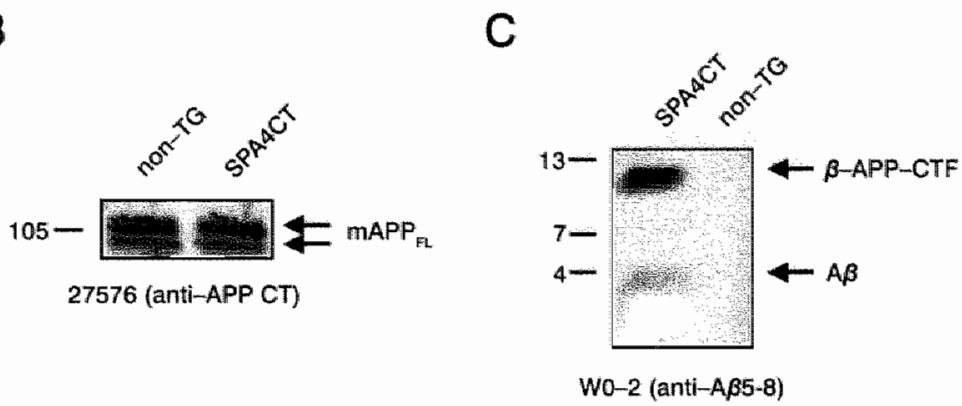

Fignre 3. Western blat analysis of SPA4CT transgenic mice and combols. A. Staining with a polyctonal ant APP-CT antibody, showing that transgenic $\beta$-CTF levels are higher wan endogenows. B. Endogenows mwhe full-hengwh APP stained with a polyctonal ant APP-CT antibody. C, WO-2 staining showing tuncleaved C-terminal fragmew of APP and AR. $\beta$-CTF, C-terminal fragment of APP; APPFL, full-length APP

\section{Immunohistochemistry}

Immunohistochemical analysis for human $\beta-C T F$ using the polyclonal anti APP-CT serum in brain sections from transgenic mice revealed immunoreactivity in dentate gyrus granule cells, as well as in pyramidal neurons in hippocampus and cortical areas. Use of the polyclonal anti APP-CT serum resulted in a granular cytoplasmic immunostaining in the somatodendritic and axonal compartments (Figure 4). None of the transgenic mice showed any staining indicative of plaque-like structures or extracellular $A \beta$ deposits. There was no indication for marked gliosis demonstrated by GFAP staining (not shown). Staining with the A $\beta$ antibodies G2-10 (anti $A \beta-40$ ) and $\mathrm{G} 2-4$ (anti $A P P / A \beta$ ) did not show any immunoreactivity. However, W0-2 elicited minor vesicular intraneuronal staining in some of the SPA4CT mice (not shown). The non-transgenic control mice were consistently negative for all antibodies.

\section{Stereology}

The mean total number of hippocampal pyramidal cells was $361,698 \pm 19,933$ (Mean \pm SEM) for the transgenic mice, and $380,606 \pm 15,366$ for the wild type controls (i.e., a reduction by approximatelly $5 \%$ in the transgenic mice compared to the wild type controls).

Mean hippocampal granule cell number was $336,101 \pm 10,117$ for the transgenic mice, and $347,056 \pm 6,460$ for the controls $(-3 \%)$. Transgenic mice exhibited hippocampi with mean volumes 
of the pyramidal cell layer (CA1 to CA3), granule cell layer, and white matter of $0.332 \pm 0.026$ $\mathrm{mm}^{3}$ (controls: $\left.0.352 \pm 0.015 \mathrm{~mm}^{3} ;-5 \%\right), 0.187 \pm 0.014 \mathrm{~mm}^{3}\left(0.173 \pm 0.009 \mathrm{~mm}^{3} ;+8 \%\right.$ ) and $2.591 \pm 0.076 \mathrm{~mm}^{3}\left(2.838 \pm 0.226 \mathrm{~mm}^{3} ;-9 \%\right)$, respectively. Furthermore, the transgenic mice showed mean SIPB densities of $99.25 \pm 6.08 / \mu \mathrm{m}^{2}$ in CA1 (controls: $101.18 \pm 4.38 / \mu \mathrm{m}^{2} ;-2 \%$ ), $102.02 \pm 5.87 / \mu \mathrm{m}^{2}$ in CA3 $(109.21 \pm 6.78 ;-6 \%)$, and $99.06 \pm 6.29 / \mu \mathrm{m}^{2}$ in DG $\left(100.71 \pm 3.79 / \mu \mathrm{m}^{2}\right.$; $-1.5 \%)$, respectively.

Thus, the transgenic mice showed a slight trend towards smaller hippocampi with less neurons and smaller SIPB density. However, these differences did not reach statistical significance. P-values were 0.474 for pyramidal cell number, 0.388 for granule cell number, and 0.527 , 0.420 , and 0.332 for the volumes of the pyramidall cell layer, the granule cell layer, and the white matter, respectively. Furthermore, p-values were $0.802,0.448$, and 0.827 for the SIPB densities in CA1, CA3, and DG, respectively. Since neither the volumes of the hippocampus nor the SIPB density showed any alteration, it is reasonable to interpret these data as indicating no alteration of the number (i.e., the product of density and volume) of SIBP in the hippocampus of the transgenic mice $\left(\mathrm{cf}^{36}\right)$.

\section{DISCUSSION}

This is the first report using rigorous application of state-of-the-art stereological techniques to answer the question whether or not accumulation of $\beta-C T F$ results in neurodegeneration (i.e., loss of synapses and/or loss of neurons) in vivo. In SPA4CT transgenic mice we observed expression of the C-terminal fragment of human APP in many large pyramidal neurons of the hippocampus and cortex, as well as in granule cells of the hippocampus. Western blot analysis of brain lysates of these animals revealed abundant $\mathrm{C} 99$ expression, representing human $\beta$-CTF with approximately fourfold higher relative levels of expression compared to the expression level of endogenous murine $\beta-\mathrm{CTF}$ in control animals. In addition, low
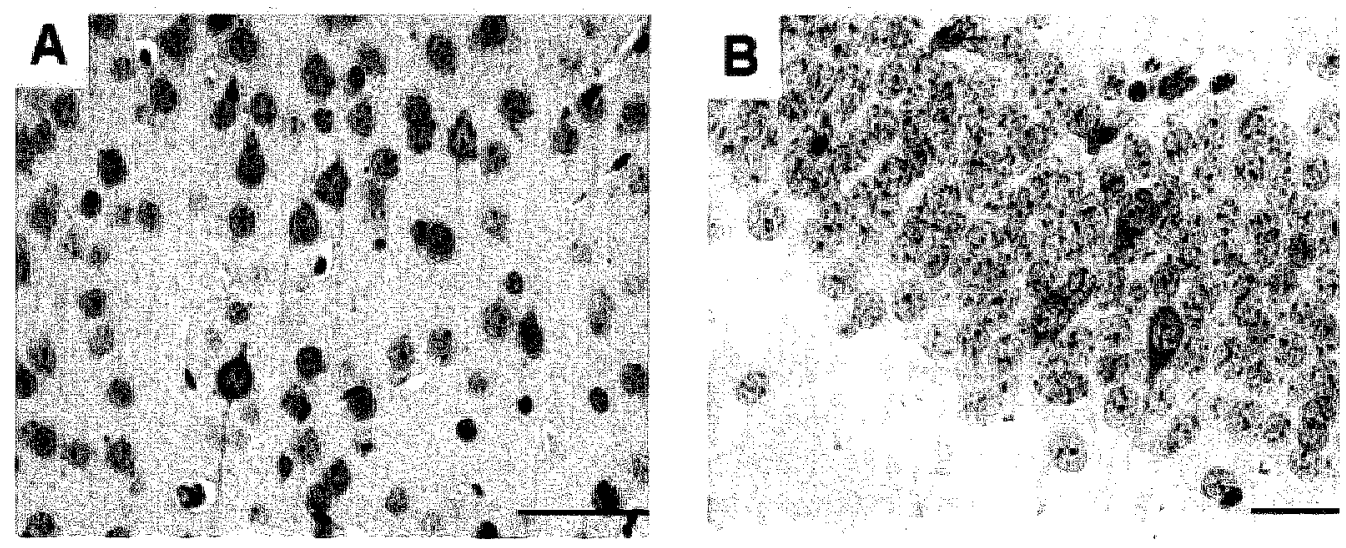

Figure 4. Immunohistochemical staining of brain sections of SPA4CT transgenic mouse brain using a polyclonal anti APP.CT antibody. A, Cortical section. B, Dentate gyrus granule cells. Counterstaining with hematoxylin. Bar $=50$ $\mu m(A)$ and $20 \mu m(B)$. 
A $\beta$ levels derived from the SPA4CT construct were found in all samples at all time points. No evidence for extracellular A immunoreactivity or marked gliosis could be found using immunohistochemistry, even in 20 months old mice. Over the entire period of investigation, no differences in health, activity pattern and maintaining of a normal dietary schedule were observed between transgenic and control animals. Most importantly, we found only a slight trend towards smaller hippocampi with less neurons and smaller synaptophysin-immunopositive presynaptic bouton density in 15 months oll transgenic animals compared to controls, with differences between $1.5 \%$ and $9 \%$ not reaching statistical significance. At the age of 15 months, no difference in body weight was found between transgenic and control animals (body weight not investigated at other time points). In general, our data further increase the understanding of the in vivo effects of $\beta$-CTF human APP, where previous studies in the lit= erature have resulted in conflicting reports on the potential neurotoxicity of the $\beta-C T F$ of APP in wivo. In their study, Sato and coworkers have shown that the major part of transgenic mice expressing $\beta-C T F$ of human APP under the cytomegalovirus enhancer and chicken $\beta$-actin promotor lack signs for neurodegeneration. ${ }^{19}$ Data from two other studies, however, stand - at first glance - in contrast to our results. In a study investigating a transgenic mouse model ${ }^{17}$ in which the gene for the $\beta$-CTF of human APP was expressed under the control of the brain dystrophin promoter, Oster-Granite and coworkers found several darkly stained neurons both in the hippocampal granule and pyramidal cell layer of transgenic mice by inspection of toluidine blue stained semil-thin sections. On the electron microscopic level, the authors found axons containing increased numbers of neurofilaments relative to those of control mice, and membranous whorls in axonal and dendritic processes within the hippocampal pyramidal cell layer of transgenic mice numerous degenerating synapses and varying degrees of signs of degeneration in the hippocampus of all 25 transgenic mice studied at an age of more than 18 months, but only in 3 of 22 nontransgenic control littermates. The authors interpreted these data as support for the hypothesis that $\beta$-CTF of human APP is critically involved in the etiology of AD. In another study, the transgenic construct was identical to that described by Oster-Granite et al. ${ }^{17}$ except for the fusion of the Flag sequence (Asp-tyr-Ly-Asp-AspAsp-Asp-Lys), preceded by a methionine, to the $N$ terminus of $\beta-C T F 18$ which has shown to enhance the neurotoxicity of $\beta-\mathrm{CTF}^{2}$ in vitro ${ }^{43}$ (see also ${ }^{17}$ ).

Homozygous Flag $\beta-$ CTF transgenic mice showed darkly stained neurons in the hippocampus already at an age of five months. Approximately 14 months old homozygous transgenic mice showed a reduction in the relative number of neurons with round, regularly-shaped white nuclei not staining darkly with the toluidine blue by approximately $35 \%$ compared to age-matched control animals. ${ }^{18}$ Interestingly, at the same time point, homozygous Flag- $\beta-\mathrm{CTF}$ transgenic mice were significantly impaired in cued, spatial and reversal performance of a Morris water maze task compared to age-matched controls. ${ }^{18}$ However, one should keep in mind that these finding might reflect the deleterious effects of Flag- $\beta-C T F$ gene expression in vivo, which might not resemble the pathopysiological situation in $\mathrm{AD}$.

The discrepancy between on the one hand the reports of Oster-Granite et al. ${ }^{17}$ and BergerSweeney et al. ${ }^{18}$ and on the other hand the data provided by Sato et al. ${ }^{19}$ and the present study might be due to several factors. Differences in the transgenic mouse models used-based, e.g., 
on the use of different promoters-might result in differences in the expression level of $\beta$-CTF and in different amounts of neurodegeneration among different transgenic mice whereas the different ages of the animals at the time point of investigation might also play a role. Furthermore, different research questions in the studies mentioned above, may have led to the use of different methods and techniques in the respective studies. In the present study, we focussed on the possible loss of neurons and/or synaptophysin-immunopositive presynaptic boutons whereas others have mainly focussed on the presence of degenerating neurons and synapses as a consequence of $\beta-C T F$ expression. Additionally, some differences in the findings of the different studies could be based on different methods applied for analyzing the amount of neurodegeneration. In the present study, modern-design-based stereological techniques were used to quantify numbers of neurons and synaptophysin-immunopositive presynaptic boutons in different areas of the hippocampus of transgenic and nontransgenic mice. Application of these techniques in the present study resulted in a thorough investigation of the entire hippocampus, comprising inspection of several hundreds of microscopical fields per animal for counting neurons as well as of up to 168 microscopical fields per animal for analyzing SIPB demsity (for a comprehensive discussion regarding the quantification of synaptic numbers by investigating SIPB density and the volume of the corresponding brain region see. ${ }^{36,42}$

To summarize, expression of $\beta$ CTF of human APP in transgenic mice resulted - if at all - only in minimal signs of neurodegeneration within the hippocampus when analyzing numbers of neurons and synaptophysin-immunopositive presynaptic boutons with modern-design-based stereological techniques, as well as signs of gliosis with immunohistochemistry. For obwious reasons, these data do not exclude the possibility that $\beta$-CTF of human APP might have neurotoxic effects in AD. Furthermore, these data do not exclude the possibility that the cognitive deficits found for the double transgenic mice (APP[V717I] $\times$ PSI (n-1-)) investigated by Dewachter et al. (2002; see Introduction) $)^{22}$ are based on neurotoxic effects of accumulating $\beta-\mathrm{CTF}$ in this transgenic mouse model which might be investigated in the future in a similar manner as carried out here. In addition, one should keep in mind that the intracellular compartment of $\beta-C T F$ generation in the model of Dewachter et al. $(2002)^{22}$ and the present one might be different.

In conclusion, the results of this study contribute to clarify further which molecules generated in the amyloid cascade of AD are neurotoxic in vivo. As shown here, the C-99 fragment of APP was not able to induce a significant loss of synapses or neurons in the hippocampus of transgenic mice. Rather, recent research has raised the appealing hypothesis that the generation of high amounts of A 3 is crucial for neurodegeneration, which does not hold true for the SPA4CT model investigated here. Nevertheless, it is currently a matter of scientific debate whether intraneuronal or extracellular $A \beta$ is neurotoxic, although it is clear that $A \beta$ is generated intraneuronally. Intraneuronal $A \beta$ accumulates prior to plaque induction in transgenic mice ${ }^{31}$ and in human post-mortem $A D$ brain. ${ }^{4 / 4}$ Furthemore, it has been shown that the $A \beta$ domain is important for intraneuronal APP sorting. 45 Therefore, a pathological accumulation of intraneuronal $A \beta$ could interfere with APP sorting and consequently with plaque formation. Indeed, Kienlen-Campard et al. ${ }^{\text {} 6}$ recently revealed that intraneuronal $A \beta$ is neurotoxic in primary neuronal cell cultures. It is therefore to expect that further studies will confirm high amounts of intraneuronal $A \beta$ as an important aspect of neurodegeneration in $\mathrm{AD}$ in wivo. 


\section{REFERENCES}

1. Glenner GG, Wong CW: Alzheimer's disease: initial report of the purification and churacterization of a nowel cerebrovascular amyloid protein. Biochem Biophys Res Conminu 1984, 120:885-890

2. Masters CL, Simms G, Weinman NA, Multhaup G, McDonald BL, Beyreuther K: Amyloid plaque core protein in Alzheimer disease and Down syndrome. Proc Natl Acad Sci U S A 1985, 82:4245-4249

3. Kang J, Lemaire HG, Unterbeck As Salbaum JM, Masters CL, Graeschik KH, Multhatip G, Beyrenther Ka, Muller-Hill B: The precursor of Alzheimer's disease amyloid A4 protein resembles a cell-surface receptor. Nature 1987, 325:733-736

4. Vassar R, Bennett BD, Babu-Khan S, Kahn S, Mendiaz EA, Denis P, Teplow DB, Rosa S, Amarante P, Loeloff $R$, Luo $Y$, Fisher $S$, Fuller I, Edenson $S$, Lile J, Jarosinski MA, Biere AL, Curran $E$, Burgess "T, Louis IC, Collins F, Treanor J, Rogers G, Citron M: Beta-secretase cleavage of Alzheimer's amyloid precursor protein by the transmembrane aspartic protease BACE. Science 1999, 286:735-741.

5. Bayer TA, Wirths O, Majienyi K, Hartmann T, Mutthanp G, Beyreuther K, Czech C: Key factors in Alzheimer's disease: beta-amyloid precursor protein processing, metabolism and intraneuronal transport. Brain Pathol 2001, 11:1-11

6. Mullan M, Craw ford F, Axelman K, Houlden $H$, Lilius L, Winblad B, Lannfelt L: A pathogenic mutation for probable Alzheimer's disease in the APP gene at the N-terminus of beta-amyloid. Nat Genet 1992, 1:345347

7. Goate A, Chartier-Harlin $M C$, Mullan $M$, Brown $J$, Crawford $\mathbb{F}$, Fidani $L_{a}$ Giuffra $L$, Haynes A, Irving $N_{n}$. James $L$, et al.: Segregation of a missense mutation in the amyloid precursor protein gene with familial Alzheimer's disease. Nature 1991, 349:704-706

8. Shernington R, Rogaev EI, Liang Y, Rogaeva EA, Levesque G, Ikeda M, Chi H, Lin C, Li G, Holman K, et al.: Cloning of a gene bearing missense mutations in early $\sim$ onset familial Alzheimer"s disease. Nature 1995, $375: 754760$

9. Levy -Lahad E, Wasco W, Poorkaj P, Romano DM, Oshima J, Pettingell WH, Yu CE, Jondro PD, Schmidt $\mathrm{SD}$, Wang $\mathrm{K}$, et al.: Candidate gene for the chromosome 1 familial Alzheimer's disease locus. Science 1995, 269:973-977

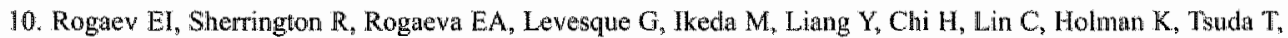
et al.: Familial Alzheimer's disease in kindreds with missense nutations in a gene on chromosome i related to the Alzheimer's disease type 3 gene. Nature 1995, 376:775-778

11. Scheuner D, Eckman C, Jensen M, Song X, Citron M, Suzuki N, Bird TD, Hardy $J$, Hutton M, Kukull W* Larson E, Levy-Lahad E, Vintanen M, Peskind E, Poorkaj P, Schellenberg G, Tanzi R, Wasco W, Lannfelt L, Selkoe D, Younkin S: Secreted amyloid beta-protein similar to that in the senile plaques of Alzheimer's disease is increased in vivo by the presenilin 1 and 2 and APP mutations linked to familial Alzheiner"s disease. Nat Med 1996, 2:864-870

1.2. Duff K, Eckman C, Zehr C, Yu X, Prada CM, Perez-tur J, Hutton M, Buee L, Harigaya Y, Yager D, Morgan D, Gordon MN, Holcomb L, Refolo L, Zenk B, Hardy J, Younkin S: Increased amyloid-beta42(43) in brains of mice expressing mutant presenilin I. Nature 1996, 383:710-713.

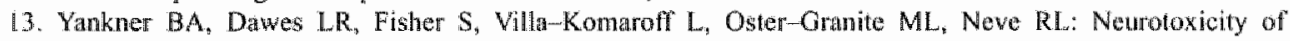
a fragment of the amyloid precursor associnted with Alzheimer's disease. Science 1989, 245:417-420

14. Bach JH, Chae HS, Rah JC, Lee MW, Park CH, Choi SH, Choi JK, Lee SH, Kim YS, Kim KY, Lee WB, Sulh $\mathrm{YH}$, Kim SS: C-terminal fragment of amyloid precursor protein induces astrocytosis. 』Neurochem 2001 , $78: 109-120$

15. McPhie DL, Golde T, Eckman CB, Yager D, Brant JB, Neve RL: beta-secretase cleavage of the annyloid precursor protein mediates neuronal apoptosis caused by familial Alzheimer's disease mutations. Brain Res Mol Brain Res 2001, 97:103-113

16. McKeon-O'Malley $C$, Wells, J, Fine R, Ullman MD, Volicer $L$ : $P C l 2$ cells transfected with a $C$-terminal fragment of the amyloid precursor protein (APPC-100), exhibit enbanced sensitivity to the calcium ionophore A23187, and diminished sensitivity to hydrogen peroxide. Brain Res Mol Brain Res 1999, 72:103-107

17. Oster-Gtanite ML, MePhie DL, Greenan J, Neve RL: Age-dependent neuronal and synaptic degeneration in mice transgenic for the $C$ terminus of the amyloid precursor protein. I Neurosci 1996, 16:6732-6741

18. Berger-Sweeney J, McPhie DL, Arters JA, Greenan J, Oster-Granite ML. Neve RL: Impairments in lieaning and memory accompanied by neurodegeneration in mice transgenic for the carboxyl-terminus of the amyloid precursor protein. Brain Res Mol Brain Res 1999, 66:150-1162.

19. Sato M, Kawarabayashi T, Shoji M, Kobayashi T, Tada N, Matsubara E, Hirai S: Neurodegeneration and gliasis in transgenic mice overexpressing a carboxy-terminal fragment of Alzheimer anyloid-beta protein precursor. Dement Geriatr Cogn Disord 1.997, 8:296-307

20. Golde TE, Younkin SG: Presenilins as therapeutic targets for the treatment of Aldheimer's disease. Trends Mol Med 2001, 7:264-269 
21. Selkoe DJ: Alzhemer"s disease: genes, proteins, and therapy. Physiol Rev 2001, 81:741-766.

22. Dewachter I, Reverse D, Caluwaents $N_{1}$ Ris L, Kuiperi $C$, Van den Haute $C$, Spittaels $\mathbb{K}_{\text {, }}$ Umans $L$, Semeels $\mathrm{L}$, Thiry E, Moechars D, Mercken M, Godaux E, Van Leuven F: Neuronal deficiency of presenilin I inhibits anyloid plaque formation and corrects hippocampal long-term potentiation but not a cognitive defect of amyloid precursor protein [V717I] transgenic mice. J Neurosci 2002, 22:3445-3453.

23. Suh YH: An etiological role of anyloidogenic carboxyl-terminal fragments of the beta-amyloid precursor protein in Alzheimer"s disease. I Neurochem 1997, 68:1781-1791

24. Suh YH, Kim HS, Lee JP, Park CH, Jeong SJ, Kim SS, 趹 JC, Seo JH: Roles of A beta and carboxyl terminal peptide fragments of amyloid precursor protein in Alzheimer disease. J Neural Transm Suppl 2000:65-82

25. Fischer M, Rulicke T, Raeber A, Sailer A, Moser M, Oesch B, Brandiner S, Aguzzi A, Weissmann C: Prion protein ( $\mathrm{PrP}$ ) with aminomproximal deletions restorimg, susceptibility of $\mathrm{PrP}$ knockout mice to scrapie. Embo J $1996,15: 1255-1264$

26. Lichtenthaler $\mathrm{SF}$, Multhaup $\mathrm{G}$, Masters $\mathrm{CL}$, Beyreuther $\mathrm{K}$ : A novel substrate for amalyzing Alzheimer"s disease gamma-Becretase. FEBS Lett 1999, 453:288-292

27. Lichtenthaler SF, Wang R, Grimm H, Uljon SN, Masters CL, Beyreuther $\mathrm{K}$ : Mechanism of the cleavage specificity of Alzheimer"s disease gamma-secretase identified by phenylalanine-scanning mutagenesis of the transmembrane domain of the amyloid precursor protein. Proc Natl Acad Sci U S A 1999, 96:3053-3058

28. Dyrks T, Dyrks E, Masters C, Beyreuther K: Mernbrane inserted APP fragments containing the beta A4 sequence of Alzheimer"s disease do not aggregate. FEBS Lett 1992, 309:20-24.

29. Ida $\mathbb{N}$, Hartmann T, Pantel $J$, Sehroder $J$, Zerfass R, Forstl $H$, Sandbrink $\mathbb{R}$, Masters $C L$, Beyreuther $K$ : Analysis of heterogeneous $\mathrm{A} 4$ peptides in human cerebrospinal fluid and blood by a newly developed sensitive Western blot assay. I Biol Chem 1996, 271:22908-22914

30. Weidemann A, Konig G, Bunke D, Fischer P, Salbaum JM, Masters CL, Beyreuther K: Identification, biogenesis, and localization of precursors of Alzheimer's disease A4 amyloid protein. Cell 1989, 57:115-126

31. Wirths $O$, Multhaup $G$, Czech $C$, Blanchard V, Moussaoui $S$, Tremp $G$, Pradier $\mathcal{L}$, Beyreuther $\mathbb{K}$, Bayer TA: Intraneuronal Abeta accumulation precedes plaque formation in beta- amyloid precursor protein and presenilin-1 double-transgenic mice. Neurosci Lett 2001, 306:116-120.

32. Wirths O, Multhaup G, Czech C, Feldmann N, Blanchard V, Tremp G, Beyreuther K, Pradier L, Bayer TA: Intraneuronal APPiA beta trafficking and plaque formation in beta-amyloid precursor protein and presenilin-1 transgenic mice. Brain Pathol 2002, 12:275-2:86

33. Schmitz $\mathrm{C}$, Axmacher B, Zunker U, Korr H: Age-related changes of DNA repair and mitochondrial DNA synthesis in the mouse brain. Acta Neuropathol (Berl) 1999, 97:71-81.

34. Schmitz $C$, Bultmann $\mathbb{E}$, Gube $M$, Korr $H$ : Newron loss in the mouse hippocampus following prenatal injection of tritinted thymidine or saline. Int J Dev Neurosei 1999, 17:185-190

35. Korr H, Thorsten Rohde H, Benders J, Dafotakis M, Grolms N, Schmitz C: Neuron loss during early adulthood following prenatal low-dose $\mathrm{X}$-irradiation in the mouse brain. Int J Radiat Biol 2001, 77:567-580

36. Van de Berg WD, Blokland A, Cuello AC, Schmitz C, Vreuls W, Steinbusch HW, Blanco CE: Perinata! asphyxia results in changes in presynaptic bouton number in striatum and cerebral corteX-a stereological and behawioral analysis. J Chem Neuroanat 2000, 20:71-82

37. Gundersen HJ, Bagger $\mathbb{P}$, Bendtsen TF, Evans SM, Korbo L, Mareussen N, Moller A, Nielsen $K_{*}$ Nyengaard: JR, Pakkenberg $\mathbf{B}$, et al.: The new stereological tools: disector, fractionator, nucleator and point sampled. intercepts and their use in pathological research and diagnosis. Apmis 1988, 96:857-881

38. Schnitz C: Variation of fractionator estimates and its prediction. Anat Embryol (Beri) 1998, 198:371 -397

39. Schmitz $\mathrm{C}$, Hof PR: Recommendations for straightforwand and rigorous methods of counting neurons based on a computer simulation approach. J Chem Neuroanat 2000, 20.93-1.14

40. Cavalieri B: Geometrica Indivisibilibus Continuorum, Bononiae: Typis Clemetis Ferronij. 1635

41. Gundersen HJ, Jensen EB: The efficiency of systematic sampling in stereology and its prediction. J Microsc $1987,147: 229-263$

42. Wong TP, Campbell PM, Ribeiro-da-Silwa A, Cuello AC: Synaptic numbers across cortical laminae and cognitive performance of the rat during ageing. Neuroscience $1998,84: 403-412$

43. Kozlowski MR, Spanoyannis A, Manly SP, Fidell SA, Neve RL: The neurotoxic carboxy-teminal fragmem of the Alzheimer amyloid precursor binds specifically to a neuronal cell surface molecule: $\mathrm{pH}$ dependence of the neurotoxicity and the binding. J Neurosci 1992, 12:1679-1687

44. Gouras GK, Tsai J, Naslund J, Vincent B, Edgar M, Checler F, Greenfield JP, Haroutunian V, Buxbaum JD, Xu H, Greengard P, Relkin NR: Intraneuronal Abeta42 accumulation in human brain. Am J Pathol 2000 , $156: 15-20$

45. Tienari PJ, De Strooper B, Ikonen E, Simons $M$, Weidemann A, Czech C, Hartmann T, Ida $N_{s}$ Multhaup $G$, Masters $\mathrm{CL}$, Van Leuven $\mathrm{F}$, Beyreuther $\mathrm{K}$, Dotti CG: The beta-amyloid domain is essential for axonal sorting of amyloid precursor protein. Embo J 1996, 15:5218-5229

46. Kienlen-Campard P, Miolet S, Tasiaux B, Octave JN: Intracellular amyloid-beta 1-42, but not extracellular soluble amyloid-beta peptides, induces neuronal apoptosis. J Biol Chem 2002, 277:15666-15670 


\section{Chapter 8}

\section{Hippocampal neuron loss exceeds amyloid plaque load in a transgenic mouse model of Alzheimer's disease}

American Journal of Pathology, 2004; 164(4): 1495-1502

Bart P.F. Rutten, Christoph Schmitz, Andrea Pielen, Stephanie Schăfer, Oliver Wirths, Günter Tremp, Christian Czech, Veronique Blanchard, Gerd Multhaup, Payam Rezaie, Hubert Korr, Harry W.M. Steinbusch, Laurent Pradier, and Thomas A. Bayer 


\section{ABSTRACT}

According to the "amyloid hypothesis of Alzheimer's disease", $\beta$-amyloid is the primary driving force in Alzheimer's disease pathogenesis. Despite the development of many transgenic mouse lines developing abundant $\beta$-amyloid-containing plaques in the brain, the actual link between amyloid plaques and neuron loss has not been clearly established, as reports on newron loss in these models have remained controversial. We investigated transgenic mice expressing human mutant amyloild precursor protein APP751 (KM670/671NL and V717I) and human mutant presenilin-1 (PS-1 M146L). Stereologic and image analyses revealed substantial age-related neuron loss in the hippocampal pyramidal cell layer of APP/PS-1 double-transgenic mice. The loss of neurons was observed at sites of $A \beta$ aggregation and surrounding astrocytes but, most importantly, was also clearly observed in areas of the parenchyma distant from plaques. These findings point to the potential involvement of more than one mechanism in hippocampal neuron loss in this APP/PS-1 double-transgenic mouse model of Alzheimer"s disease.

\section{INTRODUCTION}

The neuropathology of Alzheimer's disease (AD) is characterized by aggregates of extracellular $\beta$-amyloid $(A \beta)$, the formation of neurofibrillary tangles, neuronal and synaptic dysfunction, and loss of neurons and synapses. ${ }^{1.2}$ One of the most challenging aspects of the elucidation of $\mathrm{AD}$ pathogenesis is unraveling putative associations and causative links between these $A D$ hallmarks. According to the 'amyloid hypothesis of $\mathrm{AD}$ ', accumulation of $\mathrm{A} \beta$ in the brain is the primary driving force in $\mathrm{AD}$ pathogenesis. ${ }^{3}$ This hypothesis is supported by the fact that mutations in the amyloid precursor protein (APP) and in presenilins 1 (PS-1) and 2, causing early-onset cases of $A D$, modify $A P P$ processing and result in enhanced generation of $A B{ }^{2,3}$ However, despite the development of various APP transgenic mouse models, ${ }^{4-6}$ the actual link between amyloid plaques and neuron loss has not been clearly established. ${ }^{7,8}$ In particular, reports on neuron loss in mice transgenic for APP or PS-1 have remained controversial. ${ }^{8-12}$ We have recently developed a novel transgenic mouse model of AD expressing human mutant APP751 (carrying the Swedish and London mutations KM670/67 INL and V717I, Thy 1 promoter) and buman mutant presenilin-1 (PS-1 M146L, HMG promoter) in neurons. "With the aim to rigorously investigate whether production and aggregation of A $\beta$ or expression of mutant PS-1 may lead to neurotoxicity in wivo, we examined the hippocampus of APP/PS-1 double-transgenic mice as well as of mice transgenic only for human mutant PS-1 with detailed design-based quantitative and imaging techniques (the hippocampus was chosen due to its central role in the neuropathology of AD). In this article, we report a substantial age-related loss of hippocampal pyramidal cells in the APP/PS-1 double-transgenic mice. Neuronal loss within the hippocampus was greater than could be explained solely by the accumulation of extracellular $\beta$-amyloid. Rather areas at a distance from plaques clearly showed loss of neurons. Therefore, we propose that additional factors significantly contribute to neuron loss in this model of AD. 


\section{MATERIALS AND METHODS}

\section{Transgenic mice}

The following groups of mice were examined: 4.5-months-old wild-type control mice $(\mathrm{n}=6$; body weight $[\mathrm{BW}]=20.83 \pm 0.70 \mathrm{~g}), 17$-months-old wild-type control mice $(\mathrm{n}=6 ; \mathrm{BW}=$ $29.83 \pm 2.36 \mathrm{~g}$ ), 4.5 -months-old transgenic mice expressing human mutant APP751 (carrying the Swedish and London mutations KM670/671NL and V717I, Thy1 promoter) and human mutant presenilin-1 (PS-1 M146L, HMG promoter; $\mathrm{n}=6 ; \mathrm{BW}=19.67 \pm 0.22 \mathrm{~g}$ ), 17-monthsold APP/PS-1 double-transgenic mice $(\mathrm{n}=7 ; \mathrm{BW}=22.86 \pm 0.80 \mathrm{~g}$ ), and 17-months-old PS-1 single-transgenic mice $(\mathrm{n}=7 ; \mathrm{BW}=30.43 \pm 3.05 \mathrm{~g})$. A detailed description of these transgenic mice has been given recently.13,14 APP/PS-1 double-transgenic mice were generated by crossing PS-1 (HMG PS1 M146L) homozygous mice to hemizygous APP (Thy1 APP751 SL) transgenic mice. The PS-1 mice had been back-crossed on a C57B16 background for more than six generations, whereas the APP mice were on a CBA $(12.5 \%) \times \mathrm{C} 57 \mathrm{~B} 16(87.5 \%)$ background Hemizygous PS -1 littermates were used in the present study. Control wildtype mice were on a C57Bl6 background. All mice were female and all experiments were performed in accordance with German animal protection law.

\section{Tissue preparation, immunohistochemistry and lectin histochemistry}

Mice were anesthetized with chloral hydrate and sacrificed by intracardiall perfusion fixation with tyrode followed by the fixative containing $4 \%$ paraformaldehyde, $15 \%$ picric acid and $0.05 \%$ glutaraldehyde in phosphate buffer. Brains were removed rapidly, halved in the mediosagittal line, and post-fixed for 2 hours at $4^{\circ} \mathrm{C}$ in the fixative, omitting the glutaraldehyde. Brain tissue was then cryo-protected by immersion in $30 \%$ sucrose in tris buffered saline at $4^{\circ} \mathrm{C}$ overnight. Afterwards, brains were quickly frozen and stored at $-80^{\circ} \mathrm{C}$ until further processing. The right cerebral hemispheres were cut frontally into entire series of $30 \mu \mathrm{m}$ thick sections on a cryostat and were used for qualitative immunohistochemical visualization, and for the analysis of dying cells with the TUNEL (terminal deoxynucleotidyl transferase [TdT]-mediated dUTP nick-end labeling) assay as recently described for frozen sections. ${ }^{\text {is }}$ The entire left hemispheres were cut sagitally and every tenth section was mounted on a glass slide, dried, defatted with Triton $X-100$, and stained with cresyl violet as described.16 Another series of every tenth section of each left hemisphere was used for immunohistochemical detection and quantification of extracellular A $\beta$ and GFAP (i.e. glial fibrillary acidic protein as a marker for astrocytes). Immunohistochemistry was performed using standard immunofluorescence-labeling procedures. The following primary antibodies were used: monoclonal mouse anti-GFAP 1:1600 (Sigma, St. Louis, MO, USA), polyclonal rabbit anti-mouse GFAP 1:1600 (DAKO, Glostrup, Denmark), monoclonal mouse anti-neuronal nuclei antibody 1:100 (MAB377; Chemicon, Temecula, CA, USA), and rabbit anti-mouse polyclonal antiserum 730 1:5000 (against human $A \beta$ and P3).17 Donkey anti-rabbit IgG Alexa Fluor 488 1:100, donkey anti-rabbit IgG Alexa fluor $5941: 100$, and donkey anti-mouse IgGAlexa Fluor 488 1:100, (Molecular Probes, Eugene, OR, USA) were used as secondary antibodies. A third series of every tenth section of each left hemisphere was used for detection and quantification of extracellular A $\beta$ by thioflavine $S$ staining. Finally, lectin histochemistry with lycoparsicon esculentum (tomato lectin) and brightfield microscopy was used to identify microglia, according to standard protocols. 18 Briefly, tissue 
sections were blocked in methanol solution containing $2.5 \%$ of a $30 \%$ solution of bydrogen peroxide for 2 hours, incubated with lysis buffer (Hanks balanced saline solution containing $1 \%$ of each of the following: $1 \mathrm{M} \mathrm{MgCl} 2,1 \mathrm{M} \mathrm{CaCl} 2$, Tween 20 , bovine serum albumin) for 2 hours, and left overnight in 1:100 biotinyllated tomato lectin solution (Vector laboratories, UK) made up in lysis buffer. Following rigorous washes in TBS, lectin binding was visualized using the standard $\mathrm{ABC}-$ HRP method, with 3,3-diaminobenzidine as chromogen. Negative control sections were incubated with tomato lectin solution containing the corresponding inhibitory substrate: $400 \mathrm{mM} \mathrm{N}$-acetylglucosamine.

\section{Photography}

All photomicrographs shown in Figure I were produced using a Nikon DXM 1200F digital camera (Nikon, Tokyo, Japan) and ACT-1 software (Nikon). Final images were constructed using Corel Photo-Paint v. 11 . With respect to Figures 2,3 and 5 , photomicrograplus were produced using an Olympus U-CMAD-2 digital camera. Between 6 and 8 images were captured for the composite in Figure 2 and 3, which represent the entire hippocampus. These images were made into one montage using image software (AnalySIS $S^{\text {ai }}$-pro Münster, Germany). Images in Figure 5 were processed with Imaris imaging software (Bitplane, Zurich, Switzerland). Only minor adjustments of contrast and brightness were made, which in no case altered the appearance of the original materials.

\section{Stereologic analyses}

The granule and pyramidal cell layers were delineated on all cresyl violet-stained sections of the left hemisphere showing the hippocampus, as recently described. ${ }^{15}$ Estimates of layer volumes were made using Cavalieri's principle. ${ }^{19}$ Total numbers of neurons were evaluated with the Optical Fractionator. ${ }^{20}$ Table 1 summarizes the details of the counting procedures. The series of sections from the left hemisphere of the 17 -months-old APP/PS-1 double-transgenic mice stained for $A \beta$ and GFAP by immunohistochemistry or with thioflavine $S$, were used to investigate the volume percentage of the hippocampal cell layers as well as of the entire hippocampus that was occupied by aggregated $A \beta$ and surrounding astrocytes. This was performed using point counting methods as described in the literature." For technical reasons, one 17-months-old APP/PS-1 double-transgenic mouse could not be analyzed in this way. The percentage of the volume of the hippocampus occupied by aggregated $A \beta$ and surrounding astrocytes in the 4.5-months-old APP/PS-1 double-transgenic mice was less than $1 \%$ and was therefore not considered further.

\section{Statistical analysis}

Differences between groups were tested with analysis of wariance (ANOVA) followed by posthoc Bonferron"s multiple comparison tests for pairwise comparisons. Correlations between numbers of neurons and plaque load were tested with linear regression analysis. Statistical significance was established at $\mathrm{P}<0,05$. All calculations were performed using GraphPad Prism version 4.00 for Windows (GraphPad Software, San Diego, CA, USA). 

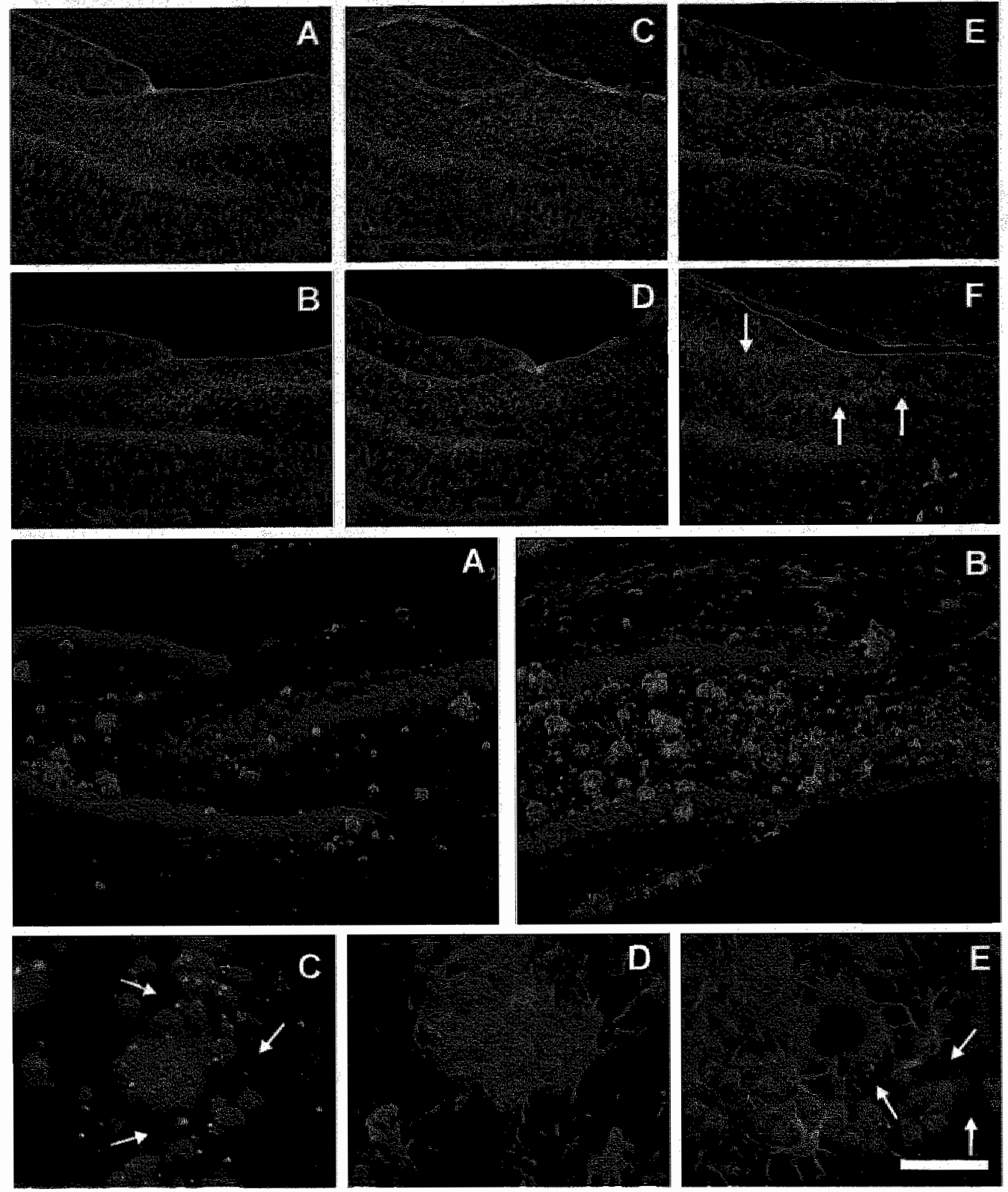

Figure 1. Agre-lated astrocytosis, aggnegation of A 9 aggregates, and loss of neurons in APP/PS-1 donble-transgentic mice. Immumohisfochemical analysis of the hippocampus of control mice (A and B), transgenic mice expressing human mulant presentilin-1 (PS-1 M146L, HMG promoter: $C$ and DJ, and iransgemic mice expressing human mutant amyloid precursor protein (APP) 75I (KM67067 INL and V717I, Thyl promater) and human mutant PS-I (E to L). $\left(A, C_{n}\right.$ E) Representative lon-power photomicragraphs from the hippocampus of 4.5-months-old mice; showing imnunchistochemical staining for GFAP (red) and NeuN (green). $(B, D, F)$ Representative low-power photomicrographs from the hippocampus of 17-months-ald wice, showing immumohistochemical staining for GFAP (red) and New (green). In all pictures, the dentate gynus is seen on the left, and the $C A 3$ and hillar region on the right. Note the sitrong increase in GEAP immunoreactivity in the APP/PS-1 double-transgenic mice. Furthermore, neuron loss was seen in the pyramidal cell layer of the 17-monhs-oldAPP/PS-1 double-transgenic mice (arrows in F). (G, H) Representative 


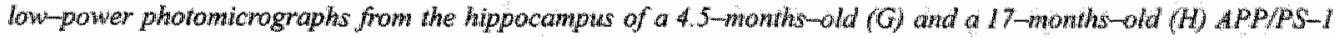
dowble-transgenic motse showing imwunohistochentical staining for NeuN (red) and p-amyloid $40-42(A \beta$, gneen). Note the age-related extracellular AB aggregation and netaran loss in the APP/PS-1 dowble-transgenic mice, partictolarly in the CA3 region. $(I, K, L)$ Representative high-power photorwicrographs from the CA 2 region of 17 -month-old APP/PS-1 double-transgenic mice, showing immunohistochewical staining for NewN (red) and AB 40-42 (green) $(\mathrm{l})$, GFAP (red) and AP 40-42 (green) (K), or GFAP (red) and NewN (green) (L). Thene were regions free of nemons in the vicinity of the $A B$ aggregations, but neuron loss was also found at distance frow $A B$ aggregations (armows in 1 ). The regions surrounding the $A B$ aggregations were partly occupied by astrocytes (shown in $K$ ). Howeven the amoum of mewron loss exceeded the accumulation of aggregated $A B$ and surrounding astrocytes (arrows in L). Bar, 250 , im in $A$ to $F$. 150 um in $G$ and $H, 20$ um in 1 to $L$.

\section{RESLILTS}

\section{Substantial Age-related Loss of Hippocampal Pyramidal Cells in APP/PS-1 Transgenic Mice}

Our previous studies have shown that these APP/PS-1 double-transgenic mice express human mutant APP and PS-1 in various neuronal populations, including the hippocampal pyramidal and granule cells. ${ }^{13}$ Moreover, these mice produce intracellular $A \beta$ and later develop extracellular $A \beta$ aggregates, beginning in the cortex, subiculum and hippocampus at three months of age. ${ }^{13,14}$ In order to directly visualize the effects of expressing human mutant APP and PS-1 on $A \beta$ aggregation and on the morphology of glial and neuronall cells in the mouse hippocampus, we performed several immunohistochemical analyses on frontal brain sections. Similar to that found in human $\mathrm{AD}$, the amount of extracellular $\mathrm{A} \beta$ aggregates increase as the $\mathrm{APP} / \mathrm{PS}-1$ double-transgenic mice age (Figure 1, A-H). Chronic activation of microglia to form brain macrophages was evident in the aged APP/PS-1 animals, particularly related to plaques but also in the surrounding parenchyma (Figure 2). Importantly, we observed a clear age-related loss of neurons in the pyramidal cell layer of the hippocampus (Figure 1, F). We comfirmed this qualitative finding quantitatively by conducting a detailed analysis with design-based stereology on cresyl violet stained sagittal sections of the other cerebral hemispheres (Figure 3 and 4). We found a substantial loss of pyramidal neurons in the hippocampus of 17-months-old APP/PS-1 double-transgenic mice compared to 4.5-months-old APP/PS-1 double-transgenic mice $(-35 \% ; \mathrm{P}<0.001)$ as well as compared to 4.5 -months-old and 17-months-old wild-type controls $(-34 \%[\mathrm{P}<0.001]$ and $-25 \%[\mathrm{P}<0.05]$, respectively) and to 17 -months-old PS-1 single-transgenic mice $(-31 \% ; \mathrm{P}<0.001)$. In contrast, there was no hippocampal neuron loss in 17-months-old PS-1 single-transgenic mice as compared to 17-months-old wild-type controls ( $\mathrm{P}>0.05$ ), indicating that the expression of humant mutant PS-1 did not result in newron loss per se (Figure 4, D).

\section{No Hippocampal Granule Cell Loss in APP/PS-1 Transgenic Mice}

By applying the same methodology to the dentate gyrus, we did not observe hippocampal granule cell loss at 17 months of age in the A.PP/PS-1 double-transgenic mice as compared to 17-months-old PS-1 single-transgenic mice ( $P>0.05$ ), and compared to 17-months-old wild-type controls $(P>0.05)$ (Figure 4, C). 


\section{Less plaque load than the level of hippocampal pyramidal cell loss in APP/PS-1 Mice}

We obserwed no increase in the local neuron density surrounding the AB aggregates (see Figure $1, E, F, H, I$ and $L$ as well as Figure $3, C$ ). This indicates that extracellular $A \beta$ has not simply displaced neuronal cell bodies. Rather the observation of cells positive for both NeuN and TUNEL reactivity in the immediate vicinity of plaques (Figure 5) indicated that the observed hippocampal neuron loss in APP/PS-1 double-transgenic mice was - at least in part - connected to extracellular accumulation of $A \beta$. We therefore attempted to find a correlation between hippocampal neuron loss and extracellular accumulation of $A \beta$ by quantifying the amount of extracellular A 3 aggregation within different layers of the hippocampus of the A.PP/ PS-1 double -transgenic mice, using a combination of immunofluorescence imaging and stereologic analysis. Interestingly, we found no correlation between the numbers of hippocampal pyramidal neurons and the percentage of the volume of either the hippocampal pyramidal cell layer or the entire hippocampus occupied by aggregated $A \beta$ and surrounding astrocytes (i.e., the plaque load) in the APP/PS-1 double-transgenic mice $\left(r^{2}<0.001\right.$ and $r^{2}=0.080$, respectively; Figure 4, F and $\mathrm{H}$ ). Importantly, we found the plaque load (averaging approximately $10 \%$ ) to be considerably smaller than the level of hippocampal pyramidal cell loss in these mice (Figure 4 , F; results obtained on thioflavine S stained sections were even somewhat smaller; details not shown). By comparison, a higher plaque load than presented here, was reported within the dentate gyrus of these APP/PS-1 double-transgenic mice in a previous study. ${ }^{14}$ The polymorph layer of the dentate gyrus was included for analysis in the study by Blanchard et al., ${ }^{14}$ which showed a very high amount of plaque load (see also Figure 1, H). Our analysis focused on the granule cell layer of the dentate gynus, showing a considerably smaller plaque load than the polymorph layer (Figure 1, H).

To further evaluate this difference between neuron loss and plaque load, we callculated "reconstructed' numbers of hippocampal pyramidal cells of the 17 -months-old APP/PS-1 double-
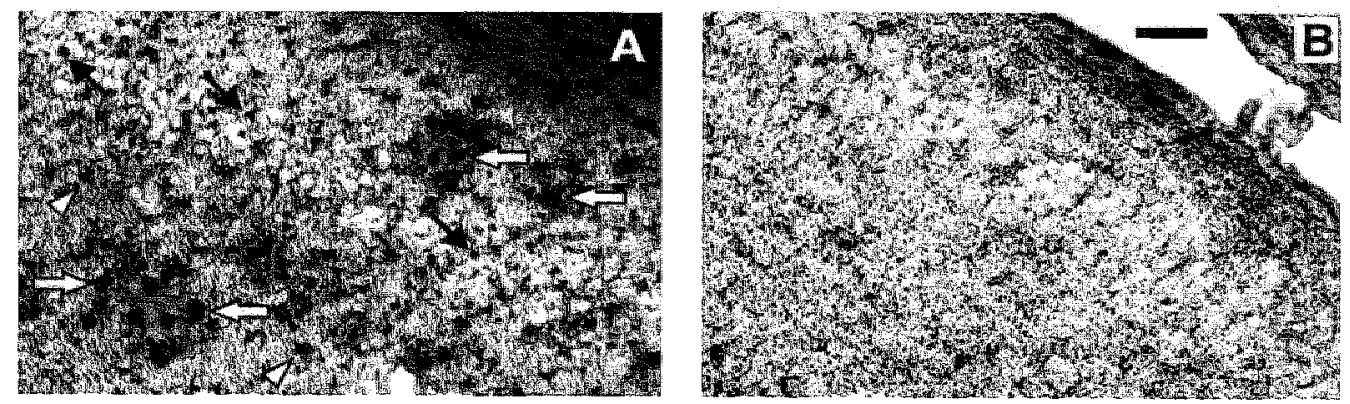

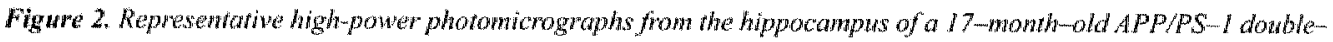

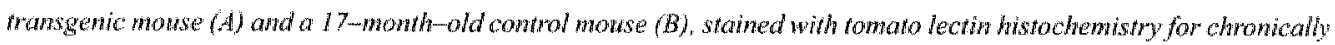

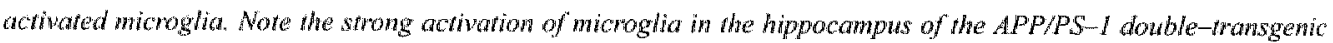

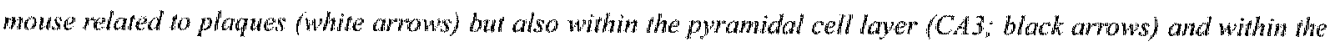

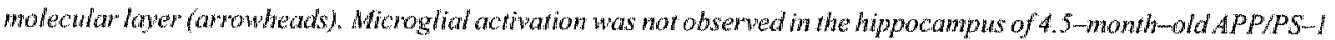

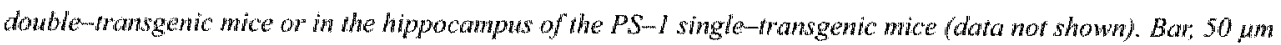


Table 1. Details of counting procedures used to evaluate volal numbers of newrons. Obj. objective used; $B$ and $H$, base $\left(\right.$ am $\left.^{2}\right)$ and heigh $\left(\mathrm{um}^{2}\right)$ of the oprical disectors; $D$, disfonce between the optical disectors in orthogonal divetions

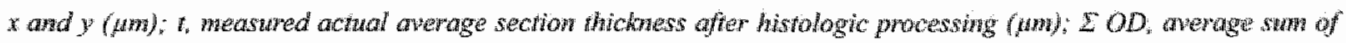

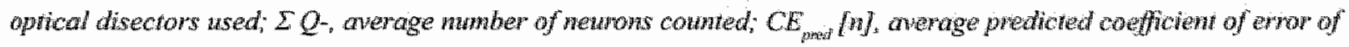
the estinnated toral mumbers of neurans.

\begin{tabular}{ccccccccc} 
Type of neuron & Obj & B & H & D & $t$ & $\sum$ OD & $\sum$ Q- & CEpred[n] \\
\hline $\begin{array}{c}\text { Pyramidal cells } \\
\text { (CA1-CA3) }\end{array}$ & $100 \times$ & 591 & 5 & 100 & 8.4 & 342 & 1246 & 0.029 \\
$\begin{array}{c}\text { Granule cells } \\
\text { (dentate gyrus) }\end{array}$ & $100 \times$ & 591 & 5 & 100 & 8.4 & 158 & 1617 & 0.025
\end{tabular}

transgenic mice on the assumption that the space within the hippocampal pyramidal cell layer occupied by aggregated $A \beta$ and surrounding astrocytes would have contained neurons at the same mean neuronal density as the other parts of this layerHowever, the mean 'reconstructed' number of hippocampal pyramidal cells of the APP/PS-1. double-transgenic mice was significantly smaller than the mean number of hippocampal pyramidal cells in the 4.5-months-old APP/PS-1 double-transgenic mice $(-28 \% ; \mathrm{P}<0.01)$ as well as in the 4.5 -months-old wild-type controls $(-26 \% ; \mathrm{P}<0.05$; Figure $4, \mathrm{~K})$. This indicated a loss of neurons at sites of $\mathrm{A} \beta$ aggregates and surrounding astrocytes but also, most importantly, neuron loss distanced from $A \beta$ aggregates. Accordingly, many regions within the hippocampal pyramidal cell layer of the 17-months-old APP/PS-1 double-transgenic mice were visibly free of neurons, even though they showed no signs of aggregated $A \beta$ or astrocytes (Figure 1, L).

\section{DISCUSSION}

The expression of human mutant APP and human mutant PS-1 (but not human mutant PS-1 alone) caused substantial hippocampal pyramidal cell loss in the present transgenic model of AD. The lack of correlation between the numbers of pyramidal cells and the plaque load was in line with a study reporting little or no correlation between the level of neuron loss and the amount of extracellular $A \beta$ in human $A D .{ }^{22}$ However, one cannot entirely exclude that the lack of correlation between the number of pyramidal cells and the plaque load within the hippocampus of the 17-months-old APP/PS-1 double-transgenic mice was due to interindividual variation in the number of hippocampal neurons between these mice before the onset of AD-like pathology (see supporting data on http://www.amjpathol.org). A previous study reported significant neuron loss in the hippocampal CAl region in APP transgenic mice which seemed to correlate well with the amount of extracellular A $\beta$ aggregates within the hippocampus. ${ }^{9}$ In that study, ${ }^{9}$ however, the correlation was based on inclusion of both homozygous and hemizygous transgenic mice in the calculations, with the latter showing hardly any extracellular $A \beta$ aggregates and normal neuron numbers (see supporting data). Other studies have failed to find hippocampal neuron loss in APP and APP/PS-1 transgenic mouse models..$^{10,11}$ Furthermore, a recent confocal analysis of APP transgenic mice and human post mortem tissue indicated that neuronal toxicity in AD is 
primarily associated with thioflavine $\mathrm{S}$ positive fibrillary $\mathrm{A} \beta$ deposits. However, correlations between the level of these deposits and actual neuron loss were not demonstrated. Altogether, we assume that - besides differences in quantitative analysis - the expression levels of APP and PS-1, the amount of generated $A \beta$, and the time interval between the beginning of $A \beta$ formation and the analysis of neuron loss were the major factors responsible for the differences between the present and the previous studies ${ }^{2-11}$ on APP transgenic lines. Finally, it has been suggested. that mutated PS-1 may already result in 'degenerative-looking' neurons in the hippocampus of tranggenic mice. ${ }^{12}$ The authors of this article concluded that PS-1 mutations may result in accelerated age-related neurodegeneration, although they did not conduct a detailed quantitatiwe analysis of neuron loss. We could not confirm this hypothesis in our study.

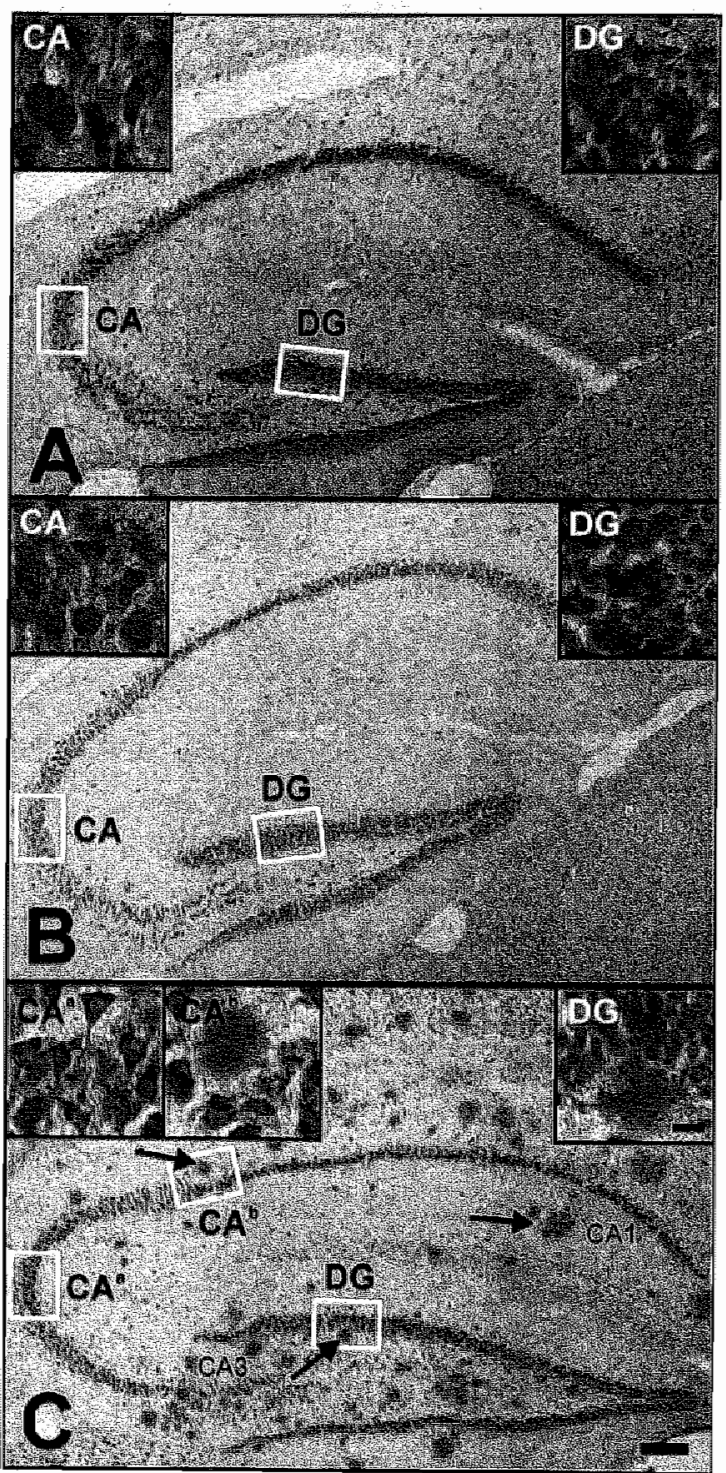

Figure 3. Representative low-power phoromicrographs of 30 um thick sagitial sections of the hippocampus of 17 -month-old control mice (A). mice transgenic for human mutant presenilin-l (B), and mice double-transgenic for human mutant APP75I and hutran mutant presenilin-1 (C), respectively. Sections were staimed with cresyl violet and represent the same parasagittal level in the mouse brain (bar, 200 um). Insets, high-power photomicrographs of the granule cell layers (dentate gyrus; $D G$ ) and the pyramidal cell layers (area $C A 3$ ) representative of the magnification at which the sterealogical estimates were made (bar; $15, \mathrm{~mm}$ ). Small rectangles depict the positions at which the inset photomicrographs wene taken. Sections like these were used for quantification of hippocampal volumes and the rotal number of hippocampal pyramidal cells and gramile cells. 


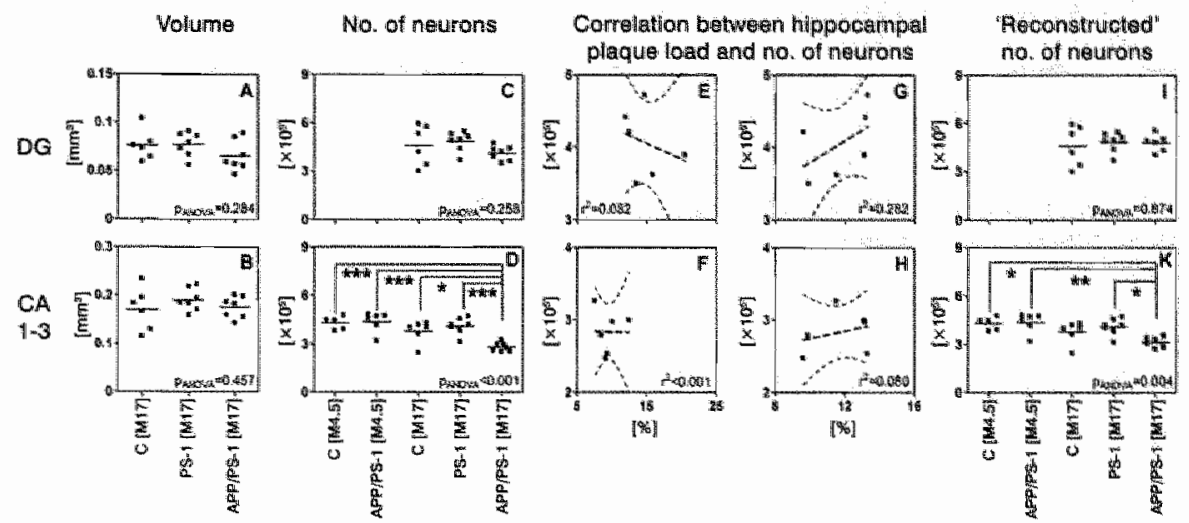

Figure 4. Results of stereologic examinations. Control mice (C), transgenic wice expressing hamam muan presenhin-1 (PS-1), and transgenic mice expressing hwnan mutant anyloid precursor protein and hwman wutam PS-I (APP/PS-I)

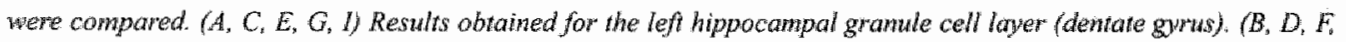
$H, K)$ Resulis obtained for the lef hippocampal pyramidal cell layer $(C A L-3),(A, B)$ Volumes of the cell layers. (C, Dy Numbers af neurons. ( $E, F)$ Correlation between nuwbers of neurons $(\gamma$-axis) and the pencentage of whe wollume of the corresponding cell layer occupied by aggregated AB and surrounding astrocytes in the APPAPS-I dowble-transgewli: wice $(X-a x i s),(G, H)$ comelation between numbers of newrons ( $Y$-axis) and the percentage of the volume of the entire hippocampus occupied by aggregated AB and sumounding astracytes in the APP/PS-I dowble-transgenic mice $(A$-axis). (I,K) Reconstructed" mumbers of newrons, calculated assuwing that in the hippocampus of the APP/PS-1 dowble-transgenic mice, the space within the corresponding cell lover occupied bB aggregated Ap awd surroumding astrocytes would hove contained newrons at he sarne mean newronal density as the other parts of the corresponding cell

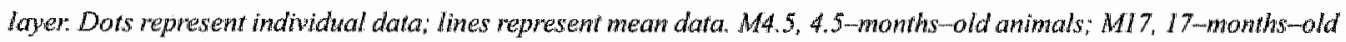
animals * $P<0.05 ; * * P<0.01 ; * * * P<0.001$. In E vo Hz the cunves indicate the upper and lower boundaries of the $95 \%$ confdence intervals of the corresponding regression lines. In all cases, the slope of the regression line was mot statistically significantly different from zero $(P>0.05)$. Differences berween groups were tested with analysis of wariance (ANOVA), followed by post hoc Bonferront s multiple companison iests for pairwise comparisons. Statistical significance was established ar $p<0.05$.
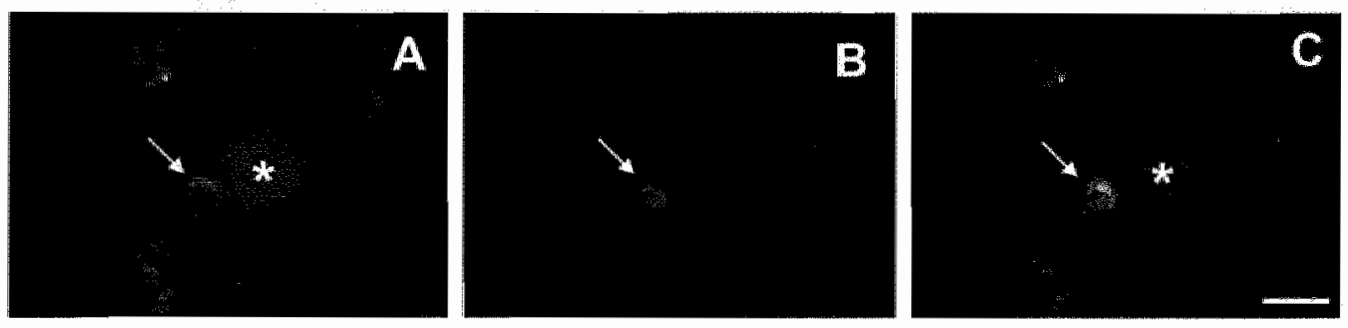

Figure 5. A cell (arrow) immunopositive for both New (green: A) and TUNEL (red; $B$; merged in Cy in the linmediate wicinity of an AB aggregate (asterisk) in a 17-month old APP/PS-1 dowble-tranggente mouse. suggerring that newronal death could be dinectly associated with accumulation of Ap. Both pictwes were taken at identical focal depth. Bar, 25 min 


\section{Hippocampal neuron loss exceeds plaque load}

The results of the present study point to the involvement of more than one mechanism in hippocampal neuron loss in this APP/PS-1 double-transgenic mouse model of AD. The first mechanism (replacement of neurons by extracellular AP aggregates and surrounding asitrocytes: Figure $1,1, K$, and L) confirms the recently introduced concept of focal toxic $A \beta$ deposits with a toxic gradient. In this respect, the role of reactive astrocytes around neuropil $A \beta$ deposits is still enigmatic. On the one hand, the presence of astrocytes has been demonstrated to enhance $A \beta$-induced neurotoxicity in hippocampal cell cultures. ${ }^{23}$ On the other hand, adult mouse astrocytes have been shown to degrade $A \beta$ in vitro and in vivo. ${ }^{2 *}$ Similarly, whereas chronically activated microglia are known to associate with $A B$ plaques in human $A D^{23,26}$ and in experimental conditions, ${ }^{27}$ their presence additionally within the neuropil points to a more widespread and plaque-unrelated response in the APP/PS-1 double-transgenic mice. With respect to the neuron loss which cannot be explained by the concept of focal toxic AB deposits with a toxic gradient, it is tempting to speculate that the additional mechanisms are similar (or even identical) to those involved in alterations of synaptic, physiological and behavioral functions in other transgenic AD models before the onset of extracellular A $\beta$ aggregation. ${ }^{28,25}$ In this context, abundant intraneuronal $A \beta 40$ and $A \beta 42$ with concurrent neuronal stress markers has been demonstrated prior to plaque formation in the present APP/PS-1 mouse model. ${ }^{13.4}$ Therefore, part of the hippocampal neuron loss may be caused by high levels of intraneuronal $A \beta$ independent of extracellular $A \beta$ aggregates. The soluble pool (intracellular and extracellular) of $A \beta$ may also contribute to neurodegeneration, since soluble $A \beta$ levels correlate better than insoluble (extracellularly aggregated) $\mathrm{A} \beta$ levels with the severity of $\mathrm{AD}^{30}$ and since a spatial segregation of $A \beta$-oligomeres and thioflavine- $-S$ positive deposits has recently been described. ${ }^{31}$

Thus, APP/PS-1 mice allow us to determine the exact roles of intracellular and extracellular A $\beta$ in hippocampal neuronal toxicity and to investigate the mechanisms of neuron loss in vivo.

\section{REFERENCES}

1. Selkoe DJ: Alzheimer's disease: genes, proteins, and therapy. Physiol Rev 2001, 81:741-766

2. Cumming $\left[\mathrm{L}_{*}\right.$ Cole $\mathrm{G}$ : Alzhemer disease JAMA 2002, 2872335-2338

3. Hardy $\mathrm{d}$, Selkoe Dd: The anyloid hypothesis of Alzheimer's disease: progress and problems on the road ro therapeutios, science 2002, 297:353-356

4. Citron M, Westaway $D$, Xa W, Carlson G, Dieh T, Levesque G, Johnson-Wood K, Lee M, Seubert P, Davis A, Kholodenko D, Motter R, Sherrington R, Perry B, Yao H, Strome R, Lieberburg I, Rommens J, Kim $\mathrm{S}_{4}$ Schenk D, Fraser P, St George Hyslop P, Selkos DJ: Mutant presenilins of Alzheimer's disease increase production of 42 - residue nmyloid beta-protein in both transfedted cells, and transgenic mice. Nat Med 1997, $3: 67-72$

5. van Leuven d": Single and multiple transgenic mice as models for Alzheimer's disease. Prog Neurobiol 2000 , $61: 305-312$

6. Bayer TA, Wirths O, Majtenyi K, Hartmann T., Multhitup G, Beyrewther K, Czech C: Key factors in Alaheimer's disease: beta-amyloid precursor protein processing, metabolism and intraneuronal transport. Brain Pathol $2001,1: 1: 1-11$

7. Robinson SR, Bishop GM: The search for an amyloid solution. Science 2002, 298:962-964; discussion 962 964

3. Urbanc B. Cruz L, Le R, Sanders I. Ashe KH, Duff K, Stanley HE, Irizary MC, Hyman BT: Neurotoxic effects of thioflavin S positive anyloid deposits in transgenic mice and Altheimer's disease. Proc Natl Acad Soi U SA2002, 99:13990-13995

9. Calhoun ME, Wiederhold KH, Abramowski D, Phinney AL, Probst A, Sturchler Pierat C, Staufenbiel M, Sommer B, Jucker M: Neuron loss in APP transgenic mice. Nature 1998, 395:755-756 
10. Irizary MC, Soricno F, McNamara M. Page KJ, Schenk D, Games D, Hyman BT. Abeta deposition is associated with netropil changes, but not with overt newronal loss in the human anyloud precursor protem V7 17F (PDAPP) transgenic mouse. J Neurasci 1997, 17:7053-7059

11. Takeuchi A, Irizary MC, Duff K, Saido TC, Hsiao Ashe K, Hasegawa M, Mamin DM, Hyan BT, Iwatsubo T: Age-related amyloid beta deposition in transgenic mice overexpressing both Alueimer nutant presthilin $I$ and amyloid beta precursor protein Swedish mutant is not associated with global meuronal loss. An I Pathol $2000,157: 331-339$

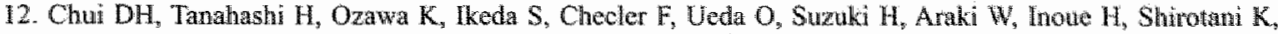
Takahashi K, Gallyas F, Tabira T: Transgernic mice with Alzheimer presenhiln I mutations show nocelerated neurodegeneration without amyloid plaque formation. Nai Med 1999, 5:560-564

13. Wirths $O$, Multhaup $G$, Czech $C$, Blanchard V, Moussaou $S_{4}$ Tremp $G_{*}$ Padier L, Beyreuther $K$, Bayer TA: Intraneuronal Abeta accumulation precedes plaque formation in bota- anyloid preoursor protein and presenilin-1 double-transgenic mice. Neurosci Let 2001, 306:116-120

14. Blanchard V, Moussawi S, Czech C, Touchet N, Bonici B, Planche M, Canton T, Jedidi I, Gohin M, Withs O, Bayer TA, Langui D, Duyckaerts C. Tremp G, Pradier L. Time sequence of maturation of dystrophue neurites associated with AP deposits in APP/PSI transgenic mice. Exp Neurol 2003;184:247-263

15. Van de Berg WD, Schmitz $C$, Steinbusch HW, Blanco CE: Perinatal asphyxia indueed neuronal loss by apoptosis in the neonatal rat striatum: a combined TUNEL and stereological study. Exp Neurol 2002, 1742936

16. Ruten BP, Wirths O, Wan de Berg WD, Lichtenthaler SF, Vehofl J, Stenbusch HW, Korr H, Beyneuther K, Multheup $G$, Bayer TA, Schmitz $C$; No alterations of hippocampal neuronal number and synaptic bouton number in a transgenic mouse model expressing the beta-deawed $\mathrm{C}$-terminal APP fragment. Neurobiol Dis $2003,12 \llbracket 10-120$

17. Borcherdt T, Camakaris $J$, Cappai $R$, Masters CL, Beyrewther $K$. Multhatp $\mathrm{G}$ : Copper inhibits beta-anyloid production and stimulates the non-amyloidogenic pathway of anyloid-precursor-protein secretion. Biochem J $1999,344: 46 l-467$

18. Acartin L, Vela IM, Gonzalez B, Castellano B: Demonstration of poly-N-acefyllactosamine tesidues in ameboid and ramified microglial cells in rat brain by tomato lectin binding. N Fistochem Cytochem 1994 , $42: 1033-1041$

19. Gundersen HJ, Jensen EB: The efficiency of systematic sampling in stereology and its prediction. I Microse $1987,147: 229-263$

20. Schmitz C, Hof PR: Recommendations for straightorward and rigorous methods of counting neurons based on a computer simulation approach. J Chem Neuroanat 2000, 20:93-114

21. Miles RE, Davy PH: Preeise and general conditions for the validity of a comprehensive set of stereological fundamental formulae. J Microsc 1976, 107, 211-226

22. Gomez-Isla $T$, Hollister $R$, Wesi $H$, Mui $S_{n}$ Growdon JH, Petersen RC, Parisi JE, Hymam BT: Neuronall loss correlates with but exceeds neurofibrillary tangles in Alzheimer's disease. Ann Neurol 1997, 41:17-24

23. Domenici MR, Paradisi S, Sacchetti B, Gaudi S, Balduzzi M, Bernardo A. Ajnone-Cat MA, Minghetï L, Malch hodi-Albedi $F$; The presence of astrocytes enhances beta amyloid-induced neturotoxicity in hippocampal cell cultures. J Physiol Paris 2002, 96:313-316

24. Wyss-Coray T, Loike JD, Brionne TC, Lu E, Anankov R, Yan F, Silverstein SC, Husenanu J: Aduli motise astrocytes degrade anyloid beta in vifo and in sin. Nat Med 2003, 9:453-457

25. MoGeer PL, McGeer EG: Local neuromflammation and Dhe progression of Alzhemer's disease. I Neurovirol $2002,8: 529-538$

26. Meda L, Baron P. Searlato G: Glial actiwation in Alzheimer's disease- the role of Abeta and its associated proteins. Neurobioll Aging 2001, 22:885 893

27. Stalder M, Phinney A, Probst A, Sommer B, Staufenbicl M, Jucker J: Association of microglia with anyloid plaques in brains of APP23 transgenic mice. Am J Pathol 1999, 154:1673-1684

28. Moechars D, Dewachter I, Lorent $K$, Reverse D, Baekelandt V, Naidu A, Tegseur I, Spittaels K, Haute CV, Checler F, Godaux $E_{3}$ Cordell B, Van Lewwen $F$ : Early phenotypic changes in trangenic mice that overexpress different mutants of armyloid precursor protein in brain. I Biol Chem 1999, 274:6483-6492

29. Pratico D, Uryu K, Leight 5 , Trojanoswki IO, Lee VM: Increased lipid peroxidation precedes amyloid plaque formation in an animal model of Alzheimer amyloidosis. J Neurosci 2001, 21:4183-4187

30, MeLean CA, Chemy RA, Fraser FW, Fuller SI, Smith MS, Beyreuther K, Bush AI, Masters CL: Soluble pool of Abeta amyloid as a determinant of severity of neurodegeneration in Alzheimer's discase. Ani Neurol 1999 . $46: 860-866$

31. Kayed R, Head E, Thompson JL, Mcintire TM, Milton SC, Coman CW, Glabe CG: Common structure of soluble anyloid oligomers implies common mechanism of pathogenesis. Science 2003, $300: 486-489$ 


\section{Chapter 9}

\section{Age-related loss of synaptophysin immunoreactive presynaptic boutons within the hippocampus of APP751 $1^{\mathrm{SL}}$, PS1 ${ }^{\text {M146L }}$ and APP751 $1^{\text {SL }} / \mathrm{PS} 1^{\text {M146L }}$ transgenic mice}

American Journal of Pathology, 2005;167(1):161-173

Bart P.F. Rutten, Nicolien M. Van der Kolk, Stephanie Schaefer,

Marc A.M.J. van Zandvoort, Thomas A. Bayer, Harry W.M Steinbusch, Christoph Schmitz 


\section{ABSTRACT}

Neuron and synapse loss are important features of the neuropathology of Alzheiner's disease (AD). Recently we observed substantial agemrelated hippocampal neuron loss in APP751 ${ }^{\text {s4 }}$ PS1 ${ }^{\mathrm{Mi} 46 \mathrm{~L}}$ transgenic mice but not in PS1 ${ }^{\mathrm{MI} 46 \mathrm{~L}}$ mice. Here we investigated APP751 ${ }^{\text {sL }}$ mice,

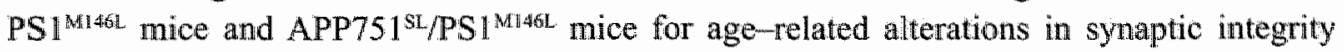
within hippocampal stratum moleculare of the dentate gyrus (SM), stratum lucidum of area CA3 (SL) and stratum radiatum of area CA $1-2$ (SR) by analyzing densities and numbers of synaptophysin-immunoreactive presynaptic boutons (SIPB). Wild-type mice, APP751 ${ }^{\text {SL }}$ mice and PS1 ${ }^{\text {ML } 146 L}$ mice showed similar amounts of age-related SIPB loss within SM, and no SIPB

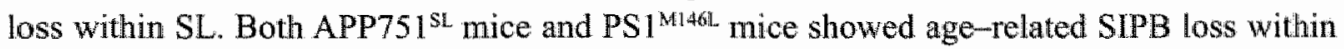
SR. Importantly, APP75I $\left.{ }^{\text {SL }} / \mathrm{PS}\right]^{\mathrm{M} 146 \mathrm{~L}}$ mice displayed the severest age-related SIPB loss within SM, SL and SR, even in regions free of extracellular A $\beta$ deposits. Together these mouse models offer a unique framework to study the impact of several molecular and cellular events caused by mutamt APP and/or mutant PSI on age-related alterations in synaptic integrity. The observation of age-related SIPB loss within SR of PS 1 $^{\text {Mi46L }}$ mice supports a role of mutant PS 1 in neurodegeneration apart from its contribution to alterations in $A \beta$ generation.

\section{INTRODUCTION}

Alzheimer"s disease ( $A D$ ) is a progressive neurodegenerative disorder comprising cognitive and memory deterioration, progressive impairment of activities of daily living, and several neuropsychiatric symptoms.' The neuropathology of AD is characterized by disturbances in neural circuits, such as loss of neurons and synapses, and by protein aggregations of $\beta$-amyloid and hyperphosphorylated tau. ${ }^{2-4}$ Accunulating evidence has indicated a crucial role for failure and loss of synapses in AD pathophysiology: ${ }^{2,4,5}$ Postmortem morphologic studies on AD neuropathology have demonstrated significantly reduced synaptic connectivity in brain regions as the neocortex and hippocampus. ${ }^{3,6,7}$ Reductions in synaptic densities showed a strong correlation with cognitive decline in $A D{ }^{5}$ However, the reasons for the reduced connectivity in $A D$ remain poorly understood. ${ }^{8}$ According to the " $\beta$-amyloid $(A \beta)$ hypothesis of $A D$ ', $A \beta$ accumulation is the primary driving force in AD pathogenesis. This hypothesis is supported by the fact that mutations in the amyloid precursor protein (APP) and in presenilins 1 (PS1) and 2, causing eamly-onset cases of $A D$, modify APP processing and result in enhanced generation of $A \beta^{*}$. We have developed a transgenic mouse model of AD expressing human mutant APP75 1 (carrying the Swedish and London mutations KM670/67 INL and V7171, Thyl promoter; APP751 ${ }^{\mathrm{sL}}$

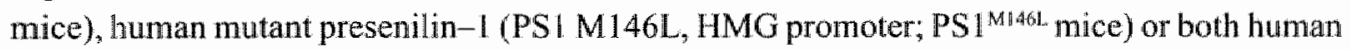
mutant APP751 and human mutant presenilin-1. (APP751 $1^{\text {sL/PS1 }}{ }^{\text {M146. }}$ mice) in neurons ${ }^{9-12}$ (see also ${ }^{8,13}$ ). Similar to what happens in human $A D$, the amount of extracellular $A \beta$ deposits as well

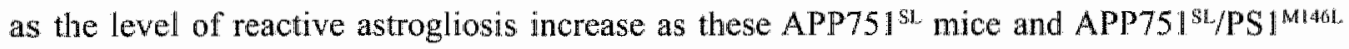
mice age. ${ }^{9-12}$ Furthermore, the APP751 $1^{\mathrm{SL} / P S 1^{\mathrm{M} / 46 \mathrm{~L}}}$ mice show substantial age-related loss of hippocampal pyramidal cells. ${ }^{12}$ Importantly, the amount of neuron loss exceeded the amount 
of $A \beta$ deposits and associated reactive astrogliosis in these mice, indicating that the observed neuron loss was at least in part independent of $A \beta$ deposits. ${ }^{12}$ Given the popular belief that extracellular $A B$ deposits are the cause of neuronal degeneration in $A D, 4$ these findings have prompted modification of the original "amyloid cascade" hypothesis for $A D^{13,14}$

It was the aim of the present study to test the hypothesis that these APP751 $1^{\mathrm{SL}}$ mice, PS1 ${ }^{\mathrm{M} 146 \mathrm{~L}}$ mice and $\mathrm{APP} 75 \mathrm{I}^{\mathrm{SL}} / \mathrm{PS} 1^{\mathrm{M} 146 \mathrm{~L}}$ mice show region-specific, age-related alterations in synaptic integrity within the hippocampus, with region-specific differences among the investigated genotypes. Another aim was to determine to what extent these alterations in synaptic integrity were due to $A \beta$ deposits within the hippocampus and to hippocampal neuron loss. The investigations were carried out by two-photon laser scanning microscopy, computerized image analysis and design-based stereology, focusing on densities and numbers of synaptophysin-immunoreactive presynaptic boutons (SIPB). Analysis of SIPB is a well established approach for investigating alterations in synaptic integrity in vivo both in our ${ }^{5,16}$ and in many other laboratories. ${ }^{17-21}$

\section{MATERIALS AND METHODS}

\section{Animals}

The following groups of either 4.5-month-old (M4.5) or 17-month-old (M17) female mice were examined in the present study: wild-type control mice (C57Bl6 background; M4.5: $\mathrm{n}=6 ; \mathrm{M17}$ : $\mathrm{n}=6$ ), APP751 $1^{\text {sL }}$ mice (transgenic mice expressing human mutant APP75 1 carrying the Swedish and London mutations KM670/67INL and V717I; Thy1 promoter; C57B16 [87.5\%] $\times \mathrm{CBA}$ [12.5\%] background; $M 4.5: n=6 ; M 17: n=3$ ), PS $1^{\mathrm{M} 146 \mathrm{~L}}$ mice (transgenic mice expressing humam mutant presenilin-1. [PS1 M146L_]; HMG promoter; back-crossed on a C57B16 background for more than six generations; M4.5: $n=6 ; M 17: n=6$ ) and APP75 $1^{\text {sL/PS }} 1^{\text {M146 }} \mathrm{L}$ mice (APP/PS1 double-transgenic mice carrying the aforementioned APP and PS1 mutations; M4.5: $n=6$; M17: $n=6$ ). All mice were generated at the SanofiAventis Centre de Recherche de Paris (Vitry sur Seine, France) (for details see ${ }^{9-12}$ ). The APP751 $1^{\text {SL }} /$ PS1 $^{\text {M146L }}$ mice were generated by crossing homozygous PS1 mice to hemizygous APP751 $1^{\text {SL }}$ mice. In the present study hemizygous PS $1^{\text {Mit4LL }}$ littermates were used. All experiments were performed in accordance with the German animal protection law.

\section{Tissue processing}

Mice were anesthetized with chloral hydrate and sacrificed by intracardial perfusion fixation with tyrode followed by fixative containing $4 \%$ paraformaldehyde, $15 \%$ picric acid, and $0.05 \%$ glutaraldehyde in phosphate buffer ( $\left(\mathrm{se}^{12}\right.$ for details). Brains were removed rapidly, halved in the mediosagittal line, and post-fixed for 2 hours at $4^{\circ} \mathrm{C}$ in the fixative, omitting the glutaraldehyde. Brain tissue was then cryoprotected by immersion in $30 \%$ sucrose in Tri-buffered saline at $4^{\circ} \mathrm{C}$ overnight. Afterward, brains were quickly frozen and stored at $-80^{\circ} \mathrm{C}$ until further processing. The right hemispheres were cut into entire series of $30 \mu \mathrm{m}$ thick frontal sections on a cryostat (Leica CM 3050; Leica, Nussloch, Germany). Afterwards these series were divided 
into 10 subseries of every 10 th section each. The hippocampus was found on five to eight sections per subseries depending on the individual rostrocaudal extension of the hippocampus. Four subseries of sections per animal (from the wild-type control mice, the PSI Mital mice and the APP751 $1^{\text {SL }} /$ PS1 $^{\text {M1462 }}$ mice but not from the APP751 $1^{\mathrm{SL}}$ mice) were used in a former study ${ }^{12}$ to investigate age-related alterations in neuron numbers, the amount of $A \beta$ deposits, apoptotic cell death and microglia activation within the hippocampus. The left hemispheres were not used for the present study.

\section{Investigation of alterations in SIPB morphology due to $A \beta$ deposits}

To investigate normal SIPB morphology and its alterations due to $A \beta$ deposits, one subseries of sections per animal was used for immunohistochemical detection of both synaptophysin and $\beta$-amyloid (monoclonal mouse anti-synaptophysin antibody, 1:2,000; Chemicon, Temecula, CA; rabbit anti-730 antibody detecting $\beta$-amyloid and $\mathrm{P} 6,{ }^{22}$ 1:5,000; generous gift from Dr. G. Multhaup). Briefly, fluorescent immunohistochemistry was carried out in a free floating manner using standard protocols. Sections were incubated overnight at $4^{\circ} \mathrm{C}$ after rinsing with tri-buffered saline (TBS) and TBS with Triton-X 100 (TBS-T) and blocking of unspecific staining with $10 \%$ fetal calf serum and $4 \%$ non-fat-dry-milk in TBS. On the following day the sections were rinsed and incubated with secondary antibodies for 1.5 hours at room temperature. Donkey anti-mouse IgG Alexa Fluor 488 antibody (1:100; Molecular Probes, Eugene, OR, USA) and donkey anti-rabbit IgG Alexa Fluor 594 antibody (1:100; Molecular Probes), were used as secondary antibodies. Sections were mounted on gelatinized glass slides, dried and coverslipped using $80 \%$ glycerol in PBS. Sections were analyzed with standard fluorescence microscopy and two-photon laser scanning microscopy (TPLSM). TPLSM was performed as preciously described 23 using a microscope objective $(60 \times$, water dipping, numerical aperture [NA] 1.0) connected to an upright Nikon E600FN microscope (Nikon Corporation, Tokyo, Japan). If needed, further magnification was achieved by an optical zoom in the scan head. To remove noise each image was filtered applying the Kalman filtering procedure on three subsequent images during experiments. The fluorescent secondary antibody Alexa 488 was mainly visible in the green channel, whereas Alexa 594 was only visible in the red channel and the obtained images (coded green and red, respectively) were combined into single images if warranted.

\section{Analysis of SIPB densities}

To analyze SIPB densities in various hippocampal subregions, one subseries of sections per animal was used for immunohistochemical detection of synaptophysin (monoclonal mouse anti-synaptophysin antibody; $1: 2,000$; Chemicon; avidin-biotin immunoperoxidase labeling) (Figure 1A to D). The M.O.M. immunodetection kit (Vector Laboratories, Peterborough, UK) was used according to the marnufacturer's protocol to minimize background labeling and labeling of intraparenchymal IgG molecules. Control experiments comprised incubations without primary antibody and incubations without use of the M.O.M. immunodetection kit (Vector). All incubations were performed in a free-floating manner under exactly identical conditions. 
After labeling procedures, sections were mounted on gelatinized glass slides, dehydrated, coverslipped and coded. The code was not broken until all analyses were completed.

SIPB densities were analyzed as previously described ${ }^{15,16}$ within three subregions of the hippocampus, stratum molleculare of the dentate gyrus (SM), stratum lucidum of area CA3 (SL) and stratum radiatum of area $\mathrm{CAI}-2$ (SR) (Figure $\mathbb{1 E}$ ). Three randomly chosen areas per section were evaluated within SM and SR each, and two randomly chosen areas within SL (Figure IE). Three high-power photomicrographs were taken from each evaluated area at approximately $2 \mu \mathrm{m}$ below the upper surface of the sections (i.e., when the SIPB were clearly in focus) with a digital camera (F-view, Olympus, Tokyo, Japan) attached to an Olympus $\mathrm{AX}-70$ microscope $(100 \times$ oil objective, Olympus UplanApo, $N A=1.35$ ). This procedure resulted in 45 to 72 photomicrographs for SM and SR each per animal ( 3 photomicrographs $\times 3$ areas $\times[5$ to 8$]$ sections), and in 30 to 48 photomicrographs for SL per animal (2 photomicrographs $\times 3$ areas $\times[5$ to 8 ] sections) (Figure $\left[F\right.$ to $H$ ). In case of the APP751 ${ }^{\text {sL }}$ mice and the APP751 $1^{\text {SL }} / P S 1^{\text {M146 }} \mathrm{L}$ mice photomicrographs were exclusively taken at regions free of $A \beta$ deposits and $A \beta$ aggregation-related disturbances in normal SIPB morphology. A $\beta$ deposits were clearly recognizable as round/oval structures not immunoreactive for synaptophysin and surrounded by multiple enlarged SIPB and disturbed neuropil (Figure 11). SIPB were detected by image analysis using AnalySI-pro software (Soft Imaging System, Münster, Germany), slightly modified for detection of grayscale punctae as previously described..$^{16}$ All settings were kept identical for all analyses. Shading error correction was performed before measurements were done to correct for irregularities in illumination of the microscopic fields. Furthermore, background levels were equalized. From these data, mean particle densities per $\mu m^{2}$ were calculated. To enable the elimination of noise signal and to differentiate between possible artifacts and specific SIPB, the normal size of SIPB was evaluated separately for SM, SL and SR in a pilot experiment. For doing so, the area occupied by individual particles with a morphological appearance of SIPB was measured separately within SM, SL and SR in three wild type mice using the AnalySI-pro software (Soft Imaging System). A total of 400 particles were measured per hippocampal subregion. SIPB areas were on average $0.33 \pm 0.12 \mu \mathrm{m}^{2}$ (mean \pm S.D.) in SM, $1.02 \pm 0.38 \mu \mathrm{m}^{2}$ in SL and $0.36 \pm 0.13 \mu \mathrm{m}^{2}$ in SR. The different SIPB size can be seen in Figure IF to $\mathrm{H}$. A region-specific range of [mean $\pm(2 \times S . D$.)] was considered as normal SIPB size, and these settings were kept identical for all analyses. Size measurements of all SIPB investigated in the present study indicated no differences in average SIPB size between the various groups of mice. Additional pilot studies (not described here) indicated that average SIPB size was independent from the plane of section (i.e., identical results were obtained on frontal, sagittal and horizontal sections of mouse brains).

\section{Measuring volumes of SM, SL and SR}

Volumes of SM, SL and SR were evaluated on the sections immunohistochemically processed for synaptophysin detection with avidin-biotin immunoperoxidase labeling with the aid of another subseries of sections per animal stained with cresyl-violet (Nissl) staining (0.01\%) as previously described. ${ }^{12.16}$ Briefly, the Nissl-stained sections were laid onto the corresponding adjacent sections processed with immunohistochemistry and were exactly aligned. Then SM, 
SL and SR were delineated according to the literature ${ }^{24}$ (Figure $1 \mathrm{~K}$ ). Delineation was carried out with a stereology workstation and StereoInvestigator software (MicroBrightField, Williston, VT, USA) as previously described. ${ }^{16}$ For doing so, the Nissl-stained sections were brought into focus. After delineation these sections were removed, and the sections processed with mmunohistochemistry were brought into focus and the boundaries of SM, SL and SR were verified. Volumes of SM, SL and SR were calculated with Cavalieri's principle ${ }^{25,26}$ from the projection area measurements and the average actual section thickness after histologic processing. The latter was measured with the electronic microcator of the stereology software and a $40 \times$ oil objective (Olympus UplanApo; NA $=1.00$ ) as described. ${ }^{26}$

\section{Calculation of SIPB numbers}

Hippocampal subregion-specific SIPB numbers were calculated by multiplying the individual SIPB density data with the corresponding volume data. Note that these SIPB numbers were not unbiased since SIPB densities were analyzed in one focal plane and thus in two dimensions (2D) instead of in three dimensions (3D) ${ }^{26}$ Thus, the calculations did not take the dimensions of the investigated parameters (i.e., $1 / \mu \mathrm{m}^{2}$ [SIPB density] and $\mathrm{mm}^{3}$ [volume]) into account. Importantly, this did not affect the results of the present study since for all groups of mice, similar distribution plots were obtained for individual SIPB size (not shown) and the average SIPB size was independent from the plane of section. Calculating unbiased total numbers of SIPB was not the aim of the present study.

\section{Calculation of corrected SIPB numbers}

For the analysis of the APP751 $1^{\mathrm{SL}}$ mice and the APP751 ${ }^{\mathrm{SL}} / \mathrm{PS} 1^{\mathrm{M} 146 \mathrm{~L}}$ mice the calculation of SIPB numbers resulted in theoretical numbers assuming that $A \beta$ deposits did not influence normal SIPB morphology (since SIPB densities were exclusively measured at regions free of $A \beta$ deposits and $A \beta$ aggregation-related disturbances in normal SIPB morphology as explained above). To take the impact of $A \beta$ deposits on SIPB numbers into account, the percent volumes of SM, SL and SR occupied by A $\beta$ deposits and A $\beta$ aggregation-related disturbances in nomal SIPB morphology (as depicted in Figure 1I) were analyzed with point counting methods ${ }^{26,27}$ oni the sections immunohistochemically processed for synaptophysin detection with avidin-biotin immunoperoxidase labeling. Point counting was performed on the stereology workstation with the $40 \times$ oil objective and a distance of $50 \mu \mathrm{m}$ between the points in mutually orthogonal directions $X$ and $Y$ for SM and SR (and $20 \mu \mathrm{m}$ for SL, respectively). Corrected SIPB numbers for the APP751SL mice and the APP751 ${ }^{\text {SL/PS1 }}{ }^{\mathrm{M} 146 \mathrm{~L}}$ mice were calculated by subtracting the volume occupied by $A \beta$ deposits and $A \beta$ aggregation-related disturbances in normal SIPB morphology from the total volume of the investigated hippocampal subregions, and by multiplying this value with the mean SIPB density found within the corresponding hippocampal subregion. Thus, corrected SIPB numbers for the APP751 $1^{\text {SL }}$ mice and the APP751 $1^{\text {SL. }} /$ PS $1^{\text {M146L }}$ mice were smaller than the corresponding uncorrected SIPB numbers. For the wild-type control mice and the PS1 ${ }^{\mathrm{M} 146 \mathrm{~L}}$ mice the corresponding uncorrected SIPB numbers could serve as corrected SIPB numbers as well. This was due to the fact that these mice did not develop $A \beta$ deposits. 

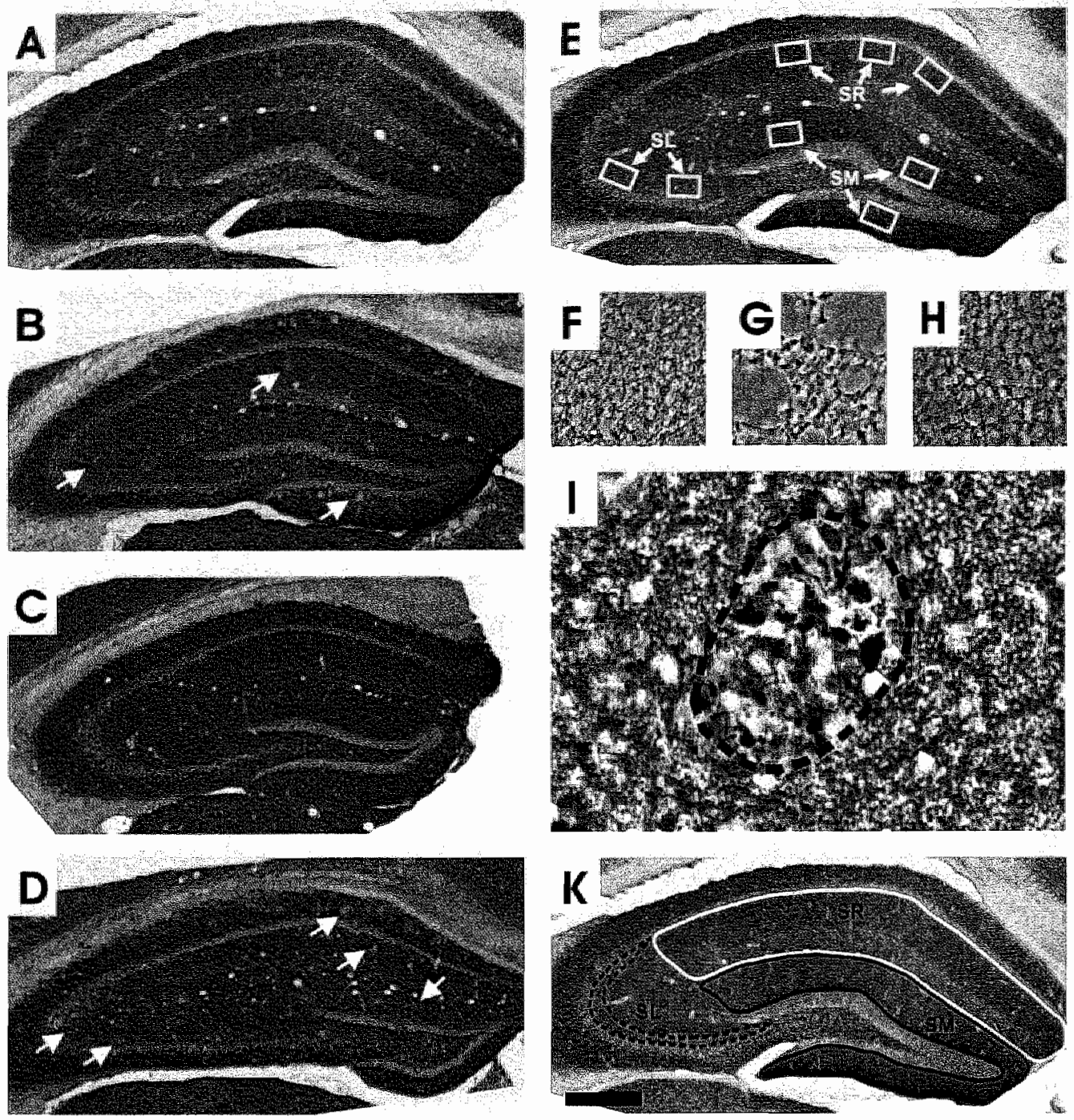

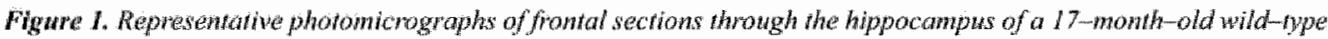

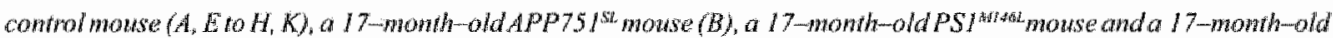

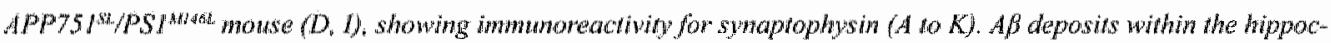

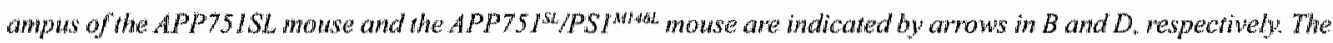
small squwes in E represent the areas where the high-power phatomicnographs for quantiratine synaptophysin-immu-

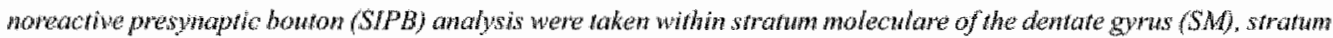
Incidum of area CA3 (SL) and stratw radianm of area CA I-2 (SR). Correspanding high-power photomicrographs depict larger SIPB with SL (G) than within SM (A) and SR (H) AB deposits were clearly recognzable as noundioval

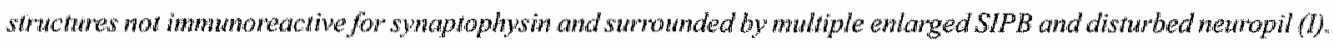
The dorted tine in Indicates the delineation of AB depasits as performed for the analysis of SRP densivies in regions

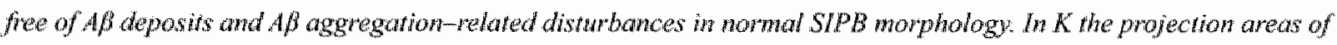

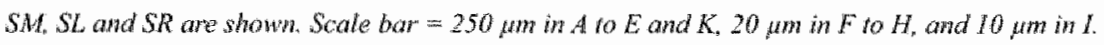




\section{Statistical analysis}

For each group of mice mean and standard error of the mean were calculated for all investigated variables (hippocampal subregion-specific SIPB density, volume of the subregion, SIPB number and corrected SIPB number if applicable). Comparisons between the groups were performed separately for SM, SL and SR with two-way analysis of variance (two-way ANOVA; four genotypes and two age groups per genotype) followed by Bonferroni post-tests to compare repllicate means focusing on age-related effects. Statistical significance was established at $\mathrm{P}<$ 0.05. All calculations were performed using GraphPad Prism (Version 4.00 for Windows, GraphPad Software, San Diego, USA).

\section{Photography}

Pictures shown in Figure IA to E and IK were generated with the stereology workstation using the Virtual Slice tool of the Stereolnvestigator software which automatically created high-resolution seamless image montages composed of approximately 100 individual field-of-view visualized at high resolution. Photomicrographs shown in Figure IF to I were taken with the Olympus AX-70 microscope. Pictures shown in Figure 2 and 3 were acquired using TPLSM. Image stacks were reconstructed into three dimensional images followed by colocalization analysis with Imaris software (Bitplane, Zurich, Switzerland). Final figures were constructed using Corel Draw Version 11.0 (Corel, Ottawa, Canada) and Adobe Photoshop Version 7.0 (Adobe, San Jose, CA, USA). Only minor adjustments of contrast and brightness were made, which in no case altered the appearance of the original materialls.

\section{RESULTS}

\section{Alterations in SIPB morphology due to $A \beta$ deposits}

$A \beta$ deposits within the hippocampus were detected in APP751 $1^{\text {SL }}$ mice at M17 and in APP751 ${ }^{\text {SL/ }}$ PS ${ }^{\text {M146L }}$ mice at M4.5 and M17. No synaptophysin immunoreactivity was observed within the core of the $A B$ deposits. Regions directly adjacent and surrounding the $A \beta$ deposits showed substantial alterations in synaptophysin immunoreactivity. Specifically, considerably enlarged SIPB were detected (up to $8 \mu \mathrm{m}$ in diameter) close to the AB deposits (Figure 2). Three-dimensional reconstruction of TPLSM image stacks showed that some of these enlarged SIPB were surrounded by $A \beta$ (Figure 2).

\section{SIPB densities}

Two-way ANOVA showed statistically significant age-- and genotype-related differences in mean SIPB densities within SM, SL and SR (all $p$ values of two-way ANOVA are summarized in Table 1). Bonferroni post-tests showed a significant age-related decline in mean SIPB densities

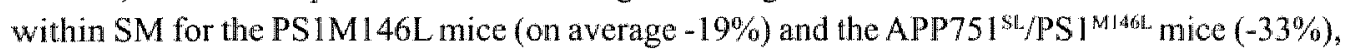
within SL only for the APP75 $1^{\mathrm{SL}} / \mathrm{PS} 1^{\mathrm{M} 146 \mathrm{~L}}$ mice $(-27 \%)$, and within SR for the PS1MI46L mice $(-24 \%)$ and the APP75 $1^{\text {sL }} /$ PS $]^{\text {M1146L }}$ mice $(-31 \%)$ (data and $p$ values of Bonferroni post-tests shown in Figure $3 \mathrm{~A}$ to $\mathrm{C}$ ). 


\section{Volumes of SM, SL and SR}

Two-way ANOVA indicated significant age-related differences in mean volumes of SM, SL and SR (see Table 1 for all $p$ values). In case of SM and SR differences in mean volumes were also significant among the investigated genotypes. However, Bonferroni post-tests showed a significant age-related decline only in the mean volume of SM in the APP751 ${ }^{\text {SL/PS }}{ }^{\mathrm{M} 146 \mathrm{~L}}$ mice (on average $-26 \%$ ) (Figure $3 \mathrm{D}$ to $\mathrm{F}$ ).

\section{SIPB numbers}

As for mean SIPB densities and the mean volumes of SM, SL and SR two-way ANOVA indicated significant age-related differences in mean SIPB numbers within all investigated hippocampal subregions (see Table 1 for all $\mathrm{p}$ values). In case of SM and SR differences in mean SIPB numbers were also significant among the investigated genotypes. Bonferroni post-tests showed a significant age-related decline in mean SIPB numbers within SM for the wild-type control mice (on average $-19 \%)$, the PSI ${ }^{\mathrm{M} 146 \mathrm{~L}}$ mice $(-24 \%)$ and the APP $751^{\mathrm{SL}} / \mathrm{PS} 1^{\mathrm{M} 146 \mathrm{~L}}$ mice $(-49 \%)$, within SL only for the APP751 $1^{\text {SL/PS }} 1^{\mathrm{Mi} 46 \mathrm{~L}}$ mice $(-33 \%)$, and within SR for the PS1 ${ }^{\mathrm{M} 146 \mathrm{~L}}$ mice $(-30 \%)$ and the APP751 1 SL $/$ PS ${ }^{\text {M } 146 L}$ mice $(-38 \%)$ (for data and p values of Bonferroni post-tests see Figure $3 \mathrm{G}$ to I).

\section{Corrected SIPB numbers}

Two-way ANOVA revealed statistically significant age- and genotype-related differences in mean corrected SIPB numbers within SM, SL and SR (the p values of two-way ANOVA are given in Table 1). Bonferroni post-tests showed a significant age-related decline in mean corrected SIPB numbers within SM for all investigated genotypes (wild-type control mice: $-19 \%$ on average; APP751 $1^{\mathrm{SL}}$ mice: $-19 \%$; PS1 ${ }^{\mathrm{M} 146 \mathrm{~L}}$ mice: $-24 \% ;$ APP751 ${ }^{\mathrm{SL}} / \mathrm{PS} 1^{\mathrm{M} 146 \mathrm{~L}}$ mice: $-56 \%$ ), within SL only for the APP751 1 SL $/$ PS1 $146 \mathrm{LL}$ mice $(-42 \%)$ and within SR for all investigated genotypes except for the wild-type control mice (APP751 ${ }^{\mathrm{SL}}$ mice: $-32 \%$; PS1 ${ }^{\mathrm{M} 146 \mathrm{~L}}$ mice: $-30 \%$; APP751 ${ }^{\mathrm{SL}} /$ PS1 $1^{\mathrm{M} 146 \mathrm{~L}}$ mice: $-51 \%$ ) (data and $\mathrm{p}$ values of Bonferroni post-tests shown in Figure $3 \mathrm{~K}$ to $\mathrm{M}$ ).

Table 1. Results of two-way ANOVA (p values).

\begin{tabular}{ccccc} 
& & SM & SL & SR \\
\hline SIPB density & Age & $<0.001$ & 0.009 & 0.001 \\
& Genotype & $<0.001$ & 0.014 & 0.001 \\
& Interaction & 0.001 & 0.004 & 0.015 \\
Volume of the subregion & Age & 0.001 & 0.002 & $<0.001$ \\
& Genotype & $<0.001$ & 0.290 & 0.036 \\
& Interaction & 0.114 & 0.755 & 0.440 \\
SIPB number & Age & $<0.001$ & 0.004 & $<0.001$ \\
& Genotype & $<0.001$ & 0.077 & $<0.001$ \\
& Interaction & 0.018 & 0.059 & 0.024 \\
Corrected SIPB number & Agge & $<0.001$ & 0.001 & $<0.001$ \\
& Genotype & $<0.001$ & 0.016 & $<0.001$ \\
& Interaction & 0.004 & 0.056 & 0.002
\end{tabular}

SM, hippocampal stratum moleculare of the dentate gyrus; SL, hippocampal stratum incidum of area CA.3: SR, hippocampal stratum radiatum of area CAl 1-2 

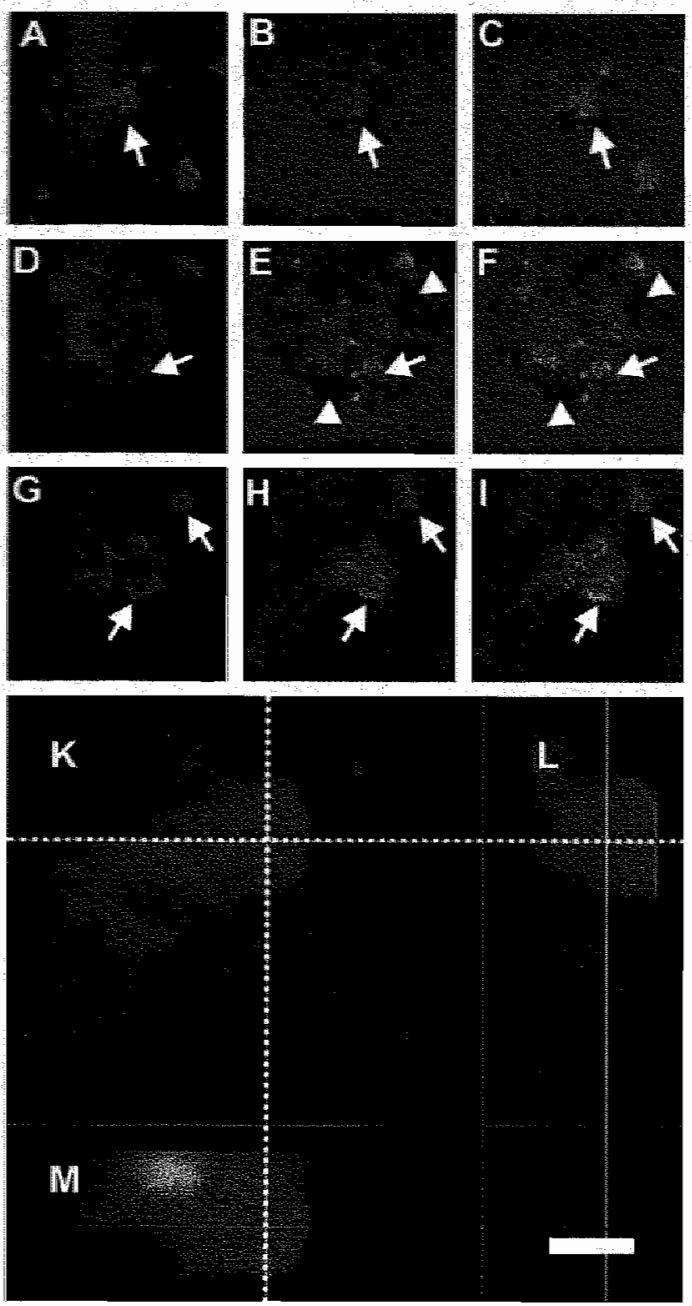

Figure 2. Representative high-power photomicngraphs obtained by two photon laser scanning microscopy (TPLSM), showing alterations in symaptic integrity caused by $A B$ deposits withim hippocampal

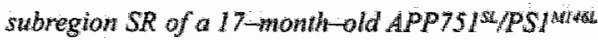
mowse. AP immunoreactivity is shown in red in $A, D$ and $G$, symaptophysin immunoreactivity at the com responding locations and focal planes in green in $B$, $E$ and $H$, and merged pictures $i n C . F$ and 1. Note the disturbed synaptophysin-immumareactive presywaptic bouton (SIPB) morphology within and in the near wicinity of the AB deposits (arnows). The SIPB-free regions around the $A B$ deposits (arrowheads in $E$ and F) are most probably caused by astrocytes surrounding the $A \beta$ deposits. Interestingly. several enlarged SIPB were entirely surroumded by R-amyloid (arrows in I). In K to M a three dimewsional reconstruction of a representative image stack acquired" with TPLSM is shown, displaying synaptophysin (green) and $A B$ (red) immumoreactivity within SR of a 17-month-old

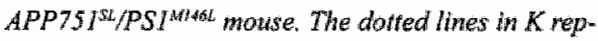
resent the position within the $X-Y$ wiew at which the $Y-Z$ view $(L)$ and the $X-Z$ wiew $(M)$ were geverated. The depicted enlarged sywaprophysin-immunoreacrive presynaptic bouton is surrounded by a rim of $A B$ immunoreactivity. Scale bar $=100 \mu \mathrm{m}$ in $\mathrm{A}$ to $\mathrm{C}$, $50 \mu \mathrm{m}$ in $D$ to $\mathrm{l}$, and 5 um in $K$ to $M$.

\section{DISCUSSION}

\section{Alterations in SIPB morphology due to $A \beta$ deposits}

In the present study enlarged SIPB were found in the near vicinity of $A B$ deposits within the hippocampus of the APP751 $1^{\mathrm{SL}}$ mice and the APP751 $1^{\mathrm{SL}} / \mathrm{PS} 1^{\mathrm{M} 1.46 \mathrm{~L}}$ mice. This finding is in line with several studies in the literature reporting the presence of enlarged SIPB in AD patients ${ }^{28}$ as well as in APP transgenic and APP/PS1 transgenic mice..$^{21,29-33}$ Furthermore, dystrophic neurites with swollen varicosities in the near vicinity of $A B$ deposits as well as spine loss and shaft atrophy have been reported in APP transgenic and APP/PS1 transgenic mice. ${ }^{29,30,34,35}$ Of particular interest was the observation of a close spatial relationship between aggregated $A B$ and enlarged SIPB in the present study. One may speculate that A.B deposits are involved in the formation of enlarged SIPB. In this respect, a study by Phinney et al. ${ }^{36}$ indicated that A.B deposits in APP23 mice may attract dystrophic axonal terminals. However, it is also possible that enlarged SIPB are involved in the production or secretion of $A \beta$. Recent evidence indicating that axonally 
SM
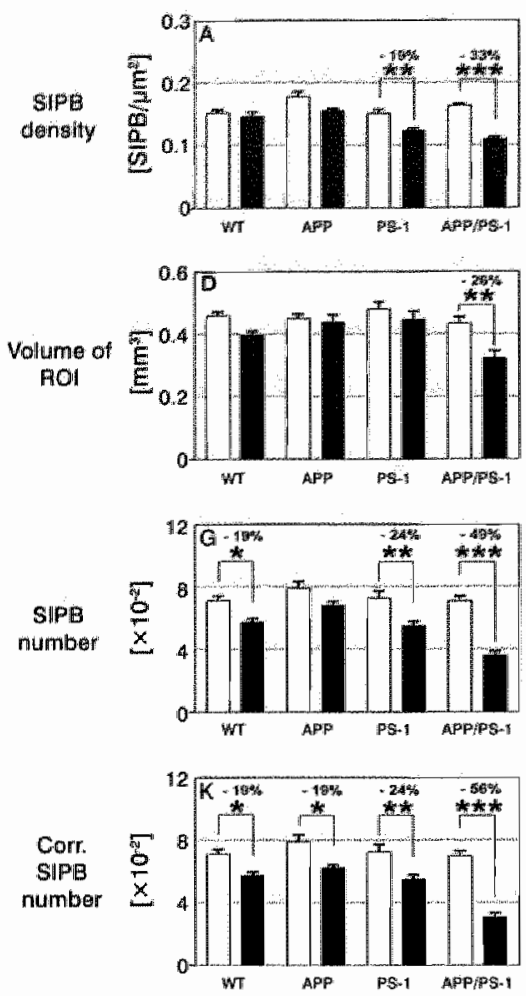

SL
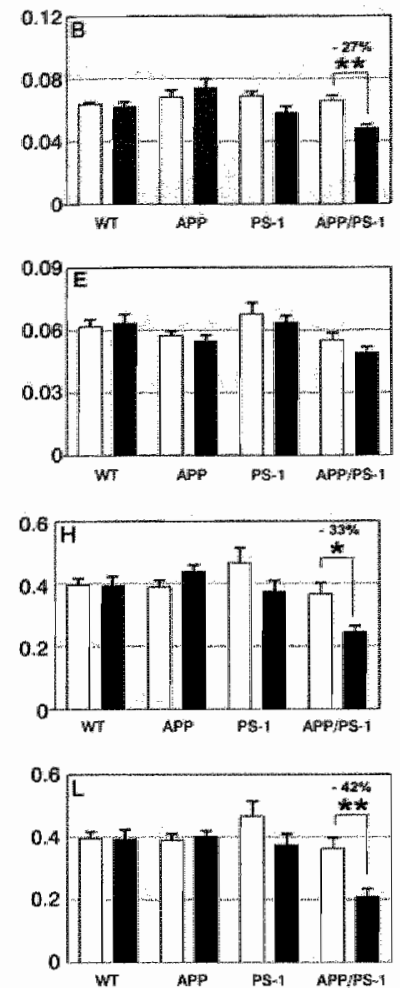

SR
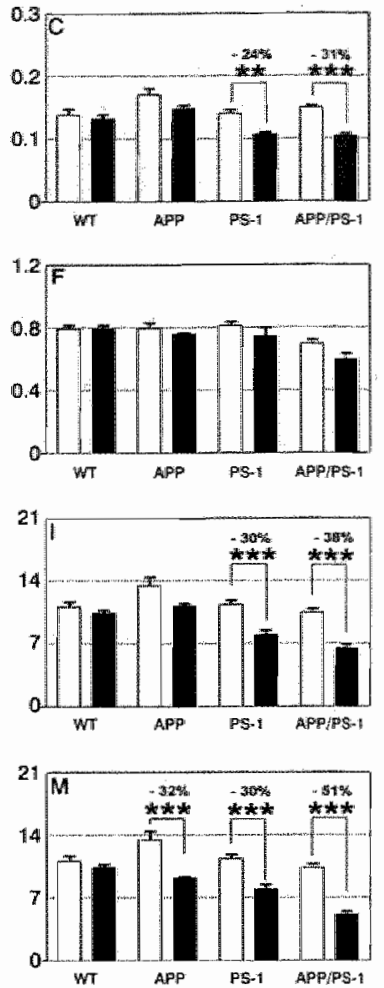

Figure 3. Resulls of the quantitative investigations in the hippocampus. Analysis of hippocampal stratum moleculare of the dentate gyrus (SM:A,D, G, K), stratum lucidum of area $C A 3$ (SL; B, E, H, L) and stratum radianum of area CA 1-2

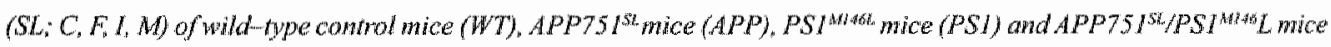
(APP/PSI) for age-related alterations in synaprophysin-immunoreactive presynaptic bouton (SIPB) densities within regions free of $A B$ deposits and AB aggregation-related disturbances in normal SIPB morphology $(A, B, C)$, volumes of SM. SL and SR (D, R, FI, SIPB numbers within regions free of A $\beta$ deposits and A $\beta$ aggregation-related disturtonces in normal SIPB morphortogy (G, H, I) and corrected SIPB number considering the amount of AB deposits within SM. SL and SR (K, Lo, M) Results of 4.5-momth-old mice (M4.5) are represented by open burs: those of 17-month-old mice (MT) by dosed bars. Dota are given as mean and S.E.M. Comparisons between the groups were performed

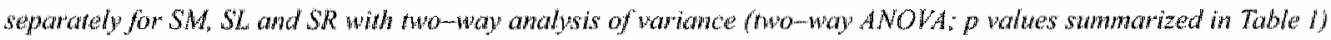
followed by Bonferroni post-tests to compane replicare means focusing on age-related effects (p values provided as *

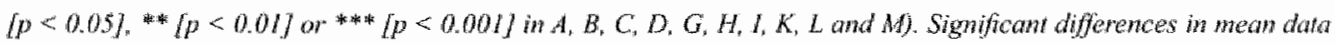
ane indicated (MI 7 W M4.5) above each graph. ROI, region of inverest; Corr, corrected. SIPB mumbers were calculared by multiplying the indivdual SIPB density data with the corresponding volume data not considering the dinnensions (see Materials and wethods for defoils).

transported $A P^{3}$ can give rise to $A \beta$ and that $A \beta$ is subsequently released from presynaptic sites and deposited in $A \beta$ deposits in wivo ${ }^{3.2}$ may argue for the latter speculation. Furthermore, APP, presenilins and synaptophysin have been shown to co-localize at the growth cones of 
developing cultured neurons. ${ }^{38}$ In summary it is reasonable to conclude that AB deposits play an important role in degeneration of presynaptic structures and have therefore considerable impact on local synaptic connectivity.

\section{Alterations in SIPB densities and SIPB numbers in APP751 ${ }^{\text {sL }}$ and APP751 ${ }^{\text {SL/PS1 }}$ M146L $^{\text {transgenic mice }}$}

The wild-type control mice investigated in the present study did not show significant differences in mean SIPB densities within hippocampal subregions SM, SL and SR and in mean volumes of these subregions between 4.5 months and 17 months of age. Furthermore, an age-related decline in mean SIPB number was only observed within SM but not within SL and SR of the wild-type control mice. These data are in line with previous reports in the literature, ${ }^{19,20,34,40}$

Transgenic expression of human mutant APP and human mutant PSI in the investigated mice had significant, region-specific effects on mean SIPB densities and SIPB numbers within the investigated hippocampal subregions. Compared to the age-matched wild-type control mice, the APP751 ${ }^{\text {sh }}$ mice showed transgene-induced age-related loss of SIPB only within SR (results of the $\mathrm{PS} 1^{\mathrm{M} 146 \mathrm{~L}}$ mice are separately discussed below). Within $\mathrm{SM}$ a similar amount of age-related loss of SIPB was observed in the wild-type control mice, the APP75 $1^{\text {SL }}$ mice and the PS $1^{\text {W1 }}$-46L. mice. Furthermore, none of these mice showed an age-related loss of SIPB within SL. In contrast, the APP75 $1^{\text {SL/PS }} 1^{\text {M146L }}$ mice displayed transgene-induced age-ratated loss of SIPB within SM, SL and SR. Besides this, there was no difference between the wild-type control mice and the APP75 $1^{\text {SL }}$ mice with respect to age-related loss of SIPB within SR as long as

$A \beta$ deposits were not taken into account. In contrast, the APP75 ${ }^{\text {SL }} /$ PS $1^{\mathrm{M} 146 \mathrm{~L}}$ mice showed a transgene-induced age-related loss of SIPB even in regions within SM, SL and SR free of $A \beta$ deposits (discussed separately below).

Based on the analysis of SIPB densities within the hippocampal subregion SM of APP ${ }_{W_{1}}$ I63 and $A P P_{\text {Iad }}$ H6 transgenic mice, Mucke et al. ${ }^{20}$ suggested evidence for A $\beta$-induced synaptotoxicity even in the absence of $A \beta$ deposits in APP transgenic mice. This is in contrast to the findings of the present study in which age-related loss of SIPB in the absence of $A B$ deposits was found only for the APP75 $1^{\text {slu }} / \mathrm{PS} 1^{\mathrm{M} 146 \mathrm{~L}}$ mice but not for the APP75 ${ }^{\mathrm{SL}}$ mice. Methodological differences might explain this discrepancy between the findings of Mucke et al. ${ }^{20}$ and the present study. Mucke et al. ${ }^{20}$ correlated their SIPB density data with the overall hippocampal plaque load and found no significant correlation between these parameters in their APP transgenic mice. Based on this lack of correlation these authors concluded that $A \beta$ is synaptotoxic even in the absence of plaques in their APP transgenic mice. ${ }^{20}$ However, in the present study no correlation between SIPB densities within SM and overall hippocampal plaque load was found in the APP75 $\|^{\text {sL }}$

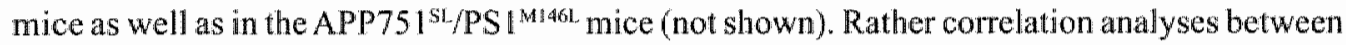
plaque load and other neuropathologic findings in transgenic mouse models of AD may be misleading, as outlined recently. ${ }^{12}$ Another reason for the discrepancy between the findings of 
Mucke et al. ${ }^{20}$ and the present study might be differences in the trangenic constructs, $1 . \mathrm{e}$. the introduced mutations and/or the promoters used. In this regard it is important to note that the APP transgenic mice investigated by Mucke et al. ${ }^{20}$ showed a significantly reduced SIPB density within SM compared to wild-type controls already at two to four months of age. This might reflect a specific neurodevelopmental defect in the APP transgenic mice investigated by these authors. In contrast, in the present study the APP751 ${ }^{\text {SL }}$ mice had the highest mean SIPB densities as well as (except for SL at M4.5) the highest mean SIPB numbers within SM, SL and SR among the investigated genotypes at both M4.5 and M17. This might indicate synaptotrophic effects of APP in the APP751 ${ }^{\text {sL }}$ mice investigated in the present study as known from other transgenic mice expressing different forms of human APP.41,42 In this regard it is important to note that Takeuchi et al. ${ }^{34}$ found slightly higher SIPB densities within hippocampal

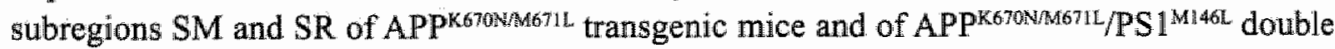
transgen 10 mice than within SM and SR of both wild-type control mice and PS1 ${ }^{\mathrm{M} 146 \mathrm{~L}}$ transgenic mice at 12 months of age. These data are fully in line with the results of the present study at M4.5. Wong et al. ${ }^{43}$ found, compared to wild-type controls, increased densities of vesicular acetylcholine transporter immunoreactive presynaptic boutons within SR of APPKM670671NL

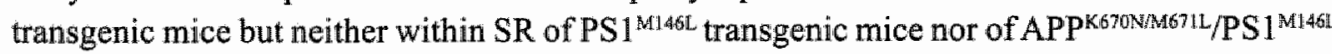
double transgenic mice at 8 months of age. Except for the results for the APPK670N/M671L/PS1 1 M146L double transgenic mice these data are in line with the findings of the present study at M4.5 as well. Takeuchi et all. ${ }^{33}$ and Wong et al. ${ }^{43}$ restricted their analyses to 12 -months-old animals (or to 8-months-old animals, respectively). Thus, these studies cannot be compared to the present study with respect to age-related alterations in hippocampal SIPB densities based on transgenic expression of human mutant APP and/or human mutant PS1 in mice. The same holds true for a study by Dodart et al. ${ }^{44}$ in which SIPB densities within several hippocampal subregions of 12-month-old APP ${ }^{\mathrm{7} 1 \mathrm{TF}}$ transgenic mice were investigated (on average no difference between APPVirf transgenic mice and wild-type control mice).

Furthermore it should be mentioned that King and Arendash ${ }^{21}$ observed a decline of approximately $40 \%$ in mean SIPB densities within hippocampal subregions SM and SR of wild-type control mice between 3 and 19 months of age, and an approximately $40 \%$ increase in SIPB densities within SM and SR of APP695 transgenic mice. Accordingly these authors found SIPB densities within SM and SR of 19-month-old APP69s transgenic mice approximately twice as high as within SM and SR of 19-month-old wild-type controls. ${ }^{21}$ These data are neither in line with the results of the present study nor with the findings of Mucke et al ${ }^{20}$ and other reports in the literature concerning age-related alterations in synaptophysin immunoreactivity within the hippocampus of wild-type rodents. ${ }^{19,20,39,40}$ Besides differences in the transgenic constructs the reason for this discrepancy might be due to different methodologies. Seemingly the image analysis approach of King and Arendash $^{21}$ did not focus on the analysis of SIPB densities within regions free of $A \beta$ deposits and $A \beta$ aggregation-related disturbances in normal SIPB morphology. Furthermore, it cannot be excluded that the intense synaptophysin staining demonstrated by King and Arendash ${ }^{21}$ for $\mathrm{APP}^{695}$ transgenic mice at 19 months of age was affected by intraparenchymal IgG molecules (blocked by using the M.O.M. immunodetection kit [Vector] in the present study). 
Finally Phinney et al. ${ }^{36}$ observed that A $\beta$ deposits in APP23 mice attracted dystrophic axonal terminals to ectopic locations which may lead to disruption of normal neuronal connectivity. Accordingly, the intense synaptophysin immunoreactivity at the periphery of neuritic placues seen in the APP751 $1^{\mathrm{SL}}$ mice and the APP751 $1^{\mathrm{SL}} / \mathrm{PSI}^{\mathrm{M} 146 \mathrm{~L}}$ mice investigated in the present study as well as described in the literature (discussed above) might reflect neurotropic properties of $A \beta$ deposits. One might even ask the question whether this mechanism could result in reduoed SIPB numbers in areas that should have received the projections. The results obtained on the APP751 ${ }^{\text {sL }}$ mice in the present study may answer this question. Provided that the main mechanism in SIPB loss in regions free of $A \beta$ deposits would have been the result of inappropriate redirection of projections to cluster around the $A \beta$ deposits (and consequently resulting in deficits in the areas that should have received the projections), the APP75 ${ }^{\mathrm{SL}}$ mice should have shown significant differences in SIPB densities and numbers (as compared to the wild-type control mice) in regions free of $A \beta$ deposits. However, as shown in Figure 3 this was not the case.

In summary the results of the present study are in line with several reports in the literature, and differences to other reports can be explained. Importantly, to the best of our knowledge, the results of the present study are the first ones demonstrating both quantitative and qualitative differences between the simultaneous transgenic expression of human mutant APP and human mutant PS1 and the single transgenic expression of either human mutant APP or human mutant PS 1 in mice on age-related loss of SIPB within the hippocampus. Potential reasons for these differences are discussed in the next paragraphs.

\section{Alterations in SIPB densities and SIPB numbers in PS1 ${ }^{\text {M146L }}$ transgenic mice}

Of particular importance was the finding of a transgene-induced age-related reduction in both mean SIPB density and mean SIPB number within the hippocampal subregion SR (CAI-2) of the PS1 ${ }^{M 146 L}$ mice in the present study. To the best of our knowledge these are the first results demonstrating a region-specific effect of transgenic expression of human mutant PS1 on age-related loss of SIPB within the mouse hippocampus.

Presenilins are considered to be the catalytic subunits of the gamma-secretase complex, but they are also essential for the fine tuning of the immunological system and for memory and synaptic plasticity. ${ }^{45} \mathrm{AD}$-associated presenilin mutations clearly affect gamma-secretase cleavage and thereby enhance $A B$ generation. ${ }^{10}$ According to previous observations by Duff et al., 46 expression of mutant PSI itself may generate murine $A \beta$. We have previously investigated the presence of human $A \beta$ in the PS1 ${ }^{\mathrm{M} 146 \mathrm{~L}}$ mice and found no A $\beta$ signal in ELISA blots using a monoclonal antibody (WO-2) against human $A B{ }^{10}$ However, we cannot exclude that there was at least some generation of endogenous murine $A \beta$ (possibly not detectable by the antibody used in our previous study) in the PS $1^{\mathrm{M} 146 \mathrm{~L}}$ mice. On the other hand, we detected considerable amounts of $A B$ in the APP75 $1^{\text {SL }}$ mice. ${ }^{10}$ The fact that we found more age-related SIPB loss within SM and SR of the PS1 ${ }^{\text {M146L }}$ mice than within SM and SR of the APP751 $1^{\text {SL }}$ mice would argue that other factors rather than $A \beta$ were the driving force in SIPB loss in the PS1 ${ }^{\text {MI } 146 L}$ mice. In this respect, it is important to address that presenilins affect intracellular calcium stores, 


\section{Synaptic integrity in APP PS1 and APP/PS1 mice}

protein trafficking and protein tumover and neuronall signaling. ${ }^{47}$ Consequently, it has beem proposed that destabilization of calcium signaling has a role in neurodegeneration in $\mathrm{AD}^{43}$ Mutations in PS1 and PS2 are known to perturb endoplasmic reticulum calcium homeostasis such that greater amounts of calcium are released upon stimulation. ${ }^{48,49}$ Furthermore, Herms et all. showed deregulation of intracellular calcium homeostasis by decreased capacitative calcium entry (CCE) in hippocampal neurons dissociated from newborn mice transgenic for mutant PS1 ${ }^{\text {A24 }}$ (CCE being a refill mechanism allowing entry of extracellular calcium ions through plasma membrane channels that are tightly regulated by and even physically linked to intracellular stores ${ }^{51}$ ). Importantly, calcium-induced formation of reactive oxidative species (ROS) and mitochondrial swelling were found higher in isolated rat mitochondria from the CAI than from the CA3 region. ${ }^{52}$ Furthermore, symaptosomal proteins from PSIM146V knock-in mice displayed increased oxidative stress compared with synaptosomal proteins from wild type mice. ${ }^{53}$ Begley et al..$^{54}$ observed evidence of disturbed calcium homeostasis and mitochondrial dysfunction in synaptosomes prepared from mice transgenic for mutant PSI; it is reasonable to hypothesize that similar to the knock-in mice studied by LaFontaine et al. ${ }^{53}$, synaptosomal proteins were also affected by increased oxidative stress in the transgenic mice investigated by Begley ef al. ${ }^{54}$. Moreover, it was recently shown that expression of the PS1 mutations M146V, I.43T, and delletion of exon 9 (D9) in human neuronal cells in wito significantly increased the activation of glycogen synthase kinase $3-\beta$ (GSK3- $\beta$ ). ${ }^{55}$ In wivo, GSK3- $\beta$ phosphorylates kinesin light chains (KLC) and causes the release of kinesin-I from membrane-bound organelles (MBO), leading to a reduction in kinesin-I-mediated fast axonal transport. ${ }^{56}$ Consistent with such a deficit in kinesin-1-mediated fast axonal transport, densities of synaptophysin-containing vesicles and mitochondria were found reduced in neuritic processes of hippocampal neurons expressing mutant $P S 1^{M 146 \%}$ in vitro. ${ }^{55}$ On the basis of these findings, it is attractive to speculate that the observed transgene-induced age rellated loss of SIPB within SR of the PS I ${ }^{M 46 L}$ mice in the present study was connected to transgene-induced alterations in cellular calcium homeostasis, fast axonal transport and the formation of ROS. At least the latter mechanism might occur preferentially within the hippocampal CA1 region, therefore triggering age-related SIPB loss preferentially within SR. Interestingly, perturbations in calcium homeostasis and alterations in GSK3- $\beta$ activation caused by mutations in PS1 might be connected to each other. Calcium signaling activates the phosphatase calcineurin and induces movement of NFATc proteins into the nucleus, whereas nuclear import of NFATc proteins is opposed by kinases such as GSK3 $\beta .^{53}$

Besides these mechanisms, recent studies indicated that presenilins also mediate cleavage of synaptic-associated adhesion molecules such as nectin $1 \alpha^{58}$ and cadherins. ${ }^{59}$ However, it remains to be determined whether PSI cadherin/catenin interaction or PS-mediated cleavage of adhesion molecules play a functional tole in synapse formation or modulate synaptic activity. Thus, one can only speculate whether altered PSI-mediated cleavage of synaptic-associated adhesion proteins influenced synaptic function and integrity and was involved in the reported age-related loss of SIPB within SR of the PSI ${ }^{\mathrm{M} 145 \mathrm{~L}}$ mice.

Finally it should be mentioned that in a recent study on 3-month-old mice in which the M146V mutation of PSI was knocked in into the endogenous mouse PS 1 gene, Wang ef al "6r found 
impaired hippocampu-dependent contextual learning and reduced adult neurogenesis in the dentate gyrus. The latter result is in line with earlier findings of increased cell cycle arrest caused by PS1 mutations overexpressed in cells in who. ${ }^{6}$ On the other hand, total numbers of hippocampal granule cells were found unchanged compared to wild-type controls in mice transgenic for the same PS1 mutation as investigated by Wang et al. ${ }^{61}$ as well as in mice in which the human PS1 mutations M233T and L235P were knocked in into the mouse PS1 gene. ${ }^{12,3}$ Thus, the possible impact of reduced neurogenesis in the dentate gyrus of PSIM46\% knock-in mice on hippocampu-dependent contextual learning remains elusive.

In summary the finding of a transgene-induced age-related loss of SIPB within the hippocampal subregion SR of the PSI ${ }^{\text {w1 }}$. mice in the present study can be explained by potential mechanisms of mutant PSI reported in the literature. One can regard the findings of the present study as among the first in vivo evidence for a role of mutant PSI in neurodegeneration without concomitant neuron loss, apart from its contribution to alterations in A $\beta$ generation. This might serve as the basis for further modifying the amyloid hypothesis of neurodegeneration in $A D .^{14}$

\section{Alterations in SIPB densities and SIPB numbers in APP751 1 SL/PS1 $1466 \mathrm{~L}$ transgenic mice independent of $A \beta$ deposits}

As explained above, there was no difference between the wild type control mice and the APP75 $1^{\text {st }}$ mice with respect to age-related loss of SIPB as long as A $\beta$ deposits were not taken into account. It can therefore not be excluded that local development of $A \beta$ deposits fully accounted for the loss of SIPB seen within hippocampal subregion SR of the APP75I I $^{\text {s. }}$ mice at M17. In contrast, the APP751 ${ }^{\text {SL }} / \mathrm{PS} 1^{\text {M146L }}$ mice showed a transgene-induced age-related loss of SIPB even in regions within SM, SL and SR free of AB deposits. This phenomenon can be due to several interacting mechanisms: (i) The aforementioned potential actions of mutant PS1 (at least within SR). (ii) Local neuron loss. Our previous study on the same APP751 ${ }^{\mathrm{SL}} /$ PS ${ }^{\text {Mi46L }}$ mice showed a substantial age-related loss of hippocampal pyramidal cells (on average approximately $30 \%)^{12}$ Loss of hippocampal pyramidal cells resulted most probably in a decreased number of dendrites in SL and SR. Thus, one cannot exclude that the combined action of hippocampal pyramidal cell loss and A $\beta$ deposits within SL and SR fully accounted for the loss of SIPB seen within these regions of the APP751.54/PS1 M140L mice. At M17 these mice showed a transgene-induced age-related reduction in mean SIPB numbers of $33 \%$ in regions within SL (and of $38 \%$ in regions within $S R$, respectively) free of $A \beta$ deposits, and an approximately $30 \%$ loss of pyramidal cells within the hippocampus. ${ }^{22}$ (ivi) Neuron loss in regions with heavy projections to the areas analyzed. In this regard, we have previously shown that age-related neuron loss occurred within the hippocampal pyramidal cell layer but not within the hippocampal granule cell layer of the APP75/ $\left.\right|^{\mathrm{SL}} / \mathrm{PS} 1^{\mathrm{M} 146 \mathrm{~L}}$ mice, ${ }^{12}$ i.e. exactly the same mice as investigated in the present study. The mossy fibers (i.e., the axons of the hippocampal granule cells) project to the hippocampal pyramidal cells (mainly to CA3). Thus, the effects seen in the stratum lucidum of area CA3 (SL) of the APP75 $1^{\mathrm{SL}} / \mathrm{PS} 1^{\mathrm{M} 146 \mathrm{~L}}$ mice cannot be explained by neuron loss in the region projecting to SL. Furthermore, age-related loss of SIPB was found in SR of the PS1 ${ }^{\text {Mi } 45 \mathrm{~L}}$ mice, which did not show age-related neuron loss in any hippocampal area. ${ }^{12}$ Preliminary evidence from microscopic inspection suggested age-related neuron loss 


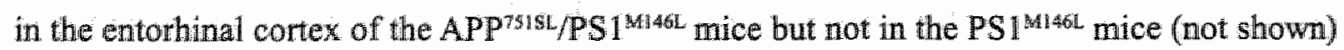
which showed SIPB loss within SM. Together these data indicate that loss of neurons at regions with heavy projections towards the areas analyzed in the present study was of limited impact on age-related SIPB loss. (iv) Action of soluble A $\beta$. Soluble A $\beta$ species have been demonstrated to induce neurotoxicity which is likely to provoke neuropathology reminiscent of $A D,{ }^{64,65}$ see also 2,66-65. In this regard, a $12 \%$ reduction in total dendritic length of hippocampal granule cells was found in 3-month-old APPvily transgenic mice, i.e., prior to amyloid deposition, in a recent study by Wu et al ${ }^{69}$ Certain subsets of granule cells (superficially located granule cells in the dorsal blade of the dentate gyrus) even exhibited a $23 \%$ loss of total dendritic length at 3 months of age. ${ }^{62}$ The authors of this study hypothesized that these alterations were due to elevated levels of soluble forms of $A B$, induced by the overexpression of APP. Comparably, one may speculate that at least part of the $30 \%$ (49\% minus $19 \%$ age-related loss of SIPB numbers seen within SM of the wild-type control mice), transgene-induced age-related reduction in SIPB numbers in regions free of $A \beta$ deposits within SM of APP751 ${ }^{\text {SL }} /$ PS $^{\text {M146L }}$ mice is due to elevated levels of soluble $A \beta$. (v) Intraneuronal $A \beta$. Previous reports have shown that intraneuronal $A \beta$ preceded the formation of AB deposits in APP751 SL/PS1M146L mice9 and that elevated levels of intraneuronal $A \beta$ were associated with several alterations in normal cell homeostasis. $11,14,64,70$ Moreover, intraneuronal $A \beta$ has been reported to substantially affect synaptic function ${ }^{26}$ and integrity $_{*}{ }^{71}$ (vi) A chronic inflammation status. Previously, we reported widespread microglia activation within the hippocampal neuropil of APP751 $1^{\text {sL }} / \mathrm{PS} 1^{\text {M146L }}$ mice which was only partly related to $A \beta$ deposits. ${ }^{2}$ Thus, one could argue that microglia activation might be an early pathogenic event preceding loss of SIPB and possibly having a causative role in SIPB loss. ${ }^{72,73}$

With respect to the potential impact of both soluble forms of $A \beta$ and intraneuronal $A B$ on SIPB loss in hippocampal regions free of $A \beta$ deposits, analysis of SIPB densities and numbers in the hippocampus of APPSL/PS1KI mice ${ }^{70}$ will be important. This is due to the fact that mutations in PS1 have been shown to enhance gamma-secretase activity towards elevated AB42 generation. ${ }^{74-76}$ The $A B 42 / A \beta$ ratio was approximately 0.2 in the APP751 ${ }^{\text {sL }}$ mice and approximately 0.4 in the APP751 ${ }^{\text {SL }} /$ PS $^{\text {ML }}$ (46L mice investigated here, ${ }^{11}$ and was increased to approximately 0.85 in APPSL/PSIKI mice which showed profound hippocampal neuron loss and intraneuronal accumulation of $A \beta$ already at 10 months of age. ${ }^{70}$ We hypothesize that in the hippocampus of APPSL/PSIKI mice profound SIPB loss will also be found in regions free of A $\beta$ deposits, and the comparison of results from APP751 $1^{\text {SL/PS }} 1^{\mathrm{M} 146 \mathrm{~L}}$ mice and APPSL/PS1KI mice will provide novel insights into the impact of transgenic expression and "knock-in" expression of mutations of PSI on impairments of synaptic integrity in AD.

\section{Relevance of the findings of the present study to human $A D$}

Loss of hippocampal synaptophysin immunoreactivity was established as an early marker in human $\mathrm{AD}$ but did not show spatial correlation with $\mathrm{AB}$ deposits. ${ }^{7}$ By simultaneously investigating the formation of neurofibrillary tangles and the relative amount of synaptophysin mRNA within the same neurons a number of studies indicated evidence for a tangle-dependent 
mechanism of hippocampal synaptophysin loss in AD. ${ }^{\text {Hower }}$, the formation of tangles accounts for only a small proportion of loss of hippocampal neurons in $A D$, at least within area CA1. Accordingly, the formation of tangles is most probably not the predominant mechanism of hippocampal synaptophysin loss in AD. This is supported by the finding of no local correlation between the degree of synaptophysin-like immunoreactivity and CD-1 immunoreactive neurons within the hippocampus of brains from patients with $A D$ (with the $C D-1$ antibody recognizing tangles, dystrophic neurites in and around $A B$ deposits and neuropil threads). ${ }^{77}$ Rather Callahan et a. ${ }^{80}$ recently found that hippocampal CA1 neurons free of both tangles and immunohistochemical detectable tau phosphorylation at Ser 262, 356 and 396/404 in brains from patients with $\mathrm{AD}$ (Braak stage $\mathrm{V}-\mathrm{VI}^{\mathrm{B} 2}$ ) showed a statistically significant reduction of more than $20 \%$ in the relative amount of synaptophysin mRNA compared with corresponding neurons in brains from controls (Braak stage I-II).

These data indicate that hippocampal synaptophysin loss in AD seems to be multifactorial. In this regard the simultaneous analysis of the APP751 $1^{\mathrm{SL}}$ mice, the PS1 $1^{\mathrm{M} 146 \mathrm{~L}}$ mice and the APP751 $1^{\mathrm{st}} /$ PS1 ${ }^{M 146 L}$ mice investigated in the present study offers a unique framework to test hypotheses on the impact of several molecular and cellular events caused by transgenic expression of human mutant APP and/or human mutant PSI on age-related alterations in synaptic integrity. Firstly, the transgene-induced age-related SIPB loss seen within hippocampal subregion SR of the APP751 $1^{\mathrm{SL}}$ mice might be almost completely due to A $\beta$ deposits. This hypothesis can be tested by vaccination or other approaches focusing on the prevention of $A \beta$ aggregation. Secondly, the transgene-induced age-related SIPB Loss seen within SL and SR of the APP751 $1^{\text {SL/PS1 }}{ }^{\text {M14GL }}$ mice might be almost completely due to the combined action of $A \beta$ deposits and neuron loss. This offers for the first time the possibility to address the question whether alterations in synaptic integrity precede neuron loss in a transgenic animal model of AD. Third]y, the transgene-induced age-related SIPB loss seen within SR of the PS1 $1^{\mathrm{M} 146 \mathrm{~L}}$ mice cannot be attributed to A $\beta$ deposits or to neuron loss. This offers for the first time the possibility to study actions of mutant PS1 in neurodegeneration apart from its contribution to altered APP processing and AB generation.

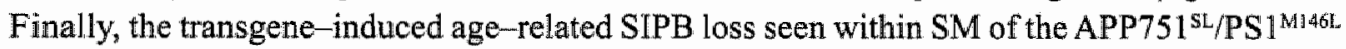
mice can also neither be attributed to $A \beta$ deposits nor to neuron loss. As age-related SIPB loss within SM of the PS1 ${ }^{\text {M } 46 \mathrm{~L}}$ mice did not exceed age-related SIPB loss within this hippocampal subregion of the wild-type control mice, one might speculate that the age-related SIPB loss

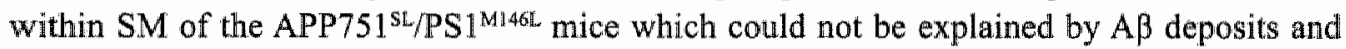
neuron loss was not due to actions of mutant PS1. Thus SIPB loss in APP751 ${ }^{\text {SL/PS }} / 1^{\mathrm{M} / 40 \mathrm{~L}}$ is most probably due to complex interactions between the $A \beta$ deposits, neuronal loss locally or at distance, generation of intraneuronal and soluble A $\beta$ and other PS1 mediated actions..

In summary the transgenic mouse models as investigated in our study can be seen among the best animal models of $\mathrm{AD}$ and provide for the first time the possibility to investigate hippocampal subregion-specific differences in interactions between neuron loss, $A \beta$ deposits, soluble $A \beta$, intraneuronal $A \beta$, and PS1 mediated actions on alterations in synaptic integrity. Future experiments are likely to have further significant impact on the field of AD research. 


\section{REFERENCES}

1. Cummings IL. A.zheimer's disease. N Engl J Med 2004, 351:56-67

2. Selko DJ: Alzheimer "s disease is a synaptic failure. Science 2002, 298:789-791

3. Mortison $\mathrm{JH}$, Hof PR: Selective vulnerability of conticocortical and hippocampal circuits in aging and Alaheimer's discase. Prog Brain Res 2002, $136: 467-486$

4. Hardy J, Selkoe DJ: The amyloid hypothesis of Alzheimer"s disease: progress and problems on the road to therapeutics. Science 2002, 297:353-356

5. Scheff SW, Price DA: Synaptic pathology in Alzheimer's disease: a review of oltrastructural studies. Neurobiol A.ging $2003,24: 1029-1046$

6. Small DH, Mok SS, Bornstein JC: Alzheiner's disease and Abeta toxicity: from top to bottom. Nat Rey Neurosei $2001,2: 595-598$

7. Davies $C A$, Man DM, Sumpter $\mathrm{PQ}_{\text {, Yates }} \mathrm{PO}$ : A quantitative morphometric analysis of the nenronal and symaptic content of the frontal and temporal cortex in patients with Alzheimer's disease. I Neurol Sci 1987 , $78: 151-164$

8. Hof $\mathrm{PR}_{3}$ Morrison $\mathbb{V H}$ : The aging brain: morphomolecular senescence of cortical circuits. Trends Neurosci $2004,27,607-613$

9. Wirths O, Multhaup $G$, Czech $C$, Blanchard V, Moussaoui S, Tremp G, Pradier $L$, Beyreuther $\mathbb{K}$, Bayer TA. Intraneuronal Abeta accumulation precedes plaque formation in beta- amylloid precursor protein and presenilin-1 double-transgenic mice. Neurosci Let 2001, 306:116-120.

10. Wirths O, Multhaup G, Czech C, Feldmann N, Blanchard V, Tremp G, Beyreuther K, Pradier L, Bayer TA: Intranetronal $A P P / A$ beta trafficking and plaque formation in beta-amyloid precursor protein and presenilin-1 transgenic mice. Brain Pathol. 2002, 12:275-286

11. Blanchard V, Moussaoui S, Czech C, Touchet N, Bonici B, Planche M, Canton T, Jedidi I, Gohin M, Wirths O, Bayer TA, Langui D, Duyckaerts C, Tremp G, Pradier L: Time sequence of maturation of dystrophic neurites associated with Abeta deposits in APP/PSI transgenic mice. Exp Neurol 2003, 184:247-263

12. Schmitz C, Rutten BP, Pieten A, Schafer S, Wirths O, Tremp G, Czech C, Blanchard V, Multhaup G, Rezate P, Korr H, Steinbusch HW, Pradier L, Bayer TA: Hippocampal neuron loss exceeds amyloid plaque load in a transgenic mouse model of Azheimer's disease. Am J Pathol 2004, 164:1495-1502

13. Dickson DW: Building a more perfect beast: APP transgenic mice with neuronal loss. Am J Pathol 2004, $164: 11.43-11.46$

14. Wirths $O$, Multhaup G, Bayer TA: A modified beta-amyloid bypothesis: intraneuronal accumulation of the beta-amyloid peptide - the first step of a fatal cascade. J Nenrochem 2004, 91:513-520

15. Van de Berg WDI, Blokland A, Schmitz C. Cuello AC, Steinbusch HWM, Blanco CE: Synaptic numbers in striatum and cortex of aged rats following perinatal asphyxia - a stereologic and behavioral correlative analysis. J Chem Neuroanat 2000, 20:71-82

16. Rutten BP, Wirths O, Van de Berg WD, Lichtenthaler SF, Vehoff J, Steinbusch HW, Korr H, Beyreuther K, Multhaup $G$, Bayer TA, Schmitz $C$ : No alterations of hippocampal neuronal number and synaptic bouton number in a transgenic mouse model expressing the beta-cleaved $C$-terminal APP fragment. Neurobiol Dis 2003. 12:110-120

17. Masliah E, Terry RD, DeTeresa RM, Hansen LA: Immunohistochemical quantification of the synapse-related protein synaptophysin in Alzheiner disease. Neurosci Lett 1989, 103:234-239

18. Wong TP, Campbell PM, Ribeiro-da-Silwa A, Cuelo AC: Synaptic numbers across cortical laminae and cognitive performance of the rat during ageing. Neuroscience 1998, 84:403-412

19. Smith TD, Adams MM, Gallagher M, Morrison JH, Rapp PR: Circuit-specific alterations in hippocampal synaptophysin immunoreactivity predict spatial learning impa irment in aged rats. I Neurosci 2000, 20:65876593

20. Mucke L, Masliah E, Yu GQ, Mallory M, Rockenstein EM, Tatsuno G, Hu K, Kholodenko D, Johnnson-Wood K. McConlogue L: High-level neuronal expression of abeta $1-42$ in wild-type human amyloid protein precursor transgenic mice: synaptotoxicity without plaque formation. J Neurosci 2000, 20:4050-4058

21. King DL, Arendash GW: Maintained synaptophysin immunoreactivity in Tg2576 transgenic mice during aging: correlations with cognitive impairment. Brain Res 2002, 926.58-68

22. Borchardt T, Camakaris J, Cappai R, Masters CL, Beyreuther K, Multhaup G: Copper inhibits betamamyloid production and stimulates the non-amyloidogenic pathway of amyloid-precursor-protein secretion. Biochem $J 1999,344 \mathrm{Pt} 2: 461-467$

23. van Zandwoort M, Engels W, Douma K, Beckers L, Oude Egbrink M, Daemen M, Slaaf DW: Two-photon microscopy for imaging of the (atherosclerotic) vascular wall: a proof of concept study. I Vase Res 2004, $41: 54-63$

24. Franklin KBJ, Paxinos G: The mouse beain in stereotaxic coordinates. San Diego, Academic Press, 1996 
25. Gundersen HJ, Jensen EB: The efficiency of systematic sampling in stereology and its prediction. $J$ Microse 1987,147 ( Pi 3):229-263

26. Schmitz C, Hof PR: Design-based stereology in neuroscience. Neuroscience 2004, 130,813-931

27. Miles RE, Davy, P.J.: Precise and general conditions for the validity of a comprehensive set of stereological fundamental formulae. J Microse 1976, 107:211-226.

28. Bugiani $O$, Giaccone $G$, Verga $L$, Pollo $B$, Gheti $B$, Frangione $B$, Tagliavini F. Alaheimer patients and Down patients: abnormal presynaptic terminals are related to cerebral preamyloid deposits. Neurosic Lett 1990, $119: 56-59$

29. Tsai $J_{3}$ Grutzendler $J_{n}$ Duff $K$, Gan WB: Fibrillar amyloid deposition leads to local synaptic abnormalities and breakage of neuronal branches. Nat Neurosci 2004, 7:1181-1183

30. Delatour B, Blanchard V, Pradier L, Duyckaerts C: Alzheimer pathology disorganizes cortico-cortical circuitry: direct evidence from a transgenic animal model. Neurobiol Dis 2004, 16:41-47

31. Brendza RP, O'Brien C, Simmons K, McKeel DW, Bales KR, Paul SM, Olney JW, Sanes JR, Holtzman DM: PDAPP; YFP double transgenic mice: at fool to study amyloid-beta associated changes in axonal, dendritic, and synaptic structures. J Comp Neurol. 2003, 456:375-383

32. Rockenstein E, Mallory M, Mante M, Sisk A, Masliaha E: Early formation of mature anyyloid-beta protein deposits in a mutant APP transgenic model depends on levels of Abeta(1-42). I Neurosci Res 2001, 66:573582

33. Takeuchi $A$, Irizarry MC, Duff K, Saido TC, Hsiao Ashe K, Hasegawa M, Mann DM, Hyman BT, Iwatsubo T: Age-related amyloid beta deposition in transgenic mice overexpressing both Alzheimer mutant presenilin $I$ and amyloid beta precursor protein Swedish mutant is not associated with global neuronal loss. Am I Pathol $2000,157: 331-339$

34. Sturchler-Pierrat C, Abramowski D, Duke M, Wiederhold KH, Mistl C, Rothacher S, Ledermana B, Burki K, Frey P, Paganetti PA, Waridel C, Cahoun ME, Jucker M, Probst A, Staufenbiel M, Sonmer B: Two amyloid precursor protein transgenic mouse models with Alzheimer disease-like pathology. Proc Natl Acad Sci U S A $1997,94: 13287-13292$

35. Boutajangout A, Authelet M, Blanchard $\mathrm{V}$, Touchet $\mathrm{N}$, Tremp G, Pradier L, Brion JP: Characterisation of cytoskeletal abnormalities in mice transgenic for wild-type human tat and familial Alqheimer's disease mutants of APP and presenilin-1. Neurobiol Dis 2004, 15:47-60

36. Phinney AL, Deller T, Stalder M, Calhoun ME, Frotscher M, Sommer B, Staufenbiel M, Jucker M: Cerebral amyloid induces aberrant axonal sprouting and ectopic terminal formation in anyloid precursor protein transgenic mice. J Neurosci 1999, 19:8552-8559

37. Lazarov O, Lee M, Peterson DA, Sisodia SS: Evidence that synaptically released beta-anyloid accumulates as extracellular deposits in the hippocampus of transgenic mice. J Neurosci $2002,22: 9785-9793$

38. Ribaut-Barassin C, Dupont JL, Haeberle AM, Bombarde G, Huber G, Moussaroui S, Mariani J, Bailly Y: Alzheimer's disease proteins in cerebellar and hippocampal synapses during postnatal development and aging of the rat. Neuroscience 2003, 120:405-423

39. Nicolle MM, Gallagher M, Mckinney M: No loss of synaptic proteins in the hippocampus of aged, behaviorally impaired rats. Neurabiol Aging 1999, 20:343-348

40. Calhoun ME, Kurth D, Phinney AL, Long JM, Hengernihle J, Mouton PR, Ingran DK, Jucker M: Hippocampal neuron and synaptophysin-positive bouton number in aging C57BL/6 mice. Neurobiol Aging 1998, 19:599606

41. Mucke L, Abraham CR, Masliah E: Neurotrophic and neuroprofective effects of hAPP in transgenic mice. Ann N Y Acad Sci 1996,777:82-88

42. Mucke L. Masliah E, Johnson WB, Ruppe MD, Alford M, Rockenstein EM, Forss--Petter S, Pietropaolo M, Mallory M, Abraham CR: Synaptotrophic effects of human amyloid beta protein precursors in the cortex of transgenic mice. Brain Res 1994, 666:151-167

43. Wong TP, Debeir T, Duff K. Cuello AC: Reorganization of cholinergic terminals in the cerebral cortex and hippocampus in transgenic mice carrying mutated presenilin-1 and anyloid precursor protein transgenes. I Neurosei 1999, 19:2706-2716

44. Dodart JC, Mathis C, Saura J, Bales KR, Paul SM, Ungerer A: Neuroanatomical abnormalities in behaviorally characterized APP(V717F) transgenic mice. Neurobiol Dis 2000, 7.71-85

45. Marjaux E, Hartmann D, De Strooper B: Presenilins in memory, Alzheimer's discase, and therapy. Neuron $2004,42: 189-192$

46. Duff K, Eckman C, Zehr C, Yu X, Prada CM, Perez-lur J, Hutton M, Buce L, Harigaya Y, Yager D, Morgan D. Gordon MN, Holcomb L, Refolo L, Zenk B, Hardy J, Younkin S: Increased amyloid-betw42(43) in brains of mice expressing mutant presenilin 1. Nature 1996,383:710-713

47. Koo EH Kopan R: Potential role of presenilin-regulated signaling pathways in sporadic neurodegeneration. Nat Med 2004, 10:S26-S33 
48. Chan SL, Furukawi K, Matton MP: Presenilins and APP in nearitic and synaptic plasticiny: implicanions for the pathogenesis of Alzheimer"s disease. Neuromolecular Med 2002, 2:167-196

49. Matuon MP, Chan SL: Neutonal and glial calcium signaling in Alaheimer's disense. Cell Calcium 2003, $34.385-397$

50. Herms J, Schneider I., Dewachter I, Caluwaeris N, Kretzschmar H, Van Leuwen F: Capacitive calcium entry is directly atienuated by mutant presenilin-1, independeni of the expression of the amyloid precursor protein. J Biol Chem 2003, 278:2484-2489

51. Blaustein MP. Golovina VA: Structural complexity and functional diversity of endoplasmie reticulum $\mathrm{Ca}(2+)$ stores. Trends Neurosci 2001, 24:602-608

52. Wattiasson $G$, Friberg $H_{3}$, Hansson $M_{4}$ Eimer $E$, Wieloch $T$ : Flow cytometric analysis of mitochondria from $\mathrm{CA} 1$ and $\mathrm{CA} 3$ regions of rat hippocampus reveals differences in permeability transition pore activation. $\mathrm{J}$ Neurochem 2003, 87:532-544

53. LaFontaine MA, Mattson MP, Butterfield DA: Oxidative stress in synaptosomal proteins from mutant presenilin-1 knock-in mice: implications for familial Alzheimer"s disease. Neurochem Res 2002, 27:417421

54. Begley JG, Duari W, Chan S, Duft K, Mattson MP: Altered callcium homeostasis and mitochondrial dysfunction in cortical synaptic compartments of presenilin-1 mutant mice. Jeurochem 1999, 72:1030-1039

55. Pigino G, Morfini G, Pilsman A, Mattson MP, Brady ST, Busciglio J: Alzheimer's presenillin 1 mutations impair kinesin-based axonal transport. J Neurosci 2003, 23:4499-4508

56. Morfini G, Szebenyi G, Elluru R, Ratner N, Brady ST: Glycogen synthase kinase-3 phosphorylates kinesin light chains and negatively regulates kinesin-based motillty. EMBO J 2002, $21: 281-293$

57. Crabtree GR, OIson EN: NFAT signaling;" choreographing the social lives of cells. Cell 2002, 109:\$67-S79

58. Kim DY, Ingano LA, Kovacs DM Nectin-l alpha, an immunoglobulin-like receptor involved in the formation of synapses, is a substrate for presenilin/gamma-secretase-like cleavage. $\mathbb{I}$ Biol Chem 2002, 277:4997649981

59. Georgakopoulos A, Marambaud P, Efthimiopoulos S, Shioi J, Cui W, Li HC, Schutte M, Gordon R, Holstein GR. Martinelli G, Mehta P, Friedrich VL Jr, Robakis NK: Presenilin-1 forms complexes with the cadherin/ catenin cell-cell adhesion system and is recruited to intercellular and synaptic contacts. Mol Cell 1999, 4:893 902

60. Thinakaran $\mathrm{G}$, Parent AT: Identification of the role of presenilins beyond Alzheimer's disease "Pharmacol Res $2004,50: 411-418$

61. Wang $\mathrm{R}$, Dineley $\mathrm{KT}$, Sweat JD, Zheng $\mathrm{H}$; Presenilin 1 familial Azheimer's disease mutation leads to defective associative learning and impaired adult neurogenesis. Neuroscience 2004, 126:305-312

62. Janicki SM, Stabler SM, Monteiro MJ" Familial Alzheimer's disease presenilin-1 mutants potentiate cell cycle arrest. Neurobiol Aging 2000, 21:829-836

63. Van der Kolk N, van de Steeg $\mathrm{E}$, Rutten BPF, Wirths $\mathrm{O}$, Blanchard $\mathrm{V}$, Itier J Tremp G, Steinbusch HWM, Pradier L, Bayer TA, Schmitz C: Age-rellated early hippocampal neuron loss in a novel transgenic/knock-in mouse model of AD. Soc Neurosci Abstr 2004, 338.4

64. Oddo S, Caccamo A, Shepherd JD, Murphy MP, Golde TE, Kayed R, Metherate R, Mattson MP, Akbari Y,

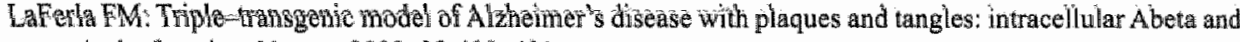
synaptic dysfunction. Neuron 2003, 39:409-421

65. Lue LF, Kuo YM, Roher AE, Brachova L, Shen X, Sue L, Beach T, Kurth JH, Rydel RE, Rogers J: Soluble amyloid beta peptide concentration as a predictor of synaptic change in Alzheimer's disease. Am J Pathol $1999,155: 853-862$

66. Walsh DM, Selkoe DJ: Deciphering the molecullar basis of memory faillure in Alzheimer's disease. Neuroti 2004, $44: 181-193$

67. Rowan MJ, Klyubin I. Cullen WK, Anwyl R: Synaptic plasticity in animal models of early Alzheimer's disease Philos Trans R Soc Lond B Biol Sci 2003, 358:821-828

68. Klein WL, Kraft GA, Finch CE: Targeting small Abeta oligomers. the solution to an Alzheimer"s disease conundrum? Trends Neurosci $2001,24: 219-224$

69. Wu CC, Chawla F, Games $D$, Rydel RE, Freedman S, Schenk D, Young WG, Montison JH, Bloom FE, Selective wulnerability of dentate gramule cells prior to amyloid deposition in PDAPP mice: digital morphometric analyses. Proc Natl Acad Sci USA 2004, 101:7141-71.46

70. Casas $C$, Sergeant $N$, ltier $J M$, Blanchard $V$, Wirths $O$, van der Kolk N, Vingtdeux $V$, van de Steeg $E$, Ret $G_{\text {t }}$ Canton T, Drobec $\mathrm{H}_{3}$ Clark A, Bonici B, Delacourte A, Benavides J, Schmitz $C_{3}$ Tremp $\mathrm{G}_{n}$ Bayer TA, Benoit P. Pradier L: Massive CA1/2 newronal loss with intraneuronal and N-terminal truncated Abeta 42 accumulation in novel Alzheimer transgenic model. Am J Pathol 2004, 165:1289-1300

71. Takahashi RH, Almeida CG, Keamey PF, Yu F, Lin MT, Milner TA, Gouras GK: Oligomerization of Alzheimer's beta-amyloid within processes and synapses of cultured neurons and brain. J Neurosei 2004 , $24,3592-3599$ 
72. Arends YM, Duyckaerts $\mathrm{C}$, Rozemuller $\mathrm{IM}$, Eikelenboom $\mathrm{P}$, Hauw J: Microglia, amyloid hnd dementha Alzheimer's disease. A correlative study. Neurobiol Aging 2000, 21:39-47

73. Cagnin A, Brooks DJ, Kennedy AM, Gunn RN, Myers $R$, Turkheimer FE; Jones $T$, Banati $\mathbb{R} B$ : In vivo measurement of microglia in dementia. Lancet $2000,358: 461467$

74. Borchelt DR, Thinakaran $G$, Eckman CB, Lee MK, Davenpont $F$, Ratovitsky $T$, Prada CM, Kin $G$, Seekins $S$, Yager D, Slunt HH, Wang R, Seeger M, Levey AI, Gandy SE, Copeland NG, Jenkins NA, Price DL, Younkin SG, Sisodia SS: Familial Alzheimer's disease-linked presenilin 1 variants elevate Abeta $1-42 / 1-40$ ratio in witro and in who. Neuron 1996, 17:1005-1013

75. Xia W, Zhang J, Kholodenko D, Citron M, Podlisny MB, Teplow DB, Haass C, Seukert P, Koo EH, Selkoe DJ: Enhanced production and oligomerization of the 42 -residue amyloid beta-protein by Chinese hamster owary cells stably expressing mutant presenilins. J Biol Chem 1997,272: 7977-7982

76. Sisodia SS, St Greorge-Hyslop PH: gamma-Secretase, Noteh, Abeta and Alzheimer"s disease: where do the presenilins fit in? Nat Rev Neurosci $2002,3: 281-290$

77. Heinonen O, Soininen H, Sorvari H, Kosunen O, Paljarvi L, Koivisto E, Riekkinen PJ Sr: Loss of symaptophysin-like immunoreactivity in the hippocampal formation is an early phenomenon in Alzheimer" ss disease. Neuroscience 1995, 64:375-384

78. Callahan LM, Coleman PD: Neurons bearing neurofibrillary tangles are responsible for selected synaptic deficits in Alzheimer's disease. Neurobiol Aging 1995, 16:311-314.

79. Callahan LM, Vaules WA. Coleman PD: Quantitative decrease in synaptophysin message expression and increase in cathepsin D message expression in Alzheimer disease neurons containing neurofibrillary tangles. J Neuropathol Exp Neurol 1999, 58:275-287

80. Callahan LM, Vaules WA, Coleman PD: Progressive reduction of synaptophysin message in single neurons in Alzheimer disease. J Neuropathol Exp Neurol 2002, 61:384-395

81. Kril JJ, Patel S, Harding AJ, Halliday GM: Neuron loss from the hippocampus of Alzheimer's disease exceeds extracellular neurofibrillary tangle formation. Acta Neuropathol 2002, 103.370-376

82. Braak $\mathrm{H}_{3}$ Braak. E: Neuropathological stageing of Alzheimer-related changes. Acta Neuropathol 1991, $82: 239-259$ 
॰

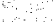

. 
Chapter 10

General discussion

Mechanisms of Neuronal Loss in Aging and Alzheimer's Disease 
To prevent or treat neuronal alterations and neuronal loss in aging and Alzheimer's disease (AD), it is crucial to identify the underlying molecular and cellular mechanisms. Although our knowledge about these mechanisms is still rather limited, the findings described in this thesis have provided nowel insights. Testing the hypotheses described in Chapter $\mathbb{1}$ led to answers to several research questions and elucidated issues in the field of aging and AD:

First, I have shown that quantitative neuromorphologic analyses on the brain should be carried out on sets of sections systematically and randomly sampled, spanning the entire brain region of interest. This resulted into new standards for quantitative neuromorphological investigations. 11,2

Second, I have shown that these types of neuron in the mouse brain with age-related decline in the rate of $\mathrm{nDNA}$ repair showed accumulation of unrepaired nDNA damage during aging without age-related loss of neurons. In contrast, those types of neuron without an age-related decline in the rate of $n D N A$ repair showed no accumulation of unrepaired nDNA damage during aging but an age-related loss of neurons. These findings indicate important cell-type-specific differences during brain aging and suggest that attenuation of age-related accumulation of nDNA damage in neurons may be reached through several strategies.

Third, I found that long term caloric restriction of mice reduced the relative amount of nDNA damage in hippocampal neurons during aging and reduced age-related shrinkage of hippocampal neurons. Transgenic upregulation of an endogenous antioxidant however did not reduce these age-related alterations in mice.

Fourth, I showed by using novel transgenic mouse models of AD that (a) transgenic expression of the C99 terminal fragment of human APP did not result in age-related loss of hippocampal neurons or synaptophysin-immunoreactive presynaptic boutons (SIPB) within the hippocampus, (b) transgenic expression of human mutant APP did not result in age-related loss of SIPB in the hippocampus, (c) transgenic expression of human mutant PS1 resulted in age-related loss of SIPB in hippocampal area CA 1-2 but not in age-related loss of hippocampal neurons, (d) transgenic expression of both human mutant APP and human mutant PS1 resulted in age-related formation of extracellular $A \beta$ aggregations, which were associated with age-related hippocampal neuron loss and with disturbances of symaptic integrity, and (e) mechanisms other than extracellular $A \beta$ aggregations significantly contributed to age-related hippocampal neuron loss in mice transgenic for both human mutant APP and human mutant PS 1 . Together these findings resulted in modifications of the original $A \beta$ cascade hypothesis of $A D$ pathogenesis. ${ }^{1,3}$

Fifth, my findings on mouse models of aging and AD indicated, in parallel to findings in humans, ${ }^{4}$ that $\mathrm{AD}$ is accompanied by dramatic neuron loss and destruction of certain neuronal circuitries while normal aging is not. I observed that aging influenced synaptic structure in selective brain regions and was connected with accumulation of nDNA damage in selective types of neuron. 


\section{FUTURE DIRECTIONS}

\section{Nuclear DNA damage and synaptic alterations in aging}

Aging affects subcellular processes in types of neuron in the hippocampus and cerebral cortex rather than inducing loss of neurons. The observed inverse correlation (cf Chapter 4 ) between accumulation of unrepaired nDNA damage and loss of neurons during aging may indicate that different types of neuron differ substantially in their cellular and molecular response to age-related stress, i.e. certain types of neuron seem to make use of distinct mechanisms to eliminate neurons with high amounts of nDNA damage during aging whereas other types of neuron do not. On the basis of recent studies indicating that the apoptotic response to nDNA damage is down-regulated in several organs during aging, ${ }^{5}$ it is tempting to hypothesize that the apoptotic response in the brain is likewise down-regulated, potentially in a cell type-specific manner. It will therefore be interesting to test this hypothesis in future studies by investigating different types of neuron for age-related changes in levels or activity of proteins involved in apoptosis. Furthermore, it appears important to identify cell type-specific differences in the molecular machinery responsible for the nDNA damage response and to identify target molecules for modulating these responses. Laser microdissection and microarray analysis ${ }^{6,7}$ of different types of neuron in the brain at various ages will be relevant for testing these hypotheses as these methodologies allow for the first time to compare gene expression among different types of neuron in situ.

Besides accumulation of nDNA damage, the aging brain is characterized by structural and functional alterations of synapses. Reductions in densities and numbers of synaptic terminals and spines preferentially occur during aging in neurons which form neocortical and hippocampal projections. ${ }^{4}$ Although unrepaired nDNA damage can lead to generation of altered proteins and proper function of various proteins is indispensable for normal synaptic function, little is known about the actual mechanisms connecting accumulation of nDNA damage with disturbed synaptic functions. In this respect strong evidence obtained from the aged human cerebral cortex indicated that age-related nDNA damage in promoter regions of genes reduced expression of genes with central roles in synaptic plasticity, vesicular transport and mitochondrial function. ${ }^{8}$ Oxidative stress selectively damaged the same gene promoters in cultured human neurons. ${ }^{8}$ Thus, nDNA damage induced by oxidative stress may selectively reduce the expression of genes responsible for normal synaptic function. A recent report in the literature suggested that increased levels of p53 may mediate effects of nDNA damage on synaptic integrity." Thus, it appears necessary to aim future investigations at the identification of preventable or recoverable molecular events associated with age-related nDNA damage and age-related disturbances in synaptic function and integrity.

Although a large number of studies have indicated that DNA mutations can result in age-related neurodegenerative disorders, evidence for a causative role of nDNA single strand breaks in neurodegeneration has been sparse. Very recently, however, a study has convincingly identified that $\mathrm{nDNA}$ single strand breaks can lead to neurodegenerative disease. ${ }^{10}$ In this study, defective repair of nDNA single stand breaks (caused by a mutation in tyrosyl phosphodiesterase 1) was shown to be the cause of spinocerebellar ataxia with axonal neuropathy. ${ }^{10}$ This defect in nDNA 
repair resulted in a several-fold increase in the number of nDNA single strand breaks after free radical-induced nDNA damage. ${ }^{10}$ Further research is however warranted to asses putative effects of accumulation of nDNA single stand breaks on neuronal function during aging.

\section{Caloric restriction and aging}

My observations that calloric restriction reduced the relative level of nDNA damage in hippocampal neurons at high age and reduced age-related neuronal shrinkage indicate that caloric restriction influences important molecular events in the brain during aging. Ongoing studies will establish whether caloric restriction also reduced age-related synaptic alterations. Recent reports in the literature have shown that caloric restriction ameliorated damage of mitochondrial DNA, "resulted in enhanced expression of protein chaperones and neurotrophic factors, ${ }^{12}$ and attenuated age-related decline in the rate of nDNA repair. ${ }^{13}$ Thus, accumulating evidence supports that caloric restriction potently attenuates the aging process in the brain and several moleculles involved in the beneficial actions of caloric restriction have recently been described. ${ }^{14-19}$ In addition, one could speculate that caloric restriction beneficially affects molecular and cellular mechanisms underlying neurodegenerative diseases. In this respect, a recent study indicated that caloric restriction reduced the burden of extracellular $A \beta$ aggregates and the associated inflammatory reaction during aging in transgenic mice for both human mutant APP and human mutant PS1. ${ }^{20}$ Nonetheless, detailed analyses with large controlled human trials involving long-term caloric restriction are necessary to actually determine the potential benefits of caloric restriction for humans.

\section{Intraneuronal $A \boldsymbol{\beta}$ and neuronal loss in $A D$}

There has been considerable discussion in the literature whether molecules proposed by the $A \beta$ cascade hypothesis of AD pathogenesis result in age-related hippocampal neuronal loss in vivo. $M y$ findings indicated that extracellular $A \beta$ deposits, high levels of intraneuronal $A \beta$ and mutant PS-1 play significant roles in hippocampal loss of neurons and synapses (Figure 1). In addition, I have recently found that overexpression of human mutant APP in mice did not result in age-related loss of hippocampal neurons (unpublished observations)

With regard to neuron loss in $A D$, intraneuronal $A \beta 42$ is a major candidate. Abundant $A \beta 42$ was observed in pyramidal neurons in APP751 $1^{\mathrm{SL} / P S}-1^{\mathrm{M} 146 \mathrm{~L}}$ mice before formation of extracellular $A \beta$ deposits and was associated with markers of neuronal stress. ${ }^{21,22}$ Recent results from a novel transgenic mouse model of AD supported the notion that high levels of intraneuronal AB42 in hippocampal pyramidal cells were connected with age-related loss of hippocampal neurons. ${ }^{23}$

Thus from the candidates hypothesized to be responsible for age-related neuron loss in these transgenic mouse models (as explained in Chapter 1), intraneuronal $A \beta$ and extracellular $A \beta$ depositions have been identified as main players (Figure 1A). Future studies focusing on temporal and spatial expression and on dose effects of $A \beta 42$ may clarify the putative causal role of $A \beta 42$ in neuron loss in AD. Nonetheless, recent studies have provided evidence about the compartment of neurons in which $A \beta$ is detectable in humans with $A D$ and in animal models of 
AD. A study in human postmortem materials described that A $\beta$ mmmoreactivity is localized in endolysosomal compartments of neurons in early stages in AD patients but not in aged people without memory complaints. ${ }^{24}$ The level of intraneuronal $A \beta$ immunoreactivity was reduced in advanced disease stages when abundant extracellular $A \beta$ deposits were formed, suggesting that $A \beta$ deposits may function as compact pools for $A \beta$ generated intraneuronally. $A B$ immunoreactivity was primarily observed in types of neuron selectively affected in $A D{ }^{24}$ The presence of $A \beta$ in neuronal endosomes and lysosomes in human brain supports previous in vitro work localizing APP, PS1 and A $\beta$ to the secretory and endolysosomal system (as explained in

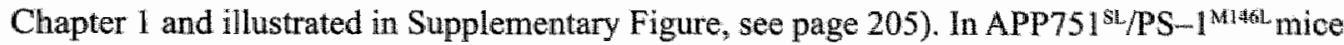
(i.e. the same mice as investigated by me in Chapter 8 and 9), $A \beta$ was detected in endolysosomal compartments of cortical and hippocampal neurons similar to the human situation. ${ }^{25}$ Similar to the temporal sequence in human $\mathrm{AD}$, young APP751 ${ }^{\mathrm{SL}} / \mathrm{PS} 1^{\mathrm{M} 146 \mathrm{~L}}$ mice showed higher levels of intraneuronal $A \beta$ than older mice which have abundant extracellular $A \beta$ deposits. ${ }^{22}$ The presence of $A \beta$ in endolysosomes may have important effects for endolysosomal and cellular function ${ }^{26}$ as disturbances of the endolysosomal system were selectively found in types of neuron prone for neurodegeneration in AD in the human brain ${ }^{27-29}$ as well as in APP/PS1 mice. ${ }^{30}$ Besides the effects on the endolysosomal system, evidence is accumulating that AP and APP are associated with disturbances in axonal transport. Previous studies had already indicated that tau protein is critically involved in the regulation of axonal transport through its microtubule-binding function, and that hyperphosphorylation of tau as well as the formation of paired helical filaments are connected with a slowdown of axonal transport. ${ }^{31}$
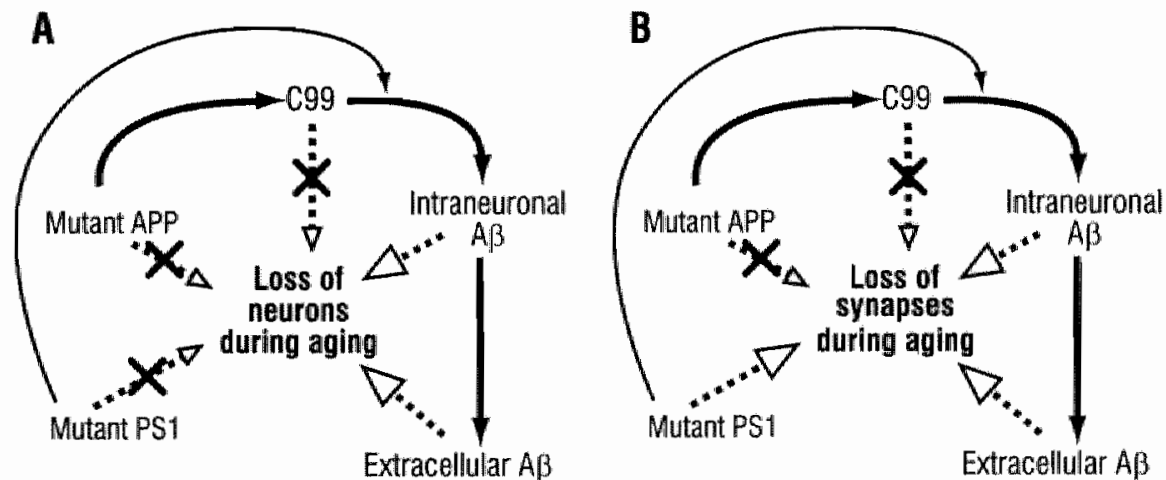

Figure 4. Scheme summarizing major candidates for age-nelated loss of neurons (A) and synapsex (B) in $A D$ acconding to the AB cascade inypothesis. Note that PSI mediates y-secratcise cleavage of Cog mo AB (thin-limed awnow). Findings of this thesis have identified intrancumond $A \beta$ and extracellatar A $\beta$ as factors strongly connected with age-related loss of newrons (open arrows in A) whereas mutant PS-I itself. mutant APP isself and the C99 ferminal fragmen of APP were shown not to be connected with age-related loss of neurons (crosised open arrows in A) in AD. Furthermore; mwan PS-1, intranewronal AB and extracellalar Ap (open arnows in B) but not mutam APP itself and the Cog rewninal fragment of APP (crossed open armows in B) have been identified as factors strongly connected whith age- related los:s of syrrapses in $A D$. 
In this respect recent evidence suggested that tau inhibits in vitro kinesin-I dependent transport of peroxisomes, neurofilaments, and Golgi-derived vesicles into neurites, particularly transport of APP, causing accumulation of APP in the neuronal cell body. ${ }^{32}$ Thus, regulation of axonal transport may substantially affect APP localization and processing. Axonal swellings filled with mitochondria, vacuoles, vesicles and kinesin were recently observed in the brains of transgenic APP mice well before any AB aggregations were formed ${ }^{33}$ (note that the morphology and localization of these swellings resembled the enlarged SIPB I have observed in the surroundings of extracellular AB aggregates in APP751 $1^{\text {sL/PS } 1{ }^{\mathrm{M} / 46} \mathrm{~L} \text { and APP751 }}{ }^{\mathrm{SL}}$ mice [cf. Chapter 9]). On the basis of the presence of kinesin in these swellings, Stokin and colleagues speculated that the APP transgenic mice they investigated had deficits in kinesin-mediated axonal transport. ${ }^{33} \mathrm{By}$ crossing the APP transgenic mice with kinesin-reduced mice, these authors found that reducing kinesin led to a decrease in anterograde transport of APP_Containing particles and to an increase of retrograde transport. ${ }^{33}$ Thus, these findings indicated that APP mutations can reduce kinesin levels leading to changes in APP transport and formation of axonal swellings. In addition, the authors found evidence that kinesin-mediated reductions of axonal transport led to a selective increase in the ratio between $A \beta 42$ and $A \beta 40$, to increased intraneuronal accumulation of $A \beta$, and (later in life) to increased formation of extracellular $A \beta$ aggregates. These findings indicate that mutations in APP alter axonal transport which in turn regulates APP localization and A generation. Mutations in PS1 have furthermore been associated with alterations in kinesinmediated axonal transport. It was recently shown that expression of the PS1 mutations M146V, I143T, and deletion of exon 9 (D9) in human neuronal cells in vitro significantly increased the activation of glycogen synthase kinase $3-\beta$ (GSK3- $\beta$ ). 34 In wivo, GSK3- $\beta$ phosphorylates kinesin light chains and causes the release of kinesin-I from membrane-bound organelles, leading to a reduction in kinesin-I-mediated axonal transport. ${ }^{35}$ Consistent with such a deficit in kinesin-I-mediated axonal transport, densities of synaptophysin-containing vesicles and mitochondria were found reduced in neuritic processes of hippocampal neurons expressing mutant PS-1 ${ }^{\mathrm{M} 146 \mathrm{~V}}$ in vitro. ${ }^{34}$ In this respect, my observation of age-related loss of SIPB in

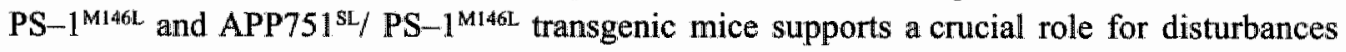
of kinesin-mediated axonal transport in $\mathrm{AD}$ pathogenesis (Chapter 9). Taken together, these findings point to the endolysosomal system and kinesin-mediated axonal transport as crucial intraneuronal systems affected early in $\mathrm{AD}$ pathogenesis. Furthermore, they point to a crucial role of intraneuronal $A \beta$ in $A D$ pathogenesis. A fundamental current issue in the field is whether intraneuronal accumulation of $A \beta$ is connected to cognitive impairments. Very recently, it was found in APP/PS1/tau transgenic mice that accumulation of intraneuronal AB accumulation is indeed associated with cognitive impairments (with initial disturbances in long-term retention). ${ }^{36}$ Moreover, it was found that immunotherapy-mediated clearance of $A \beta$ was able to reverse early disturbances in cognitive function. ${ }^{36}$ It thus appears plausible that intraneuronal accumulation of $A \beta$ is a key, potentially preventable, event in $A D$ pathogenesis.

Many questions however await elucidation. What is the normal function of $A \beta$ ? Why is $A \beta$ generated at all during aging and why is it increased in $A D$ ? Is $A \beta$ really the primary causative factor in $A D$ pathogenesis, or is $A \beta$ formed as a consequence to other alterations? Do endolysosomal disturbances lead to $A \beta$ generation or does $A \beta$ generation lead to endolysosomal disturbances? How is $A \beta$ connected to abnormalities in tau proteins and vice versa? Does generation of intraneuronal $A \beta$ occur in the same cells that harbor tau abnormalities in humans? In any 
case, further detailed neurobiological research is highly warranted to answer these questions and to determine whether strategies that decrease $A \beta$ levels in the brain will prevent or halt the pathogenesis of AD. In this respect it is hopeful that implementation of several approaches in mouse models of $\mathrm{AD}$ has resulted in attenuation of neurodegeneration. ${ }^{37-40}$ Animal models of AD serve as an excellent framework to test hypotheses on these issues, to scrutinize the temporall sequence of events in AD and to determine the exact relationships between key molecules.

\section{Protein aggregations in neurodegenerative diseases}

Although my work mainly focused on intracellular and extracellular aggregations of $A \beta$ protein as a culprit for neuronal loss in Alzheimer's disease, neuronal degeneration in $\mathrm{AD}$ is also associated with intracellular aggregations of another protein, i.e. hyperphosphorylated tau protein. ${ }^{41}$ Moreover, converging lines of evidence have revealed that many (if not all) age-related neurodegenerative diseases are characterized by aggregations and depositions of proteins. ${ }^{42-44}$ As such, Parkinson's disease is characterized by cytoplasmic Lewy bodies and aggregations of $\alpha$-synuclein, Huntington's disease by nuclear and cytoplasmic inclusions, and amyotrophic lateral sclerosis by hyalinized inclusions of SODI. ${ }^{43}$ The identification of genetic mutations in familial forms of these diseases and the development of mouse models of these diseases have provided insights into the corresponding disease's pathogenesis. Based on these insights, it appears that these diseases share a common pathogenic mechanism: the generation of misfolded proteins that eventually accumulate and aggregate during aging. ${ }^{44}$ It is known that the conformation and assembly of misfolded proteins generally follows certain transi-

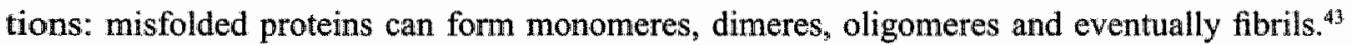
Misfolded proteins are normally recognized by chaperone proteins, transported and degraded by the proteasome or phagolysosomes. However, when these systems become inefficient or overwhellmed, misfolded proteins accumulate within cells. Depending upon the nature of the proteins and the cell itself, misfolded proteins can be excreted and may aggregate extracellularly or can aggregate intracellularly.43 It is currently a matter of scientific debate in which conformational state misfolded proteins are most toxic. In regard of $A \beta$ protein, recent evidence suggested that protofibrillar conformational states of A $\beta$ can associate with APP and form pores in cellular membranes. ${ }^{45}$ In addition, intraneuronal soluble $A \beta$ oligomeres have been found to affect synaptic integrity. ${ }^{46}$ Recent work suggested that intraneuronal $A \beta$ levels decrease as a result of extracellular deposition of fibrillar $A \beta .^{22,24}$ Thus, one could speculate that aggregation of $A \beta$ peptides in the form of extracellullar depositions of fibrillar $A \beta$ may be an escape mechanism for pooling excess amounts of intraneuronal $A \beta$ peptides. Recent developments in other neurodegenerative disease support that neurodegeneration and neuronal loss depend on the localization and conformational state of misfolded proteins. ${ }^{42,47}$ One could therefore hypothesize that attenuation of neuronal loss in various age-related neurodegenerative diseases may be reached via enhancement of molecules with chaperoning and degrading functions and via modulation of conformational states of misfolded proteins.

In conclusion, despite the fact that our knowledge on how the brain changes during aging and in $\mathrm{AD}$ is still rather limited, considerable progress has been made over the last years in understanding some of the molecular and cellular events underlying neuronal loss in aging and AD. The identification of several prewentable or reversible events offers hope for rational intervention. 


\section{REFERENCES}

1. Dickson DW: Building a more perfect beast: APP transgenic mice with neuronal loss. Am J Pathol 2004 , $164: 1143-1146$

2. Schmitz $C$, Hof PR: Design-based stereology in neuroscience. Neuroseience 2005, 130:813-83 I

3. Wirths $O$, Multhaup $\mathrm{G}_{5}$ Bayer TA: A modified beta-amyloid hypothesis: intraneuronal accumulation of the beta-amyloid peptide - the first step of a fatal cascade. J Neurochem $2004,91: 513-520$

4. Hof PR, Morrisoni $\mathrm{MH}$ : The aging brain: morphomolecular senescence of cortical circuits. Trends Neurasci $2004,27: 607-613$

5. Suh Y, Lee KA, Kim WH, Han BG, Vijg J, Park SC: Aging alters the apoptotic response to genotoxic stress. Nat Med 2002, 8:3-4

6. Hergenhahn $M$, Kenzelmann $M$, Grone HJ: Laser-controlled microdissection of tissues opens a window of new opportunities. Pathol Res Pract 2003, 199:419-423

7. Balin S, Alugood $\mathrm{S} J_{7}$ Ryan M, Standaer DG, Starkey M, Emson PC: Gene expression profiling in the postmortem human brain - no cause for dismay. J Chem Neuroanat 2001, 22:79-94

8. Lu T, Pan Y, Kao SY, Li C, Kohane I, Chan J, Yankner BA: Gene regulation and DNA danage in the ageing humanan brain. Nature $2004,429: 883-891$

9. Gilman CP, Chan SL, Guo Z, Zhu X, Greig N, Mattson MP: p53 is present in synapses where it mediates mitochondrial dysfunction and synaptic degeneration in response to DNA damage, and oxidative and excitotoxic insults. Neuromolecular Med 2003, 3:159-172

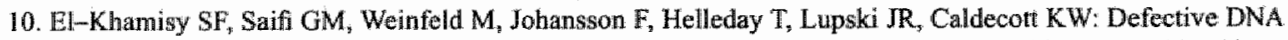
single-strand break repair in spinocerebellar ataxia with axonal neuropathy-1. Nature 2005, 434:108-113

11. Melov $S$, Hinerfeld D, Esposito L, Wallace DC: Multi-organ characterization of mitochondrial genomic rearrangements in ad libitum and caloric restricted mice show striking somatic mitochondrial DNA rearrangements with age. Nucleic Acids Res 1997, 25:974-982.

12. Prolla TA, Mattson MP: Molecular mechanisms of brain aging and neurodegenerative disorders: lessons from dietary restriction. Trends Neurosci $2001,24: 521-31$

13. Rao KS: Dietary calorie restriction, DNA-repair and brain aging. Mol Cell Biochem 2003, 253:313-318

14. Matison MP, Chan SL, Duan W: Modification of brain aging and neurcdegenerative disorders by genes, diet, and behavior. Physiol Rev 2002, 82:637-672

15. Smith JV, Heilbronn LK, Ravussin E: Energy restriction and aging. Curr Opin Clin Nutr Metab Care 2004, $7: 615-622$

16. Barja G: Free radicals and aging. Trends Neurosci 2004, 27:595-600

17. Quarrie JK, Riabowol KT: Murine models of life span extension. Sci Aging Knowledge Environ 2004, 2004: res

18. Ingram DK, Anson RM, de Cabo R, Mamezarz J, Zhu M, Mattison J, Lane MA, Roth GS: Development of calorie restriction mimetics as a prolongevity strategy. Ann N Y Acad Sci 2004, 1019:412-423

19. Blander $G$, Guarente $L:$ The Sir2 family of protein deaceiylases. Annu Rev Biochem 2004, 73:417-435

20. Patel NV, Gordon MN, Connor KE, Good RA, Engelman RW, Mason J, Morgan DG, Morgan TE, Finch CE: Caloric restriction attenuates Abeta -deposition in Alzheimer transgenic models. Neurobiol Aging 2005, 26:995-1000

21. Blanchard W, Moussaoui S, Czech C, Touchet N, Bonici B, Planche M, Canton T, Jedidi I, Gohin M, Wirths O, Bayer TA, Langui D, Duyckserts $C$, Tremp $G_{3}$, Pradier L: Time sequence of maturation of dystrophic neurites associated with Abeta deposits in APP/PS I transgenic mice. Exp Neurol 2003, 184:247-263

22. Wirths $\mathrm{O}$, Multheup $\mathrm{O}$, Czech $\mathrm{C}$, Blanchard V, Moussaoui $S$, Tremp $G$, Pradier $L$, Beyreuther $K$, Bayer CA: Intruneuronal Abeta accumulation precedes plaque formation in beta- amyloid precursor protein and presenilin-1 double -transgenic mice. Neurosci Lett 2001, 306:116-120.

23. Casas $C$, Sergeant $N$, Itier JM, Blanchard V, Wirths $\mathrm{O}$, van der Kolk N, Vingtdeux V, van de Steeg E, Ret $G_{*}$ Canton T, Drobecq H, Clark A, Bonici B, Delacourte A, Benavides J, Schmitz C, Tremp G, Bayer TA, Benoit P, Pradier L: Massive CA $1 / 2$ neuronal loss with intraneuronal and $\mathrm{N}$-terminal truncated $\mathrm{A}$ beta 42 accumulation in a novel Alaheimer transgenic model. Am J Pathol 2004, 165:1289-1300

24. Cataldo AM, Petanceska S, Terio NB, Peterhoff CM, Durham R, Mercken M, Mehta PD, Buxbaum J, Haroutunian $\mathrm{V}$, Nixon RA: Abeta localization in abnormal endosomes: association with earliest Abeta elevations in AD and Down syndrome. Neurobiol Aging 2004, 25:1263-1272

25. Langui D, Girardot N, El Hachimi $\mathbb{K H}$, Allinquant B, Blanchard V, Pradier $\mathbb{L}$, Duyckaerts C: Subcellular Topography of Neuronal A $\beta$ Peptide in APPxPSI Transgenic Mice. Am J Pathol 2004, 165:1465-1477

26. Nixon RA: Endosome function and dysfunction in Alzheimer's disease and other meurodegenerative diseases. Neurobiol Aging 2005, 26:373-382

27. Cataldo AM, Harnilton DI, Barnett JL, Paskevich PA, Nixon RA: Abnormalities of the endosomal-lysosomal system in Alzheimer's disease; relationship to disease pathogenesis. Adv Exp Med Biol 1996, 389:271-280 
28. Nixon RA, Cataldo AM, Mathews PM: The endosomal--lysosonal system of neurons in Aljheimer's diserase pathogenesis: a review. Neurochem Res 2000, 25:1161-1172.

29. Cataldo AM, Peterhoff CM, Troncoso JC, Gomez-Isla T, Hyman BT, Nixon RA: Endocytic pathway abnormallities precede amyloid beta deposition in sporadic Alzheimer's disease and Down syndrome: differential effects of APOE genotype and presenilin mutations. Am J Pathol 2000, 157:277-286

30. Cataldo AM, Petterhoff CM, Schmidt SD, Terio NB, Duff K, Beard M, Mathews PM, Nixon RA: Presenilin mutations in familial A zheimer disease and transgenic mouse modtels accelerate neuronal lysosomal pathology. J Neuropathol Exp Neurol 2004, 63:821 -830

31. Drubin DG, Kirschner MW: Tau protein function in living cells. J Cell Biol 1986, 103:2739-2746

32. Stamer K, Vogel R, Thies E, Mandelkow E, Mandelkow EM: Tau blocks traffic of organelles, neurofilaments, and APP vesicles in neurons and enhances oxidative stress. J Cell Biol 2002, 156:1051-1063.

33. Stokin GB, Lillo C, Falzone TL, Brusch RG, Rockenstein E, Mount SL, Raman $R$, Davies $P$, Masliah E, Williams DS, Goldstein LS: Axonopathy and transport deficits early in the pathogenesis of Alzheimer"s disease. Science 2005, 307:1282-1288

34. Pigino G, Morfini G, Pelsman A, Mattson MP, Brady ST, Busciglio $J_{:}$Alzheimer"s presenilin 1. mutations impair kinesin-based axonal transport. J Neurosci 2003, 23:4499-4508

35. Morfini G, Pigino G, Beffert U, Busciglio J, Brady ST: Fast axonal transport misregulation and Alzheimer"s disease. Neuromolecular Med 2002, 2:89-99

36. Billings LM, Oddo S, Green KN, McGaugh IL, Laferla FM: Intraneuronal abeta causes the onset of early Alzheimer's disease-related cognitive deficits in transgenic mice. Neuron 2005, 45:675-688

37. Weiner HL, Lemere CA, Maron R, Spooner ET, Grenfell TJ, Mori C, Issazadeh S, Hancock WW, Selkoe DJ: Nasal administration of amyloid-beta peptide decreases cerebral amyloid burden in a mouse nodel of Alzheimer"s disease. Ann Neurol 2000, 48:567-579

38. Oddo S, Billings L, Kesslak JP, Cribbs DH, LaFerla FM: Abeta immunotherapy leads to cllearance of early, but not late, hyperphosphorylated tau aggregates via the proteasome. Neuron 2004, 43:321-332

39. Hock C, Konietzko U, Streffer JR, Tracy $\mathrm{J}_{*}$ Signorell A, Muller-tillmanns B, Lemke U, Henke K, Moritz E, Garcia E, Wollmer MA, Umbricht D, de Querwain DJ, Hofmann $M_{v}$ Maddalena A, Papassotiropoulos A, Nitsch RM: Antibodies against beta-amyloid slow cognitive decline in Alzheimer"s disease. Neuron 2003, 38:547-554

40. Marr RA, Rockenstein E, Mukherjee A, Kindy MS, Hersh LB, Gage FH, Verma IM, Masliah E: Neprilysin gene transfer reduces human amyloid pathology in transgenic mice. J Neurosci 2003, 23:1992-1996

41. Morrison JH, Hof PR: Selective vulnerability of corticocortical and hippocampal circuits in aging and Alzheimer's disease. Prog Brain Res 2002, 136:467-486

42. Dawson TM, Dawson VL: Molecular pathways of neurodegeneration in Parkinson's disease. Science 2003, 302:819-822

43. Forman MS, Trojanowski JQ, Lee VM: Neurodegenerative diseases: a decade of discoveries paves the way for therapeutic breakthroughs. Nat Med 2004, 10:1055-1063

44. Selkoe DJ: Folding proteins in fatal ways. Narure 2003, 426:900-904

45. Lashuel HA, Hartley D, Petre BM, Walz T, Lansbury PT, Ir.:. Neurodegenerative disease: amyloid pores from pathogenic mutations. Nature 2002, $418: 291$

46. Takahashi RH, Almeida CG, Kearney PF, Yu F, Lin MT, Mitner TA, Gouras GK: Oligomerization of Alzheiner"s beta-amyloid within processes and synapses of culfured neurons and brain. J Neurosei 2004 , $24: 3592-3599$

47. Prusiner SB: Shattuck lecture-neurodegenerative diseases and prions. N Engl I Med 2001, 344:15161526. 


\section{Summary}

To prevent or treat neuronal alterations and neuronal loss in aging and Alzheimer's disease (AD), it is crucial to identify the underlying molecular and cellular mechanisms. Although our knowledge about these mechanisms is still rather limited, recent findings have provided novel insights and envision potential candidates for intervention. The findings of my thesis have contributed to this development. In Chapter 1, I describe background information on the current knowledge on the aging process in the brain and on the molecular and cellular events that are involved in the pathogenesis of AD. In addition, I discuss current issues on the mechanisms underlying neuronal loss in aging and $\mathrm{AD}$ and on potential strategies to attenuate these mechanisms. Based on these issues, I have formulated several hypotheses which were tested in my PhD research. The studies which tested my hypotheses are described in Chapters 2 to 9.

A major prerequisite for performing adequate investigations is that the methodology used is appropriately measuring the parameter under investigation. In Chapter 2, I describe that quantitative neuromorphologic analyses on the brain should be carried out on sets of sections systematically and randomly sampled to span the entire brain region of interest and not on single sections. These findings resulted into new standards for quantitative neuromorphological investigations, based on which I carried out all further investigations. In Chapter 3, I speculate (on the basis of a review of the literature) on the existence of a potential, previously unknown, inverse association in the aging brain between types of neuron showing a accumulation of nuclear (n) DNA damage and types of neuron showing an age-related reduction in numbers. This speculation was tested for the first time in a controlled study (described in Chapter 4) on one mammalian species, i.e., a cohort of aging mice of a specific strain. In Chapter 4, I describe this study in which I showed that types of neuron in the mouse brain with age-related decline in the rate of $\mathrm{nDNA}$ repair showed accumulation of unrepaired $\mathrm{nDNA}$ damage during aging without age-related loss of neurons. In contrast, types of neuron without an age-related decline in the rate of nDNA repair showed no accumulation of unrepaired nDNA damage during aging but an age-related loss of neurons. These findings indicate that the aging process in the brain affects certain types of neuron differently than others. In addition, these findings suggested that attenuation of age-related accumulation of $\mathrm{nDNA}$ damage in neurons may be reached through several strategies.

One of the best documented sources for damage during aging is oxidative stress (the increased production of highly reactive oxygen molecules). In Chapter 5, current evidence for a central 
role of oxidative stress in Alzheimer"s disease and for the value of antioxidants (molecules that scavenge these reactive molecules) in preventing or treating Alzheimer's disease is critically discussed. In Chapter 6, I describe the study which was designed to investigate the effects of an upregulation of an endogenous antioxidant (through transgenic overexpression of superoxide dismutase) and of a reduction in dietary caloric intake. The effects were studied by investigating the amount of DNA damage in neurons and on the total number and size of neurons in the hippocampus during aging. I chose to investigate the hippocampus as this brain region is known to be highly vulnerable during aging. I found that life-long upregulation of superoxide dismutase did not have any effect on the amount of DNA damage in neurons and on the total number and size of neurons in the hippocampus during aging. In contrast, a dietary reduction in caloric intake resulted in an extension of life span, a reduction in the amount of DNA damage, a reduced volume of the hippocampus, and attenuation of neuronal shrinkage during aging.

Although AD is the most common age-related mental health disorder, very little is known about the molecular and cellular events underlying neuronal alterations in AD. The most striking neuronal alterations in $A D$ are loss of neurons and synapses. So far, there is no available treatment which modifies the molecular and cellular processes involved in AD pathogenesis. Several candidate molecules have recently been proposed to be responsible for loss of neurons. and synapses in $A D$. The ' $\beta$-amyloid-hypothesis' is the most commonly accepted hypothesis. This hypothesis poses that aggregations of $\beta$-amyloid protein result into damage in the brains of people with Alzheimer's disease. Loss of neurons and synapses (connections between neurons) are the most important forms of damage amd these parameters can be investigated with modern techniques. A way to investigate numbers of synapses is quantification of the number of synaptophysin-immunoreactive presynaptic boutons [SIPB]). Transgenic animals (animals whose DNA is altered so that they produce a certain molecule in a higher amount than normal animals do) are very useful to investigate the effects of these molecules on living organisms. With the help of several transgenic mouse models, I have rigorously assessed the effects of several of the proposed candidates on the numbers of neurons and synapses in the hippocampus during aging.

In Chapters 7,8 and 9 I describe that

a) overexpression of the C99 terminal fragment of human Amyloid Precursor Protein (APP) did not result in age-related loss of hippocampal neurons or synaptophysinimmunoreactive presynaptic boutons within the hippocampus,

b) overexpression of human mutant APP did not result in age-related loss of SIPB in the hippocampus,

c) overexpression of human mutant Presenilin 1 (PS1) resulted in age-related loss of SIPB in hippocampal area CAI-2 but not in age-related loss of hippocampal neurons, 
d) overexpression of both human mutant APP and human mutant PS1 resulted in age-related formation of extracellular $A B$ aggregations, which were associated with age-related hippocampal neuron loss and with disturbances of synaptic integrity,

e) mechanisms other than extracellular $A \beta$ aggregations contributed significantly to age-related hippocampal neuron loss in mice that overexpress both human mutant APP and human mutant PSI.

Together, these findings have prompted for modifications of the original ' $\beta$-amyloid hypothesis" as they indicated that certain molecules are much more likely to be held responsible for loss of neurons and synapses in the hippocampus of patients with $A D$ than other molecules. By defining the molecules responsible for neuronal loss, these findings may initiate the development of novel treatment strategies to prevent or treat this devastating disease. In Chapter 10, I summarize the major results of my thesis and discuss them in light of the current literature. Furthermore, possible avenues for future reseach are discussed. 


\section{Samenvatting}

Om veranderingen en verlies van materiaal in zenuwcellen (i.e. neuronen) tijdens veroudering en bij de ziekte van Alzheimer te voorkomen of te behandelen, is het cruciaal om de onderliggende moleculaire en cellulaire mechanismen te identificeren. Ondanks de beperkte kennis over deze mechanismen, hebben recente bevindingen geleid tot nieuwe inzichten en liggen er potentiele kandidaten voor interventie in het verschiet. De bevindingen zoals beschreven in dit proefschrift hebben bijgedragen aan deze ontwikkeling. In Hoofdstuk $\boldsymbol{I}$ beschrijf ik achtergrond informatie over de huidige kennis van het verouderingsproces in de hersenen en van de moleculaire en cellulaire gebeurtenissen die betrokken zijn bij de pathogenese van de ziekte van Alzheimer. Verder bespreek ik huidige discussie punten over de mechanismen die ten grondslag liggen aan neuronaal verlies bij veroudering en bij de ziekte van Alzheimer. Met deze punten als uitgangsbasis heb ik verschillende hypotheses geformuleerd die ik tijdens mijn promotieonderzoek heb getest. In Hoofdstukken 2 tot en met 9 bespreek ik de studies waarin ik de hypotheses heb getest.

Een belangrijke voorwaarde om adequat onderzoek te doen, is een correcte meetmethode om de parameter van interesse op een juiste manier te onderzoeken. In Hoofdstuk 2 beschrijf ik dat quantitatieve neuromorfologische meetmethoden voor het brein moet worden uitgevoerd met series van hersencoupes die op een systematische doch willekeurige manier worden verzameld en die de gehele hersenregio onder analyse omvatten, en niet met een enkele hersencoupe door die hersenregio. Op basis van deze bevinding heb ik al mijn verdere neuromorfologische onderzoeken uitgevoerd met series van hersencoupes die op een systematische doch wille= keurige manier werden verzameld en die de gehele hersenregio onder analyse omvatten. In Hoofdstuk 3 speculeer ik (op basis van een analyse van de literatuur) over het mogelijke bestaan van een vooralsmog onbekende, omgekeerde associatie in de hersenen tussen typen neuronen die DNA schade ophopen in de celkern tijdens veroudering en typen neuronen die verminderen in aantal tijdens veroudering. Deze speculatie werd voor de eerste keer getest in een gecontroleerde studie met één diersoort, muizen van een bepaalde stam. In Hoofdstuk 4 beschrijf ik deze studie waarin ik heb aangetoond dat, tijdens het verouderingsproces van deze muizen, de typen neuronen met een vermindering van de snelheid van DNA reparatie een ophoping van ongerepareerde DNA schade hadden in hun celkern zonder dat het totale aantal neuronen significant verminderde. Andersom had een ander type neuron geen vermindering van de snelheid van DNA reparatie en geen ophoping van ongerepareerde DNA schade in de celkern maar wel een significante vermindering van het aantal neuronen. Deze bevindingen laten zien 
dat het verouderingsproces bepaalde typen neuronen anders beînvloedt dan andere. Eén wan de best gedocumenteerde bromnen voor schade tijdens veroudering is oxidatieve stress (i.e. de verhoogde produktie van snel-reactieve zuurstof moleculen). In Hoofdstuk 5 , bediscussieer ik de centrale rol van oxidatieve stress bij de ziekte wan Alzheimer en de waarde van antioxidanten (i.e. moleculen die deze snel-reactieve moleculen kunnen wegvangen) om de ziekte van Alzheimer te voorkomen of te behandelen. In Hoofdstuk 6 beschrijf ik de studie die ik heb uitgevoerd on de effecten van een verhoging van een endogene antioxidant (door transgene overexpressie van superoxide dismutase) en van een beperking van caloriën in de voeding op de hoeveelheid DNA schade in neuronen en op het totale aantal en de grootte van neuronen in de hippocampus tijdens veroudering te onderzoeken. De hippocampus werd gekozen omdat deze hersenregio erg kwetsbaar is tijdens veroudering. Ik heb gevonden dat levenslange verhoging van superoxide dismutase geen effect had op de hoeveelheid DNA schade en op het totale aantal en de grootte van neuronen in de hippocampus tijdens veroudering. Tegengesteld hieraan resulteerde een beperking van caloriën in de voeding tot een verlenging van de llevensduur, een vermindering van de veroudering-gerelateerde ophoping van DNA schade, een vermindering van het volume van de gehele hippocampus en een mindere veroudering-gerelateerde verkleining van neuronen. Dus, beperking van calorieën heeft meer effecten op de gemeten veroudering-gerelateerde parameters dan de verhoging van het endogene antioxidant.

Ondanks dat de ziekte van Alzheimer de meest voorkomende veroudering-gerelateerde stoornis is van de geestelijke gezondheid, is slechts weinig bekend over de moleculaire en cellulaire gebeurtenissen die ten grondslag liggen aan de neuronale veranderingen bij de ziekte van Alzheimer. Tot nu toe is er geen behandeling beschikbaar die de moleculaire en cellulaire gebeurtenissen die in de pathogenese van de zilekte van Alzheimer betrokken zijn, verandert. De laatste jaren werden verschillende kandidaat moleculen als verantwoordelijk gesteld voor de schade in de hersenen bij mensen met de ziekte van Alzheimer. De " $\beta$-amyloid-hypothese" is de meest gangbare hypothese. Deze stelt dat ophopingen van het $\beta$-amyloid eiwit leiden tot schade in de hersenen bij mensen met de ziekte van Alzheimer. Verlies van neuronen en van synapsen (verbindingspunten tussen neuronen) zijn hierbij belangrijke vormen van schade. Deze parameters kunnen worden onderzocht met moderne meettechnieken. Een methode om het aantal synapsen vast te stellen is het quantificeren van het aantal synaptophysine-immunoreactieve presynaptische boutons (SIPB). Met gebruik van transgene dieren (dieren waarvan het DNA zodanig gemanipuleerd is dat ze een bepaald molecuul meer aanmaken dan normale muizen) is het mogelik om de effecten van (over)expressie van bepaalde moleculen op levende organismen te bestuderen. In mijn promotieonderzoek heb ik de effecten onderzocht van verschillende van de voorgestelde kandidaat-moleculen op het aantal neuronen en synapsen in de hippocampus tijdens veroudering van deze dieren:

In Hoofdstukken 7, 8 en 9 beschrijf ik dat:

a) transgene overexpressie van het C99-terminale fragment van het humane amyloidprecursor-protein (APP) geen verlies van hippocampale neuronen of SIPB tot gevolg had, 
b) transgene overexpressie van humaan gemuteerd. APP niet leidde tot verlies van SIPB in de hippocampus tijdens veroudering,

c) transgene overexpressie van het humane gemuteerde preseniline 1 (PS1) leidde tot verlies van SIPB in een speciaal gebied (het CA1-2 gebied) van de hippocampus maar niet tot verlies van hippocampale neuronen tijdens veroudering,

d) transgene overexpressie van het humane gemuteerde APP en PS1 leidde tot de vorming van extracellulaire ophopingen van het $\beta$-amyloid eiwit, die verband hielden met verlies van neuronen, verstoringen van de synaptische integriteit en verlies van SIPB in de hippocampus tijdens veroudering

e) andere mechanismen dan de extracellulaire ophopingen van $\beta$-amyloid significant bijdroegen aan verllies van neuronen in de hippocampus tijdens veroudering van transgene muizen voor APP en PS1.

Gezamenlijk hebben mijn bevindingen uitgewezen dat verlies van neuronen en synapsen in de hippocampus bij mensen met de ziekte van Alzheimer waarschijnlijk wordt veroorzaakt door bepaalde moleculen en hoogst waarschijnlijk niet door andere, hetgeen tot modificaties van de originele ' $\beta$-amyloid hypothese' heeft geleid. Bovendien kunnen mijn bevindingen fungeren als een basis voor de ontwikkeling van nieuwe strategleên om deze verwoestende ziekte te voorkomen of te behandelen. In Hoofdstuk $\mathbf{I 0}$ vat ik de voornaamste bevindingen van mijn promotieonderzoek samen en bediscussieer ik deze in het licht wan de huidige literatuur. Verder bespreek ik mogelijke richtingen voor toekomstig onderzoek. 


\section{Dankwoord}

Dit proefschrift is tot stand gekomen met de hulp van velen, waarvan ik helaas niet ieder bij naam kan bedanken.

Allereerst wil ik mijn promotor prof. dr. Harry Steinbusch bedanken. Beste Harry, jij hebt me geïntroduceerd in de wereld van het fundamentele neurobiologische onderzoek en mij verder op een geweldige manier begeleid bij het opdoen van een scala aan wetenschappelijke ervaringen: het bedenken, uitwoeren en publiceren van wetenschappelijk onderzoek, ondernemen van stages bij verschillende buitenlandse universiteiten en bedrijven, organiseren van conferenties, het omgaan met media-aandacht, inzicht krijgen in de politieke 'ins and outs' van de academische wereld en het voeren van de redactie van een wetenschappelijk tijdschrift. Je hebt me geleerd dat de academie uit meer bestaat dan het opstellen van een hypothese en het testen daarvan. Verder heb ik ons goede persoonlijke contact en de trips langs Highway 1 and naar Cape Canaveral ontzettend op prijs gesteld. Ik ben ervan overtuigd dat onze aangename samenwerking nog verdere vruchten zal afwerpen.

Mijn copromotor, dr. Christoph Schmitz. Dear Christoph, I remember 'very well the day we met and went to Aachen for the first time. Since that day, you have shown and taught me many things which are very important for becoming a scientist: from which I can only summarize a few here: the important of being very critical about methods, results and interpretations in the literature, to fight futile comments of reviewers in a polite but effective way and... to work for $200 \%$. Our working trips to Aachen, Bonn, Rostock, the SFN Meetings and to Burlington have furthermore been a very pleasurable time as they have been a great success in a scientific way. Finally, I hope that your language skills in Dutch will soon surpass mine in German, and that you can outgrow the level of:"twee bloodjes kaas en ééén melluk".

Prof. dr. H. Korr, an important part of this thesis has been the result of the gratifying collaboration between the department of cellular neuroscience and your group at the department of Cell Biology and Anatomy at RWTH University Aachen. In our joint efforts, you have educated me in the methodology and interpretation of important quantitative, cell-type-specific techniques and, furthermore, in the value of precision.

Prof. dr. T. A. Bayer, dr. O. Wirths and dr. S. Schaefer, dear Thomas, Oliver and Steffie great thanks for the very successful joint 'Arbeid' and for the pleasurable collaboration.

Prof. dr. P.R. Hof, dear Patrick, great thanks for the continuous connection and the highlevel scientific exchange.

Dr. L. Pradier, your mouse models of AD and our collaboration have had a tremendous value for my research. Merci beaucoup.

Prof. dr. Rainald Schmidt-Kastner, dear Rainald, although I hope that nobody takes this the wrong way, I sincerelly hope that the "Bochumer-Miami Maastricht-story of decapitation- 
to-unmask-GFAP" (sounds like a bad movie) will continue. 1 look forward to seeing you again, hopefully soon in Maastricht.

Mr. Jack Glaser, dear Jack, thanks for the wonderful and scientifically thrilling time at MicroBrightField Inc. Headquarters in Burlington, Vermont and for the best BrdU-countingday one can ever have.

Prof, dr. D. Wallace and dr. Pinar-hypomanic-Coskun and the rest of the Wallace-team, great thanks for most learningfull and enjoyable times in Atlanta and Woods Hole.

Dr. Marc van Zandvoort en dr. Wim Engels, hartelijke dank voor de goede samenwerking met de 2-foton-imaging technieken.

Dr. Bert Smeets en Alexandra, hartelijke dank voor de "mitochondriale samenwerking".

Prof. dr. Frederik-Jan van Schooten en dr. Roger Godschalk, van harte bedankt voor de goede samenwerking betreffende oxidatieve DNA schade.

Dr. Erik Storkebaum, bedankt voor je komst naar Maastricht en de vruchtbare samenwerking. Veel succes in de nabije toekomst met je post-doc onderzoek.

Dr. Payam Rezaie, thanks for the best Brittish microglia stainings I have ever seen.

Hellen en Marjan, hoe had ik het ik het lab werk zonder jullie tot een succes kumnen brengen. Super bedankt!

Nicole Senden, Beste Nicole, het was een groot plezier om met de moeder van Euron op zo'n leuke manier te werken.

Akke en Mirese, bedankt voor de geweldige secretariele ondersteuning.

Zonder de hulp van de diverse hard werkende studenten had ik nog geen $30 \%$ van mijn proefschrift kunnen afkrijgen: Andrea, Diana, Emmily, Oliver, Nicolien, Hans, Nico, Laura, Merlijn, Dave, Imke, en Evita, Super bedankt voor jullie input tijdens jullie stages!

Pawel, it's now up to you! Thanks for your help and the various triple Carmeliet.

'Zazkia', je werkte qua tijdsinvestering op een Duitse manier aan je proefschrift, maar je hebt je Bourgondische kanten daarbij gelukkig duidelijk behouden. Ik hoop je snel weer tegen te komen in de klinische kant van de psychiatrie.

Orsi and Helga, great thanks for our joint Aachener work.

Dr. Jan de Vente, beste Jan, je hebt mij vanaf mijn eerste aanraking met de wetenschap het voorbeeld gegeven dat een fascinatie met een onderwerp de beste motivatie is om goed onderzoek te doen.

Govert, Wiel, Bert, Ronald, Daniel, Gunther, Jos, Arjan, Marjo, Mu, Wilma, Wilma, Evi, Eva, Roselie, Yasin en Guido ontzettend bedankt woor alle leuke momenten in het lab en in de stad.

Dr. Wilma van de Berg: voor het nuttige en plezierige synaptophysin-werk.

Dr. Robbert van Oostenbrugge, beste Robbert, het is geen Neurologie geworden, maar dat kwam niet door jou.

Dr. Johannes Vogt, thanks for the great time together. I hope your carreer will continue to be succesfull.

Medewerkers van het RNL en het CPV, met name Sandra, Paulien, Peter, Roger, Harry, hartelijke dank voor jullie ondersteuning.

Luc, Nick, Erik, Vincent, en Jorgen (en jullie wederhelften natuurlijk ook) de ontspannende dagjes-weg, mountainbike-tochten, en stapavonturen met jullie waren natuurlijk onmis- 
baar tijdens het verwerken van mijn onderzoekservaringen. Verder was jullie wetenschappelijke input en interesse buitengewoon hulpzaam om de promotieperiode met succes af te ronden.

Clint Ullrich, Sti, Ty and Tej, I remember with great merriment our experiences in and around San Francisco.

Michal and Adam, for all help with printing this thesis.

Medy, mama en Peter voor de geweldige artistieke aanvulling op mijn proefschrift.

Heren 1 Scoop, bedankt voor de ontspanning door inspanning, voor de derde helften en voor het accepteren dat ik vaak te laat en soms niet kwam opdagen op trainingen.

Familie Werner, opa en oma Rutten en Slegers, PieterJan en de rest van de families, bedankt voor de liefde en voor de steun en interesse voor mijn onderzoek.

Erik, het was erg leuk om een groot deel van onze promotieperiode gezamenlijk te doorlopen. Onze discussies, squaspartijen en samen-woonperiode waren me een waar genoegen.

Nicolien, ik heb je met veel plezier en waardering leren kennen als goede stage-student, goede college en goede vriend en ik denk dat de combinatie tussen jouw pessimistische/kritische en mijn positieve/opportunistische kijk op de wetenschap een mooi samenspel vormde. Ik hoop verder een nauwe band met je te onderhouden nu je in Utrecht met je verkorte Geneeskunde studie bent begonnen. Succes in ieder geval.

Boris, Monica, Peter, Sas, en pa en ma! Superbedankt voor alle liefde, interesse en ondersteuning.

Philo, Bedaank veur alles gedurende de letste zes joar, de witst: ich hout van dich. 


\section{Curriculum vitae}

Bart Rutten was born on May $21^{\text {rst }} 1975$ in Sittard. He graduated for secondary school, VWO, at Serviam Lyceum in Sittard in 1993. From 1993 until 1994, he studied medicine at Catholic University Leuven (Belgium). In 1994, he continued his medical training at Maastricht University. The author received his doctoral diploma in medicine with first class honours in 1998. After a research internship at University of California at San Francisco (UCSF, USA), an elective internship in pediatrics at Frere Hospital in East London (South Afrika) and experimental research at the division of Cellular Neuroscience (Department of Psychiatry and Neuropsychology), he received his medical doctor degree with first class honours in 2000. The author started with his Ph.D. research on neuronal loss in aging en Alzheimer's disease with dr. C. Schmitz and prof. dr. HWM Steinbusch, division Cellular Neuroscience in 2001. In the framework of his PhD research, the author was granted a Marie-Curie scholarship of the European Union for a one year research period with prof. dr. H Korr, Department of Anatomy and Cell Biology at RWTH University in Aachen (Germany). In addition, the author received grants from the Dutch Scientific Organization (NWO) for a working visit with prof. dr. DC Wallace at the Center for Molecular Medicine at Emory University in Atlanta (Georgia, USA), from the Ellison Medical Foundation for attendance of the course Molecular Biology of Aging in Woods Hole (Massachussets, USA), from the International Alzheimer's Disease Association for a working visit at MBF Inc. in Burlington (Vermont, USA) and travel grants for the Human Brain Conference (Rome, Italy), and the yearly conferences of the Society of Neuroscience in the USA. Furthermore, he has been assistant-editor of the Journal of Chemical Neuroanatomy and advisor of the Committee of Reseach Management at Maastrich University for a period of one year. The results of his PhD research were described in this thesis. In April 2005, the author started his residency in Psychiatry at the Academic Hospital Maastricht and Psycho Medisch Streekcentrum Vijverdal, headed by prof. dr. J van Os and dr. K. Schruers. 


\section{Curriculum vitae}

Bart Rutten werd geboren op 21 mei 1975 in Sittard. In 1993 behaalde hij het eindexamen VWO aan het Serviam Lyceum in Sittard. Van 1993 tot 1994 studeerde hij geneeskunde aan de Katholieke Universiteit Leuven (België). In 1994 startte hij met de studie geneeskunde aan de Universiteit Maastricht. In 1998 behaalde hij zijn doctoraal diploma geneeskunde cum laude. Na een wetenschapsstage aan de Universiteit van Californie te San Francisco (UCSF, Verenigde Staten van Amerika), een keuze coschap Kindergeneeskunde bij het Frere Hospital te East London (Zuid Afrika) en onderzoek bij de divisie Cellulaire Neurowetenschappen (vakgroep Psychiatrie en Neuropsychologie), behaalde hij in 2000 zijn arts diploma cum laude. In 2001 is de auteur begonnen met zijn promotieonderzoek naar veroudering en de ziekte van Alzheimer bij dr. C Schmitz en prof. dr. HWM Steinbusch, divisie Cellulaire Neurowetenschappen. In het kader hiervan heeft hij een Marie-Curie beurs gekregen van de Europese Unie om gedurende 1 jaar onderzoek te verrichten bij prof. dr. H Korr, vakgroep Anatomie en Cellulaire Biologie aan de RWTH Universiteit in Aken (Duitsland). Verder verkreeg de auteur beurzen van de Nederlandse Wetenschappelijke Organisatie (NWO) voor een werkbezoek in het kader van zijn promotieonderzoek bij prof. dr. DC Wallace in het Center for Molecular Medicine aan de Emory University in Atlanta (Georgia, USA), van de Ellison Medical Foundation voor de cursus Molecular Biology of Aging in Woods Hole (Massachussets, USA), van de Internationale Stichting Alzheimer Onderzoek voor een werkbezoek aan MBF Inc. in Burlington (Vermont, USA), en reisbeurzen voor de Human Brain Conference (Rome, Italië) en de jaarlijkse congressen van de Society of Neuroscience in de Verenigde Staten. Tevens was hij assistent-editor van het tijdschrift Journal of Chemical Neuroanatomy en adviseur van de Commissie Onderzoeks Beleid van de Universiteit Maastricht gedurende 1 jaar. De resultaten van zijn promotieonderzoek heeft u kunnen lezen in dit proefschrift. In april 2005 startte de auteur met de opleiding psychiatrie van het Academisch Ziekenhuis Maastricht en het Psycho Medisch Streekcentrum Vijverdal, bij opleiders prof. dr. J van Os en dr. K. Schruers. 


\section{Publications}

\section{Journal articles}

1. Jo K, Rutten B, Bumn RC, Bredt DS. Actinin-Associated LIM Protein-Deficient Mice Maintain Normal Development and Structure of Skeletal Muscle. Molecular and Cellular Biology, 21 : 1682-1687 (2001)

2. Rutten BPF, Steinbusch HWM, Korr H, Schmitz C: Antioxidants and Alzheimer's disease: from bench to bedside (and back again). Current Opinions in Clinical Nutrition and Metabolic Care 5: 645-651 (2002)

3. Rutten BP*, Wirths O*, Van de Berg WD, Lichtenthaler SF, Vehoff J, Steinbusch HW, Korr H, Beyreuther K, Multhaup G, Bayer TA, Schmitz C. No alterations of hippocampal neuronal number and synaptic bouton number in a transgenic mouse model expressing the beta-cleaved C-terminal APP fragment. Neurobiology of Disease 12: $110-120(2003)$

4. Rutten BPF, Korr H, Steinbusch HWM, Schmitz $C_{\text {: }}$ The aging brain: less neurons could be better. Mechanisms of Ageing and Development 124: 349-355 (2003)

5. Rutten BPF. Informatie over de ziekte van Alzheimer op het Internet. Tijdschrift voor Neurologie en Neurochirurgie 4:" 249-250 (2003)

6. Schmitz C*, Rutten BP*, Pielen A, Schafer S, Wirths O, Tremp G, Czech C, Blanchard V, Multhaup G, Rezaie P, Korr H, Steinbusch HW, Pradier L, Bayer TA.: Hippocampal neuron loss exceeds amyloid plaque load in a transgenic mouse model of Alzheimer"s disease. American Journal of Pathology 164:1495-1502 (2004)

7. Aerden LA, Kessels FA, Rutten BP, Lodder I, Steinbusch HW. Diazepam reduces brain lesion size in a photothrombotic model of focal ischemia in rats. Neuroscience Letters $367: 76-78(2004)$ 
8. Storkebaum E, Lambrechts D, Dewerchin M, Moreno-Murciano MP, Appelmans S, OhH, Van Damme $P_{\text {, Rutten }} \mathrm{B}$, Man WY, De Mol M, Wyns S, Manka D, Vermeulen $\mathrm{K}$, Van Den Bosch L, Mertens N, Schmitz C, Robberecht W, Conway EM, Collen D, Moons $L$, Carmeliet $P$. Treatment of motoneuron degeneration by intracerebroventricular delivery of VEGF in a rat model of ALS. Nature Neuroscience 8:85-92 (2005)

9. Schmitz C, Born M, Dolezel P, Rutten B, de Saint-Georges L, Hof P, Korr H. Prenatal protracted irradiation at very low dose rate induces severe neuronal loss in rat hippocampus and cerebellum. Neuroscience 130:935-948 (2005)

10. Temel Y, Visser-Vandewalle V, Aendekerk B, Rutten B, Tan S, Scholtissen B, Schmitz $C$, Blokland A, Steinbusch H. Acute and separate modulation of motor and cognitive performance in parkinsonian rats by bilateral stimulation of the subthalamic nucleus. Exp. Neurology, 193(1):43-52 (2005)

11. Rutten BPF, van der Kolk NM, Schaefer $S_{\text {, van }}$ Zandvoort M, Bayer T, Steinbusch C, Schmitz C. Age-related loss of synaptophysin immunopositive presynaptic boutons within the hippocampus of APP751SL, PS1M146L and APP751SL/PS1M146L transgenic mice. American Journal of Pathology.167(1):161-73 (2005)

" joint first authors

\section{Submitted:}

1. Rutten BPF, Schmitz C, Gerlach $O H H$, Oyen HM, Bueno de Mesquita E, Steinbusch HWM, Korr $H$. The aging brain: accumulation of DNA damage or neuron loss?

2. Rutten BPF, van Kooten IAJ, van Iersel D, Steinbusch HPJ, Markerink M, Asayama K, Korr H, Steinbusch HWM, Schmitz C. Caloric restriction reduces nuclear DNA damage accumulation and age-related neuronal shrinkage in mouse hippocampus without inducing neuron loss.

3. Kántor $\mathrm{O}$, Temel $\mathrm{Y}$, Holzmann $\mathrm{C}$, Krotova $\mathrm{J}$, Cao $\mathrm{C}$, Türkoglu HO, Rutten BPF, Visser-Vandewalle V, Steinbusch HWM, Blokland A, Korr, Riess O, von Hörsten $\mathrm{S}$, Schmitz C. Selective striatal neuron loss and alterations in behavior in line with impaired striatal activity in Huntington's disease transgenic rats

\section{Book Chapters}

1. Brasnjevica J, Rutten BPF, Steinbusch HWM, Schmitz C. Synapse and neuron loss in transgenic mouse models of Alzheimer's disease, in Progress in Alzheimer's Disease Research. Nova Science Publishers, Inc., Hauppauge, New York, USA. 


\section{Abstracts}

1. Rutten BPF, Korr H, Schoen SW, Steinbusch HWM, Schmitz C. Controlled neuronal death during aging might be an attractive therapeutic target for preventing Alzheimer's disease. Society for Neuroscience Meeting, San Diego, USA, 2001

2. Rutten BPF, Korr H, Schoen SW, Steinbusch HWM, Sclmitz C. Controlled neuronal death during aging might be an attractive therapeutic target for preventing Alzheimer's disease EndoNeuroMeeting, Doorwerth, The Netherlands, 2002

3. Schmitz C, Rutten BPF, Korr H, Steinbusch HWM, Might a controlled neuronal death during aging be a therapeutic target for preventing Alzheimer's disease? XIXth International Winter Meeting of the Swiss Society of Neuropathology, entitled "Degeneration and Regeneration of the Nervous System", St. Moritz, Switzerland, 2002

4. Rutten BPF, Pielen A, Wirths O, Schaefer S, Korr H, Steinbusch HWM, Pradier L, Bayer TA, Schmitz C, Plaque induced neuronal loss in the hippocampus of mice doubly transgenic for mutant human $\beta$-amyloid precursor protein and presenilin-1.The Human Brain, Rome, 2002

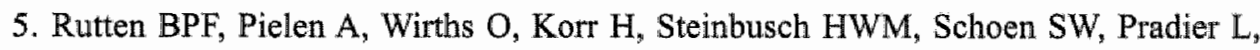
Bayer TA, Schmitz C, Plaque induced massive neuronal loss in the hippocampus of beta-annyloid precursor protein and presenilin-1 transgenic mice. Society for Neuroscience Meeting, Orlando, 2002

6. Rutten BPF, Pielen A, Wirths O, Schaefer S, Korr H, Steinbusch HWM, Pradier L, Bayer TA, Schmitz $C$, Plaque induced neuronal loss in the hippocampus of mice doubly transgenic for mutant human $\beta$-amyloid precursor protein and presenilin-1. EndoNeuroMeeting, Doorwerth, The Netherlands, 2003

7. Gerlach OHH, Rutten BPF, Korr H, Oyen HM, Steinbusch HWM, Schmitz C. The aging brain: less neurons could be better. The cerebellum. EndoNeuroMeeting, Doorwerth, The Netherlands, 2003.

8. Rutten BPF, Korr H, Gerlach OHH, Oyen HM, Bueno de Mesquita E, Steinbusch HWM, Schmitz C. The aging brain: less neurons could be better. Society for Neuroscience Meeting, New Orleans, USA, 2003

9. Rutten BPF, Steinbusch HWM, Wirths O, Schaefer S, Korr H, Pradier L, Bayer T, Schmitz C. Prominent hippocampal neuron loss in pyramidal cell layer but not in dentate gyrus of APP/PS-1 transgenic mice. FENS course on "Neural Stem Cells", Kitzbuhl, Austria, 2003 
10. Rutten BPF, Korr $H_{3}$ Gerlach $O H H$, Oyen HM, Bueno de Mesquita E, Steinbusch HWM, Schmitz C. The aging brain: fewer neurons could be better. EndoNeuroMeeting. Doorwerth, The Netherlands, 2004

11. van Kooten LAI, Rutten BPF, Korr H, Steinbusch HWM, Schmitz C. Long term caloric restriction induces hippocampal volume loss in mice. EndoNeuroMeeting, Doorwerth, The Netherlands, 2004

12. Rutten BPF, van der Kolk N, Schaefer S, Korr H, Bayer T, Pradier L, Steinbusch HWM, Schmitz C. Loss of hippocampal synaptophysin-immunoreactive presynaptic boutons in transgenic mouse models of Alzheimer's disease. EndoNeuroMeeting, Doorwerth, The Netherlands, 2004

13. Steinbusch HWM, Rutten BPF, Schmitz C. Mosaic of discrete quantitative histologic alterations in the brain of schizophrenics, providing clues to the disease pathogenesis. EndoNeuroMeeting, Doorwerth, The Netherlands, 2004

14. Rutten BPF, van der Kolk N, Schäfer S, Bayer TA, Blanchard V, Steinbusch HWM, Pradier, $\mathbb{L}$, Schmitz C. Alterations in synaptic morphology and loss of synaptophysinimmunoreactive presynaptic boutons in a transgenic mouse model of Alzheimer's disease. Society for Neuroscience Meeting, San Diego, USA, 2004

15. Schrnitz C; Kreczmanski P; Rutten BPF; Steinbusch HWM; Heinsen H; Perl D; Hof PR. Neuropathology of the anterior cingulated cortex in a well characterized sample of brains from schizophrenics. Society for Neuroscience Meeting, San Diego, USA, 2004

16. van der Kolk N, van de Steeg E, Rutten BPF, Wirths O, Blanchard V, Itier JM, Tremp G, Steinbusch HWM, Pradier L, Bayer TA, Schmitz C. Age-related early hippocampal newron loss in a novel transgenic/knock-in mouse model of AD. Society for Neuroscience Meeting, San Diego, USA, 2004

\section{Presentations}

1. Rutten BPF, Korr H, Steinbusch HWM, Schmitz C. Controlled neuronal death during aging might be an attractive therapeutic target for preventing Alzheimer's disease. EURON Course 'Neurodegeneration', 2002, Kerkrade, The Netherlands

2. Rutten BPF: Stereology and quantitative morphology. EURON Course 'Modern Techniques in Microscopy'. 2002. Maastricht, The Netherlands

3. Rutten BPF, Korr H, Steinbusch HWM, Schmitz C. The aging brain: less neurons could be better. EURON PhD days, 2003. Brussels, Belgium. 

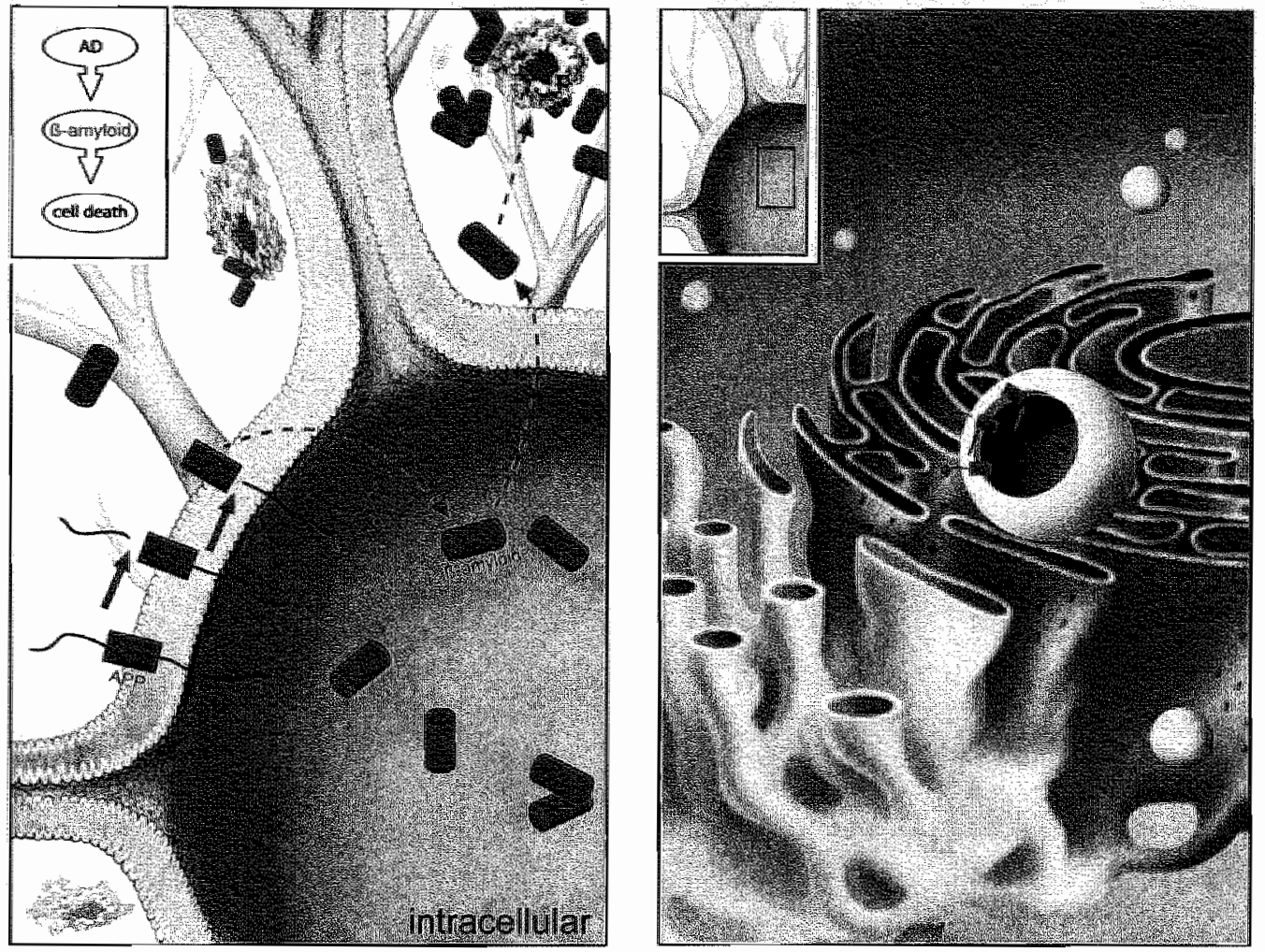

Supplementary figure. Illustrations depicting generation and localization of intranewronal B-amyloid (AB). Amyloid Precursor Protein (APP, red structure with two tails) is localized in membranes and can be cleaved by Busecrefase and subsequenty by $\gamma$-secretase into AR. These cleavage steps (depicted by green arrows) may occum in the cellular membrane (as shown in the left panel) but may also occur in membranes of structures belonging to the Golgi network and endolysosomal system (right panel). Intracellular AB way form dimers and oligomers intraneuronally and may be secreted into the extracellular watrix where AB may furthermore aggregate in the form of plagues (see left panel).

Illustrations by Medy Oberendorff 


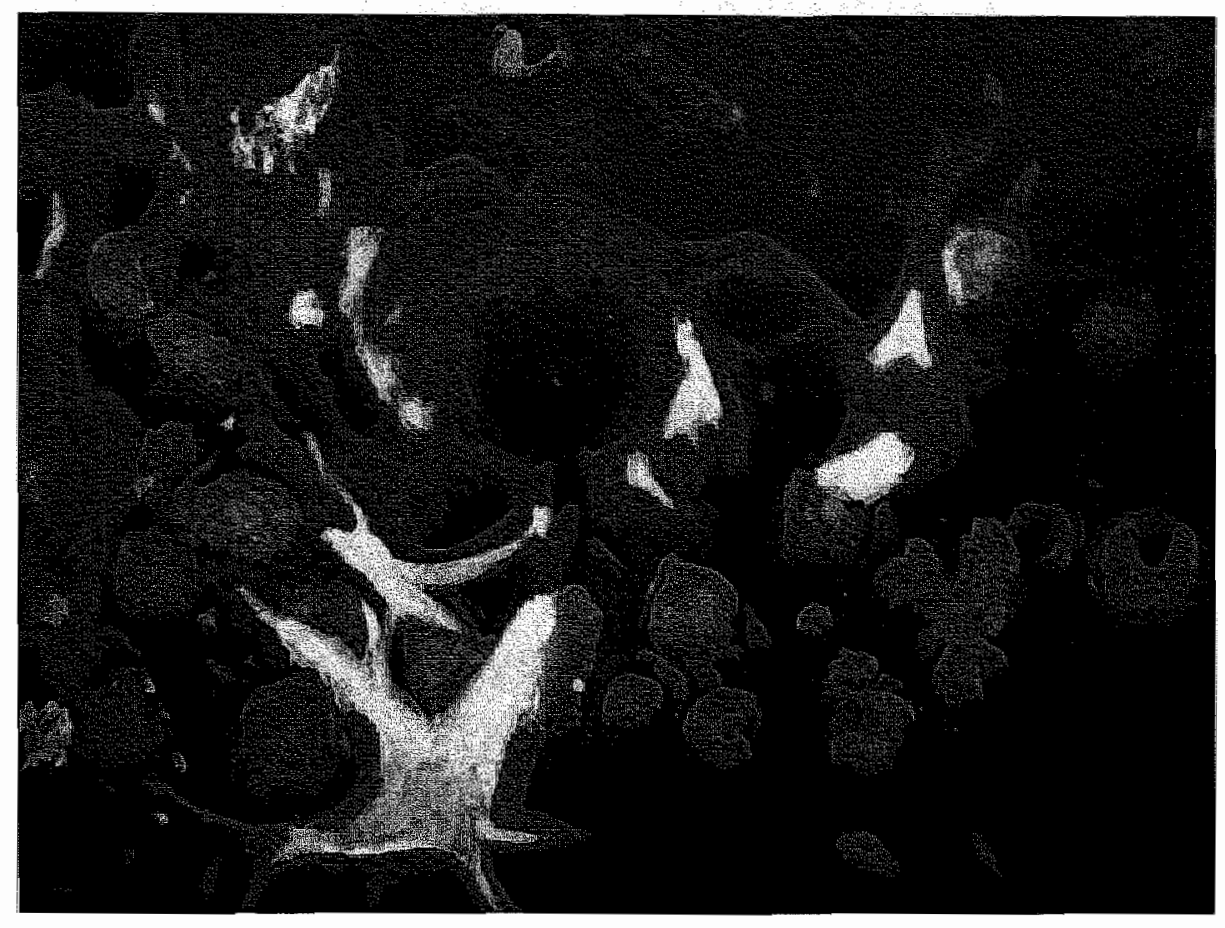

Creation by Ineke Rwtien-Slegers 